\title{
DEVELOPMENT OF ADHERENT CERAMIC COATINGS TO REDUCE CONTACT STRESS DAMAGE OF CERAMICS
}

S. F. Wayne, J. H. Selverian, and D. O'Neil

ORNL/SUb--89-95915/2

DE 93012518

Date Published-November 1992

FINAL REPORT

Prepared by

GTE Laboratories Incorporated

40 Sylvan Road

Waltham, Massachusetts 02254

\author{
Funded by \\ Office of Transportation Materials \\ Office of Transportation Technologies \\ the Assistant Secretary for Conservation and Renewable Energy \\ U.S. Department of Energy \\ EE 5101000
}

for

Oak Ridge, Tennessee 37831

managed by

MARTIN MARIETTA ENERGY SYSTEMS, INC.

for the

U.S. DEPARTMENT OF ENERGY

under Contract DE-AC05-84OR21400 


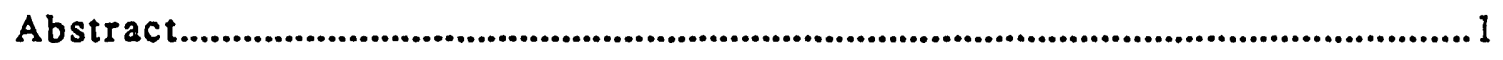

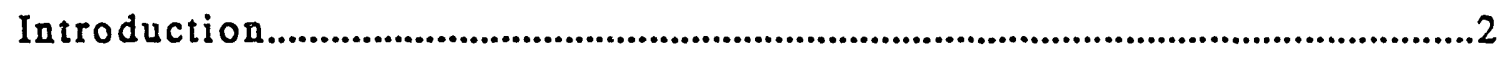

Executive Summary................................................................................................5

Design of Coating Configuration..................................................................

Requirements of the Application............................................................8

Chemical, Physical, and Mechanical Property Considerations..............9

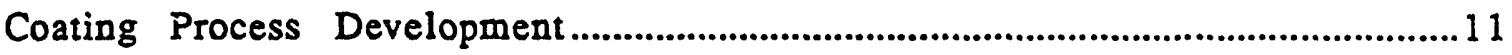

Thermodynamic Analysis of Coating Process.........................................11

High Temperature Coating Deposition Reactor ........................................11

Experimental Coating Process..................................................................13

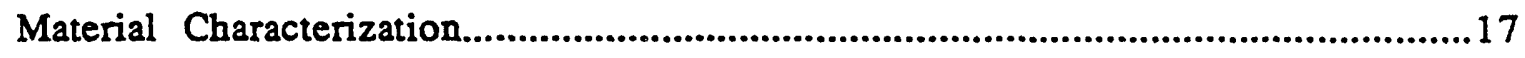

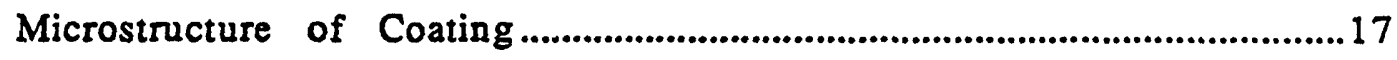

Phase I Coating ...................................................................... 17

Phase II Coating........................................................................20

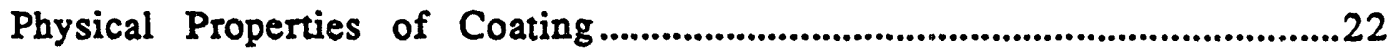

Oxidation-Literature Review.....................................................22

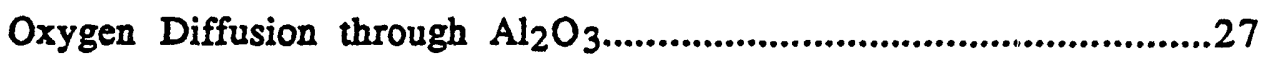

Oxidation Testing ...........................................................................28

Coatings on Sapphire Substrates.....................................29

AlN Coated Sapphire Substrates...............................29

$\mathrm{Al}_{2} \mathrm{O}_{3} / \mathrm{AlN}$ Coated Sapphire Substrates.....................29

$\mathrm{Al}_{2} \mathrm{O}_{3}+\mathrm{ZrO}_{2} / \mathrm{AlN}$ Coated Sapphire Substrates............30

Oxidation Kinetics of Uncoated and AlN Coated Substrates.................................................................................30

Phase Formation During Oxidation of Uncoated and

Coated Substrates .................................................................33

Contact Stress Testing...................................................................3 34

Friction Coefficient Tests...........................................................39

Scratch Tests...................................................................................44

Measurement of Fracture Stress and Toughness of Coatings on Substrates..................................................................................5 51

Computer Modelling of Brittle Coatings.............................................................52

Computer Simulation of Residual Stress.................................................552

Simple Beam Theory ....................................................................54 
Composite Plate Theory ...............................................................56

Comparison to Finite Element Results..............................59

$\mathrm{Si}_{3} \mathrm{~N}_{4}$ Substrate ..............................................................60

SiC Substrate.............................................................61

Computer Simulation of Coating Fracture .................................................63

Single Layer with Interface - Initial Vertical Flaw.....................63

Geometry........................................................................63

Boundary Conditions.........................................................66

Material Properties........................................................65

Crack Propagation Studies..................................................66

Multilayer Analysis - Initial Vertical Flaw...................................73

Geometry..............................................................................73

Material Properties.........................................................73

Crack Propagation Studies.................................................74

Multilayer Analysis - Initial Horizontal Flaw.................................75

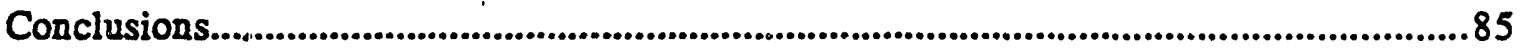

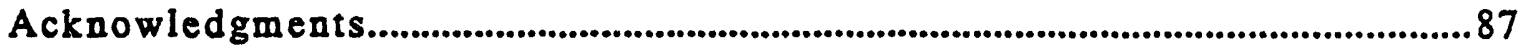

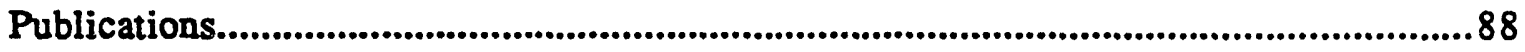

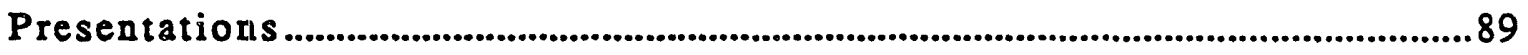

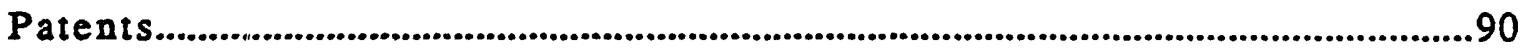

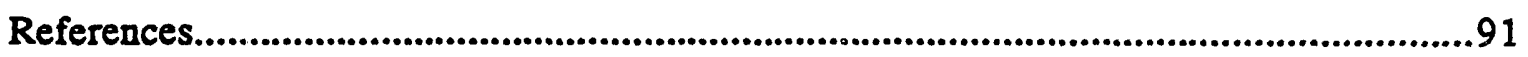

Appendix A - Oxidation Results......................................................................95

Appendix B - Method to Measure Fracture Stress and Fracture

Toughness of Coatings on Substrates................................................................111

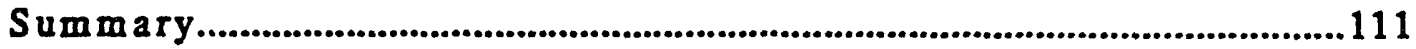

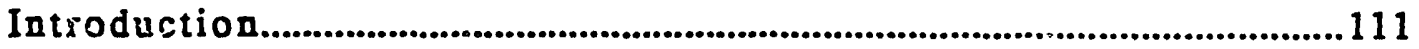

Stresses in Coatings - Theory ...........................................................114

Stresses in Uncracked Coatings............................................ 114

Stresses in Cracked Coatings ................................................117

Determination of the Weibull Modulus - Theory...........................119

Determination of Surface Energy - Theory ...................................... 122

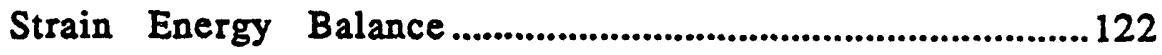

Griffith Energy Balance...................................................126

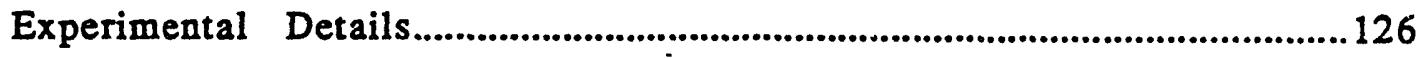


Coating Procedure......................................................................126

Residual Stress Measurements...............................................127

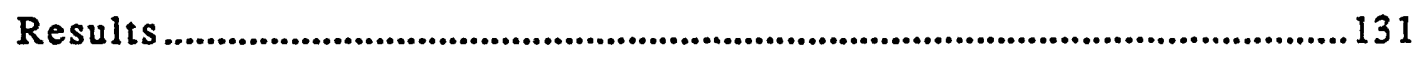

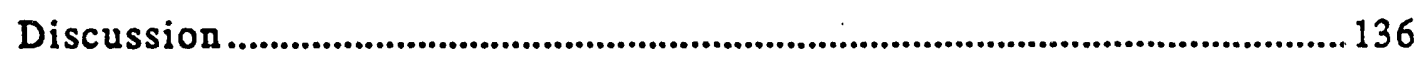

Coating Properties............................................................................136

Limitations on Modeling and Experimental Data..........................140

Conclusions............................................................................................. 143

Appendix C - Curve Fitting of Profilometer Data.................................................. 144

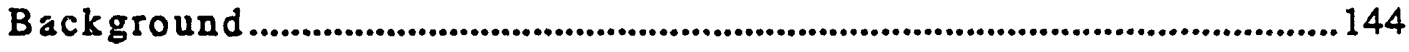

Experiments and Results.............................................................................. 144

Conclusions........................................................................................150

Computer Routines for Curve Fitting of Profilometer Data.....................150

Appendix D - Simple Composite Plate and Beam Theory .....................................154

Composite Plate Theory ................................................................................... 154

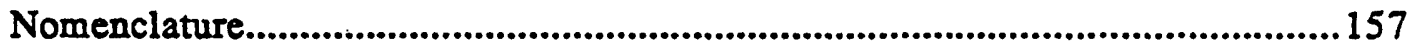


Table 1. Properties of the materials used in this study.

Table 2. Process conditions for CVD deposition of AlN and $\mathrm{Al}_{2} \mathrm{O}_{3}+\mathrm{ZrO}_{2}$.

Table 3. Summary of oxidation tests for uncoated and AlN coated RBSN, SSC, and HSN substrates. The tests were done in static air at $1200^{\circ} \mathrm{C}$ and $1275^{\circ} \mathrm{C}$ in a box fumace.

Table 4. Summary of contact testing and post-contact MOR strength testing for CVD coated RBSN........................................36

Table 5. Summary of contact testing and post-contact MOR strength testing for CVD coated HSN.

Table 6. Summary of contact testing and post-contact MOR strength testing for CVD coated SSC...............................................38

Table 7. Results from pin-on-disk friction tests of uncoated and $\mathrm{Al}_{2} \mathrm{O}_{3}+\mathrm{ZrO}_{2} / \mathrm{AlN}$ coated RBSN, HPSN, and SSC. All tests were done on self-mated samples. Reported values, unless otherwise indicated, are an average of three tests on the same pair of samples.

Table 8. Calculated fracture stress, fracture toughness, and Weibull modulus for $\mathrm{Al}_{2} \mathrm{O}_{3}$ and $\mathrm{Al}_{2} \mathrm{O}_{3}+\mathrm{ZrO}_{2}$ coatings............................5

Table 9. Material properties used for substrates and coating layers in this part of the study.

Table 10. Comparison of 2-D finite element results using special hybrid elements to the composite plate theory described here. Stress values are from reference [SHA88], values in parentheses are results from the composite plate code described here. For both tables $\Delta \mathrm{T}=-1000^{\circ} \mathrm{C}$. Note use of $\mathrm{Si}_{3} \mathrm{~N}_{4}$ and $\mathrm{SiC}$ substrates.

Table A-1. Weight gain as a function of oxidation time for AlN coated sapphire oxidized in static air at $1000^{\circ} \mathrm{C}$. The weight gain at a given time was calculated from the original weight and the measured weight after a given oxidation time.

Table A-2. Phases identified by $\mathrm{X}$-ray diffraction after oxidation in static air. Samples were sapphire with $\mathrm{AlN}, \mathrm{Al}_{2} \mathrm{O}_{3} / \mathrm{A} I \mathrm{~N}$, 
and $\mathrm{Al}_{2} \mathrm{O}_{3}+\mathrm{ZrO}_{2} / \mathrm{AlN}$ coating. Phases associated with substrate reflection are not listed.

Table A-3. Weight gain as a function of oxidation time for $\mathrm{Al}_{2} \mathrm{O}_{3} / \mathrm{AlN}$ coated sapphire oxidized in static air at $1100^{\circ} \mathrm{C}, 1200^{\circ} \mathrm{C}$, and $1275^{\circ} \mathrm{C}$. The weight gain at a given time was calculated from the original weight and the measured weight after a given oxidation time.

Table A-4. Weight gain as a function of oxidation time for $\mathrm{Al}_{2} \mathrm{O}_{3}+\mathrm{ZrO}_{2} / \mathrm{AlN}$ coated sapphire oxidized in static air at $1100^{\circ} \mathrm{C}, 1200^{\circ} \mathrm{C}$, and $1275^{\circ} \mathrm{C}$. The weight gain at a given time was calculated from the original weight and the measured weight after a given oxidation time.

Table A-5. Phases identified by X-ray diffraction after 500 hours of oxidation in static air. Samples include uncoated and AIN coated RBSN, SSC, and HSN.

Table A-6. Phases identified by X-ray diffraction after 500 hour oxidation in static air. Samples had coating of AlN, $\mathrm{Al}_{2} \mathrm{O}_{3} / \mathrm{AlN}$, and $\mathrm{Al}_{2} \mathrm{O}_{3}+\mathrm{ZrO}_{2} / \mathrm{AlN}$. Phases associated with substrate reflection are not listed.

Table B-1. Material elastic constants used in calculations

Table B-2. Coating and substrate thicknesses, measured radius of curvature, predicted stress and predicted radius of curvature of samples tested..

Table B-3. Calculated fracture stress, temperature at the onset of cracking, fracture toughness, Weibull modulus, and surface energy for coatings in this study. All of the reported values are valid at "The Temperature at First Cracking"

Table B-4. Fracture toughness, tensile strength, and surface energy of bulk ceramics from the literature. 


\section{List of Figures}

Figure 1. Schematic of coating design....................................................9

Figure 2. Phase II high temperature CVD reactor being used for coating deposition.............................................................................12

Figure 3. SEM micrograph of the surface of a $\mathrm{Phase} I \mathrm{Al}_{2} \mathrm{O}_{3}$ coating on SSC................................................................................................. 18

Figure 4. SEM micrograph of a Phase $\mathrm{I} \mathrm{Al}_{2} \mathrm{O}_{3}+\mathrm{ZrO}_{2}$ coating on SSC.

a) Back scattered electron image, b) Al X-ray map, c) $\mathrm{Zr} X$ ray map.

Figure 5. SEM micrograph of the surface of Phase II Al2O3 coating on SSC.

Figure 6. SEM micrograp'a of a Phase II $\mathrm{Al}_{2} \mathrm{O}_{3}+\mathrm{ZrO}_{2}$ coating on SSC.

a) Back scattered electron image, b) Al X-ray map, c) $\mathrm{Zr} X$ ray map.

Figure 7. Plot of silicon nitride oxidation data [BAB83, SIN76a, POR84].

Figure 8. Plot of silicon carbide oxidation data [DUT84, SIN76b]................25

Figure 9. Plot of AlN oxidation data [LAV83, BOC82] ..................................27

Figure 10. Schematic of pin-on-disk wear test system. $F$ is the normal force on the pin, $d$ is the pin diameter, $D$ is the disk diameter, $R$ is the wear track radius, and $w$ is the rotation velocity of the disk.

Figure 11. Wear tracks on the pins and disks for uncoated HPSN (top), RBSN $\mathrm{Si}_{3} \mathrm{~N}_{4}$ (middle), and SSC (bottom), after a sliding distance of 500 meters at a sliding velocity of $0.01 \mathrm{~m} / \mathrm{s}$.

Figure 12. Wear tracks on the $\mathrm{AlN} / \mathrm{Al}_{2} \mathrm{O}_{3}+\mathrm{Z}_{\mathrm{rO}_{2}}$ coated pins and disks for HPSN (top), RBSN (middle), and sintered SSC (bottom), after a sliding distance of 500 meters at a sliding velocity of $0.01 \mathrm{~m} / \mathrm{s}$

Figure 13. Scratch test results of uncoated HSN. The load trace is the solid line (left axis) and the acoustic signal is represented by the spikes (right axis).

Figure 14. Scratch test results of coated HSN. The load trace is the solid line (left axis) and the acoustic signal is represented by the spikes (right axis). 
Figure 15. Scratch test results of uncoated RBSN. The load trace is the solid line (left axis) and the acoustic signal is represented by the spikes (right axis).

Figure 16. Scratch test results of coated RBSN. The load trace is the solid line (left axis) and the acoustic signal is represented by the spikes (right axis).

Figure 17. Scratch test results of uncoated SSC. The load trace is the solid line (left axis) and the acoustic signal is represented by the spikes (right axis).

Figure 18. Scratch test results of coated SSC. The load trace is the solid line (left axis) and the acoustic signal is represented by the spikes (right axis).

Figure 19. Thermal expansion coefficients of the various materials present in this system over the temperature range $25^{\circ} \mathrm{C}$ to $1500^{\circ} \mathrm{C}$.

Figure 20. At coating thicknesses less than $10 \%$ of the substrate thickness most of the stress in the coating is due to the axial component and is therefore independent of the coating and substrate thicknesses..................................................55

Figure 21. Stress in coating versus $\Delta \mathrm{T}$ for $\mathrm{AlN}$ coatings on $\mathrm{SiC}$ and $\mathrm{Si}_{3} \mathrm{~N}_{4}$, and $\mathrm{Al}_{2} \mathrm{O}_{3}$ coatings on $\mathrm{SiC}$ and $\mathrm{Si}_{3} \mathrm{~N}_{4} \ldots \ldots \ldots \ldots \ldots \ldots \ldots \ldots . . . \ldots . . . . . .56$

Figure 22. Flow chart for computer code implementation of composite plate theory. Layer properties were used to get transformed stiffnesses for each layer, and these were cumulated into a total stiffness matrix for the entire coated system. Unknown mid-plane strains were then solved for, and stresses in each of the layers recovered...............57

Figure 23. Schematic of the coated substrate model ........................................58

Figure 24. Numbering scheme for a multicoated system. $h$ is the total coating thickness, and all interface positions are measured relative to the mid-plane at $b / 2$, which the $z=0$ plane. Note that layers below this plane have negative interlayer position values. 
Figure 25. Schematic of the finite element mesh relative to microstructural cross section. Direction and positioning of scratch test indenter is shown.

Figure 26. Schematic of the boundary conditions used in the fracture simulation. Coefficient of friction was 0.5 . The value of ' $p$ ' (the maximum magnitude of the load distribution) was assigned a value such that the stress results are normalized....................................................................................667

Figure 27. Energy release rate for the interface as a function of mode mixity. A mode-mixity of 0.0 describes pure mode I loading at the crack tip, and a mode-mixity of 90 (degrees) describes pure mode II loading at the crack tip.

Figure 28. Initial (uncracked) mesh used in the fracture simulation study. The top four elements are the $\mathrm{Al}_{2} \mathrm{O}_{3}+\mathrm{ZrO}_{2}$ coating material......................................................................................69

Figure 29. Initial vertical flaw, 0.5 microns long ( $1 / 4$ coating thickness ) ............................................................................70

Figure 30. Deformed shape and crack growth direction prior to crossing the bimaterial interface..................................................71

Figure 31. Deformed shape and crack path in final increment...................72

Figure 32. Energy release rate for both interfaces as a function of mode mixity. A mode-mixity of 0.0 describes pure mode I loading at the crack tip, and a mode-mixity of 90 (degrees) describes pure mode II loading at the crack tip.............................74

Figure 33. Initial (uncracked) mesh used in the fracture simulation study. The top four elements are the $\mathrm{Al}_{2} \mathrm{O}_{3}+\mathrm{ZrO}_{2}$ coating material. The next four were the AlN coating material................77

Figure 34. Initial vertical flaw, 0.5 microns long ( $1 / 4$ coating thickness). Solid lines are deformed geometry (thermal and mechanical loads). Dashed lines are undeformed geometry ........................................................................................78

Figure 35. Deformed shape and crack growth direction as the crack encountered the top bimaterial interface...................................79 
Figure 36. Deformed shape and crack path in final increment. The crack has propagated through both coating layers.....................8 80

Figure 37. Initial horizontal flaw in the second coating layer. The flaw is positioned at the middle of the layer. Solid lines are deformed geometry (thermal and mechanical loads). Dashed lines are undeformed geometry.

Figure 38. Deformed shape and crack path in final increment for the case where the initial flaw was in the second (middle) coating layer. The crack has been directed away from the substrate.

Figure 39. Initial horizontal flaw in the top coating layer. The flaw is positioned at the middle of the top layer. Solid lines are deformed geometry (thermal and mechanical loads). Dashed lines are undeformed geometry.

Figure 40. Deformed shape and crack path in final increment for the initial flaw in the top coating layer. The crack has been directed away from the substrate.

Figure A-1. Weight gain versus time for $\mathrm{AlN}, \mathrm{Al}_{2} \mathrm{O}_{3} / \mathrm{AIN}$, and $\mathrm{Al}_{2} \mathrm{O}_{3}+\mathrm{ZrO}_{2} / \mathrm{AlN}$ coated sapphire oxidized in static air at $1100^{\circ} \mathrm{C}$.

Figure A-2. Weight gain versus time for $\mathrm{AlN}$ and $\mathrm{Al}_{2} \mathrm{O}_{3}+\mathrm{ZrO}_{2} / \mathrm{AlN}$ coated sapphire oxidized in static air at $1200^{\circ} \mathrm{C}$.

Figure A-3. Weight gain versus time for $\mathrm{Al}_{2} \mathrm{O}_{3} / \mathrm{AlN}$ and $\mathrm{Al}_{2} \mathrm{O}_{3}+\mathrm{ZrO}_{2} / \mathrm{AlN}$ coated sapphire oxidized in static air at $1275^{\circ} \mathrm{C}$.

Figure A-4. Weight gain versus time for uncoated and AlN coated RBSN oxidized in static air at $1100^{\circ} \mathrm{C}$

Figure A-5. Waight gain versus time for uncoated and AlN coated SSC oxidized in static air at $1100^{\circ} \mathrm{C}$.......................................................... 102

Figure A-6. Weight gain versus time for uncoated and AlN coated HSN oxidized in static air at $1100^{\circ} \mathrm{C}$.

Figure A-7. Weight gain versus time for uncoated and $\mathrm{Al}_{2} \mathrm{O}_{3} / \mathrm{AlN}$ and $\mathrm{Al}_{2} \mathrm{O}_{3}+\mathrm{ZrO}_{2} / \mathrm{AlN}$ coated $\mathrm{RBSN}$ oxidized in static air at $1100^{\circ} \mathrm{C}$. 
Figure A-8. Weight gain versus time for uncoated and $\mathrm{Al}_{2} \mathrm{O}_{3} / \mathrm{AlN}$ and $\mathrm{Al}_{2} \mathrm{O}_{3}+\mathrm{ZrO}_{2} / \mathrm{AlN}$ coated SSC oxidized in static air at $1100^{\circ} \mathrm{C}$ 104

Figure A-9. Weight gain versus time for uncoated and $\mathrm{Al}_{2} \mathrm{O}_{3} / \mathrm{AlN}$ and $\mathrm{Al}_{2} \mathrm{O}_{3}+\mathrm{ZrO}_{2} / \mathrm{AlN}$ coated $\mathrm{HSN}$ oxidized in static air at $1100^{\circ} \mathrm{C}$.

Figure A-10. Weight gain versus time for uncoated and AlN coated RBSN oxidized in static air at $1200^{\circ} \mathrm{C}$

Figure A-11. Weight gain versus time for uncoated and AIN coated SSC oxidized in static air at $1200^{\circ} \mathrm{C}$.

Figure A-12. Weight gain versus time for uncoated and AIN coated HSN oxidized in static air at $1200^{\circ} \mathrm{C}$

Figure A-13. Weight gain versus time for $\mathrm{Al}_{2} \mathrm{O}_{3} / \mathrm{A} I \mathrm{~N}$ and $\mathrm{Al}_{2} \mathrm{O}_{3}+\mathrm{ZrO}_{2} / \mathrm{AlN}$ coated $\mathrm{RBSN}$ oxidized in static air at $1200^{\circ} \mathrm{C}$

Figure A-14. Weight gain versus time for $\mathrm{Al}_{2} \mathrm{O}_{3} / \mathrm{AlN}$ and $\mathrm{Al}_{2} \mathrm{O}_{3}+\mathrm{ZrO}_{2} / \mathrm{AlN}$ coated SSC oxidized in static air at $1200^{\circ} \mathrm{C}$

Figure A-15. Weight gain versus time for $\mathrm{Al}_{2} \mathrm{O}_{3} / \mathrm{AlN}$ and $\mathrm{A} !{ }_{2} \mathrm{O}_{3}+\mathrm{ZrO}_{2} / \mathrm{AlN}$ coated $\mathrm{HSN}$ oxidized in static air at $1200^{\circ} \mathrm{C}$

Figure A-16. Weight gain versus time for uncoated and AIN coated RBSN oxidized in static air at $1275^{\circ} \mathrm{C}$

Figure A-17. Weight gain versus time for uncoated and AlN coated SSC oxidized in static air at $1275^{\circ} \mathrm{C}$

Figure A-18. Weight gain versus time for uncoated and AlN coated HSN oxidized in static air at $1275^{\circ} \mathrm{C}$.

Figure A-19. Weight gain versus time for $\mathrm{Al}_{2} \mathrm{O}_{3} / \mathrm{AlN}$ and $\mathrm{Al}_{2} \mathrm{O}_{3}+\mathrm{ZrO}_{2} / \mathrm{AlN}$ coated $\mathrm{RBSN}$ oxidized in static air at $1275^{\circ} \mathrm{C}$

Figure A-20. Weight gain versus time for $\mathrm{Al}_{2} \mathrm{O}_{3} / \mathrm{AIN}$ and $\mathrm{Al}_{2} \mathrm{O}_{3}+\mathrm{ZrO}_{2} / \mathrm{AlN}$ coated SSC oxidized in static air at $1275^{\circ} \mathrm{C}$.

Figure A-21. Weight gain versus time for $\mathrm{Al}_{2} \mathrm{O}_{3} / \mathrm{AlN}$ and $\mathrm{Al}_{2} \mathrm{O}_{3}+\mathrm{ZrO}_{2} / \mathrm{AlN}$ coated $\mathrm{HSN}$ oxidized in static air at $1275^{\circ} \mathrm{C}$.

Figure B-1. Scanning electron micrograph of a crack in a coating 112 
Figure B-2. Schematic of stress versus $\Delta T$ plot for a cracked ceramic coating on a substrate. $\Delta \mathrm{T}$ is the deposition temperature minus the instantaneous temperature, $\sigma_{p}$ is the predicted stress at $T_{1}$ and $T_{2}$ (Eq. B-3), sm is the measured stress at $T_{1}$ and $T_{2}$ (Eq. $\left.B-4\right)$, and $s f$ is the fracture stress of the coating.

Figure B-3. Schematic of coating on substrate with a single crack. The ends are treated as crack faces. The relative size of the coating was greatly exaggerated to show detail......................115

Figure B-4. At coating thicknesses less than $10 \%$ of the substrate thickness most of the stress in the coating was due to the axial component and was therefore independent of the coating and substrate thicknesses..................................................117

Figure B-5. Plot of the stress distribution in a 4.7 microns $\mathrm{Al}_{2} \mathrm{O}_{3}$ coating on a SiC substrate according to Eq. (B-5) for three different crack spacings $(10,30$, and 100 microns). The crack is located at $x=0$.

Figure B-6. Plot of theoretical stress in coating and measured stress in coating.

Figure B-7. Plot of number of cracks (NC) versus the average stress in the coating, for a 2.3 microns $\mathrm{Al}_{2} \mathrm{O}_{3}$ coating on $\mathrm{SiC}$.

Figure B-8. Schematic of bent substrate. NA is the location of the neutral axis, ' $b$ ' is the distance from the NA to the uncoated side of the substrate, ' $a$ ' is the distance from the coated side to the NA, and ' $r$ ' is the radius to any given location in the substrate.

Figure B-9. Flow chart of experimental procedure outlining important steps in the force balance used to calculate the fracture strength, fracture toughness, Weibull modulus, and temperature of first cracking of thin coatings on substrates.

Figure B-10. Flow chart of experimental procedure outlining important steps in the energy balance used to calculate the surface energy of thin coatings on substrates 


\section{List of Figures}

Figure B-11. Flot of the coefficients of thermal expansion for materials used in this study [TOU75]. Data for the $\mathrm{Al}_{2} \mathrm{O}_{3}+5$ v/o $\mathrm{ZrO}_{2}$ coating is from the volume weighted average of $\mathrm{Al}_{2} \mathrm{O}_{3}$ and $\mathrm{ZrO}_{2}$. Data for $\mathrm{Si}_{3} \mathrm{~N}_{4}$ at temperatures below $20^{\circ} \mathrm{C}$ was extrapolated.

Figure B-12. Plot of stress versus $\Delta \mathrm{T}$ for a 2.34 microns $\mathrm{Al}_{2} \mathrm{O}_{3}$ coating on $\mathrm{SiC}$. The predicted stress was calculated frorn Eq. (B-3) and the measured maximum stress $(\bullet)$ was calculated from Eqs. (B-5) and (B-8)

Figure B-13. Scanning electron micrograph of the coatings deposited on a $\mathrm{SiC}$ substrate at $950^{\circ} \mathrm{C}$ in a) $\mathrm{Al}_{2} \mathrm{O}_{3}$ deposited in an Inconel chamber, b) $\mathrm{Al}_{2} \mathrm{O}_{3}$ deposited in a graphite chamber, and c) $\mathrm{Al}_{2} \mathrm{O}_{3}+5$ v/o $\mathrm{ZrO}_{2}$ deposited in a graphite chamber

Figure B-14. Scarning electron micrograph of the coatings deposited on a SiC substrate at $970^{\circ} \mathrm{C}$ in a) TiN sample \# 1, b) TiN sample \#2

Figure C-1. Plot of experimental profilometer data. In this example the RMS noise is approximately 0.94 microns and the radius of curvature was calculated to be $7.8151 \mathrm{~m} \pm 5 \%$ using the "GUESS" routine (see end of Appendix), compared to $6.229 \mathrm{~m}$ calculated by the Rodenstock software

Figure C-2a. Plot of computer generated data for a radius of curvature of $7.861 \mathrm{~m}$ and an RMS noise level of 0.94 microns with a uniform distribution, calc"lated $R=8.002 \mathrm{~m}$. The calculated radius of curvature value is within $2 \%$ of the actual radius of curvature of $7.861 \mathrm{~m}$

Figure C-2b. Plot of computer generated data for a radius of curvature of $7.861 \mathrm{~m}$ and an RMS noise level of 0.94 microns with a Gaussian distribution, calculated $R=8.204 \mathrm{~m}$. The calculated radius of curvature value is within $4 \%$ of the actual radius of curvature of $7.861 \mathrm{~m}$

Figure C-3. Ratio of the calculated radius of curvature to the actual radius of curvature versus the signal-to-noise ratio for 
data sets with 2000 data points. For the Gaussian distribution the critical $S / N$ ratio was 1.8 and for the uniform distribution it was 0.7. Only the results from the Gaussian distribution are shown.................................................... 148

Figure C-4. Values of the maximum RMS noise level for which the fitted radius of curvature is within $5 \%$ of the true radius of curvature. A critical $S / \mathrm{N}$ ratio of 1.8 was used.

Figure C-5. Plot of error in the radius of curvature versus $S / N$......................149

Figure D-1 In-plane residual stresses for a $\mathrm{Si}_{3} \mathrm{~N}_{4}$ substrate coated with alumina-zirconia without an interlayer. Stresses for 1,4 and 10 microns coating thicknesses are shown. Thickness of the coating layer has negligible effect on residual stress

Figure D-2. In-plane residual stresses for a $\mathrm{Si}_{3} \mathrm{~N}_{4}$ substrate coated with alumina-zirconia with an AlN interlayer. Stresses for 1,4 and 10 microns interlayer thicknesses are shown. Thickness of the interlayer has negligible effect on residual stress.

Figure D-3. In-plane residual stresses for a $\mathrm{Si}_{3} \mathrm{~N}_{4}$ substrate coated with AlN and an alumina-zirconia interlayer (coating order is reversed from the previous figure). Stresses for 1,4 and 10 microns interlayer thicknesses are shown. Comparing to the previous figure, order of the coating layers has negligible effect on residual stress............................... 160

Figure D-4. In-plane residual stresses for a $\mathrm{SiC}$ substrate coated with AIN and alumina-zirconia. Stresses shown are applicable for a wide range of coating thicknesses 


\section{ABSTRACT}

This report is a summary of results of a study aimed at the development of thin, oxidation-resistant ceramic coatings to reduce contact stress damage of ceramic heat engine componentst. Strongly adherent coatings were deposited on reaction bonded $\mathrm{Si}_{3} \mathrm{~N}_{4}$ (RBSN), sintered $\mathrm{SiC}$ (SSC), and HIP'ed $\mathrm{Si}_{3} \mathrm{~N}_{4}$ (HSN) and using a newly developed chemical vapor deposition (CVD) process. The performance of the coating was assessed by oxidation, strength and contact stress testing. A new method was developed to experimentally determine the strength and Weibull modulus of thin brittle films on ceramic substrates. A significant portion of the study was devoted to numerical modeling of the coatings in order to understand the contributions of residual stress as different coating materials and thicknesses were combined. Coating designs were further analyzed by simulating the crack growth behavior in multilayer films while accounting for the interface fracture mechanics. This work has shown that the $\mathrm{Al}_{2} \mathrm{O}_{3}+\mathrm{ZrO}_{2}$ composite coating developed in this program can provide resistance to oxidation and contact stress, as determined by laboratory measurements. Commercial application of the composite coating has been successfully demonstrated by use of the $\mathrm{Al}_{2} \mathrm{O}_{3}+\mathrm{ZrO}_{2}$ composite as a protective coating on a $\mathrm{Si}_{3} \mathrm{~N}_{4}$ cutting tool.

$\dagger$ Research sponsored by the Advanced Materials Development Program, Office of Transportation Systems, U.S. Department of Energy, under contract DE-AC05-840R21400 with Martin Marietta Energy Systems, Inc. 


\section{INTRODUCTION}

Heat engine operating efficiencies have been significantly improved by using uncooled ceramics components at temperatures above those attainable with superalloys. A large number of studies have used $\mathrm{Si}_{3} \mathrm{~N}_{4}$-based and SiC based materials, and these have shown considerable potential for use as heat engine components. However, due to their brittle nature, high : surface stresses in contact regions cannot redistribute as in metals. This can result in localized stresses which may exceed the baseline strength, thus damaging the surface of the component and reducing its strength. This susceptibility to contact stress damage has led to projections of premature failure of ceramic heat engine components that undergo sliding contact.

It has been suggested that surface damage and strength loss under these conditions can be substantially reduced by applying a thin ceramics coating [LAC84]. Exploratory studies using plasma sprayed oxide coatings [GTE81] demonstrated improvements in the contact stress damage resistance of both $\mathrm{Si}_{3} \mathrm{~N}_{4}$ and $\mathrm{SiC}$ ceramics, but the adherence of these coatings was inadequate. Yttria-stabilized zirconia coatings deposited by electron beam physical vapor deposition were also studied [SCH87], but adherence was still poor. The poor adherence precluded performance testing of coated components.

A new coating designed specifically for heat engine applications was proposed for this work. This coating is unique in that it consists of two layers, each of which is compositionally graded so that there are not sharp interfaces. The outer layer is oxidation resistant and should provide toughness and a low coefficient of friction, while the intermediate layer serves primarily as a bonding layer. A composite of $\mathrm{Al}_{2} \mathrm{O}_{3}$ and $\mathrm{ZrO}_{2}$ was selected for the outer layer, and AlN was selected for the intermediate layer. Figure 1 is a schematic of the proposed coating configuration.

Unlike previous studies, one coating configuration was used for all substrates in this program. However, coating properties (e.g., composition, thickness, microstructure) could in principle be varied to achieve compatibility with each substrate by modifying the coating deposition conditions. Chemical vapor deposition (CVD) was proposed as the coating 
application technique. CVD is preferred for this application because with this technique, athesion can be enhanced via chemical bonding or solio solution formation between coating ani substrate, interdiffusion at the interface, or formation of new phases at the interface due to reaction between the CVD gas mixture and the substrate surface. In contrast, alternative deposition techniques such as those based on physical vapor deposition or spraying produce coating/substrate attachment which is usually mechanical. Additional advantages of CVD include its ability to uniformly coat parts with complex shapes and its ability to be scaled-up to produce commercial quantities.

The development of the coating configuration and the CVD processes for applying the coating was guided by mathematical modeling. A model based on finite element analysis was developed to calculate relationships between thickness of the various coating layers and residual stress levels in the coating and substrate. Although predictive capability was not achieved, the model did give insight into control of stress build-up in the coating. Mathematical models were also used to determine (1) feasibility of growing the desired coating under various sets of CVD operating conditions, (2) dependence of coating yield and growth rate on operating conditions, and (3) relationships between coating composition and operating conditions. Results were plotted in the form of "CVD phase diagrams" for growth of $\mathrm{Al}_{2} \mathrm{O}_{3}+\mathrm{ZrO}_{2}$ composite and AlN coatings.

During this program, the CVD processes were developed and coatings were deposited on three substrates-reaction bonded $\mathrm{Si}_{3} \mathrm{~N}_{4}$ (RBSN), hot isostatically pressed $\mathrm{Si}_{3} \mathrm{~N}_{4}$ (HSN), and sintered $\mathrm{SiC}$ (SSC) (Table 1). Work was done on test bars measuring 2 in. $\times 1 / 4$ in. $\times 1 / 8$ in. that were either whole or cut into three equal size pieces before coating. Adherence of the coating was assessed using a conventional scratch test (Revetest type). The effect of the coating on the flexure strength of each substrate material was measured at room and elevated temperature. The thermal shock resistance was tested by rapidly and repeatedly cycling samples to typical engine operating temperatures. Long term, high temperature oxidation resistance in static air was also studied. In each case, the effect of the test on coating adhesion was evaluated. Finally, a set of samples was coated for contact stress tests which 
will be conducted by Garrett Turbine Engine Company, Auxiliary Power Division.

The results obtained in this phase of the program demonstrated significant potential for the use of this coating configuration on ceramic engine components to reduce contact stress damage of the substrate. The coatings generally remained intact during performance tests at temperatures of $1000^{\circ} \mathrm{C}$. However, the $\mathrm{AlN}$ and $\mathrm{Al}_{2} \mathrm{O}_{3}+\mathrm{ZrO}_{2}$ coatings, deposited by CVD, were cracked. Finite element analysis was used to show that these coatings, deposited by convential CVD, would always crack, and that the concept of "graded" layers would not prevent the cracking problem. 


\section{EXECUTIVE_SUMMARY}

This report summarizes the Phase II findings on the development of an $\mathrm{Al}_{2} \mathrm{O}_{3}+\mathrm{ZrO}_{2}$ composite coating, intended to reduce the contact stress damage of $\mathrm{Si}_{3} \mathrm{~N}_{4}$ and $\mathrm{SiC}$ ceramics. An AlN interlayer ( -5 microns thick) was demonstrated to be an effective means of providing good adhesion between $\mathrm{Al}_{2} \mathrm{O}_{3}+\mathrm{ZrO}_{2}$ ( $\sim$ micron thick) and the ceramic substrates. During this program, CVD processes were developed and used to successfully deposit the multilayer coating. The performance of the coatings produced in Phase II was assessed by oxidation tests, scratch tests, and pin-on-disk sliding contact.

Modeling the diffusion of oxygen through an $\mathrm{Al}_{2} \mathrm{O}_{3}$ layer at elevated temperatures suggested that the coating would be an adequate diffusion barrier to oxygen. However, experimental results revealed that the composite coating configuration was not oxidation resistant for 500 hours at temperatures above $1000^{\circ} \mathrm{C}$. The lack of protection is attributed to cracks in the $\mathrm{Al}_{2} \mathrm{O}_{3}+\mathrm{ZrO}_{2}$ layer, which allowed oxygen to penetrate and react with AlN. The kinetics of oxidation of AlN are sufficiently slow at $1000^{\circ} \mathrm{C}$ for the coating to protect the substrate for 500 hours. However, above $1000^{\circ} \mathrm{C}$, the oxidation rate of AlN is rapid enough to cause the AlN to fully oxidize to $\mathrm{Al}_{2} \mathrm{O}_{3}$.

A major aspect of this program has dealt with the use of finite element methods and fracture mechanics to model the behavior of brittle multilayer coatings. Detailed analysis of the residual stresses in uncracked coatings on ceramic substrates revealed that the coating thickness, order of coating layers (including grading of the coefficient of thermal expansion), and elastic modulus of the coating all have a negligible effect on the residual stress in the coating. It was concluded that due to the high temperatures used in CVD processing and inherent thermal expansion mismatch between the materials, the $\mathrm{Al}_{2} \mathrm{O}_{3}+\mathrm{ZrO}_{2}$ coatings would contain uracks upon cooling to room temperature.

To better understand the behavior of cracks in the coating and possibly identify a means to eliminate them from the coating, additional modeling was performed. The effect of crack propagation during solid body contact was studied using interface fracture mechanics coupled with finite element analysis. Several geometries were studied; one coating layer with a vertical 
flaw, twc coating layers with a vertical flaw, and two coating layers with a horizontal flaw. Thermal residual stress and point contact loads (which simulated the scratch test) were applied to the coated system and the crack was allowed to propagate. For vertical flaws, the cracks always propagated into the substrate. Further analysis showed that improving the fracture toughness of the interface would not improve the performance of the coating, since the interface was not a weak point. In contrast, the horizontal crack did not reach the substrate. A crack in the middle layer of a two layer coating, stayed within that layer. A crack in the outer layer of a coating moved away from the substrate and towards the f'ee surface. Therefore, cracks of this type would not degrade the oxidation performance of a coated substrate.

The possibilities for working around the problem inherent to thin brittle coatings could lie in the area of controlled brittle fracture of multilayers, controlling the residual stress in the deposited film, or by the use of "ductile" layers which would permit stress relief and alleviate pre-service cracking. Physical vapor deposition (PVD) methads, which allow the residual stress state to be controlled, or low temperature CVD processes may allow for crack-free coatings to be deposited. The coating would then be in a compressive stress state at the service temperature and would not crack. It is anticipated that without cracks, the $\mathrm{Al}_{2} \mathrm{O}_{3}+\mathrm{Z}_{\mathrm{rO}_{2}}$ composite coating would be an effective means of reducing the contact stress damage and oxidation of $\mathrm{Si}_{3} \mathrm{~N}_{4}$ ceramics.

A single point scratch test was used to assess the protective nature of the coatings during contact loading on unoxidized samples at room temperature. The coating protected the $\mathrm{SiC}$ (SSC) and reaction bonded $\mathrm{Si}_{3} \mathrm{~N}_{4}$ (RBSN) substrates by reducing chipping and cracking of the substrates. No significant differences were seen in the scratch resistance of the uncoated and coated hot pressed $\mathrm{Si}_{3} \mathrm{~N}_{4}$ (HSN).

A method was developed to measure the ultimate tensile strength, iracture toughness, and Weibull modulus of thin brittle coatings on suisstrates. The technique is based on measuring the radius of curvature of a coated substrate, and equating the resulting calculated stress with a theoretical shear-lag stress distribution model. The Weibull modulus and fracture stress of $\mathrm{Al}_{2} \mathrm{O}_{3} \mathrm{CVD}$ coatings on $\mathrm{SiC}$ substrates were measured. The 
fracture stresses for coatings of these materials ranged from $190 \mathrm{MPa}$ to 480 $\mathrm{MPa}$, the Weibull modulus ranged from 16 to 28 , and the fracture toughness ranged from $0.5-1.1 \mathrm{MPa} \sqrt{\mathrm{m}}$. This work has shown that the tensile strength of $\mathrm{Al}_{2} \mathrm{O}_{3}$ and $\mathrm{Al}_{2} \mathrm{O}_{3}+\mathrm{ZrO}_{2}$ coatings can be approximated by bulk values, however, the fracture toughness of these coatings was found to be significantily lower than bulk values.

Additional contact stress tests on Phase I coatings were carried out by Garrett Turbine Engine company. These tests were deemed inconclusive due to the lack of coating oxidation resistance at $1200^{\circ} \mathrm{C}$.

Pin-on-disk tests were used to measure the breakaway and kinetic friction coefficients for coated and uncoated materials. Room temperature results showed that the $\mathrm{Al}_{2} \mathrm{O}_{3}+\mathrm{ZrO}_{2}$ coating reduces the kinetic friction coefficient of RBSN and HSN by as much as 50\% in self-mated tests. No apparent reduction in friction was observed for the SSC substrate. An improvement in sliding wear resistance was obtained with $\mathrm{Al}_{2} \mathrm{O}_{3}+\mathrm{Z}_{2} \mathrm{O}_{2}$ coated HSN in the pin-on-disk test, whereas the coatings on RBSN and SSC were ineffective. 


\section{DESIGN OF COATING CONFIGURATION}

REQUIREMENTS OF TEE APPLICATION

Advanced heat engine components are subjected to high localized stresses in contacting areas during operation. In addition, they are exposed to extreme conditions of thermal cycling. The use of thin ( $<100$ microns) ceramic coatings on various components has been shown to reduce contact stress damage by reducing the relative coefficient of friction and elastic modulus of the contacting parts. However, the coating must be strongly adherent and not degrade under thermal shock and oxidizing conditions at engine operating temperatures. These requirements dictate six major design criteria:

1. Strong coating/substrate adherence.

2. Low residual stress in the coating and at the coating/substrate interface.

3. Excellent oxidation resistance and low permeability of oxygen through the coating.

4. High thermal shock resistance.

5. Imtroved mechanical strength and low coefficient of friction at room and elevated temperatures.

6. Minimum chemical interaction between the substrate and the coating and coating stability at operating temperatures.

A single monolithic ceramic coating which could satisfy all of these criteria could not be identified. Hence, a multilayered coating configuration was proposed (see Figure 1). This coating consists of an intermediate layer whose primary function is to promote bonding with the substrate, and an outer layer which provides the required mechanical properties and oxidation resistance. 


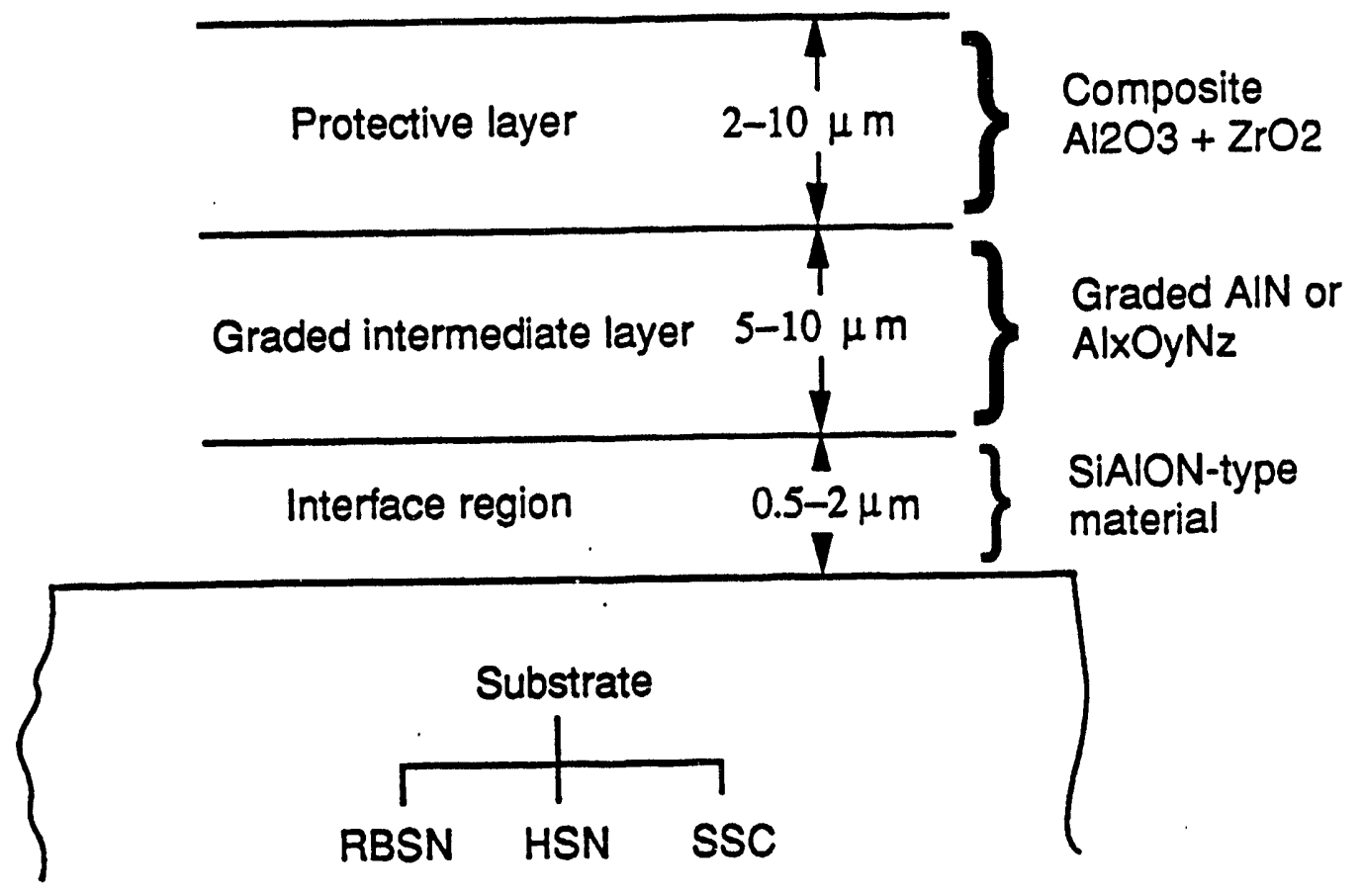

Figure 1. Schematic of coating design.

\section{Chemical, physical, and Mecianical Property Considerations}

The important chemical properties required of the outer coating layer are oxidation resistance and low permeability to oxygen. The oxidation resistance of $\mathrm{Al}_{2} \mathrm{O}_{3}$ is well known. Even with this outer layer, it would still be possible for oxygen to diffuse through the layer via pores or cracks. Hence, an intermediate layer which can dissolve or react with oxygen is necessary. Aluminum nitride forms polytypes and solid solutions with oxygen over wide ranges of composition, so it is a candidate for the intermediate layer. In addition, AlN forms solid solutions with $\mathrm{Si}_{2} \mathrm{~N}_{2} \mathrm{O}$, and these solutions are the basis for some SiAlON-type compounds. Since $\mathrm{Si}_{3} \mathrm{~N}_{4}$ readily oxidizes to form $\mathrm{Si}_{2} \mathrm{~N}_{2} \mathrm{O}$, the surface of $\mathrm{Si}_{3} \mathrm{~N}_{4}$ materials generally contains $\mathrm{Si}_{2} \mathrm{~N}_{2} \mathrm{O}$. Hence the potential for SiAlON formation exists at the $\mathrm{Si}_{3} \mathrm{~N}_{4} /$ coating interface. It is therefore expected that if AlN is used as the intermediate layer, it will act as a chemical oxygen barrier and as a bonding agent with $\mathrm{Si}_{3} \mathrm{~N}_{4}$-based substrates.

Physical and mechanical properties which are considered to be relevant to coating design include density, thermal expansion coefficient, 
fracture toughness, elastic modulus, hardness, and Poisson's ratio. The composition and selected properties are listed in Table 1 for the substrate materials as well as for the candidate coating materials. The values reported are for bulk materials; it is assumed for purposes of coating design that the property values are the same for thin films.

Table 1. Properties of the materials used in this study.

\begin{tabular}{|c|c|c|c|c|}
\hline Material & $\begin{array}{c}\text { Nominal } \\
\text { Composition } \\
(w t \%)\end{array}$ & $\begin{array}{c}\text { Density } \\
\text { (actual/ } \\
\text { theoretical) } \\
\left(\mathrm{g} / \mathrm{cm}^{2}\right)\end{array}$ & $\begin{array}{c}\text { KHN } \\
\text { (GPa) } \\
\text { Face/Edge }\end{array}$ & $\begin{array}{l}\text { Identation } \\
\text { Fracture } \\
\text { Toughness } \\
(\mathrm{MPa} \sqrt{\mathrm{m}}) \\
\text { Face/Edge }\end{array}$ \\
\hline $\begin{array}{l}\text { RBSN } \\
\text { (Airesearch) }\end{array}$ & $\begin{array}{l}>95 \% \mathrm{Si}_{3} \mathrm{~N}_{4} \\
<3 \mathrm{Si} \\
<2 \mathrm{Fe}\end{array}$ & $2.75 / 3.19$ & $\begin{array}{l}9.846 \pm 0.56 \\
9.395 \pm 0.80\end{array}$ & $\begin{array}{l}3.5 \pm 0.3 \\
4.0 \pm 0.6\end{array}$ \\
\hline $\begin{array}{l}\text { SSC } \\
\text { (Hexalloy SA) }\end{array}$ & $\begin{array}{l}>95.5 \mathrm{SiC} \\
<0.5 \mathrm{~B} \\
<0.1 \text { impurities }\end{array}$ & $3.17 / 3.21$ & $\begin{array}{l}25.29 \pm 0.91 \\
23.91 \pm 0.46\end{array}$ & $\begin{array}{l}2.2 \pm 0.2 \\
2.3 \pm 0.2\end{array}$ \\
\hline $\begin{array}{l}\text { HSN } \\
\text { (GTE AY6) }\end{array}$ & $\begin{array}{l}92 \mathrm{Si}_{3} \mathrm{~N}_{4} \\
2 \mathrm{Al}_{2} \mathrm{O}_{3} \\
6 \mathrm{Y}_{2} \mathrm{O}_{3} \\
<0.1 \text { impurities }\end{array}$ & $3.25 / 3.26$ & $\begin{array}{l}13.22 \pm 0.15 \\
13.11 \pm 0.17\end{array}$ & $\begin{array}{l}3.4 \pm 0.2 \\
3.3 \pm 0.3\end{array}$ \\
\hline $\mathrm{Al}_{2} \mathrm{O}_{3}$ & & 3.99 & $13-15$ & 2.5 \\
\hline AlN & & 3.28 & $\ldots$ & $2-3$ \\
\hline
\end{tabular}




\section{COATING PROCESS DEVELOPMENT}

\section{THERMODYNAMIC ANALYSIS OF COATING PROCESS}

Thermodynamic analysis of the coating procedure was preformed in Phase I of this program. The results are listed in Appendix B of the Phase I final report.

\section{HIGH TEMPERATURE COATING DEPOSITION REACTOR}

A new CVD reactor was built, the Phase II reactor. This reactor is a hotwall, crucible type reactor that is heated resistively with graphite heating elements. The system was leak checked and found to be leak-free down to a pressure of $10^{-6}$ torr. Source gases enter at the bottom, flow upward past the parts to be coated, and exit through exhaust tubes terminating above the deposition zone. This is illustrated in Figure 2. A perforated plate defines the upper limit of the deposition zone. Graphite rods are hung from this plate to form a finture for supporting the substrates. The substrates are placed on a grid of thin alumina rods that pass through holes in the graphite rods. The volume of the reactor is 5 liters. An internal reactor is used for generating volatile $\mathrm{AlCl}_{3}$ and $\mathrm{ZrCl}_{4}$, which are the aluminum and zirconium source materials being used for the $\mathrm{AlN}$ and $\mathrm{Al}_{2} \mathrm{O}_{3}+\mathrm{ZrO}_{2}$ coatings. 


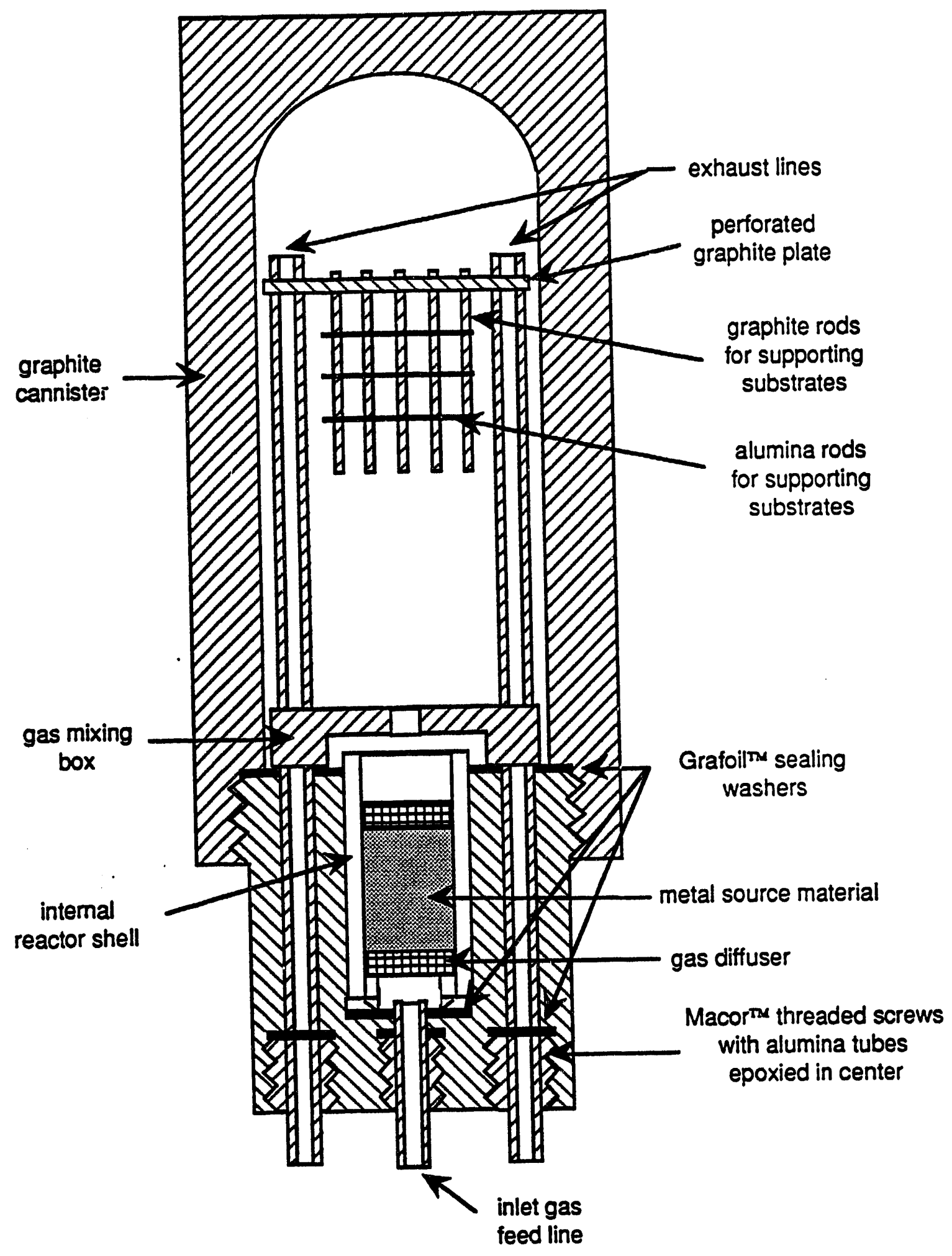

Figure 2. Phase II high temperature CVD reactor being used for coating deposition. 
Formation of a coating at high temperatures $\left(\mathrm{T}>1000^{\circ} \mathrm{C}\right)$ was complicated by the tendency for gas phase nucleation to occur in CVD processes that use $\mathrm{AlCl}_{3}$ as a surce material. To compensate for the higher thermal driving furce for gas phase nucleation, we reduced the pressure to 10 torr. The system can be operated at pressures as low as 1 torr depending on the total gas flow rate.

The CVD reacior which was previously being used for Phase I of this program was modified to incorporate two internal reactors for simultaneously generating two different source materials. Previously, all source materials were zenerated in one internal reactor. This resulted in poor control over the relative amounts and distribution of $\mathrm{ZrO}_{2}$ and $\mathrm{Al}_{2} \mathrm{O}_{3}$, in the $\mathrm{Al}_{2} \mathrm{O}_{3}+\mathrm{ZrO}_{2}$ composite layer. Details of the composite layer composition were discussed in the October, 1989 Bimonthly Progress Report. The new design was expected to allow better control of the relative rates of generation of $\mathrm{AlCl}_{3}$ and $\mathrm{ZrCl}_{4}$ for deposition of the $\mathrm{Al}_{2} \mathrm{O}_{3}+\mathrm{ZrO}_{2}$ composite layer.

\section{EXPERIMENTAL COATIIG PROCESS}

Process development for deposition of the coating at temperatures above $1000^{\circ} \mathrm{C}$ was carried out for the Phase II graphite high temperature CVD reactor (Figure 2). Initially, attempts were made to deposit a pure $\mathrm{Al}_{2} \mathrm{O}_{3}$ coating. The first experiment was done at $1000^{\circ} \mathrm{C}$ to establish reproducibility of coatings obtained in the Phase J. CVD reactor. The coating produced was not analyzed, although it appeared to be similar to those obtained in the Phase I reactor. Based on weight gain, the deposition rate was approximately 0.5 microns/hour, which was typical of the deposition rate obtained in the other reactor. The deposition temperature was then raised to $1200^{\circ} \mathrm{C}$. This gave a 1.5 micron thick coating in one hour. However, $\mathrm{Al}_{2} \mathrm{O}_{3}$ powder also formed cue to zas phase nucleation. Most of this powder was easily removed from the samples, and the remaining coating appeared to be nonporous and smooth on the surface. In order to determine if there was a relationship between deposition temperature and gas phase nucleation, an experiment was done at $1120^{\circ} \mathrm{C}$. This run produced extensive amounts of powder, causing the reactor exhaust line to plug. In addition, melting of the $\mathrm{Al}$ metal in the $\mathrm{AlCl}_{3}$ 
generator occurred, so samples from this run were not analyzed. The remainder of the experiments done were deposition of $\mathrm{Al}_{2} \mathrm{O}_{3}+\mathrm{ZrO}_{2}$ or AIN.

Since some success was achieved with deposition of pure $\mathrm{Al}_{2} \mathrm{O}_{3}$ at $1200^{\circ} \mathrm{C}$, the first $\mathrm{Al}_{2} \mathrm{O}_{3}+\mathrm{ZrO}_{2}$ experiment was done at $1200^{\circ} \mathrm{C}$. This resulted in extensive gas phase nucleation. The deposit that collected on the substrates was loosely adherent and easily rubbed off. No weight gain of the substrate was detected, which suggested that no coating had formed. Another experiment was done at this temperature, but with the relative amounts of $\mathrm{AlCl}_{3}$ and $\mathrm{ZrCl}_{4}$ source varied; i.e., a higher ratio of $\mathrm{Zr} / \mathrm{Al}$. This resulted in a moderate amount of powder formation due to gas phase nucleation. In addition, a very thick, loosely adberent coating was again easily removed. A third experiment was done at $1200^{\circ} \mathrm{C}$ with the same ratio of source materials but with a steeper temperature profile so that the source gases did not get preheated to as high a temperature. It was hypothesized that this would reduce the amount of gas phase nucleation. This succeeded in producing less powder. Additional experiments were done with the original $\mathrm{Zr} / \mathrm{Al}$ ratio in the source gases and with deposition temperatures of $1300^{\circ} \mathrm{C}$ and $1375^{\circ} \mathrm{C}$. The experiment at $1300^{\circ} \mathrm{C}$ produced a thick, nonporous, well adherent coating and a small amount of powder. The coating thickness indicated a deposition rate of 11 microns/hour. The experiment at $1375^{\circ} \mathrm{C}$ gave a moderate amount of powder and a thick coating.

Analysis of the high temperature $\mathrm{Al}_{2} \mathrm{O}_{3}$ and $\mathrm{Al}_{2} \mathrm{O}_{3}+\mathrm{ZrO}_{2}$ experiments suggests that there is a transition temperature, below which gas phase nucleation dominates, and above which surface nucleation dominates. At the lowest deposition temperature used in this program $\left(975^{\circ} \mathrm{C}\right.$ used throughout Phase I and early Phase II), gas phase nucleation was not measurable, but the deposition rate was very low ( $<1$ micron/hour for either $\mathrm{Al}_{2} \mathrm{O}_{3}$ or $\mathrm{Al}_{2} \mathrm{O}_{3}+\mathrm{ZrO}_{2}$ ). At $1200^{\circ} \mathrm{C}$ for pure $\mathrm{Al}_{2} \mathrm{O}_{3}$ and $1300^{\circ} \mathrm{C}$ for $\mathrm{Al}_{2} \mathrm{O}_{3}+\mathrm{ZrO}_{2}$, the deposition rate was much higher and an adherent coating was formed with only moderate amounts of powder from gas phase nucleation. At intermediate temperatures, extensive powder formation took place, and little or no adherent coating was formed. The only experiment that did not fit this trend was the one in which $\mathrm{Al}_{2} \mathrm{O}_{3}+\mathrm{Z}_{\mathrm{rC}}$ was deposited at $1375^{\circ} \mathrm{C}$. It should be emphasized that these resulis are specific to our deposition system and should therefore not be generalized 
to predict the behavior of other systems. This is especially important since the temperature profile in the gas phase upstream of the deposition zone appears to strongly influence the results.

The remainder of the experiments were directed towards the deposition of AlN. Initially, an experiment was done at $1000^{\circ} \mathrm{C}$ to establish reproducibility of coatings obtained in the low temperature CVD reactor. This resulted in quite different behavior than that which typically occurred in the low temperature reactor. Specifically, an adherent, thick coating formed along with an extensive amount of powder. The coating thickness varied substantially on a given sample, corresponding to a deposition rate of 6-9 microns/hour. The difference in behavior can be attributed to the different temperature profile experienced by the gas phase, suggesting that the AlN system is very sensitive to this parameter. A second experiment at $1200^{\circ} \mathrm{C}$ also gave extensive powder formation, but a lower and more variable deposition rate (1-5 microns/hour). It should be emphasized that the reported deposition rates are only apparent rates since they are determined by measuring coating thickness at several locations and dividing by the total deposition time. Loss of loosely adherent coating or flaking or chipping of strongly adherent coating, during fracture of the sample, could skew the measurement.

In Phase I of this work $\mathrm{Al}$ and $\mathrm{Zr}$ metals were mixed together to generate the $\mathrm{AlCl}_{3}$ and $\mathrm{ZrCl}_{4}$ reactant gases for composite layer deposition. This led to a nonuniform distribution of $\mathrm{Zr}$ in the coating. The $\mathrm{Zr}$ reacted first and a layer of pure $\mathrm{ZrO}_{2}$ was deposited followed by an $\mathrm{Al}_{2} \mathrm{O}_{3}$ layer. In Phase II an $\mathrm{Al}-\mathrm{Zr}$ metal alloy was used as the metal source to generate the $\mathrm{AlCl}_{3}$ and $\mathrm{ZrCl}_{4}$ reactant gases for composite layer deposition. The $\mathrm{Al}-\mathrm{Zr}$ alloy was prepared by melting under argon and had a composition of 88 wt\% Al-12 wt\% $\mathrm{Zr}$. Use of this $\mathrm{Al}-\mathrm{Zr}$ alloy produced a composite film with a uniform $\mathrm{Zr}$ distribution. The "best set" of deposition conditions used to deposit AlN and $\mathrm{Al}_{2} \mathrm{O}_{3}+\mathrm{ZrO}_{2}$ coatings are listed in Table 2. The microstructure of these coatings is detailed in the next section. 
Table 2. Process conditions for CVD deposition of $\mathrm{AlN}$ and $\mathrm{Al}_{2} \mathrm{O}_{3}+\mathrm{ZrO}$.

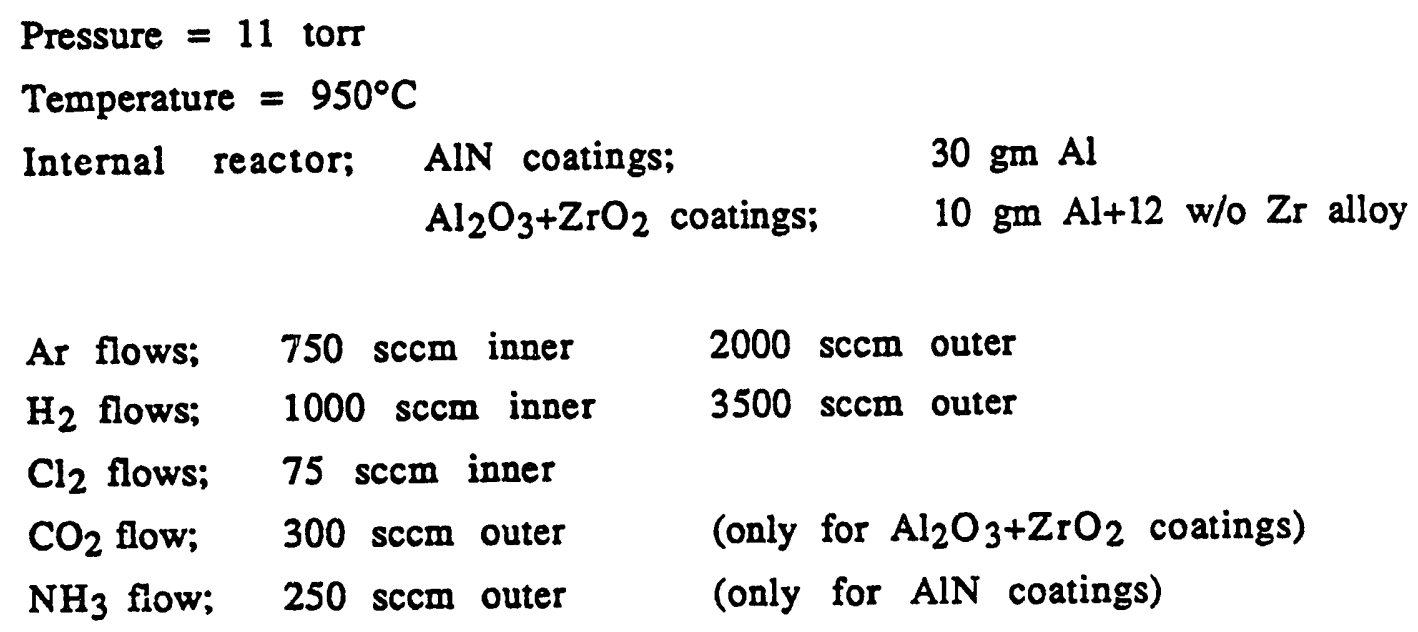




\section{MATERIAL CHARACTERIZATION}

\section{MICROSTRUCTURE OF COATING}

\section{Phase I Coating}

Figure 3 shows the surface of an $\mathrm{Al}_{2} \mathrm{O}_{3}$ coating deposited on SSC substrate. The rough surface topology is attributed to $\mathrm{Ni}$ contamination from the Inconel vessel in the CVD reactor [COL86]. This problem was eliminated in the Phase II coating where a graphite CVD reactor was used.

Figure 4 shows a cross-section of the $\mathrm{AlN} / \mathrm{Al}_{2} \mathrm{O}_{3}+\mathrm{ZrO}_{2}$ coating on the SSC substrate, the coating had the same morphology on the RBSN and HSN substrates. The $\mathrm{Zr}$ is concentrated at the AlN/composite interface.

The microstructure of the $\mathrm{Al}_{2} \mathrm{O}_{3}+\mathrm{ZrO}_{2}$ composite layer has been studied by TEM and analytical electron microscopy. A sample of the Phase I $\mathrm{Al}_{2} \mathrm{O}_{3}+\mathrm{Z} \cdot \mathrm{rO}_{2}$ coating on a $\mathrm{TiC}$ whisker reinforced $\mathrm{Al}_{2} \mathrm{O}_{3}$ substrate was analyzed. This substrate was used because previous attempts at preparing a thin foil specimen of coated silicon nitride-based materials were unsuccessful. The failure was attributed to uneven milling rates of the coating and substrate during ion beam milling. The coating was 3 microns thick and contained approximately $3 \mathrm{w} / \mathrm{o} \mathrm{Zr}$. It was found that the majority of the coating was essentially pure $\mathrm{Al}_{2} \mathrm{O}_{3}$ with the $\mathrm{Zr}$ concentrated at the interface between the coating and the substrate. The $\mathrm{Zr}$ was present as 30 nanometer particles containing impurities that were identified as silicon, tungsten, and probably oxygen. These impurities are very likely introduced during deposition of the coating as a result of residue inside the CVD equipment from coating of other substrate materials. The TEM study did not determine that the $\mathrm{Z}_{\mathrm{r}}$ was present as $\mathrm{ZrO}_{2}$. An amorphous Si-rich phase was also present at the interface. This glass probably formed from the binder material in the substrate. The grain size of the $\mathrm{Al}_{2} \mathrm{O}_{3}$ in the coating ranged from 40 to 200 nanometers with the majority being 50 nanometers.

The TEM results are consistent with earlier studies done using electron microprobe. In particular, $\mathrm{ZrO}_{2}$ was found to be concentrated at the interface. 


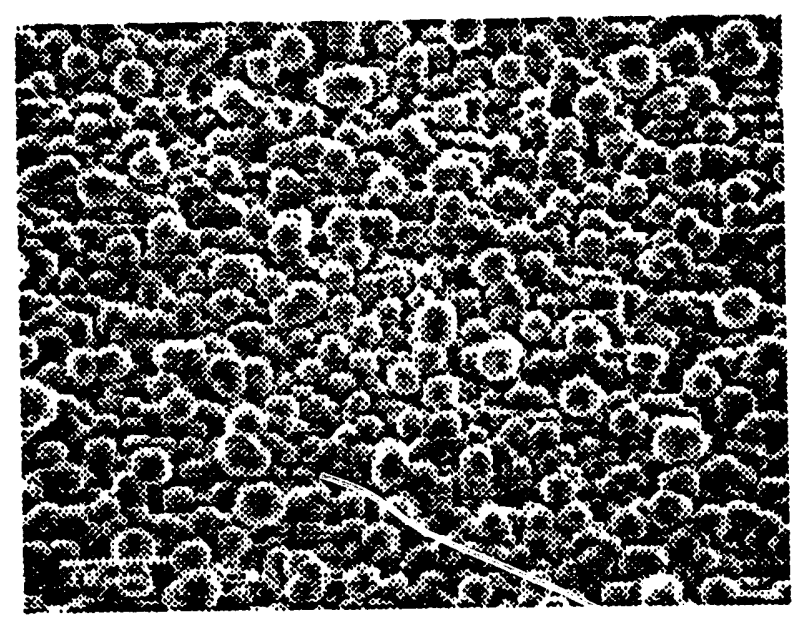

Figure 3. SEM micrograph of the surface of a Phase I $\mathrm{Al}_{2} \mathrm{O}_{3}$ coating on SSC. 


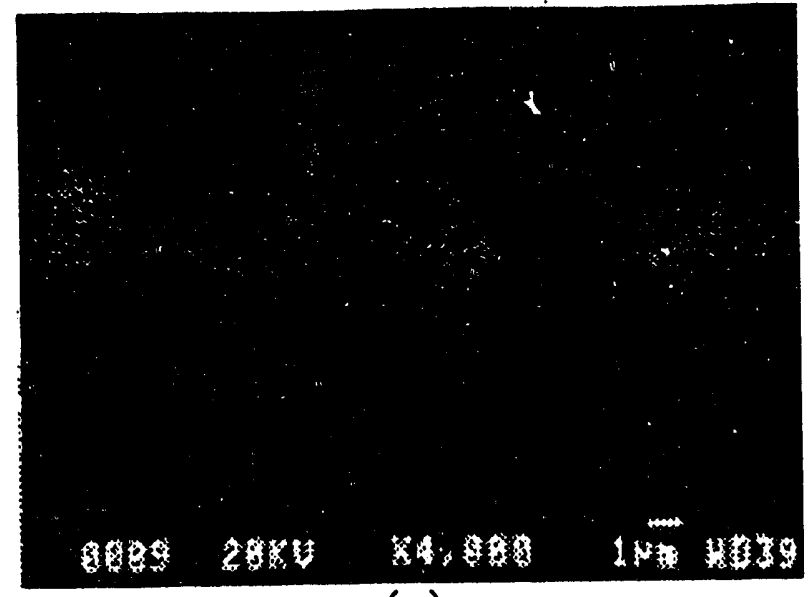

(a)

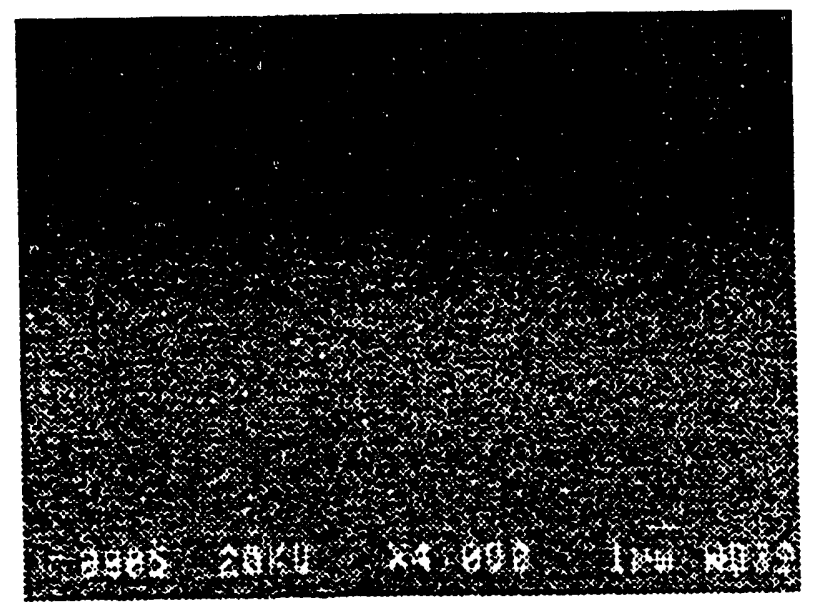

(b)

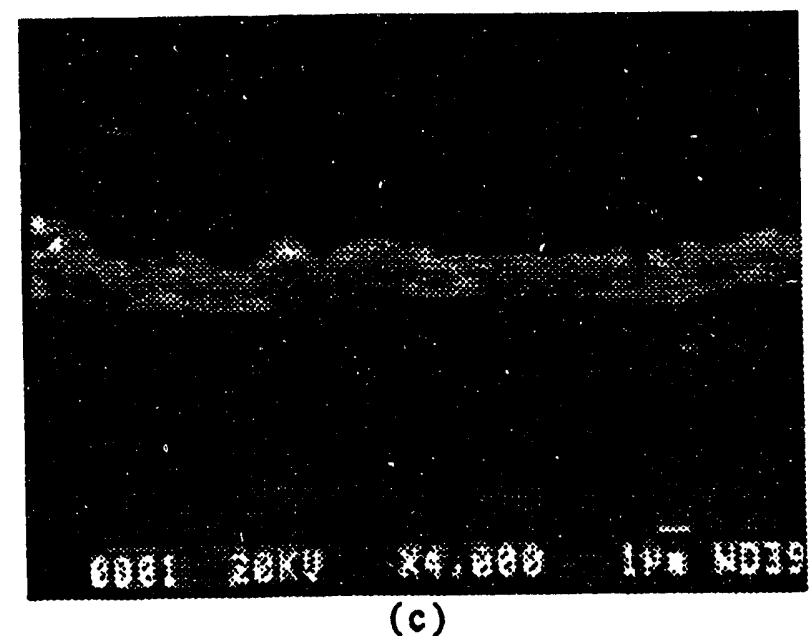

Figure 4. SEM micrograph of a Phase $\mathrm{I} \mathrm{Al}_{2} \mathrm{O}_{3}+\mathrm{ZrO}_{2}$ coating on SSC. a) Back scattered electron image, b) Al X-ray map, c) $\mathrm{Zr} \mathrm{X}$-ray map. 


\section{Phase II Coating}

Figure 5 shows the surface of an $\mathrm{Al}_{2} \mathrm{O}_{3}$ coating deposited on SSC substrate. The smooth surface topology is contrasted with the rough surface of the Phase I coatings, Figure 3.

Figure 6 shows a cross-section of the $\mathrm{AlN} / \mathrm{Al}_{2} \mathrm{O}_{3}+\mathrm{ZrO}_{2}$ coating on the SSC substrate, the coating morphology on the RBSN and HSN substrates were identical. The $\mathrm{Zr}$ is uniformly dispersed throughout the composite region. A sample was prepared for transmission electron microscopy (TEM). This sample showed that the $\mathrm{Al}_{2} \mathrm{O}_{3}$ grain size was $30-50 \mathrm{~nm}$ and was alpha $\mathrm{Al}_{2} \mathrm{O}_{3}$. $\mathrm{ZrO}_{2}$ particles were not identified, this is believed to be due to the small volume fraction of $\mathrm{ZrO}_{2}(5 \%)$ in the composite making it very difficult to identify $\mathrm{ZrO}_{2}$ particles directly. While the phase of $\mathrm{ZrO}_{2}$ was not identified it is believed that the $\mathrm{ZrO}_{2}$ grain size was the same as the $\mathrm{Al}_{2} \mathrm{O}_{3}(30-50 \mathrm{~nm})$.

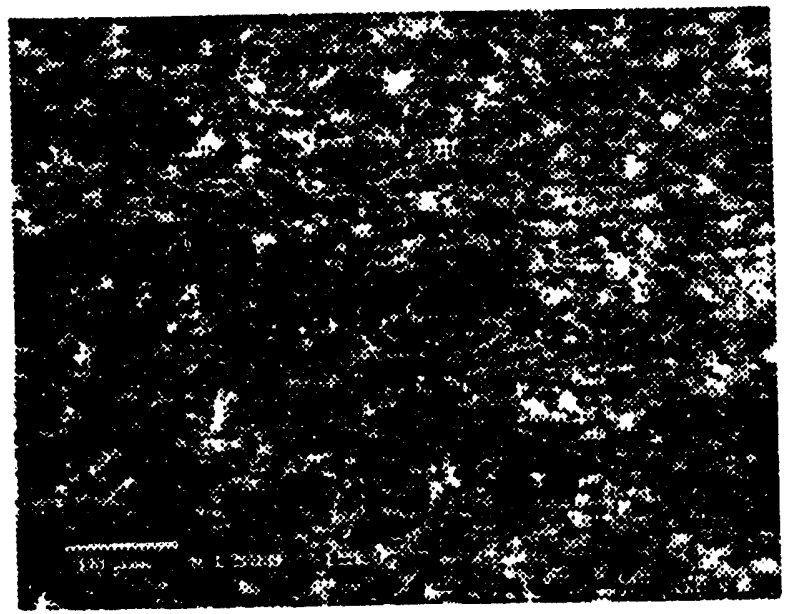

Figure 5. SEM micrograph of the surface of Phase II $\mathrm{Al}_{2} \mathrm{O}_{3}$ coating on SSC. 


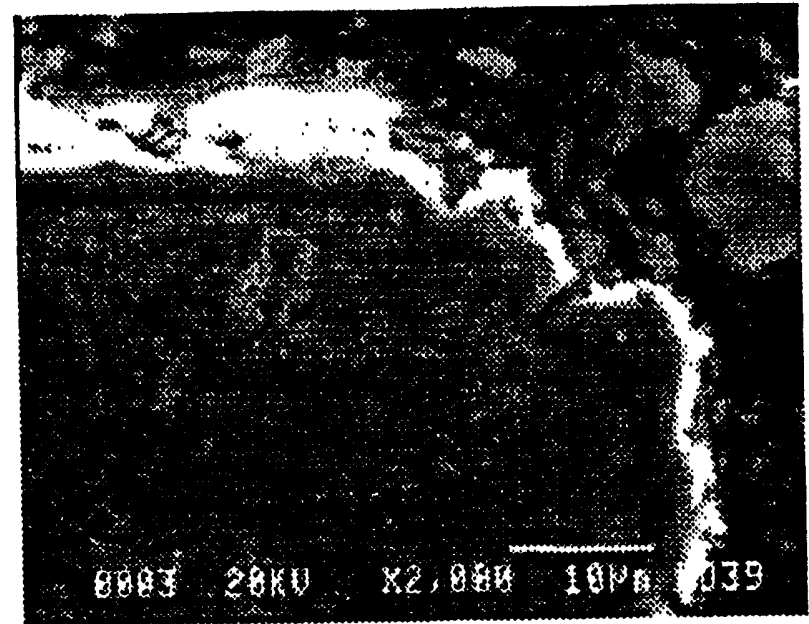

(a)

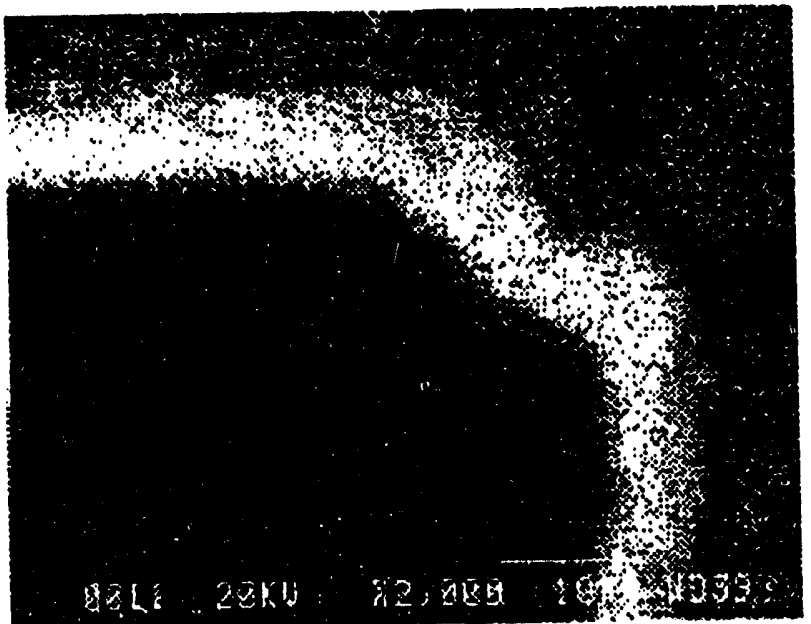

(b)

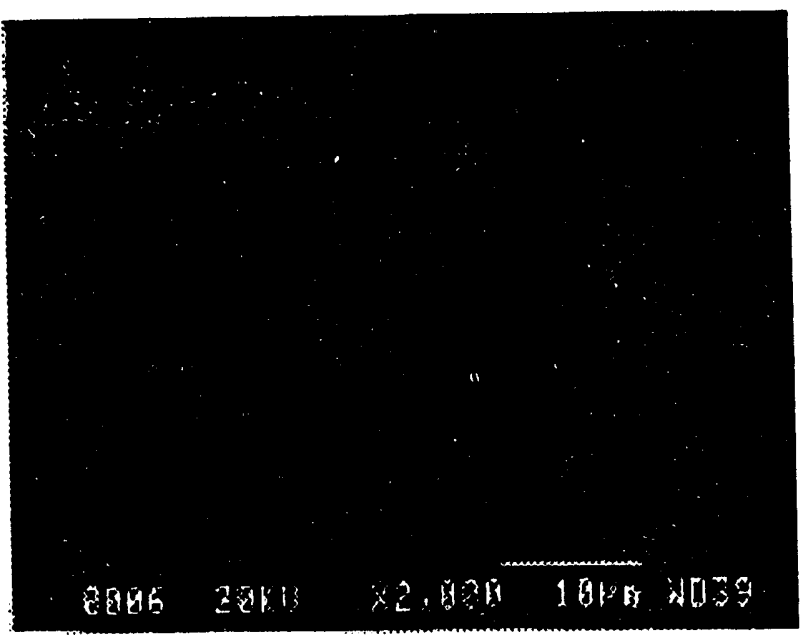

(c)

Figure 6. SEM micrograph of a Phase $I I \mathrm{Al}_{2} \mathrm{O}_{3}+\mathrm{ZrO}_{2}$ coating on SSC. a) Back scattered electron image, b) Al X-ray map, c) $\mathrm{Zr} \mathrm{X}$-ray map. 


\section{PaYsical PROPERTIES OF COATING}

\section{Oxidation-Literature Review}

During Phase I, the oxidation resistance of the coating in static air was studied. The coating was found to be oxidation resistant for up to 500 hours at $1000^{\circ} \mathrm{C}$, but was not oxidation resistant at $1200^{\circ} \mathrm{C}$ or higher. The lack of oxidation resistance at elevated temperatures was studied in Phase II.

The oxidation behavior of silicon nitride, silicon carbide, and aluminum nitride were the subjects of several previous studies. A brief summary of the literature is provided in the following sections. These summaries are intended to provide basic information and to indicate some relevant articles in the literature.

\section{Oxidation of Silicon Nitride}

The oxidation of $\mathrm{Si}_{3} \mathrm{~N}_{4}$ depends on the type and amount of porosity, the flow rate of the oxidizing gas, and the types of additives and/or impurities present. Figure 7 shows the weight gain versus time for liquid phase sintered $\mathrm{Si}_{3} \mathrm{~N}_{4}$ [BAB83, SNN76a] and RBSN [POR84] for comparison. All samples were oxidized at $-1300^{\circ} \mathrm{C}$, except $\mathrm{RBSN}-1100^{\circ} \mathrm{C}$ which was oxidized at $1100^{\circ} \mathrm{C}$. The oxidation rate was strongly dependant on the type of $\mathrm{Si}_{3} \mathrm{~N}_{4}$ under study. The general oxidation reaction is:

$$
\mathrm{Si}_{3} \mathrm{~N}_{4}+3 \mathrm{O}_{2}=3 \mathrm{SiO}_{2}+2 \mathrm{~N}_{2}
$$

However, when impurities are present, a mixed glass phase forms instead of $\mathrm{SiO}_{2}$. This mixed glass may have a lower viscosity and can have a significant effect on the oxidation rate. Full oxidation of $\mathrm{Si}_{3} \mathrm{~N}_{4}$ to $\mathrm{SiO}_{2}$ is accompanied by a $28.3 \%$ increase in weight.

The oxidation of liquid phase sintered $\mathrm{Si}_{3} \mathrm{~N}_{4}$ probably depends on the diffusion rate of the cation impurities. An activation energy of $374 \mathrm{~kJ} / \mathrm{mole}$ ( 93 $\mathrm{kcal} / \mathrm{mole}$ ) was reported [SIN76a]. During oxidation the cations became concentrated in the outer $\mathrm{SiO}_{2}$ layer. $\mathrm{MgO}$ and $\mathrm{CaO}$ increase the oxidation rate. This increase in oxidation rate was probably due to a lowering of the melting point of the glassy phase which increases the diffusion rate. Impurities can increase the oxidation rate by two orders of magnitude or more [BAB83]. 
Varying the $\mathrm{N}_{2}$ and/or $\mathrm{O}_{2}$ partial pressures had no effect on the oxidation rate of liquid phase sintered $\mathrm{Si}_{3} \mathrm{~N}_{4}$ [SIN76a]. The velocity of the oxidizing gas over the sample had no effect on the oxidation rate of liquid phase sintered $\mathrm{Si}_{3} \mathrm{~N}_{4}$ [SIN76a], however it did effect the oxidation rate of RBSN [MAE89, BA.R79]. During oxidation of RBSN a SiO boundary layer forms which reduces the oxygen partial pressure at the surface and therefore favors internal oxidation of the RBSN.

Oxidation of RBSN is very dependent on the amount of open porosity [POR84]. Open porosity results in the effective surface area of the sample changing with time in a complex way. Open porosity allows oxygen to reach the interior of the sample. As oxidation continues, the $\mathrm{SiO}_{2}$ which forms will slowly close the pores. The closing of the pores is accompanied by a sharp decrease in the oxidation rate.

Below $900^{\circ} \mathrm{C}$ the oxidation was parabolic with time and an activation energy of $198 \mathrm{~kJ} / \mathrm{mole}(\sim 50 \mathrm{kcal} / \mathrm{mole})$ was reported [POR84]. At $1200^{\circ} \mathrm{C}$, oxidation effectively stopped after 1.5 hours, due to the pores being closed by the viscous $\mathrm{SiO}_{2}$ layer. At $1100^{\circ} \mathrm{C}$ the weight gain was faster than at $1200^{\circ} \mathrm{C}$ and the oxidation stopped after 8 hours. This increased oxidation at lower temperatures is due to the pores being open longer which allows more internal oxidation to occur, and therefore larger weight gains were reported. 


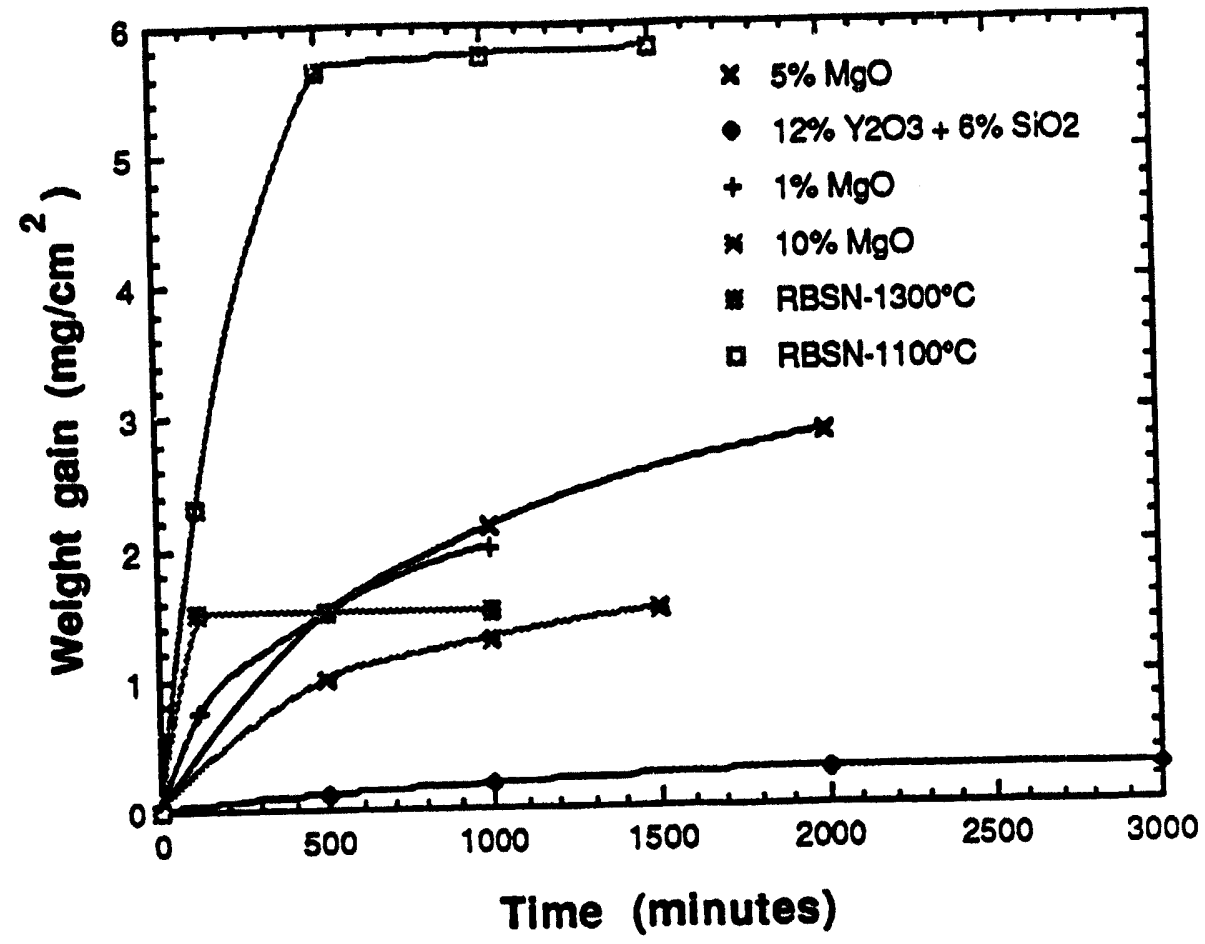

Figure 7. Plot of silicon nitride oxidation data [BAB83, SIN76a, POR84].

\section{Oxidation of Silicon Carbide}

Several studies dealt with the oxidation of SiC powders [ERV58, JOR59, JPR61]. For times less than 10 hours the oxidation of $\mathrm{SiC}$ powder was parabolic with time. At longer times the oxidation was faster, which was probably due to cracking of the $\mathrm{SiO}_{2}$ surface film [ERV58]. Oxidation of $\mathrm{SiC}$ in air, $\mathrm{O}_{2}$, and $\mathrm{CO}_{2}$ showed the same behavior.

Figure 8 shows weight gain versus time for two types of sintered SiC [DUT84] in air and a hot pressed SiC [SIN76b] in dry oxygen. The oxidation of the sintered $\mathrm{SiC}$ was sensitive to the sintering aid, SiC-1 had no reported sintering aids and SiC-2 had $B$ and $C$ additions. The oxidation reaction is:

$$
2 \mathrm{SiC}+3 \mathrm{O}_{2}=2 \mathrm{SiO}_{2}+2 \mathrm{CO}
$$

Eq. 2 
Complete conversion of $\mathrm{SiC}$ to $\mathrm{SiO}_{2}$ is accompanied by a $49.9 \%$ increase in weight.

Impurities concentrate in the $\mathrm{SiO}_{2}$ film. Above $1200^{\circ} \mathrm{C}$ the $\mathrm{SiO}_{2}$ layer was crystalline and the activation energy increased, $-50 \mathrm{kcal} / \mathrm{mole}$ [JOR59]. This indicated that diffusion, probably molecular $\mathrm{CO}$, through the $\mathrm{SiO}_{2}$ film was rate controlling [JOR59, MIE84, FUN84]. At low oxygen partial pressures, less than $10^{-6} \mathrm{~Pa}$, the protective $\mathrm{SiO}_{2}$ film cannot form and volatile oxidation products result in rapid oxidation of SiC [WAR84].

The presence of water vapor in the oxidizing atmosphere increased the oxidation rate [WAR84, JOR61]. Hydrogen prevented the protective $\mathrm{SiO}_{2}$ film from forming and increased the oxidation rate of SiC.

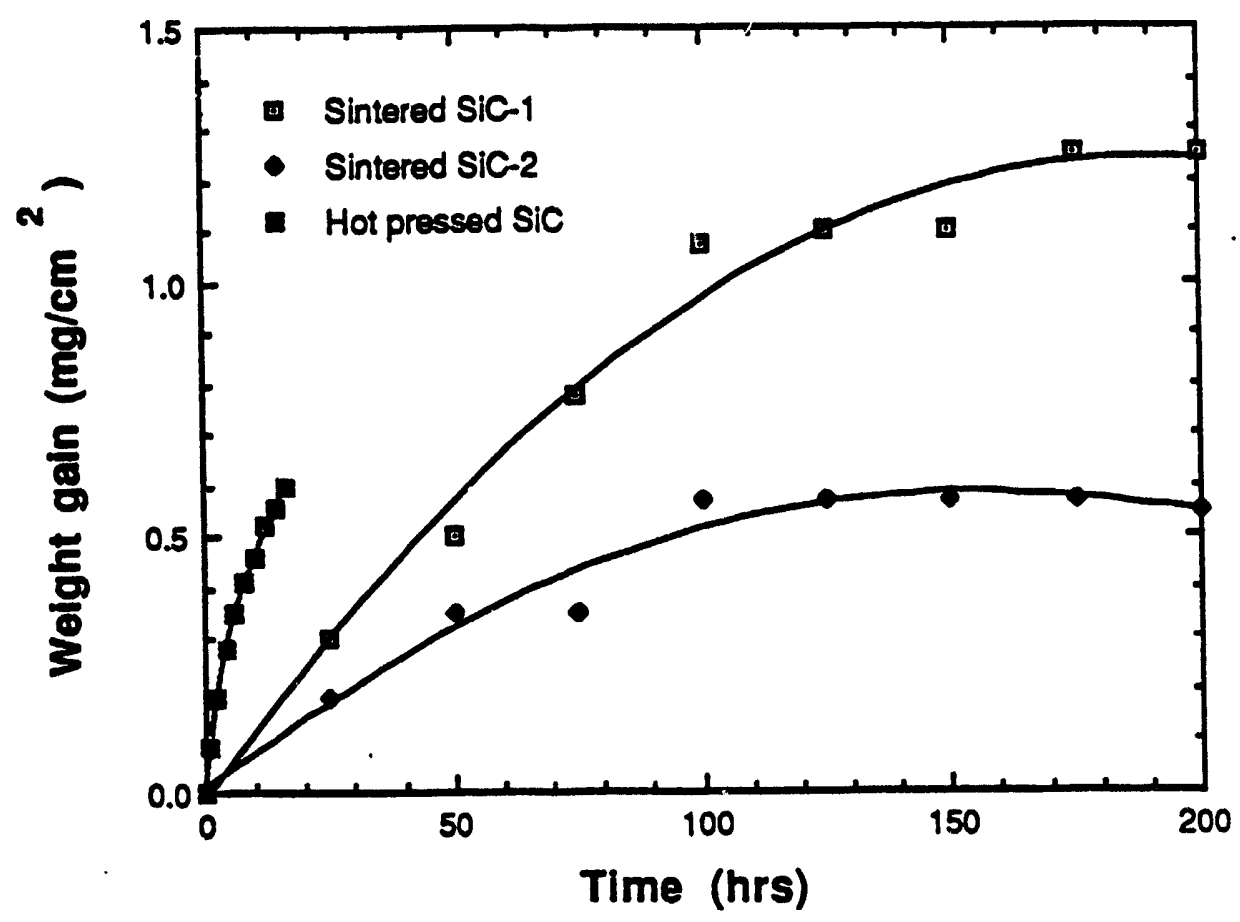

Figure 8. Plot of silicon carbide oxidation data [DUT84, SIN76b].

Oxidation of Aluminium Nitride

The oxidation of AlN is not clearly understood and the literature indicates that the "oxidation rate" of AlN has little meaning. The oxidation 
rate must be determined for the specific oxidizing conditions the AlN part will experience. The reaction was very sensitive to the water content of the oxidizing atmosphere, which may explain the discrepancies between the different studies. Oxidation was faster in wet $\mathrm{N}_{2}$ than in dry air [SAT87] and increased with increasing water partial pressure.

Oxidation starts at $800-1150^{\circ} \mathrm{C}$. The weight gain began as a linear relationship with time and became parabolic with time. The parabolic rate constant had an activation energy of $60-65 \mathrm{kcal} / \mathrm{mole}$ [KAT87, LAV83], which is reasonable for a diffusional process. The probable reaction is:

$$
4 \mathrm{AlN}+3 \mathrm{O}_{2}=2 \mathrm{Al}_{2} \mathrm{O}_{3}+2 \mathrm{~N}_{2}
$$

$\mathrm{NO}_{2}$ and aluminum oxynitride may also form. Complete conversion of AlN to $\mathrm{Al}_{2} \mathrm{O}_{3}$ is accompanied by a $24.4 \%$ increase in weight.

The weight gains due to oxidation are in the range of $0-10 \mathrm{mg} / \mathrm{cm}^{2}$. Figure 9 is a plot of weight gain versus time for the data in references LAV83 and BOC82. Reference LAV83 studied the oxidation behavior of AlN in $\mathrm{O}_{2}$ (at $900^{\circ} \mathrm{C}, 1000^{\circ} \mathrm{C}, 1050^{\circ} \mathrm{C}$, and $1100^{\circ} \mathrm{C}$ ) and reference $\mathrm{BOC} 82$ studied the oxidation behavior of AlN in air (at $1300^{\circ} \mathrm{C}, 1420^{\circ} \mathrm{C}, 1490^{\circ} \mathrm{C}, 1620^{\circ} \mathrm{C}$, and $1680^{\circ} \mathrm{C}$ ).

The $\mathrm{Al}_{2} \mathrm{O}_{3}$ oxide layer that formed was very adherent [BOC82]. Sato et al [SAT87] found that porous $\mathrm{Al}_{2} \mathrm{O}_{3}$ formed at low temperatures, $1250^{\circ} \mathrm{C}$, and solid $\mathrm{Al}_{2} \mathrm{O}_{3}$ formed at high temperatures, $1400^{\circ} \mathrm{C}$. However, Boch et al [BOC82] found that porous $\mathrm{Al}_{2} \mathrm{O}_{3}$ formed above $1600^{\circ} \mathrm{C}$ and solid $\mathrm{Al}_{2} \mathrm{O}_{3}$ formed below $1600^{\circ} \mathrm{C}$. The reason for this disagreement is unclear. 


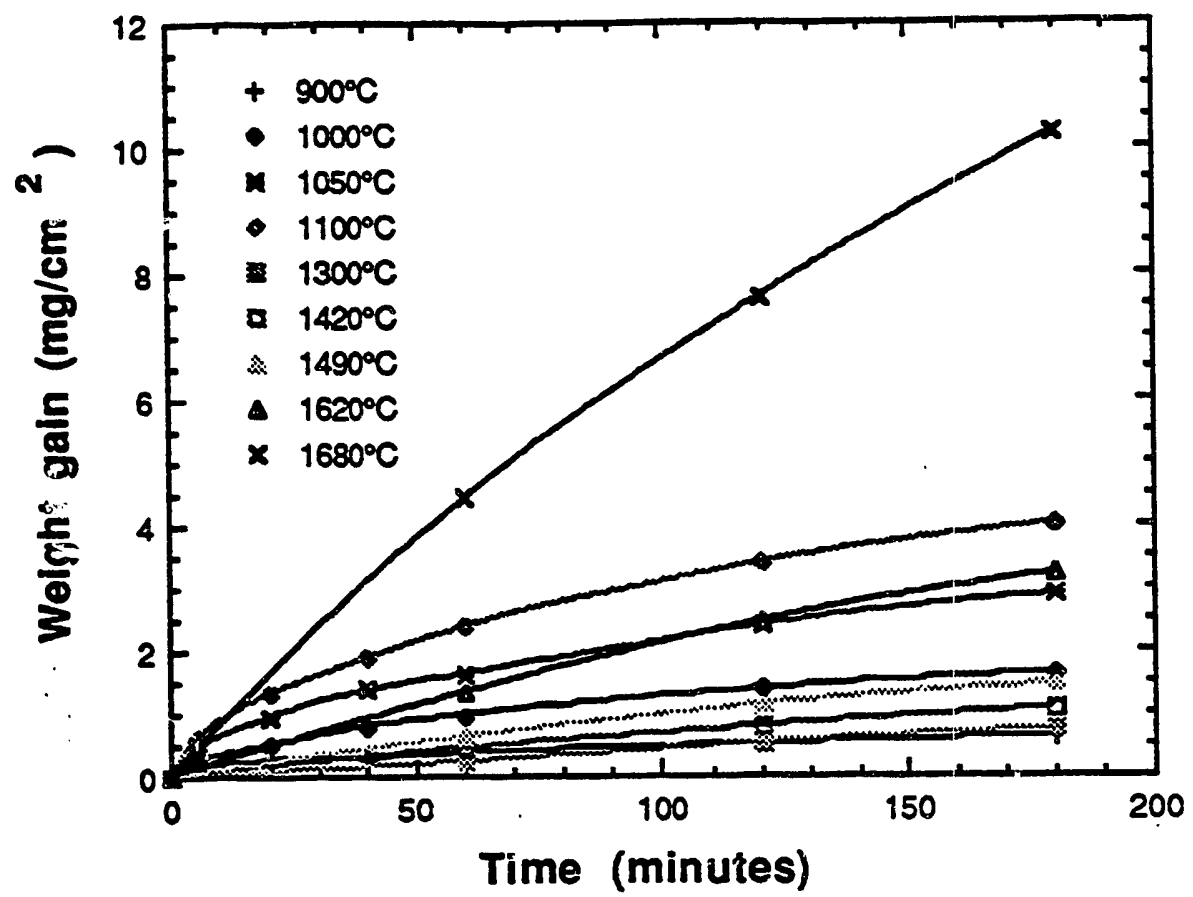

Figure 9. Plot of AlN oxidation data [LAV83, BOC82].

\section{Oxygen Diffusion through $\mathrm{Al}_{2} \mathrm{O}_{3}$}

The possibility of oxygen diffusion, either grain boundary or lattice, was theoretically evaluated. This was done by calculating the oxygen concentration in an $\mathrm{Al}_{2} \mathrm{O}_{3}$ coating as a function of temperature, time, and distance. The approach used was taken from Fisher [FIS51]. Three types of diffusion were included in the calculation: 1) diffusion from the surface down the grain boundary, 2) diffusion normal to the grain boundary into the grain, and 3) diffusion from the surface through the grain (bulk diffusion). Fisher's treatment was used for the first two types of diffusion, and the constant surface concentration solution to Fick's second law was used for the third type. For purposes of the calculation, the coating was treated as pure $\mathrm{Al}_{2} \mathrm{O}_{3}$.

Oxygen concentration profiles calculated at temperatures of $1100^{\circ} \mathrm{C}$, $1200^{\circ} \mathrm{C}, 1300^{\circ} \mathrm{C}, 1400^{\circ} \mathrm{C}$, and $1500^{\circ} \mathrm{C}$ for times up to 234 years $(2,048,000$ hours $)$ 
and diffusion distances of 0.5 microns, 1.0 micron, and 1.5 microns. The following parameters were used: grain boundary width $=5 \times 10^{-8} \mathrm{~cm}$, bulk diffusivity for oxygen in $\mathrm{Al}_{2} \mathrm{O}_{3}$ at $1500^{\circ} \mathrm{C}=3.5 \times 10^{-16} \mathrm{~cm}^{2} / \mathrm{s}$, grain boundary diffusivity of oxygen in $\mathrm{Al}_{2} \mathrm{O}_{3}$ at $1500^{\circ} \mathrm{C}=5.0 \times 10^{-15} \mathrm{~cm}^{2} / \mathrm{s}$, activation energy for oxygen lattice diffusion in $\mathrm{Al}_{2} \mathrm{O}_{3}=152,000 \mathrm{cal} / \mathrm{mole} \mathrm{K}$, pre-exponential factor for oxygen lattice diffusion in $\mathrm{Al}_{2} \mathrm{O}_{3}=1.9 \times 10^{3} \mathrm{~cm}^{2} / \mathrm{s}$, activation energy for oxygen grain boundary diffusion in $\mathrm{Al}_{2} \mathrm{O}_{3}=57,600 \mathrm{cal} / \mathrm{mole}{ }^{\circ} \mathrm{K}$, pre-exponential factor for oxygen lattice diffusion in $\mathrm{Al}_{2} \mathrm{O}_{3}=6.3 \times 10^{-8} \mathrm{~cm}^{2} / \mathrm{s}$. The activation energies and pre-exponential factors were taken from Oishi and Kingery [OIS60]. The calculations indicated that, at $1200^{\circ} \mathrm{C}$, the oxygen concentration 0.5 microns below the surface of the coating was less than $10^{-4}$ atomic per cent at 500 hours. At $1200^{\circ} \mathrm{C}$ and 1.0 micron below the surface, the oxygen concentration was zero after 500 hours and $1 \times 10^{-2}$ atomic per cent after 8000 hours. At a depth of 1.5 microns at $1200^{\circ} \mathrm{C}$, the oxygen concentration was $2 \times 10^{-4}$ atomic percent after 8000 hours. The oxygen concentration only became significant for a depth of 1.5 microns and a temperature of $1500^{\circ} \mathrm{C}$ after 8000 hours. This sombination of time and temperature is well beyond the anticipated service range of these coatings. Hence, these results suggest that the coating should not fail due to oxygen diffusion through an $\mathrm{Al}_{2} \mathrm{O}_{3}$ layer and that the composite layer is an adequate diffusion barrier.

\section{Oxidation Testing}

Oxidation tests of coated RBSN, SSC, and HSN were conducted with substrates measuring $1^{n} \times 0.25^{n} \times 0.02^{n}$. For oxidation tests of coated sapphire the substrate size was $1^{\prime \prime} \times 0.25^{\prime \prime} \times 0.08^{\prime \prime}$. This sample size was selected to maximize the weight of the coating while minimizing the weight of the substrate, thereby increasing the magnitude of the weight gain due to oxidation and allowing for more sensitive weight gain measurements.

The oxidation treatments were done in a Lindberg box furnace, model 51314, in static air. The samples were weighed using a Mettler analytical balance with a readability of $1 \mu \mathrm{g}$ and an accuracy of $-0.5 \mu \mathrm{g}$. After oxidation testing, some samples are analyzed by X-ray diffraction (XRD) to identify the oxidation products. 


\section{Coatings on Sapphire Substrates}

Substrates of single crystal alumina (sapphire) were used to eliminate the contribution of substrate oxidation from the weight gain experiments. Three coating configurations were examined, AlN/sapphire, $\mathrm{Al}_{2} \mathrm{O}_{3} / \mathrm{AlN} / \mathrm{sapphire}$, and $\mathrm{Al}_{2} \mathrm{O}_{3}+\mathrm{ZrO}_{2} / \mathrm{AlN} /$ sapphire, these were oxidized in static air at $1000^{\circ} \mathrm{C}, 1100^{\circ} \mathrm{C}, 1200^{\circ} \mathrm{C}$, and $1275^{\circ} \mathrm{C}$ for up to 500 hours. The samples were periodically removed from the furnace and weighed (after 2, 8, 30, 125, and 500 hours). One sample was removed and set aside for X-ray diffraction analysis at each weighting. Due to flaking of the AlN coating, the weight gain as a function of time did not provide useful information, however, X-ray diffraction allowed the degree of AlN oxidation to be estimated.

\section{AlN Coated Sapphire Substrates}

Three samples with this coating configuration were examined at $1000^{\circ} \mathrm{C}$ for 2, 8, 30, 125, and 500 hour oxidation times. Table A-1 (in Appendix A) lists the times and weights gains of these samples, and Table A-2 (in Appendix A) shows the phases present after oxidation identified by XRD. The AIN coatings appeared to have flaked off during the oxidation treatments since the weight gains in Table A-1 did not increase with time. The flaking was attributed to poor adhesion between the AlN and the optically polished sapphire. The weight gain data is plotted versus oxidation time at $1100^{\circ} \mathrm{C}, 1200^{\circ} \mathrm{C}$, and $1275^{\circ} \mathrm{C}$ in Figures A-1 - A-3 respectively.

XRD results indicated that some AIN was present in all of the samples up to 500 hours and $\mathrm{Al}_{2} \mathrm{O}_{3}$ formed with its $c$-axis perpendicular to the plane of the substrate. Two unidentified peaks of low intensity were found at $0.418 \mathrm{~nm}$ and $0.432 \mathrm{~nm}$ in all of the samples in Table A-1.

\section{Al2 $O_{3}$ LAlN Coated Sapphire Substrates}

Three samples with this coating configuration were examined at $1100^{\circ} \mathrm{C}, 1200^{\circ} \mathrm{C}$, and $1275^{\circ} \mathrm{C}$ for $2,8,30,125$, and 500 hour oxidation times. Table A-3 below lists the times and weights gains of these samples. The weight gains listed in Table A-3 were expected to increase with time but did not due to flaking of the coating. 
$X$-ray diffraction of the oxidized samples (Table A-2) indicated that AlN was seen in some of the samples in Table A-3, however, the AIN peak intensity appeared to be reduced in the sample oxidized for 500 hours at $1100^{\circ} \mathrm{C}$. Additional low intensity peaks were found indicating that AlON may be present.

The samples oxidized at $1200^{\circ} \mathrm{C}$ were similar to those oxidized at $1100^{\circ} \mathrm{C}$ except the AIN peak intensity was reduced after 125 hours, and at $1275^{\circ} \mathrm{C}$ the AlN peak intensity was reduced after 30 hours. In all of the samples discussed above the $\mathrm{Al}_{2} \mathrm{O}_{3}$ was present in the alpha form.

\section{Al2 $\mathrm{O}_{3}+\mathrm{ZrO}_{2} L A l N$ Ceated Sapphire Substrates}

Thiee samples with this coating configuration were examined at $1100^{\circ} \mathrm{C}, 1200^{\circ} \mathrm{C}$, and $1275^{\circ} \mathrm{C}$ for $2,8,30,125$, and 500 hour oxidation times. Table A-4 lists the times and weights gains of these samples.

$X$-ray diffraction of the oxidized samples (Table A-2) indicated that AlN was seen in some of the samples in Table A-4. The AlN peak intensity was reduced in the samples oxidized for 2 hours and longer at $1100^{\circ} \mathrm{C}$. The samples oxidized at $1200^{\circ} \mathrm{C}$ were similar to those oxidized at $1100^{\circ} \mathrm{C}$ except that the AlN peak intensity was not observed for oxidation times longer than 2 hours, and at $1275^{\circ} \mathrm{C}$ only a very faint AlN peak was detected after 2 hours. In all of the above samples $\alpha-\mathrm{Al}_{2} \mathrm{O}_{3}$ was the predominate $\mathrm{Al}_{2} \mathrm{O}_{3}$ phase, however, $\chi-\mathrm{Al}_{2} \mathrm{O}_{3}$ may have been present in the oxidized coatings. Also, both the orthorhombic and monoclinic forms of $\mathrm{ZrO}_{2}$ were found in the oxidized and unoxidized coatings.

\section{Oxidation Kinetics of Uncoated and AIN Coated Substrates}

Results of the tests are summarized in Tables 3, A-5 and A-6 and Figures A-4 - A-21. The growth exponents listed in Table 3 were calculated by fitting the data to an equation of the form:

$$
\text { (wt. gain, } m g)^{n}=C *(\text { time, } h r)
$$

Eq. 1 
where ' $C$ ' is a constant and ' $n$ ' is the growth exponent. A value of 2.0 for ' $n$ ' is typical of growth processes which are diffusion controlled.

In all of the oxidation tests, 3 samples were oxidized at each condition in Table 3. In the cases of large variability, samples with the highest weight gains are reported. The discrepancy between samples oxidized under identical conditions was thought to be due to flaking of the oxidized layer.

The weight gain versus time plots for the substrates with AlN coatings had two distinct regions (Figures A-4 - A-21). The first region lasted from 8 to 30 hours and was thought to be due to the rapid oxidation of the AlN layer. The second region exists at longer times and is essentially flat, was probably due to the oxidation of the substrate.

The results in Table 3 show that the oxidation of the AlN coating on SSC and HSN substrates had a growth exponent of $\sim 2$. This implies diffusion controlled oxidation at $1200^{\circ} \mathrm{C}$ and $1275^{\circ} \mathrm{C}$. The growth exponent of the AIN coated substrates after the AlN coating was fully oxidized were 4 or higher. A growth exponent larger than 2 can be due to cracking of the oxidized layer or "ageing" of the oxide layer [MEI59]. Growth exponents of 1 are attributed to interface controlled kinetics. 
Table 3. Summary of oxidation tests for uncoated and AIN coated RBSN, SSC, and HSN substrates. The tests were done in static air at $1200^{\circ} \mathrm{C}$ and $1275^{\circ} \mathrm{C}$ in a box furnace.

\begin{tabular}{|c|c|c|c|c|}
\hline Sample & $\begin{array}{c}\text { Number } \\
\text { Samples }\end{array}$ & $\begin{array}{c}\text { Average } \\
\text { Weight Gain } \\
\pm 1 \text { std. dev. } \\
\left(\mathrm{mg} / \mathrm{cm}^{2}\right)\end{array}$ & $\begin{array}{c}\text { Time to } \\
100 \% \text { AlN } \\
\text { conversion } \\
(\mathrm{hrs}) \\
\end{array}$ & $\begin{array}{c}\text { Growth } \\
\text { Exponent } \\
\pm 1 \text { std. dev. }\end{array}$ \\
\hline Uncoaied RBSN & & & & \\
\hline $1200^{\circ} \mathrm{C}$ & 1 & 0.931 & $\cdots$ & $\ldots$ \\
\hline $\begin{array}{l}1275^{\circ} \mathrm{C} \\
\text { Uncoated SSC }\end{array}$ & 2 & $0.994 \pm 0.007$ & $\ldots$ & $1.2 \pm 0.1$ \\
\hline $1200^{\circ} \mathrm{C}$ & 3 & 0.167 & $\ldots$ & $4.5 \pm 0.4$ \\
\hline $\begin{array}{l}1275^{\circ} \mathrm{C} \\
\text { Uncoated HSN }\end{array}$ & 2 & $0.219 \pm 0.039$ & $\ldots$ & $1.6 \pm 0.1$ \\
\hline $1200^{\circ} \mathrm{C}$ & 3 & $0.279 \pm 0.014$ & $\cdots$ & $2.6 \pm 0.2$ \\
\hline $\begin{array}{l}1275^{\circ} \mathrm{C} \\
A L N / R B S N\end{array}$ & 2 & $0.990 \pm 0.007$ & $\cdots$ & $2.2 \pm 0.1$ \\
\hline $1200^{\circ} \mathrm{C}$ & 3 & $0.334 \pm 0.219$ & $<30$ & $1.0 \pm 0.3$ \\
\hline $\begin{array}{l}1275^{\circ} \mathrm{C} \\
\text { AlN'SSC }\end{array}$ & 1 & 2.736 & $<8$ & 2.6 \\
\hline $1200^{\circ} \mathrm{C}$ & 1 & 0.456 & $<30$ & $2.1 \pm 0.1$ \\
\hline $\begin{array}{l}1275^{\circ} \mathrm{C} \\
\text { AlN/HSN }\end{array}$ & 2 & $1.511 \pm 0.283$ & $<8$ & $1.9 \pm 0.4$ \\
\hline $1200^{\circ} \mathrm{C}$ & 3 & $0.483 \pm 0.091$ & $<8$ & $1.9 \pm 0.1$ \\
\hline $1275^{\circ} \mathrm{C}$ & 2 & $1.816 \pm 0.057$ & $<8$ & $1.9 \pm 0.3$ \\
\hline
\end{tabular}

t the growth exponents for the AlN coated substrates are only for oxidation times up to the "Time to $100 \%$ AlN conversion". 
Phase Formation During Oxidation of Uncoated and Coated Substrates

The phases identified after the full 500 hours of oxidation on uncoated and AIN coated RBSN, SSC, and HSN are listed in Table A-5 for all temperatures tested. Uncoated RBSN was predominantly $\alpha-\mathrm{Si}_{3} \mathrm{~N}_{4}$ and tended to form $\mathrm{SiO}_{2}$ when oxidized. Uncoated SSC consisted of predominantly the $8 \mathrm{H}$ and $12 \mathrm{H}$ polytypes and formed $\mathrm{SiO}_{2}$ when oxidized. Uncoated $\mathrm{HSN}$ was predominantly $\beta-\mathrm{Si}_{3} \mathrm{~N}_{4}$ and formed $\alpha-\mathrm{Y}_{2} \mathrm{Si}_{2} \mathrm{O}_{7}, \mathrm{Y}_{2} \mathrm{SiO}_{5}$, and $\mathrm{SiO}_{2}$ when oxidized. The yittrium came from the grain boundary phase. Yttria was added to this material as a densification aid.

The oxidation of the AlN coated materials resulted in similar phase formation as the uncoated materials with the addition of $\mathrm{Al}_{2} \mathrm{O}_{3}$. The $\mathrm{Al}_{2} \mathrm{O}_{3}$ came from the oxidation of the AlN phase. No phases were identified that suggested a reaction between the $\mathrm{AlN}$ and $\mathrm{Si}_{3} \mathrm{~N}_{4}$ or $\mathrm{SiC}$.

The conventional coating $\left(\mathrm{Al}_{2} \mathrm{O}_{3}+\mathrm{ZrO}_{2} / \mathrm{AlN}\right)$ was tested, along with $\mathrm{Al}_{2} \mathrm{O}_{3} / \mathrm{AlN}$, Table A-6. The latter coating was evaluated to eliminate the effect of $\mathrm{ZrO}_{2}$ to make the interpretation of the oxidation results simpler. $\mathrm{ZrO}_{2}$ undergoes a phase transformation and $10 \%$ volume change at $-1200^{\circ} \mathrm{C}$ which may cause the coating to crack or flake.

The oxidation tests showed that all coating/substrate configurations failed at all temperatures. A post-failure analysis was initiated to determine the cause(s). One possibility was porosity in the oxide layer of the coating. Examination of as-grown coatings has shown a variety of features ranging from cauliflower shaped clusters of grains to faceted grains. Examination of the cauliflower shaped clusters at 5000x shows the presence of large gaps between clusters. Due to the thinness of the oxide layer of the coating (typically less than 2 microns), these gaps could penetrate to the AlN layer. An attempt was made to determine if AlN was exposed by doing a nitrogen map using an electron microprobe analyzer. Two samples were examined, and neither gave a nitrogen signal, suggesting that the $\mathrm{Al}_{2} \mathrm{O}_{3}+\mathrm{ZrO}_{2}$ coating was continuous. However, the sensitivity of the microprobe to nitrogen was -3 weight per cent and the detection limit for gaps was $\sim 1$ micron ; i.e., only gaps larger than 1 micron could be detected.

The results indicate that the current coating configuration is not oxidation resistant for 500 hours at temperatures above $1000^{\circ} \mathrm{C}$. The lack of 
protection is attributed to cracks in the $\mathrm{Al}_{2} \mathrm{O}_{3}+\mathrm{ZrO}_{2}$ layer, which allow oxygen to penetrate and react with AlN. The kinetics of oxidation of AlN are sufficiently slow at $1000^{\circ} \mathrm{C}$ for the coating to protect the substrate for 500 hours. However, above $1000^{\circ} \mathrm{C}$, the oxidation rate of AlN is rapid enough to cause the AIN to fully oxidize to $\mathrm{Al}_{2} \mathrm{O}_{3}$ before 500 hours. This oxidation is accompanied by further cracking, which in turn increases the oxidation of the substrate. The cause of cracking in the $\mathrm{Al}_{2} \mathrm{O}_{3}+\mathrm{ZrO}_{2}$ layer is large residual stress due to thermal expansion mismatch between $\mathrm{Al}_{2} \mathrm{O}_{3}$ or $\mathrm{ZrO}_{2}$ and $\mathrm{Si}_{3} \mathrm{~N}_{4}$ or $\mathrm{SiC}$. The stress in the $\mathrm{Al}_{2} \mathrm{O}_{3}+\mathrm{ZrO}_{2}$ layer is approximately $1900 \mathrm{MPa}$ for a $\mathrm{Si}_{3} \mathrm{~N}_{4}$ substrate and $1300 \mathrm{MPa}$ for a $\mathrm{SiC}$ substrate, which is well in excess of the fracture strength of the $\mathrm{Al}_{2} \mathrm{O}_{3}+\mathrm{ZrO}_{2}$ layer. Physical vapor deposition (PVD) methods, which allow the residual stress state to be controlled, or low temperature CVD processes may allow for crack-free coatings to be deposited. When these coatings are heated to $1200^{\circ} \mathrm{C}$ the stress in the coatings would be compressive and they would not crack, although they may fail by buckling. The thermal stress and coating cracking problems are addressed in a following section.

\section{Contact Stress Testing}

The contact stress testing from Phase I of the program was completed by Garrett Turbine Engine Company. Twenty coated MOR bars (dimensions 2" $\times 1 / 4^{\prime \prime} \times 1 / 8^{n}$ ) and pins of each substrate (RBSN, SSC, and HSN) were tested for contact stress using point sliding contact. The test procedure was described elsewhere [SCH87]. Each sample had a $\sim 5$ micron thick AlN intermediate layer and a 1 micron thick outer layer of $\mathrm{Al}_{2} \mathrm{O}_{3}+\mathrm{ZrO}_{2}$ composite. The coated MOR bars were oxidized in static air at $1200^{\circ} \mathrm{C}$ for 100 hours before application of the contact stress. After oxidation, the composite coatings exhibited good adherence to the RBSN and SSC substrates and poor adherence to the HSN substrates. Flexure strength (using 4-point bending). was measured after application of the contact stress. The friction coefficient was also calculated by Garrett.

Tables 4 - 6 show the strength loss and maximum friction coefficient measured for each set of conditions. The "As-coated strengths" were taken from samples that were oxidized at $1200^{\circ} \mathrm{C}$ for 500 hours and tested at $25^{\circ} \mathrm{C}$ and 
from unoxidized samples tested at 1000 and $1200^{\circ} \mathrm{C}$. These measurements were made at GTE on a separate set of samples. All samples contact stress tested showed a strength loss of $30-50 \%$. The increase in strength of the HSN samples tested at $1200^{\circ} \mathrm{C}$ (see Table 5) is not understood.

It was previously reported [DAN89] that the $\mathrm{Al}_{2} \mathrm{O}_{3}+\mathrm{ZrO}_{2}$ coatings flaked off the substrates and that the samples were fully oxidized after 100 hours of oxidation at $1200^{\circ} \mathrm{C}$. Based on the previous oxidation data and the multiple factors involved in the contact stress testing (oxidation, contact stress, and variable friction), no firm conclusions are drawn from this contact stress data. 
Table 4. Summary of contact testing and post-contact MOR strength testing for CVD coated RBSN.

\begin{tabular}{|c|c|c|c|c|c|c|}
\hline $\begin{array}{l}\text { Test } \\
\text { Temp. } \\
\left({ }^{\circ} \mathrm{C}\right)\end{array}$ & $\begin{array}{l}\text { Applied } \\
\text { Load } \\
\text { (lbs) }\end{array}$ & $\begin{array}{c}\text { Max. } \\
\text { Friction }\end{array}$ & $\begin{array}{c}\text { As-Coated } \\
\text { Strength } \\
(\mathrm{MPa})\end{array}$ & $\begin{array}{c}\text { Retained } \\
\text { Strength } \\
(\mathrm{MPa})\end{array}$ & $\begin{array}{c}\text { Contact } \\
\text { Damage }\end{array}$ & $\begin{array}{c}\text { Change in } \\
\text { Strength } \\
(\%)\end{array}$ \\
\hline 25 & 25 & 0.44 & 197 & 154 & yes & -22 \\
\hline$n$ & $n$ & 0.47 & $n$ & 157 & yes & -20 \\
\hline$n$ & $n$ & 0.54 & " & 137 & yes & -30 \\
\hline$n$ & 50 & 0.35 & $n$ & 188 & yes & -5 \\
\hline$"$ & " & 0.43 & $n$ & 130 & yes & -34 \\
\hline " & $n$ & 0.37 & $"$ & 124 & yes & -37 \\
\hline n & 60 & 0.50 & $n$ & 116 & yes & -41 \\
\hline " & $n$ & 0.48 & n & 119 & yes & -40 \\
\hline " & " & 0.45 & " & 131 & yes & -34 \\
\hline 1000 & 25 & 1.36 & 245 & 150 & yes & -39 \\
\hline$n$ & $n$ & 1.65 & $n$ & 137 & yes & -44 \\
\hline$n$ & 50 & 0.82 & " & 164 & yes & -33 \\
\hline$"$ & $n$ & 0.63 & " & 115 & yes & -53 \\
\hline 1200 & 25 & 1.02 & 224 & 90 & yes & -60 \\
\hline$n$ & $n$ & 1.03 & $"$ & 105 & yes & -53 \\
\hline$n$ & 50 & 0.94 & $n$ & 92 & yes & -59 \\
\hline$"$ & $n$ & 0.81 & $"$ & 95 & yes & -58 \\
\hline
\end{tabular}


Table 5. Summary of contact testing and post-contact MOR strength testing for CVD coated HSN.

\begin{tabular}{|c|c|c|c|c|c|c|}
\hline $\begin{array}{l}\text { Test } \\
\text { Temp. } \\
\left({ }^{\circ} \mathrm{C}\right)\end{array}$ & $\begin{array}{l}\text { Applied } \\
\text { Load } \\
\text { (lbs) }\end{array}$ & $\begin{array}{c}\text { Max. } \\
\text { Friction }\end{array}$ & $\begin{array}{c}\text { As-Coated } \\
\text { Strength } \\
(\mathrm{MPa})\end{array}$ & $\begin{array}{c}\text { Retained } \\
\text { Strength } \\
(\mathrm{MPa})\end{array}$ & $\begin{array}{l}\text { Contact } \\
\text { Damage }\end{array}$ & $\begin{array}{c}\text { Change in } \\
\text { Strength } \\
(\%)\end{array}$ \\
\hline $\begin{array}{c}25 \\
n \\
n\end{array}$ & $\begin{array}{l}50 \\
" \\
n\end{array}$ & $\begin{array}{l}0.81 \\
0.43 \\
0.69\end{array}$ & $\begin{array}{c}520 \\
n \\
n\end{array}$ & $\begin{array}{l}267 \\
564 \\
330\end{array}$ & $\begin{array}{l}\text { yes } \\
\text { no } \\
\text { yes }\end{array}$ & $\begin{array}{l}-49 \\
+8 \\
-37\end{array}$ \\
\hline $\begin{array}{l}n \\
n \\
n\end{array}$ & $\begin{array}{c}60 \\
n \\
n\end{array}$ & $\begin{array}{l}0.71 \\
0.72 \\
0.65\end{array}$ & $\begin{array}{l}n \\
"\end{array}$ & $\begin{array}{l}318 \\
322 \\
368\end{array}$ & $\begin{array}{l}\text { yes } \\
\text { yes } \\
\text { yes }\end{array}$ & $\begin{array}{l}-39 \\
-38 \\
-29\end{array}$ \\
\hline $\begin{array}{l}n \\
n \\
n\end{array}$ & $\begin{array}{c}75 \\
n \\
n\end{array}$ & $\begin{array}{l}0.54 \\
0.71 \\
0.67\end{array}$ & $\begin{array}{l}n \\
n\end{array}$ & $\begin{array}{l}334 \\
310 \\
316\end{array}$ & $\begin{array}{l}\text { yes } \\
\text { yes } \\
\text { yes }\end{array}$ & $\begin{array}{l}-36 \\
-40 \\
-39\end{array}$ \\
\hline 1000 & $\begin{array}{c}50 \\
n\end{array}$ & $\begin{array}{l}0.60 \\
0.68\end{array}$ & $\begin{array}{c}557 \\
n\end{array}$ & $\begin{array}{l}316 \\
\ldots *\end{array}$ & $\begin{array}{l}\text { yes } \\
\ldots . .\end{array}$ & $\begin{array}{l}-43 \\
\ldots .-\end{array}$ \\
\hline n & $\begin{array}{c}75 \\
n\end{array}$ & $\begin{array}{l}0.87 \\
0.85\end{array}$ & " & $\begin{array}{l}\ldots * \\
109\end{array}$ & $\begin{array}{l}\cdots \\
\text { yes }\end{array}$ & -8 \\
\hline $\begin{array}{c}1200 \\
n\end{array}$ & $\begin{array}{c}50 \\
n\end{array}$ & $\begin{array}{l}0.36 \\
0.48\end{array}$ & $\begin{array}{c}393 \\
n\end{array}$ & $\begin{array}{l}466 \\
453\end{array}$ & $\begin{array}{l}\text { no } \\
\text { no }\end{array}$ & $\begin{array}{l}+19 \\
+15\end{array}$ \\
\hline " & $\begin{array}{c}75 \\
n\end{array}$ & $\begin{array}{l}0.43 \\
0.42\end{array}$ & $n$ & $\begin{array}{l}531 \\
545\end{array}$ & $\begin{array}{l}\text { no } \\
\text { no }\end{array}$ & $\begin{array}{r}+35 \\
+39\end{array}$ \\
\hline
\end{tabular}

* Tested improperly 
Table 6. Summary of contact testing and post-contact MOR strength testing for CVD coated SSC.

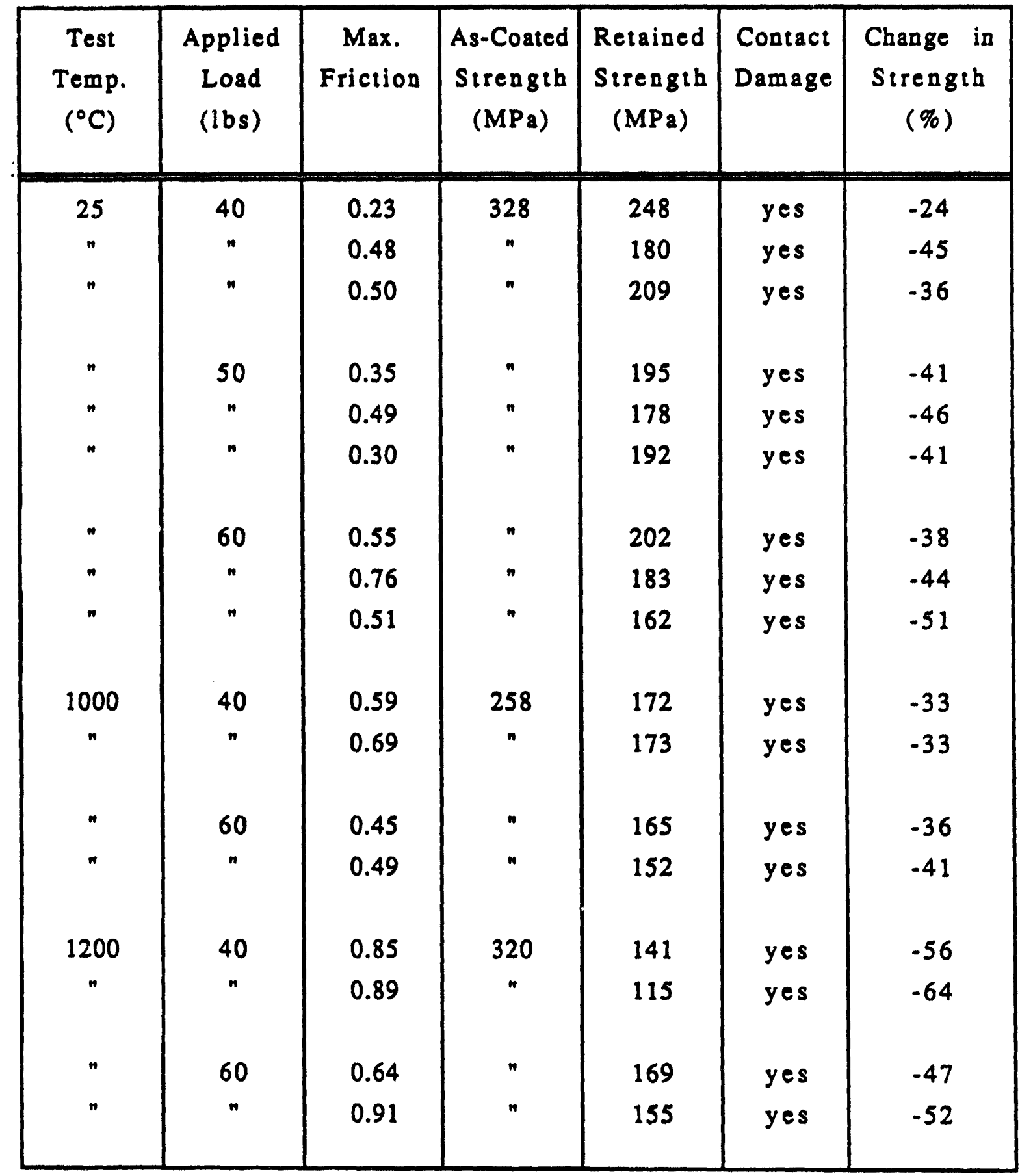




\section{Friction Coefficient Tests}

Self-mated sliding wear tests have been carried out at room temperature with uncoated and coated samples. In the tests of uncoated substrates the pin and disk were of the same material. In the tests of coated substrates the pin and disk were both coated. These samples included RBSN, SSC, and hot-pressed silicon nitride (HPSN). Hot-pressed material was used in place of hot isostatically pressed material (HSN) for this study due to the ayailability of HPSN of the proper size for fabricating into pins and disks.

Tests were conducted using a pin-on-disk set-up, Figure 10. The tip of the pin is spherical, which gives similar results to those obtained in a ballon-disk test. The testing procedure is based upon the conditions used for the VAMAS round-robin on wear test methods [RUF89]. Tests are carried out in air with an applied force of $10 \mathrm{~N}$ and a sliding velocity of $0.01 \mathrm{~m} / \mathrm{s}$.

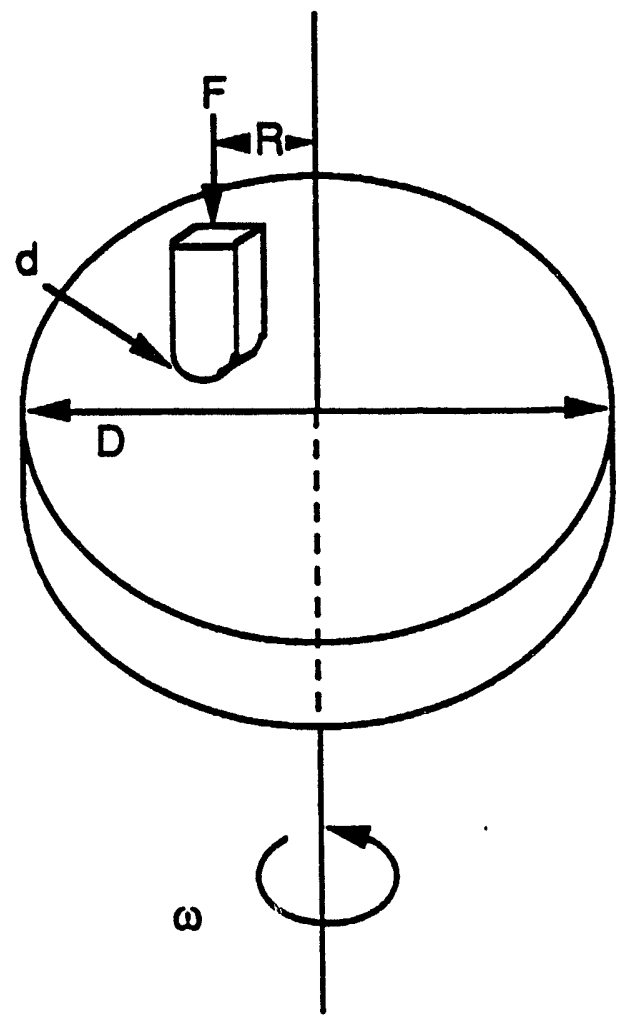

Figure 10. Schematic of pin-on-disk wear test system. $F$ is the normal force on the pin, $d$ is the pin diameter, $D$ is the disk diameter, $R$ is the wear track radius, and $\omega$ is the rotation velocity of the disk. 
Table 7 summarizes the friction results obtained. The breakaway friction coefficients were measured prior to wear testing on surfaces polished to a 1 micron finish. The values reported for the kinetic friction coefficients are the steady state values obtained after 500 meters of sliding. These results show that in some instances the $\mathrm{Al}_{2} \mathrm{O}_{3}+\mathrm{ZrO}_{2}$ coatings reduce friction. A significant reduction in kinetic friction value is obtained in the case of HPSN and RBSN, while no apparent benefit is observed with SSC at room temperature. The results at $1000^{\circ} \mathrm{C}$ were not sufficient to determine coating performance. The wear surfaces of uncoated HPSN, RBSN, and SSC are shown in Figure 11 and the wear surfaces of coated HPSN, RBSN, and SSC are shown in Figure 12. Figure 11 shows the worn pin and disk surfaces of uncoated ceramics after 500 meters of sliding contact. The spherical tip of the pins develop a circular wear scar, the extent of which is a measure of wear resistance. Coating the pin and disk materials leads to a noticeable improvement in wear resistance for HPSN as seen by the reduced wear scar on the pin and the polished wear track surface of the disk. Figure 12 . The RBSN and the SSC materials were not protected as effectively by the coating, which is in part attributed to the poor adhesion of these coatings to the substrates. The wear results obtained with coated materials do agree with the lower kinetic friction results for HPSN and RBSN in Table 7. 
Table 7. Results from pin-on-disk friction tests of uncoated and $\mathrm{Al}_{2} \mathrm{O}_{3}+\mathrm{ZrO} /$ AlN coated RBSN, HPSN, and SSC. All tests were done on self-mated samples. Reported values, unless otherwise indicated, are an average of three tests on the same pair of samples.

\begin{tabular}{|c|c|c|c|c|}
\hline Material & $\begin{array}{c}\text { Test } \\
\text { Temperature } \\
\left.{ }^{\circ} \mathrm{C}\right)\end{array}$ & $\begin{array}{c}\text { Breakaway } \\
\text { Friction } \\
\text { Coefficient }\end{array}$ & \multicolumn{2}{|c|}{$\begin{array}{c}\text { Kinetic Friction } \\
\text { Coefficient } \\
\text { initial }\end{array}$} \\
\hline \hline $\begin{array}{c}\text { RBSN } \\
\text { uncoated }\end{array}$ & 25 & 0.10 & 0.5 & 0.8 \\
coated & 25 & 0.17 & 0.3 & 0.4 \\
$\begin{array}{c}\text { HPSN } \\
\text { uncoated }\end{array}$ & 25 & 0.3 & $\ldots . .5$ & 0.8 \\
uncoated & 1000 & 0.15 & 0.5 & $0.9^{*}$ \\
coated & 25 & 0.14 & 0.3 & 0.4 \\
$\begin{array}{c}\text { SSC } \\
\text { uncoated }\end{array}$ & 25 & 0.1 &..- & 0.3 \\
uncoated & 1000 & 0.25 & 0.5 & 0.7 \\
coated & 25 & 0.17 & 0.3 & 0.4 \\
\hline
\end{tabular}

* only I sample has been tested at this condition. 


\section{UNCOATED}

Pin
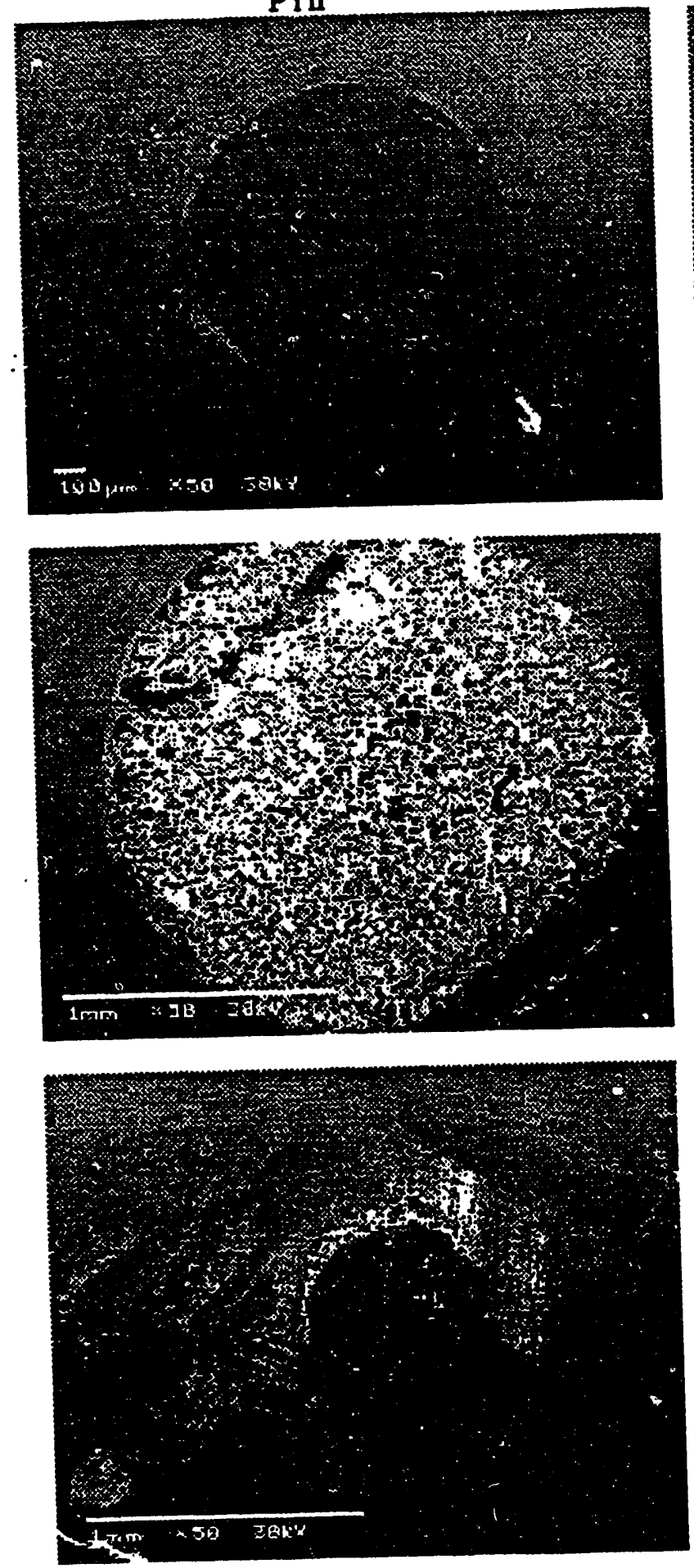

Disk
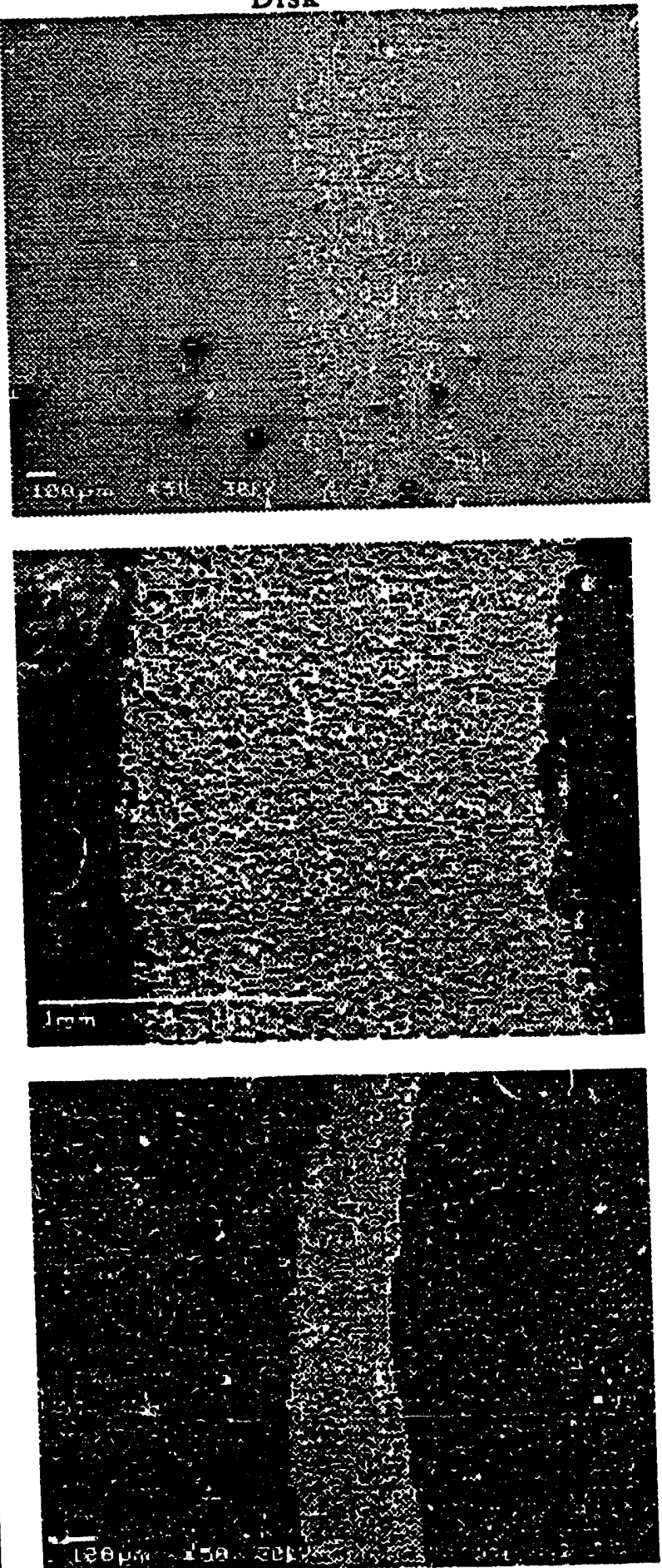

Figure 11. Wear tracks on the pins and disks for uncoated HPSN (top), RBSN (middle), and SSC (bottom), after a sliding distance of 500 meters at a sliding velocity of $0.01 \mathrm{~m} / \mathrm{s}$. 


\section{COATED}

$\mathrm{Pin}$
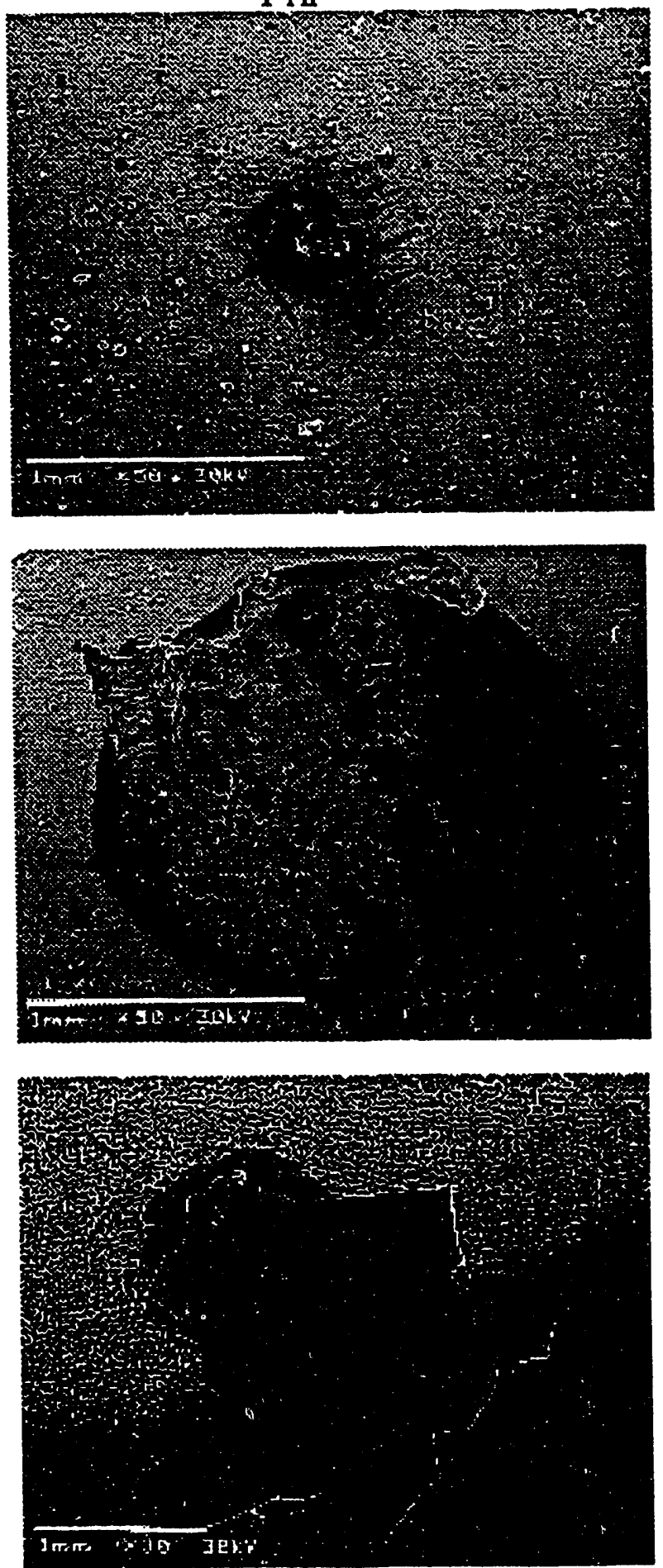

Disk
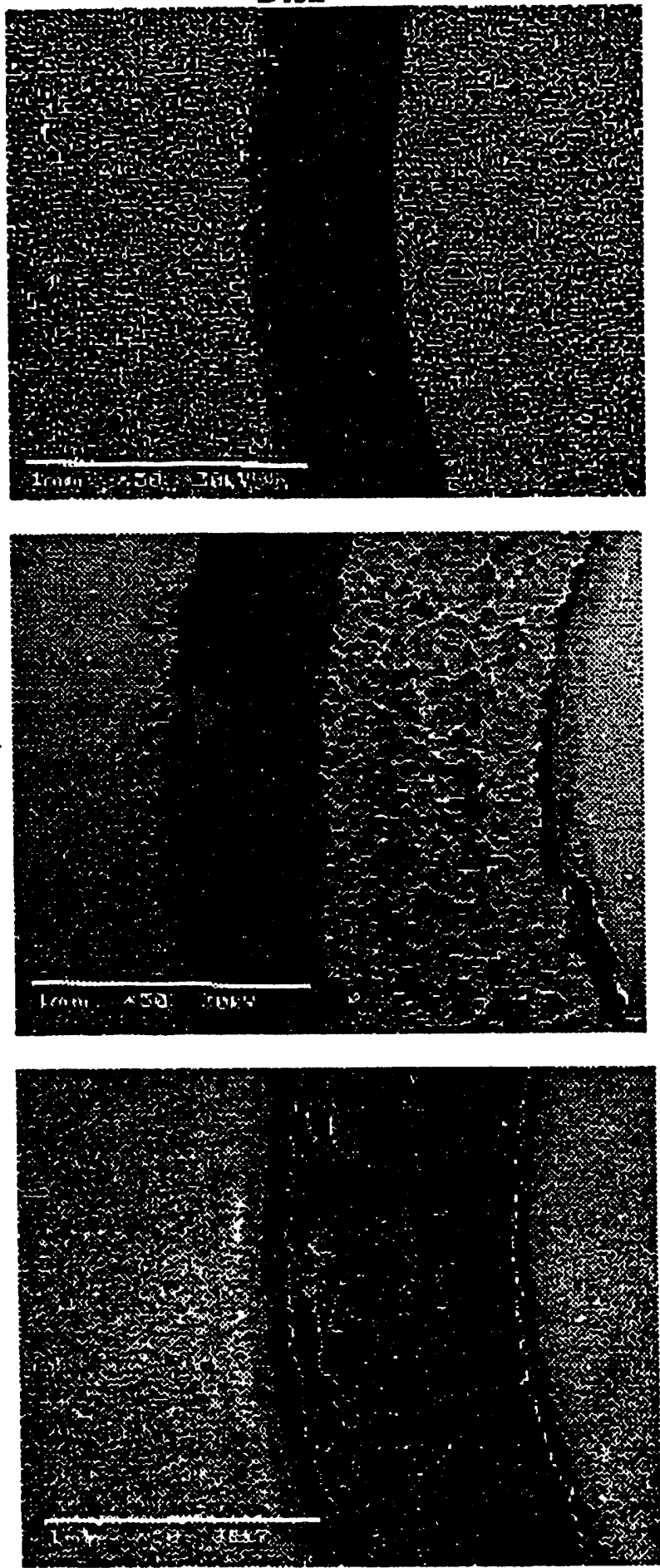

Figure 12. Wear tracks on the $\mathrm{AlN} / \mathrm{Al}_{2} \mathrm{O}_{3}+\mathrm{ZrO}_{2}$ coated pins and disks for HPSN (top), RBSN (middle), and SSC (bottom), after a sliding distance of 500 meters at a sliding velocity of $0.01 \mathrm{~m} / \mathrm{s}$. 


\section{Scratch Tests}

In a scratch test a diamond indenter (Rockwell C) is drawn over a sample at a constant velocity while the normal force is monotonically increased ( 0 to $100 \mathrm{~N}$ ). An acoustic pick-up is attached to the sample holder and both the force and acoustic signals are recorded during the test.

The uncoated and $\mathrm{Al}_{2} \mathrm{O}_{3}+\mathrm{ZrO}_{2} / \mathrm{AlN}$ coated disks of $\mathrm{HSN}, \mathrm{RBSN}$, and SSC from the pir-on-disk wear tests were scratch tested. Figures 13 - 18 show the load, acoustic emission, and wear traces for each sample. Several points can be made from these figures. The force traces of the uncoated and coated samples were similar with the exception of uncoated SSC, which showed several large load drops. In general, the acoustic emission of the coated samples was less than the acoustic emission of the uncoated samples. Acoustic emission is regarded as an indicator of substrate cracking. The scratches themselves are very informative and vary from sample to sample. The individual samples are discussed below.

Cracking of the uncoated SSC disk began at $-40 \mathrm{~N}$ (Figure 13). As the force increased the cracking became massive failure of the SSC disk. The coated SSC disk (Figure 14) had a lower acoustic signal than the uncoated SSC disk, indicating that the coating protected the SSC substrate from damage. The scratches on the uncoated and coated SSC are very different. The uncoated SSC showed massive cracking and chipping, while the coated SSC showed no chipping and less cracking. The major damage to the coated SSC was in the form of flaking of the coating in the scratch track beginning at $\sim 30 \mathrm{~N}$, indicating low adhesion of the coating to the SSC.

Vent cracks began to form in the uncoated RBSN disk $\sim 30 \mathrm{~N}$ (Figure 15). As the force increased the size of the vent cracks increased, however, the RBSN did not chip. The coated RBSN disk (Figure 16) had a lower acoustic signal than the uncoated RBSN disk indicating that the coating protected the RBSN substrate from damage. The scratches on the uncoated and coated RBSN were similar. The major damage to the coated RBSN was in the form of flaking of the coating in the scratch track beginning at very high forces, $-90 \mathrm{~N}$, indicating high adhesion of the coating to the RBSN.

Uncoated HSN behaved differently than the SSC and RBSN (Figure 17). HSN did not exhibit massive chipping (like SSC) or vent crack formation (like 
RBSN). The uncoated HSN failed at a high force, $-90 \mathrm{~N}$, by small scale chipping at the edge of the scratch track. The coated HSN (Figure 18) was similar to the coated RBSN. The coated began to flake at $-50 \mathrm{~N}$. However, the flaking was not continuous at forces greater than $50 \mathrm{~N}$. The discontinuous nature of the flaking may be related to processing defects in the coating.
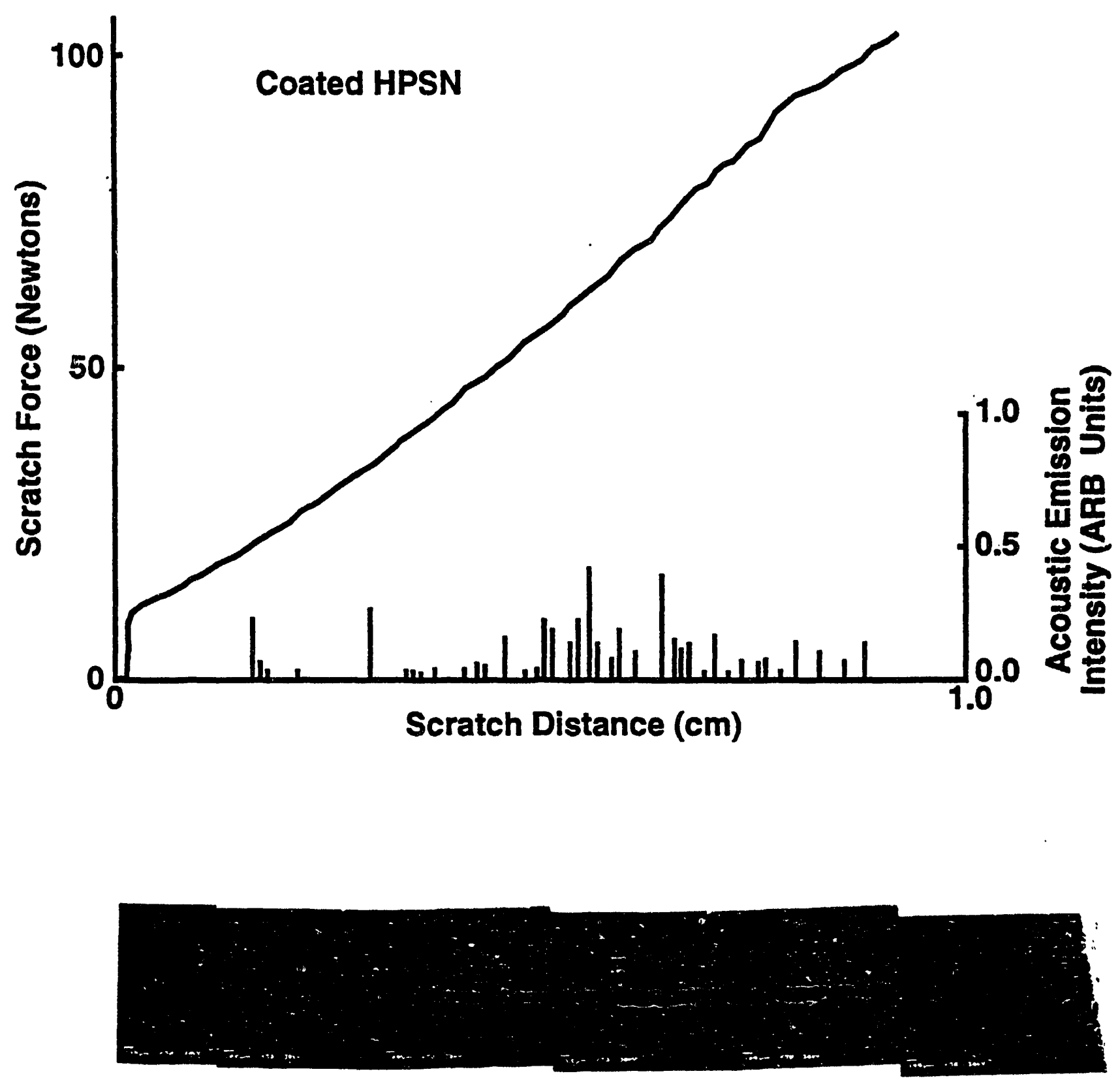

Figure 13. Scratch test results of uncoated HSN. The load trace is the solid line (lefi axis) and the acoustic signal is represented by the spikes (right axis). 

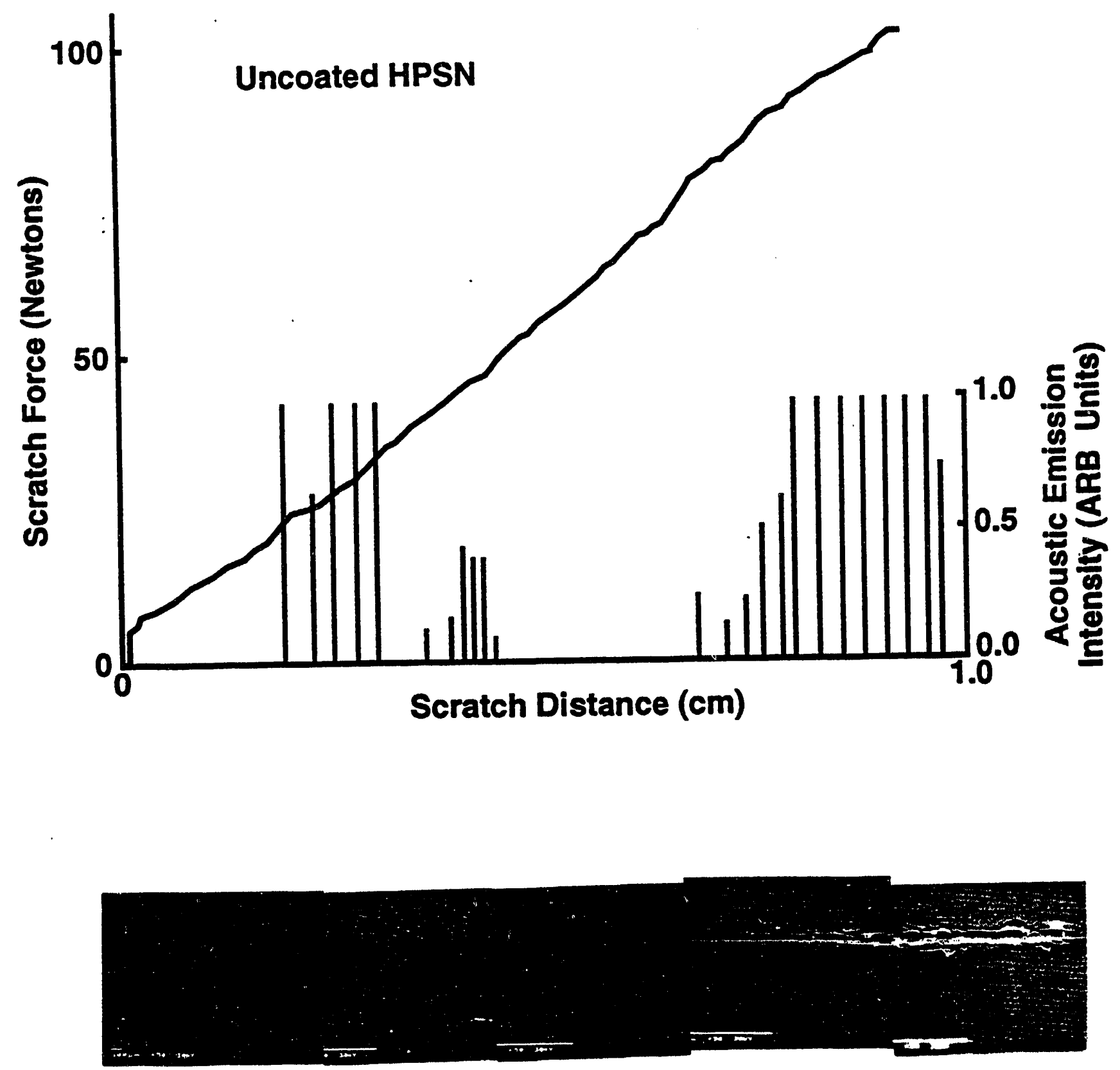

Figure 14. Scratch test results of coated HSN. The load trace is the solid line (left axis) and the acoustic signal is represented by the spikes (right axis). 

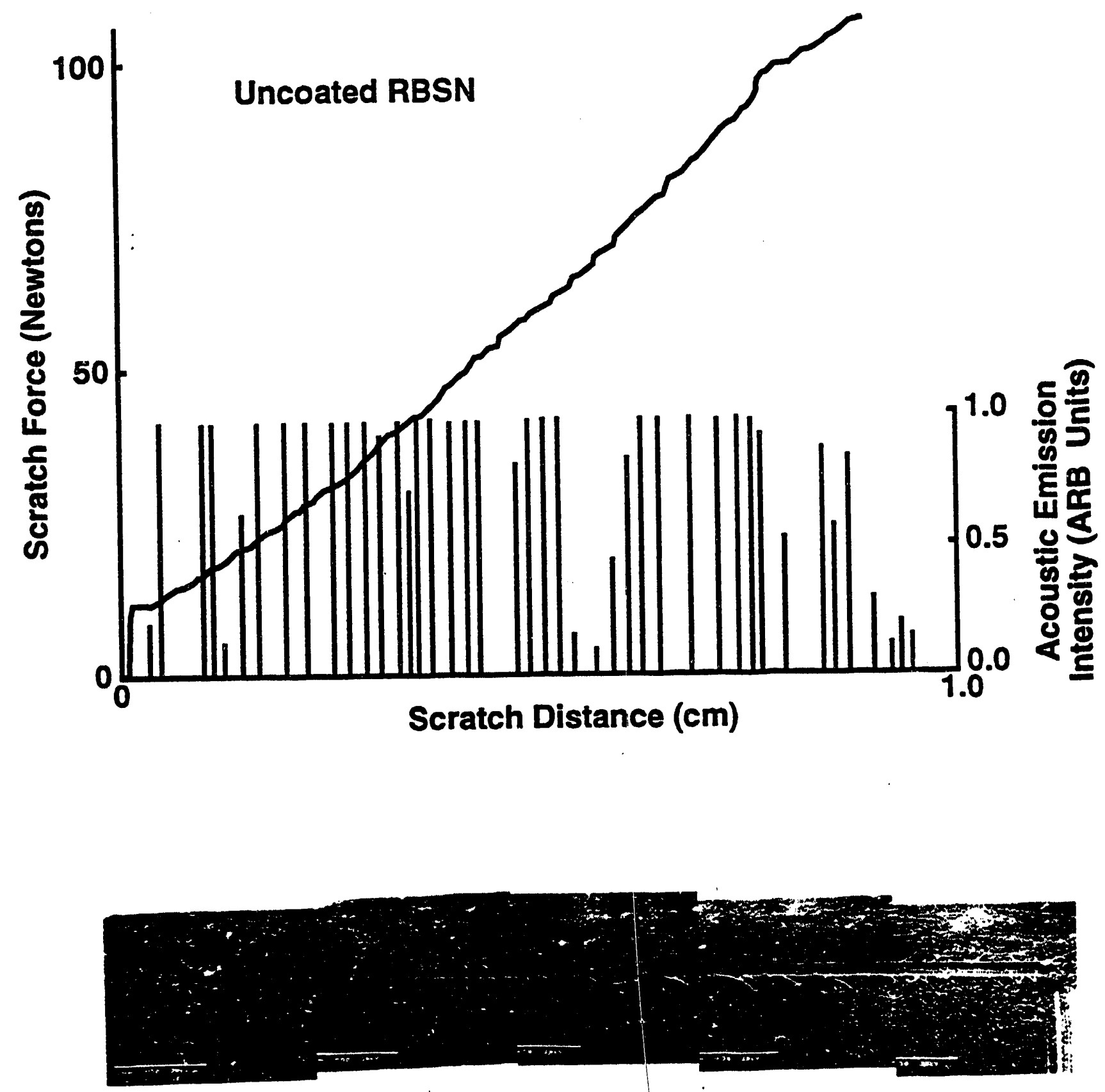

Figure 15. Scratch test results of uncoated RBSN. The load trace is the solid line (left axis) and the acoustic signal is represented by the spikes (right axis). 

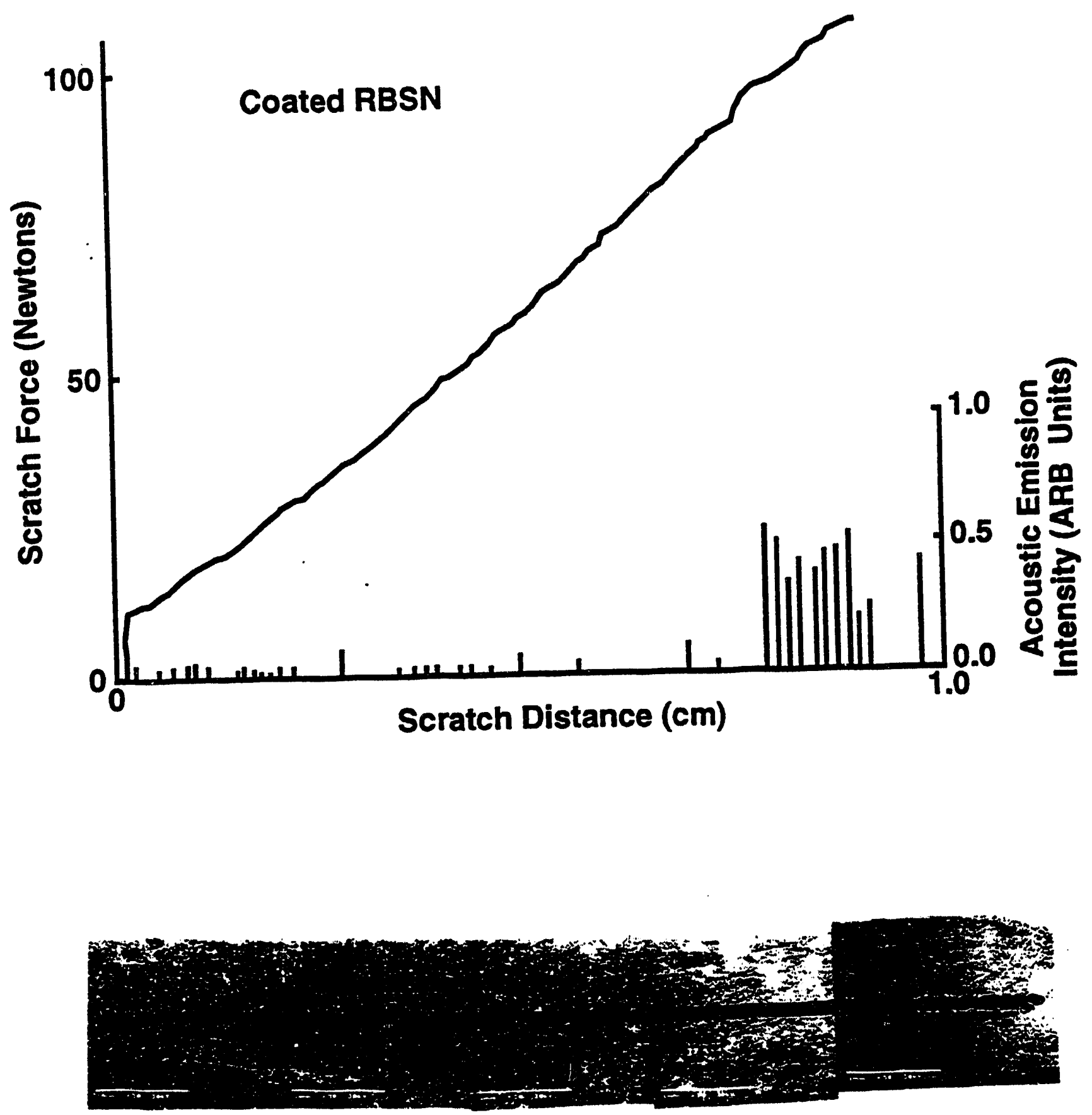

Figure 16. Scratch test results of coated RBSN. The load trace is the solid line (left axis) and the acoustic signal is represented by the spikes (right axis). 

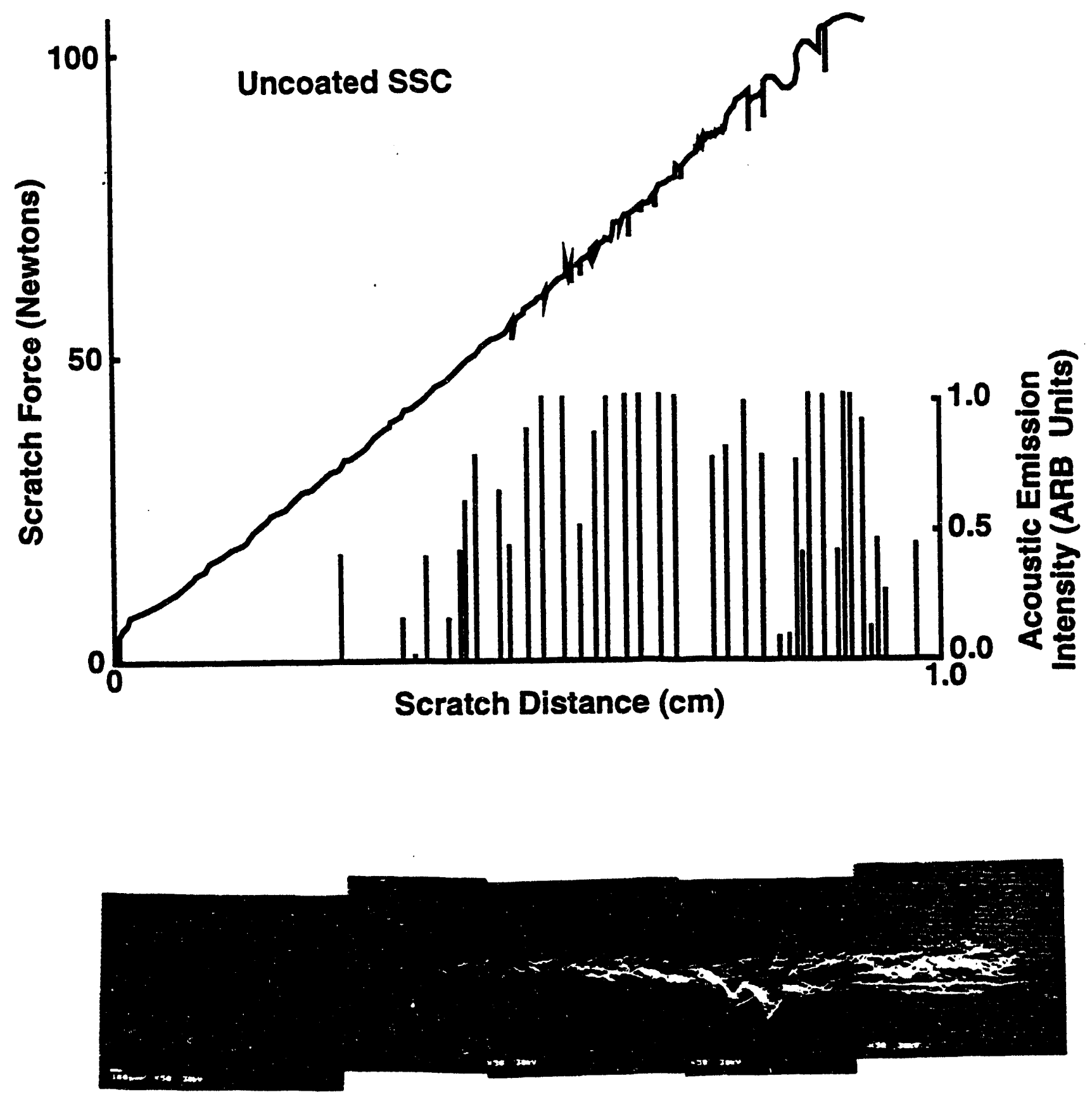

Figure 17. Scratch test results of uncoated SSC. The load trace is the solid line (left axis) and the acoustic signal is represented by the spikes (right axis). 

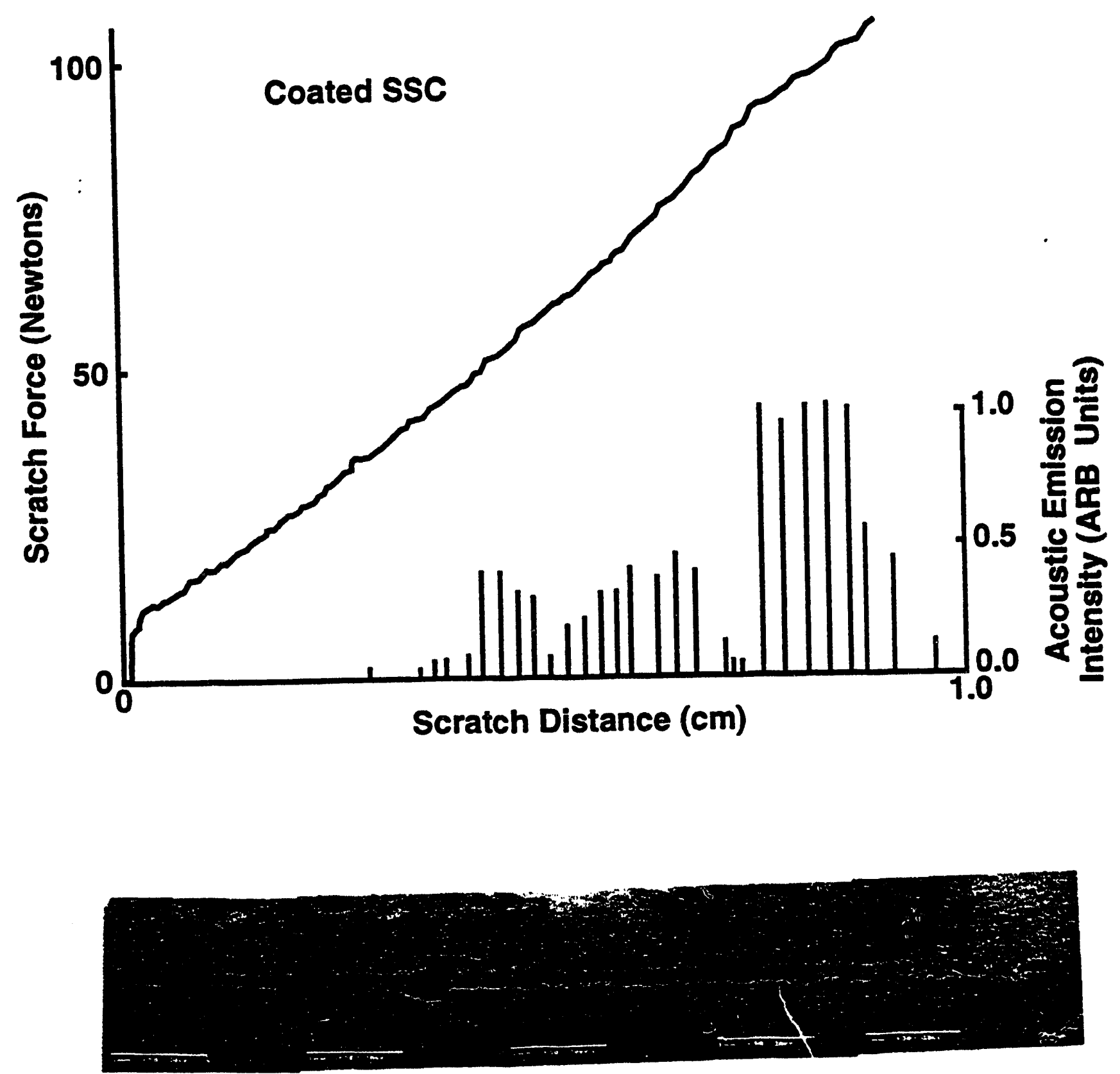

Figure 18. Scratch test results of coated SSC. The load trace is the solid line (left axis) and the acoustic signal is represented by the spikes (right axis). 
Measurement of Fracture Stress and Toughness of Coatings on Substrates

Conventional mechanical property measurement techniques usually cannot be applied to thin ceramic coatings because of the small amount of material involved. A method is described to determine the ultimate tensile strength, Weibull modulus, and crack density of micron-sized ceramic coatings. This technique is based on measuring the radius of curvature of a coated substrate, and equating the resulting calculated stress with a theoretical shear-lag stress distribution model. The Weibull modulus and fracture stress of chemical vapor deposited coatings of $\mathrm{Al}_{2} \mathrm{O}_{3}$ have been measured on $\mathrm{SiC}$ and $\mathrm{Si}_{3} \mathrm{~N}_{4}$ substrates. The fracture stresses for coatings of these materials ranged from $190 \mathrm{MPa}$ to $480 \mathrm{MPa}$, the Weibull modulus ranged from 16 to 28 , and the fracture toughness ranged from $0.5-1.1 \mathrm{MPa} \sqrt{\mathrm{m}}$. These results are summarized in Table 8 . This work has shown that the tensile strength of $\mathrm{Al}_{2} \mathrm{O}_{3}$ and $\mathrm{Al}_{2} \mathrm{O}_{3}+\mathrm{ZrO}_{2}$ coatings can be approximated by bulk values, however, the fracture toughness of these coatings was found to be significantly lower than bulk values. This method is detailed in Appendix B.

Table 8. Calculated fracture stress, fracture toughness, and Weibull modulus for $\mathrm{Al}_{2} \mathrm{O}_{3}$ and $\mathrm{Al}_{2} \mathrm{O}_{3}+\mathrm{ZrO}_{2}$ coatings.

\begin{tabular}{lcccc}
\hline \multicolumn{1}{c}{ Sample } & $\begin{array}{c}\text { Temp.of First } \\
\text { Cracking } \\
\left({ }^{\circ} \mathrm{C}\right)\end{array}$ & $\begin{array}{c}\text { Fracture } \\
\text { Stress, of } \\
(\mathrm{MPa})\end{array}$ & $\begin{array}{c}\text { Fracture } \\
\text { Toughness, KIc } \\
(\mathrm{MPa} \sqrt{\mathrm{m}})\end{array}$ & $\begin{array}{c}\text { Weibull } \\
\text { Modulus }\end{array}$ \\
\hline $\begin{array}{l}\mathrm{Al}_{2} \mathrm{O}_{3} / \mathrm{SiC} \\
\text { Inconel =eacior } \\
\text { Graphite reactor }\end{array}$ & 800 & 190 & 0.5 & 19 \\
& 770 & 240 & 0.5 & 28 \\
$\mathrm{Al}_{2} \mathrm{O} 3+5$ v/o $\mathrm{ZrO}_{2}$ & 590 & 480 & 1.1 & 16 \\
\hline
\end{tabular}




\section{COMPUTER MODELUING OF BRITTLE COATINGS}

\section{COMPUTER SIMULATION OF RESIDUAL STRESS}

Numerical models were developed to predict residual stresses in the coating and substrate. The goal was to develop a model with predictive capability which could be used to determine the optimum thickness of each layer.

In coatings deposited at elevated temperatures, where the coating and substrate materials have different coefficients of thermal expansion (CTE), large stresses are generated in the coating after cooling to room temperature. Figure 19 shows CTE values for the materials in this study. If tensile, these stresses often lead to cracking of the coating. The stress component we are most concerned with is the in-plane normal stress away from the edges of a coated sample. The word "stress" is used here to describe this component.

As a coated substrate is cooled, stresses build-up in the coating. For most ceramic coatings these stresses can be described by elastic relationships. Because the coating is often a ceramic, it has a distribution of fracture strengths. Once the fracture stress of the weakest part of the coating is reached, the coating will crack. The coating will not crack again until it is cooled further because of the distribution of failure strengths and because the remaining uncracked coating has a smaller volume and therefore a higher failure strength.

In phase I conventional FEA was used to predict residual stresses for the case of AlN coatings on pure $\mathrm{Si}_{3} \mathrm{~N}_{4}$ and $\mathrm{SiC}$ substrates. The model assumed linear elastic behavior, constant physical properties within a coating layer, and zero deposition stresses. Calculations for 10 micron thick coatings gave residual stresses which oscillated between elements, regardless of mesh pattern. This was found to be caused by the large aspect ratios of the finite elements. Consequently, a technique for varying the mesh size was incorporated [SHA88]. The model was used to predict edge effects (Figure A-2).

One drawback of the second generation model was that the predicted stress was insensitive to edge effects. In addition, the model used $90^{\circ}$ angles at comers. In an effort to overcome these problems, the model was modified to use a hybrid-stiess technique [SHA88]. 
In phase II, a generalized treatment of the thermal expansion mismatch problem was carried out. In addition, finite element analysis involving the complex combination of thermal stress, linear elastic fracture mechanics and fracture mechanics of bimaterial interfaces was implemented. This work was based on contact stress issues for ceramic coatings. The method has been applied to the single and multilayer coatings of this study and deal with the presence of pre-existing flaws which are in the form of vertical or horizontal cracks. The driving force for crack initiation and propagation stems from thermal loads and a resultant normal load which simulates single point contact. The following sections describe theory and results of the newly developed technique.

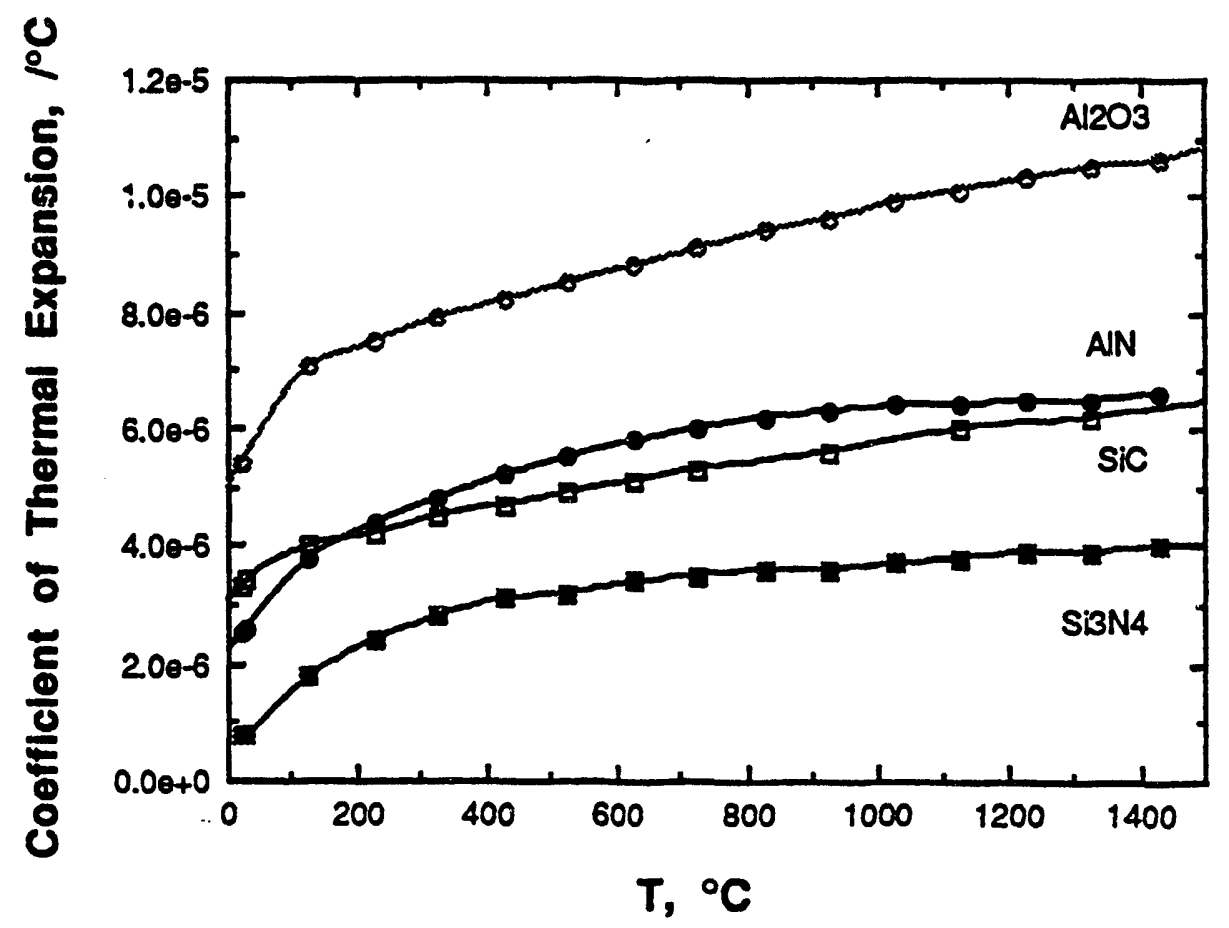

Figure 19. Thermal expansion coefficients of the various materials present in this system over the temperature range $25^{\circ} \mathrm{C}$ to $1500^{\circ} \mathrm{C}$. 


\section{Simple Beam Theory}

The in-plane stress in a narrow bimaterial strip generated by a change in temperature was derived by Timoshenko [TIM25].

$$
\begin{aligned}
& \frac{1}{\rho}=\frac{\left(\alpha_{2}-\alpha_{1}\right)\left(T_{d}-T_{i}\right)}{\frac{t}{2}+\frac{2\left(E_{1} I_{1}+E_{2} I_{2}\right)}{t}\left(\frac{1}{E_{1} t_{1}}+\frac{1}{E_{2} t_{2}}\right)} \\
& \sigma_{\max }=\frac{1}{\rho}\left(\frac{2}{t t_{1}}\left(E_{1} I_{1}+E_{2} I_{2}\right)+\frac{t_{1} E_{1}}{2}\right)
\end{aligned}
$$

where $p$ is the radius of curvature, $\alpha$ is the coefficient of thermal expansion, $T_{i}$ is the final temperature, $T_{d}$ is the initial temperature, " $E$ " is the elastic modulus, " $\mathrm{I}$ " is the moment of inertia, " $\mathrm{t}_{1,2}$ " is the layer thickness, and " $\mathrm{t}$ " is the total thickness $\left(t=t_{1}+t_{2}\right)$. More details are given in Appendix B. For systems of interest in this study a coating is thin if it less than $10 \%$ of the substrate. Figure 20 shows the bending and axial contributions to the stress in a coa:ing. The coefficient of thermal expansion and elastic modulus of the materials are treated as temperature dependent quantities and Equations 2 and 3 are numerically integrated over temperature range $\left(T_{d}\right.$ to $\left.T_{i}\right)$ to solve for the stress in the coating. The treatment of the coefficients of thermal expansion as temperature independent constants can lead to significant errors in materials where these coefficients are strong functions of temperature. An example of such a material is diamond.

The stresses in AlN and $\mathrm{Al}_{2} \mathrm{O}_{3}$ coatings deposited onto $\mathrm{SiC}$ and $\mathrm{Si}_{3} \mathrm{~N}_{4}$ at $1000^{\circ} \mathrm{C}$ are shown as a function of cooling temperature in Figure 21. $\mathrm{Al}_{2} \mathrm{O}_{3}$ coatings on $\mathrm{SiC}$ and $\mathrm{Si}_{3} \mathrm{~N}_{4}$, and AlN coatings on $\mathrm{Si}_{3} \mathrm{~N}_{4}$ have very large stresses at room temperature, while AlN has only moderate stress level at room temperature. Based on these calculated stresses the $\mathrm{Al}_{2} \mathrm{O}_{3}$ coatings would be expected to be cracked at room temperature. The presence of cracks in the $\mathrm{Al}_{2} \mathrm{O}_{3}$ coating has obvious consequences for the ability of the coating to act as an oxidation barrier for the substrate. 


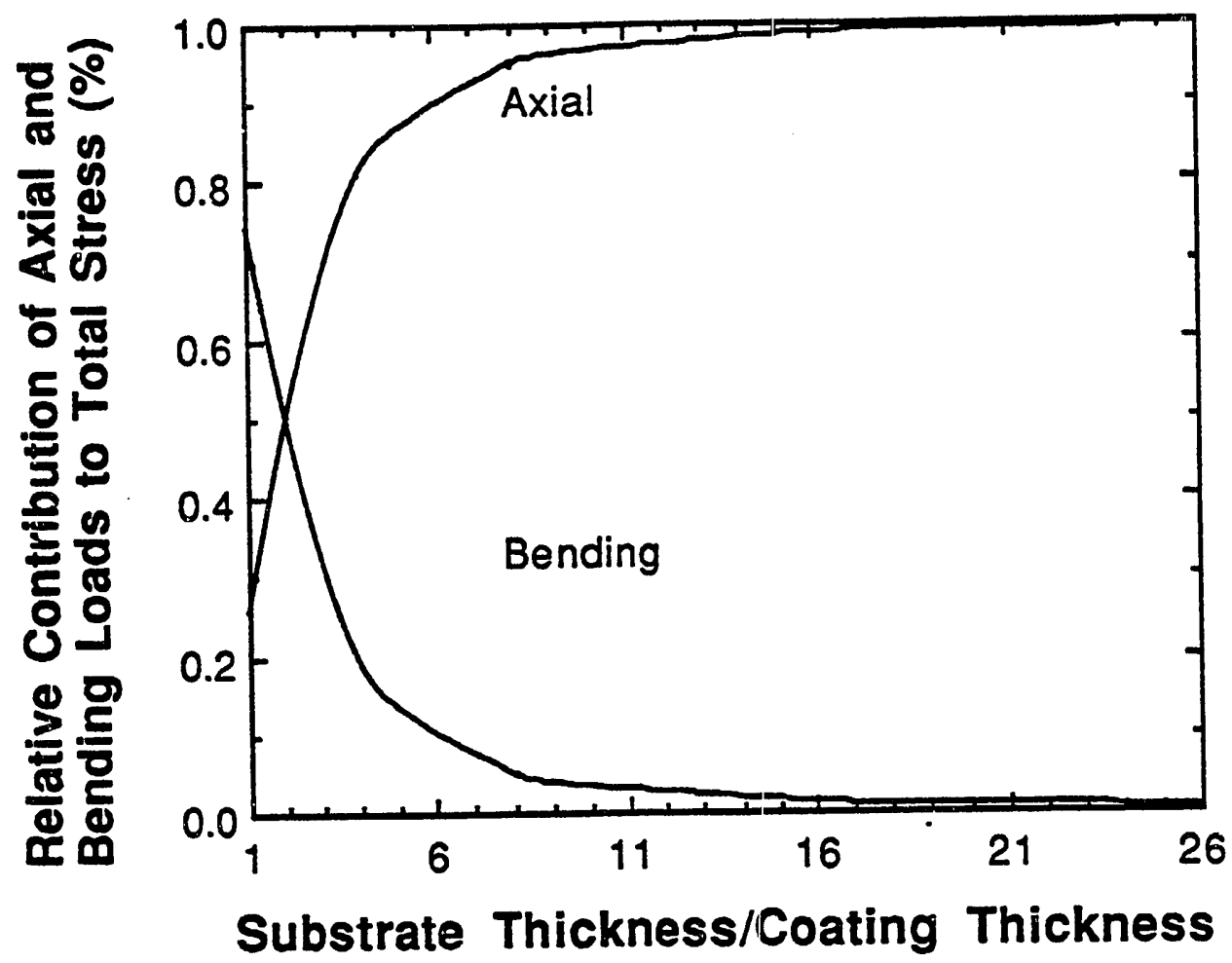

Figure 20. At coating thicknesses less than $10 \%$ of the substrate thickness most of the stress in the coating is due to the axial component and is therefore independent of the coating and substrate thicknesses. 


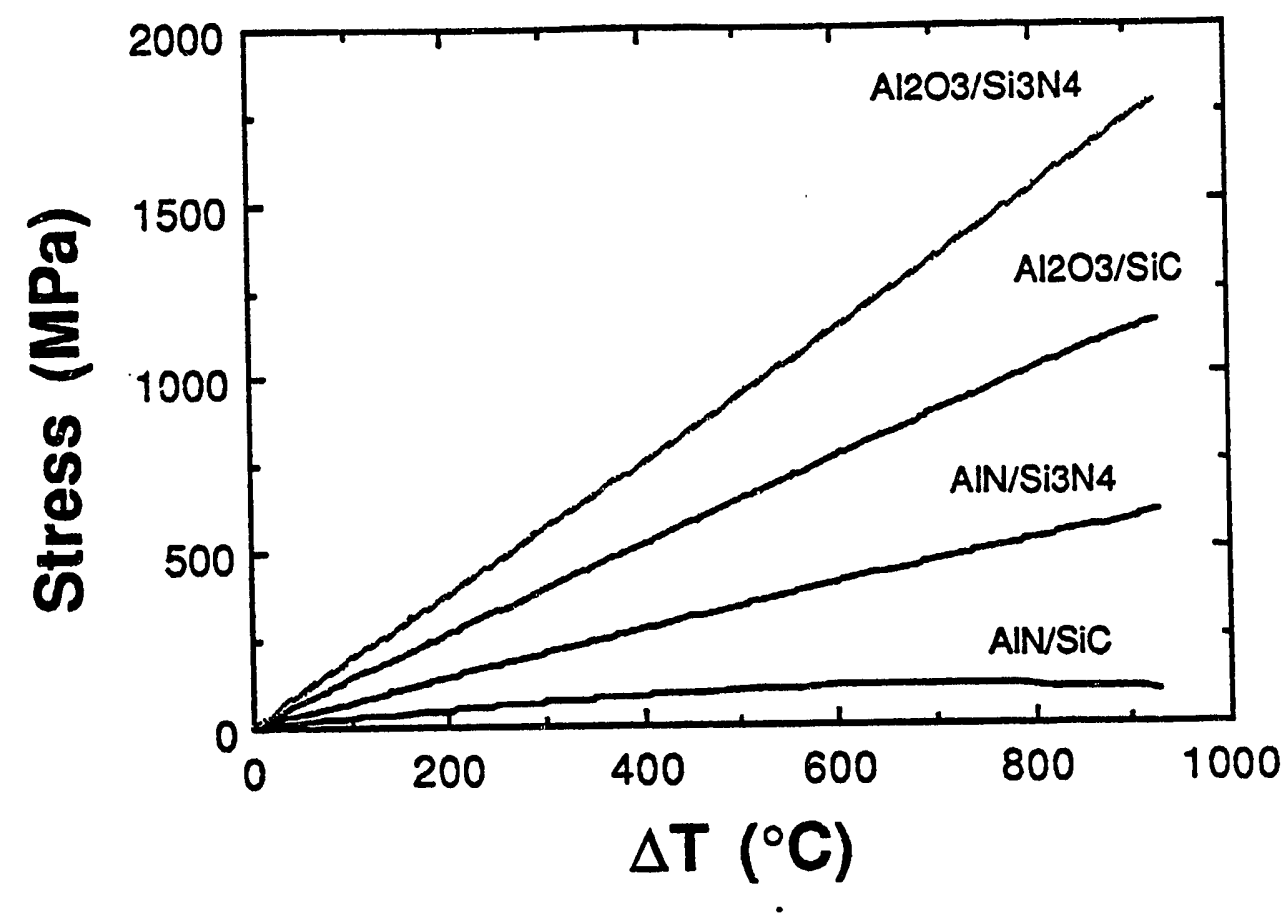

Figure 21. Stress in coating versus $\Delta \mathrm{T}$ for AlN coatings on $\mathrm{SiC}$ and $\mathrm{Si}_{3} \mathrm{~N}_{4}$, and $\mathrm{Al}_{2} \mathrm{O}_{3}$ coatings on $\mathrm{SiC}$ and $\mathrm{Si}_{3} \mathrm{~N}_{4}$.

\section{Composite Plate Theory}

The method follows the flow chart illustrated in Figure 22 . Nomenclature is given at the end of the report. The geometry of the coated system is shown in Figure 23, and Figure 24 illustrates the numbering scheme for a multi-coated substrate. In figure 24 , layer 1 could be the substrate, and 5 coating layers could be represented by layers 2 through 6 . The method is flexible for describing any number of coating layers. Note that $h$ is the total thickness of the substrate and all the coatings. (See appendix $D$ for details). 


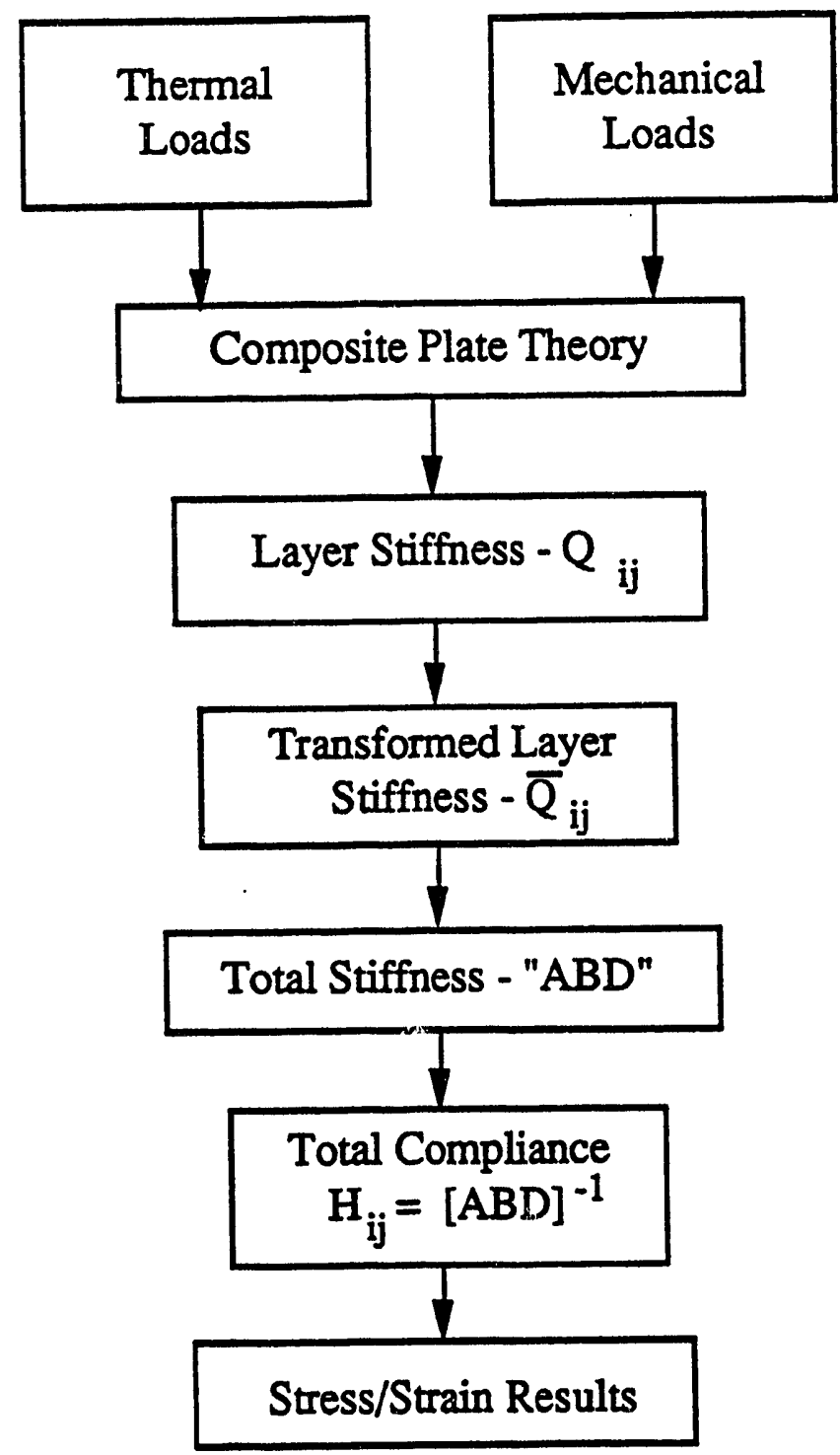

Figure 22. Flow chart for computer code implementation of composite plate theory. Layer properties were used to get transformed stiffnesses for each layer, and these were cumulated into a total stiffness matrix for the entire coated system. Unknown midplane strains were then solved for, and stresses in each of the layers recovered. 


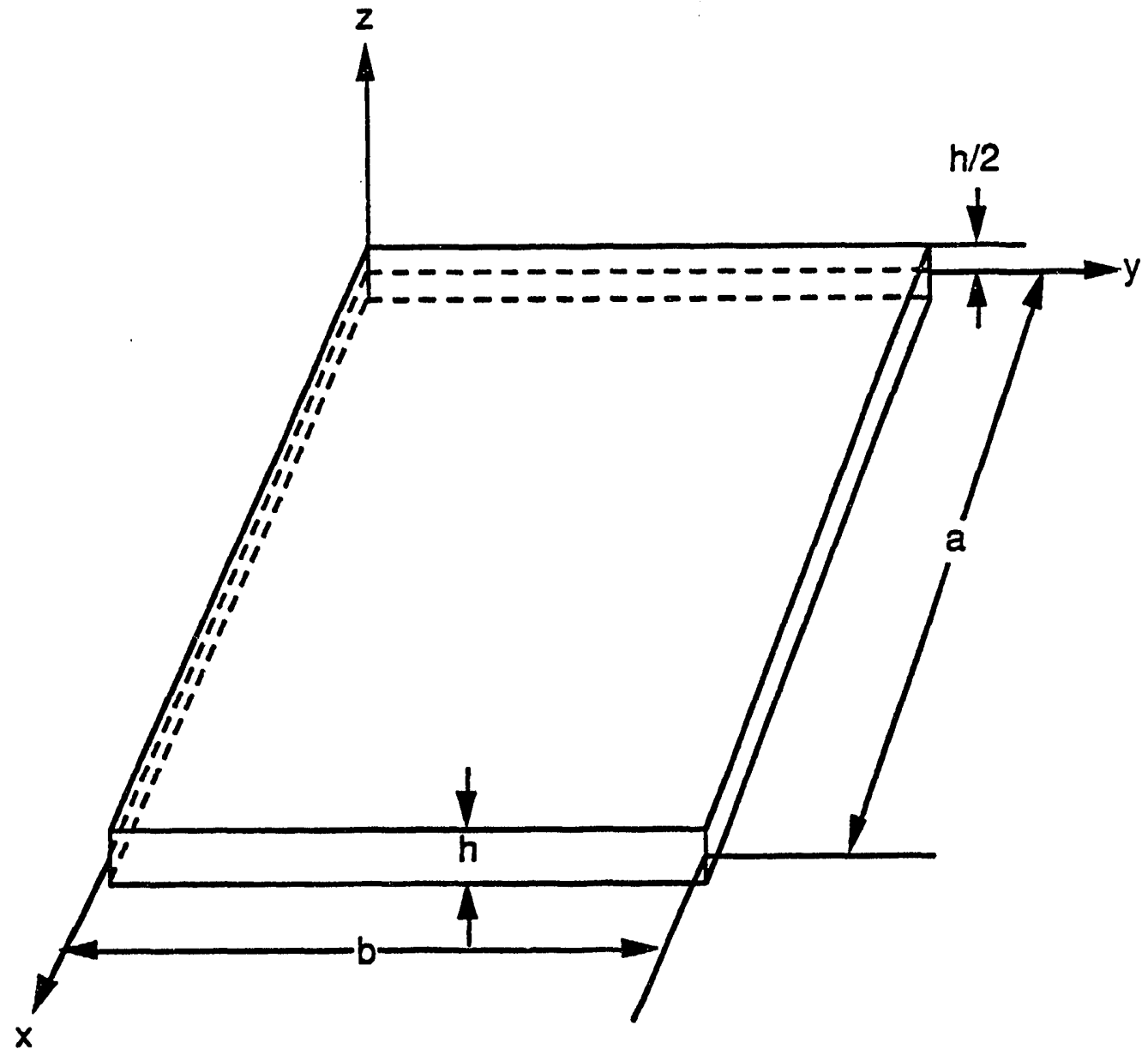

Figure 23. Schematic of the coated substrate model; $h$ is the total thickness, and the mid-plane is at $h / 2$. The $z$ direction is normal to the plane of the coatings. 

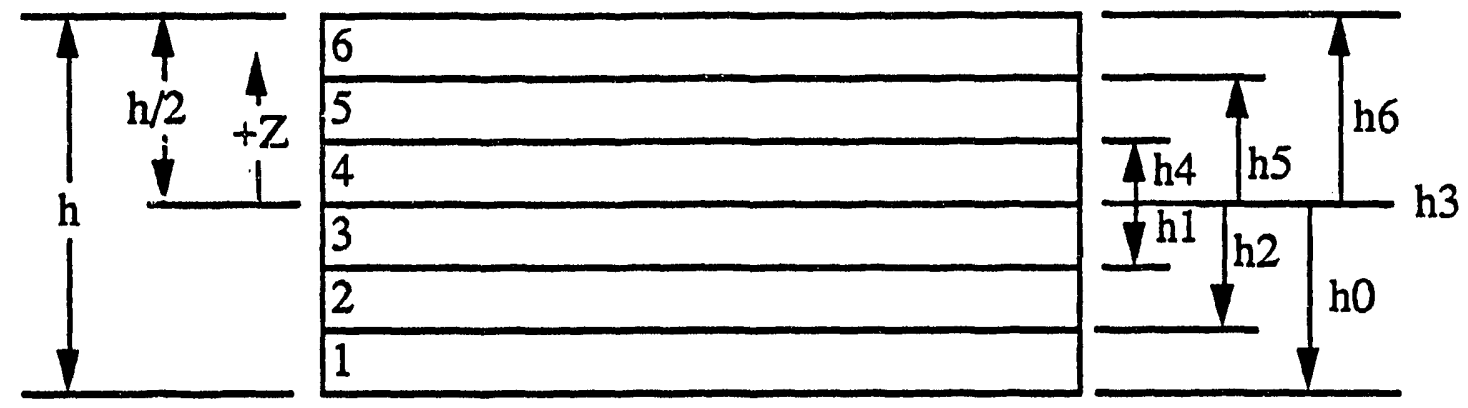

Figure 24. Numbering scheme for a multicoated system. $h$ is the total coating thickness, and all interface positions are measured relative to the mid-plane at $h / 2$, which the $z=0$ plane. Note that layers below this plane have negative interlayer position values.

\section{Comparison to Finite Element Results}

Numerical experiments were performed to compare the generalized composite plate theory to those obtained by the finite element method.. Table 9 shows the material properties used in all stress analyses. Each of the systems was cooled from $1000^{\circ} \mathrm{C}$ to find the residual stress in each of the materials present. The substrate was 6350 microns thick for all studies.

Table 9. Material properties used for substrates and coating layers in this part of the study.

\begin{tabular}{|l|c|c|c|c|}
\hline Material & $\begin{array}{c}\text { Young's } \\
\text { Modulus } \\
(\mathrm{GPa})\end{array}$ & $\begin{array}{c}\text { Poisson's } \\
\text { Ratio }\end{array}$ & $\begin{array}{c}\text { Fracture } \\
\text { Toughness } \\
(\mathrm{MPa} \sqrt{\mathrm{m}})\end{array}$ & $\begin{array}{c}\text { Thermal } \\
\text { Expansion Coeff. } \\
\left(/{ }^{\circ} \mathrm{C}\right) \times 10^{-6}\end{array}$ \\
\hline \hline $\mathrm{Al}_{2} \mathrm{O}_{3}$ & 390 & 0.22 & - & 7.8 \\
$\mathrm{AlN}$ & 340 & 0.24 & 1.0 & 4.9 \\
Interface & 320 & 0.255 & - & 3.8 \\
$\mathrm{SiC}$ & 207 & 0.22 & - & 4.3 \\
$\mathrm{Al}_{2} \mathrm{O}_{3} \mathrm{ZrO}_{2}$ & 380 & 0.22 & 5.0 & 9.4 \\
$\mathrm{Si}_{3} \mathrm{~N}_{4}$ & 296 & 0.27 & 3.5 & 2.7 \\
\hline
\end{tabular}


To ensure that the composite plate theory code was working correctly, the stress results were compared to a finite element solution of a similar problem [SHA88]. The finite element method used in Sham and Sarin [SHA88] was specially formulated to exploit hybrid finite elements because of the relative size of the elements used for the coating and for the substrate.

Resulis for both substrate materials are shown in Table 10 . Excellent agreement between the two methods is shown, thus confirming the applicability of composite plate theory to this problem.

\section{$\mathrm{Si}_{3} \underline{N}_{4}$ Substrate}

Three numerical experiments were performed with the silicon nitride substrate. Firstly, residual stress with no interlayer but with varying thickness of the alumina-zirconia coating was calculated. Next an AlN interlayer between the alumina-zirconia and $\mathrm{Si}_{3} \mathrm{~N}_{4}$ substrate was varied in thickness and residual stresses found for each material. Lastly, the AlN coating was placed above the $\mathrm{Si}_{3} \mathrm{~N}_{4}$ coating to illustrate the irrelevance of thermal expansion grading.

Results are shown in Figures D-1, D-2, and D-3 (see Appendix D). The results indicate that the presence or absence of an interlayer, thickness of the coating layers, and order of the coatings on the substrate have negligible effect on residual stress in each of the layers. 
Table 10. Comparison of 2-D finite element results using special hybrid elements to the composite plate theory described here. Stress values are from reference [SHA88], values in parentheses are results from the composite plate code described here. For both tables $\Delta \mathrm{T}=-1000^{\circ} \mathrm{C}$. Note use of $\mathrm{Si}_{3} \mathrm{~N}_{4}$ and $\mathrm{SiC}$ substrates.

\begin{tabular}{|c|c|c|c|c|c|}
\hline : Layer & $\begin{array}{l}\text { Young's } \\
\text { Modulus } \\
\text { (GPa) }\end{array}$ & $\begin{array}{l}\text { Poisson's } \\
\text { Ratio }\end{array}$ & $\begin{array}{c}\text { Thermal } \\
\text { Expansion } \\
\text { Coeff. }\left(/^{\circ} \mathrm{C}\right)\end{array}$ & \multicolumn{2}{|c|}{$\begin{array}{l}\text { Residual Stress }(\mathrm{MPa}) \\
\text { [Layer Thickness, } \mu \mathrm{m} \text { ] } \\
\begin{array}{ll}\text { (a) } 1 & \text { (b) }\end{array}\end{array}$} \\
\hline $\mathrm{Al}_{2} \mathrm{O}_{3}{ }^{*}$ & 390 & 0.22 & $7.8 \times 10^{-6}$ & $\begin{array}{c}2475(2527) \\
{[10]}\end{array}$ & $\begin{array}{c}2482(2534) \\
{[4]}\end{array}$ \\
\hline $\operatorname{AlN}^{*}$ & 340 & 0.24 & $4.9 \times 10^{-6}$ & $\begin{array}{c}938(964) \\
{[3]}\end{array}$ & $\begin{array}{c}943(970) \\
{[9]}\end{array}$ \\
\hline Interface & 320 & 0.255 & $3.8 \times 10^{-6}$ & $\begin{array}{c}442 \text { (453) } \\
\text { [1] }\end{array}$ & $\begin{array}{c}448(459) \\
{[1]}\end{array}$ \\
\hline $\mathrm{Si}_{3} \mathrm{~N}_{4}{ }^{*}$ & 296.5 & 0.27 & $2.7 \times 10^{-6}$ & $\begin{array}{l}-16 \\
(-17)\end{array}$ & $\begin{array}{l}-11 \\
(-12)\end{array}$ \\
\hline $\mathrm{Al}_{2} \mathrm{O}_{3}^{\dagger}$ & 390 & 0.22 & $7.8 \times 10^{-6}$ & $\mid \begin{array}{c}1731(1728) \\
{[10]}\end{array}$ & $\begin{array}{c}1740 \text { (1738) } \\
{[4]}\end{array}$ \\
\hline $\operatorname{AlN}^{\dagger}$ & 340 & 0.24 & $4.9 \times 10^{-6}$ & $\begin{array}{c}282(249) \\
{[3]}\end{array}$ & $\begin{array}{c}290(258) \\
{[9]}\end{array}$ \\
\hline $\mathrm{SiC}^{\dagger}$ & 207 & 0.22 & $4.3 \times 10^{-6}$ & $-11(-11.5)$ & $-6(-6)$ \\
\hline
\end{tabular}

† SiC substrate.

${ }^{*} \mathrm{Si}_{3} \mathrm{~N}_{4}$ substrate.

SiC Substrate

Since it has been shown that coating stresses are not sensitive to thickness or coating order variations, all pertinent stresses for the SiC substrate coating systems can be found with a single residual stress analysis. 
The stresses shown in Figure D-4 (appendix D) are applicable for changes in any of the layer thickness or order sequence.

Based on these studies, our conclusions for brittle ceramic coatings on $\mathrm{Si}_{3} \mathrm{~N}_{4}$ and $\mathrm{SiC}$ substrates are:

- Verifying that coating thickness has negligible effect on residual stress in any of the coating layers.

- The order (i.e., grading the thermal expansion mismatch in a multilayer coated system) has negligible effect on residual stress in any of the coating layers.

- Modulus of elasticity has almost no effect on residual stress in any of the coating layers.

- Because each of the coatings are thin films relative to the size of the substrate thickness, the strain in the coatings is the same as the strain at the top fiber of the substrate, that zone which has an interface with the first coating layer.

- If material properties vary as a function of temperature, magnitudes of stress will be different, but the above conclusions still hold.

It should be noted that these conclusions apply to brittle thin films, and that simulations were performed on uncracked coating layers. The stresses calculated in each of the layers would be those which induce cracking in any of the layers, and as such are indicators of the tendency for cracking during cooling from the CVD process.

The effect of crack propagation during solid body contact of these elastic layers is not known, so thickness and layer ordering may have an effect in that case. The possibilities for working around the problem inherent to brittle coatings could lie either in the area of controlled brittle fracture using multilayer coating, or by the use of "ductile" layers which would permit stress relief of the ceramic layers when they are bonded to 
other brittle layers. However, the required thickness of the ductile interlayer wqould probably be too thick for practial applications [SCH92].

COMPUTER SIMULATION OF COATING FRACTURE

Single Laver with Interface. Initial Vertical Flaw

Studies were performed on a single-layer coating of $\mathrm{Al}_{2} \mathrm{O}_{3}+\mathrm{ZrO}_{2}$ on a substrate of silicon nitride. Subsequent sections will describe results for a multi-layer coated substrate. Loads were imposed on the body in the form of residual thermal stress, and mechanical loads resulting from solid body contact with friction. The finite element model allows automatic changes in mesh topology due to crack growth, and a bimaterial fracture model which takes into account the different fracture toughnesses of the coating, interface, and substrate when the cracks are at or near the interface. Results indicate that, subject to these loads, a vertical flaw in the coating propagates approximatcly downward until the coating-substrate interface region. Once the crack has entered the interface, it moves away from the contact loads along the interface a distance of approximately half the coating thickness, after which it continues in a direction nearly normal to the net direction of the applied load. Since the crack did not continue along the interface, improvements in the interface bond strength would not have significantly influenced the crack growth direction.

\section{Geometry}

A finite element mesh was created to simulate the cross-section of a wide sample (plane-strain) of a single layer coated substrate. Coating thickness was 2 microns, substrate thickness was arbitrary, and assigned a value of 58 microns.

The plane of the mesh is shown in Figure 25. For the single layer analysis the $\mathrm{AlN}$ interlayer was not used. The model was simply $\mathrm{Al}_{2} \mathrm{O}_{3}+\mathrm{ZrO}_{2}$ on a $\mathrm{Si}_{3} \mathrm{~N}_{4}$ substrate. The width of the model was 60 microns. A set of boundary markers exists between the elements which describe the coating and those that define the substrate. These boundary markers locate the bimaterial fracture boundary. During remeshing, this boundary must lie on element 
boundaries to keep the interface coherent. The model initially was crackfree. A vertical flaw 0.5 microns long was positioned 1 micron from the mechanical load. As the crack propagated, the model was automatically remeshed to take into account the change in surface, the bimaterial interface, and the stress concentration at the crack tip. Eight noded quadratic elements were used for the original mesh. Mesh changes were mapped with 6 noded triangular elements, and the crack tip was modeled with 6 noded singularity elements. When the crack tip was at or near the bimaterial interface, singularity elements were not used. For each crack increment, the next propagation direction was predicted by using a maximum energy release rate criterion, which is also applicable in the region of the interface. The energy release rate was calculated by comparing the energy released by the system for candidate directions in each of the materials in the vicinity of the crack tip. Once a direction was found, the crack length was increased a small amount and the calculation repeated. This procedure was continued until no significant change in the direction of crack propagation was seen.

\section{Boundary Conditions}

Thermal loads were applied to the entire body by including a temperature change of $-1000^{\circ} \mathrm{C}$ into the analysis. This temperature is typical of temperatures used in the CVD process for this material system. It was assumed that the coating was applied to the substrate in the CVD chamber in a stress-free state and that stresses were generated upon cooling by thermal expansion mismatch between the coating and the substrate. A mechanical load was also applied to the coating. The mechanical loads represents the load applied by solid body contact. The load was distributed over a 1 micron region; the shape of the distribution was parabolic. The magnitude of the maximum value of the distribution was scaled such that the stress results were normalized from zero to one. The coefficient of friction used was 0.5 , resulting in the same form of the distribution of shear stress on the surface of the coating. Figure 26 is a schematic of the boundary conditions. As previously mentioned, the AlN interlayer, while shown in Figure 25, was not used in the single layer analysis. On the lower edge of the model, the central node of the 
edge was pinned, and all other nodes on the edge were constrained in the vertical direction.

\section{Material Properties}

The coating material was $\mathrm{Al}_{2} \mathrm{O}_{3}+\mathrm{Z}_{\mathrm{rO}_{2}}$ and the substrate was silicon nitride. Both materials were modeled as elastic in both thermal and mechanical properties. Material properties were assigned to the coating, substrate and interface. Elastic and thermal properties for the coating and substrate are shown in Table 9. The interface energy release rate as a function of mode-mixity is shown in Figure 27.

\section{Crack Propagation Studies}

The crack propagation occurred over 14 crack increments, after which the direction of crack growth remained constant. Since the crack crossed the bimaterial interface, the bimaterial interface fracture model was used for several crack growth steps. Other crack growth steps used linear elastic fracture mechanics theory solved using finite element methods. This bimaterial fracture model has been implemented into a finite element framework [FRA91], and the key concept in the numerical scheme is that the crack is predicted to propagate in the direction of maximum energy release rate. This energy release rate is analogous to that described for homogeneous fracture theory. The difference is that there may be several candidate directions where the energy release rate is a maximum. All candidate directions for all materials must be considered and conpared. The method was developed to apply in cases where the crack tip is in or near a bimaterial interface. Figure 28 shows the finite element mesh prior to crack growth. The upper four elements comprise the coating region. Elements below the upper four comprise the substrate. An enlargement of the initial vertical flaw, showing the original and deformed shape of the coated system is shown in Figure 29. Note that the deformed shape was a result of the thermal, normal and shear loads on the structure. Figure 30 illustrates the direction of crack growth prior to crossing the bimaterial interface. The crack has begun a slight tum away from the applied mechanical loading. Figures 31 shows the deformed shape for the final crack increment. Note that the crack did not 
remain in the interface, as it would for a material with a lower range of interface fracture toughnesses (lower $G_{I c}$ curve), and also that the final crack direction is approximately normal to the applied mechanical loading direction. The fracture modeling of coated systems continues in the next section with a two layered coated substrate; under the same thermal and mechanical loads.

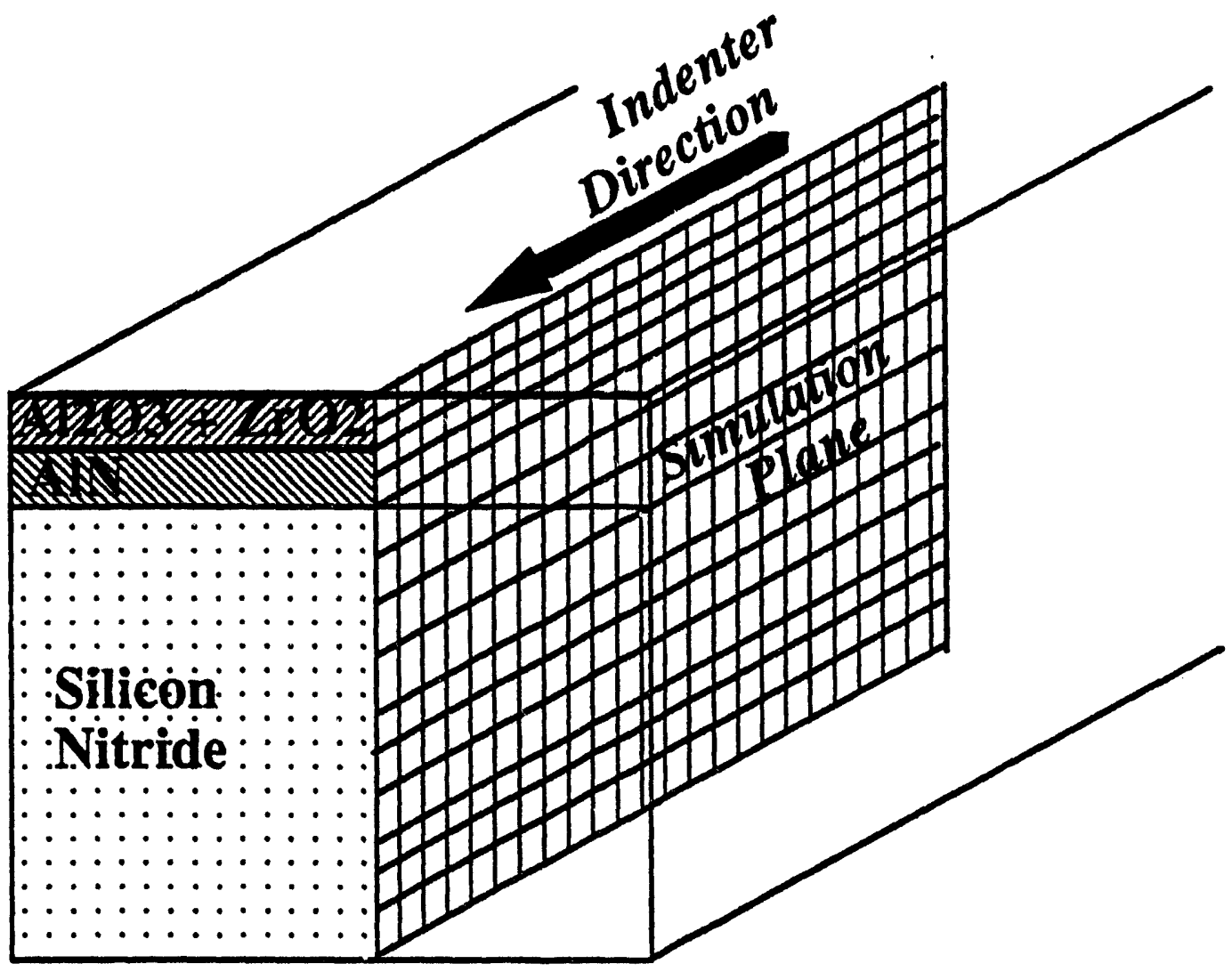

Figure 25. Schematic of the finite element mesh relative to microstructural cross section. Direction and positioning of scratch test indenter is shown. 


\section{$\Delta \mathrm{T}=-1000^{\circ} \mathrm{C}$}

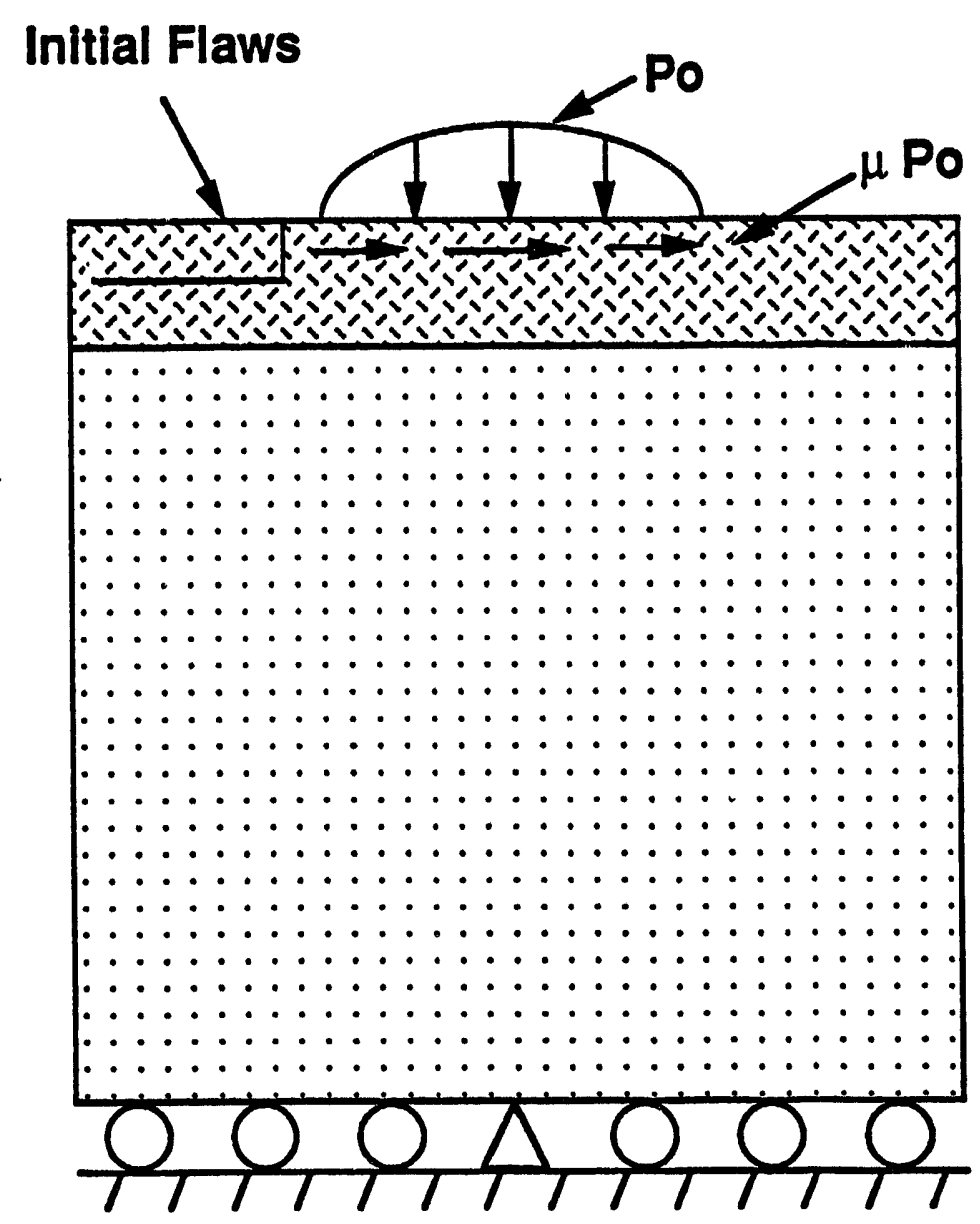

Figure 26. Schematic of the boundary conditions used in the fracture simulation. Coefficient of friction was 0.5 . The value of ' $p$ ' (the maximum magnitude of the load distribution) was assigned a value such that the stress results are normalized. 


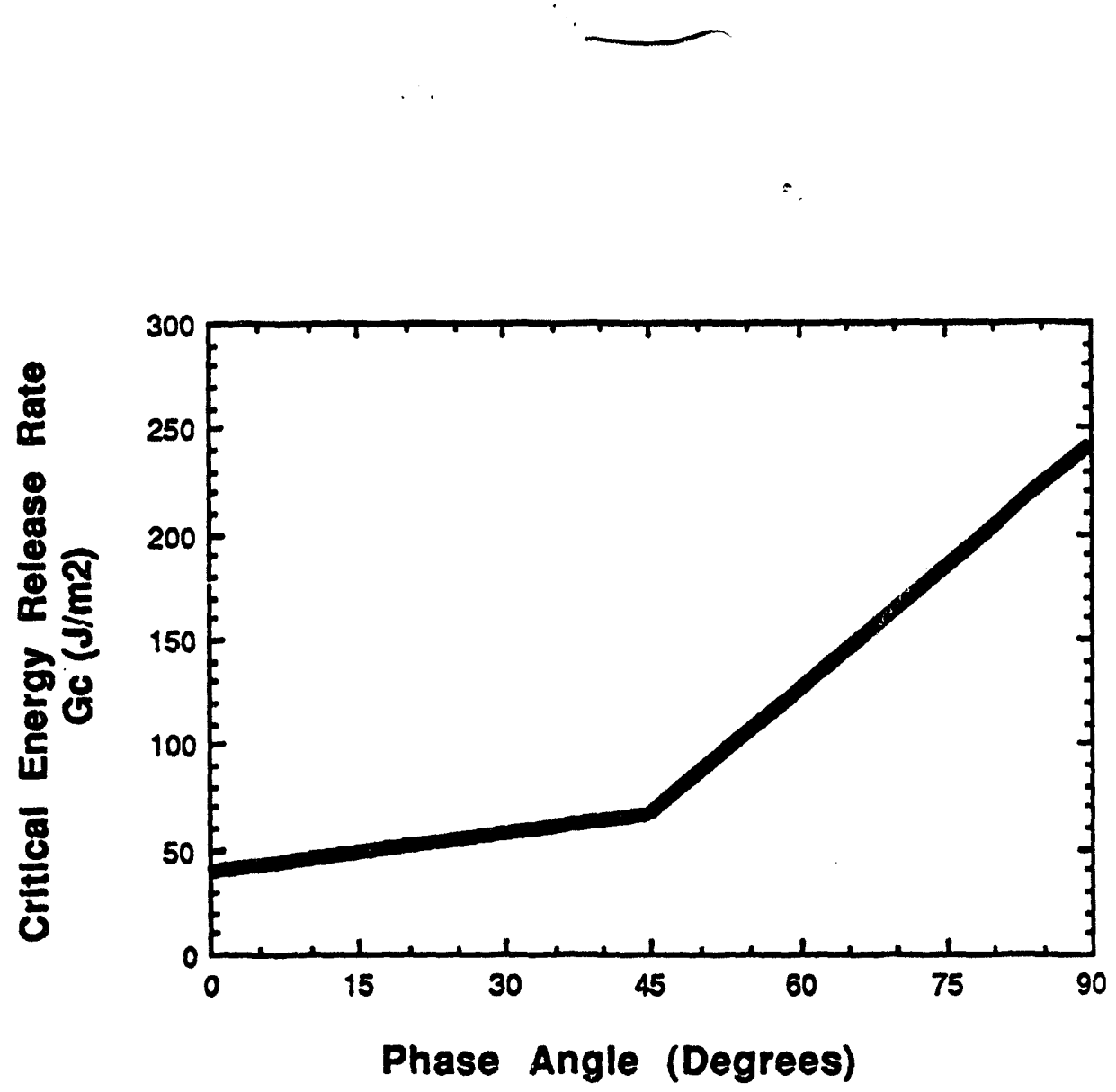

Figure 27. Energy release rate for the interface as a function of mode mixity. A mode-mixity of 0.0 describes pure mode $I$ loading at the crack tip, and a mode-mixity of 90 (degrees) describes pure mode II loading at the crack tip. 


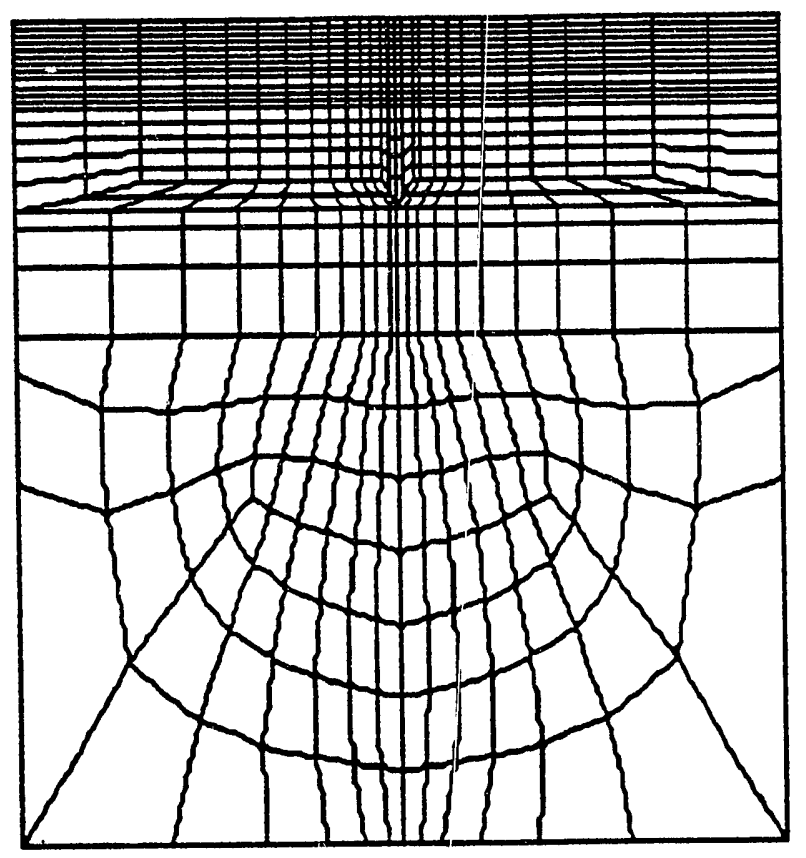

Figure 28. Initial (uncracked) mesh used in the fracture simulation study. The top four elements are the $\mathrm{Al}_{2} \mathrm{O}_{3}+\mathrm{ZrO}_{2}$ coating material. 


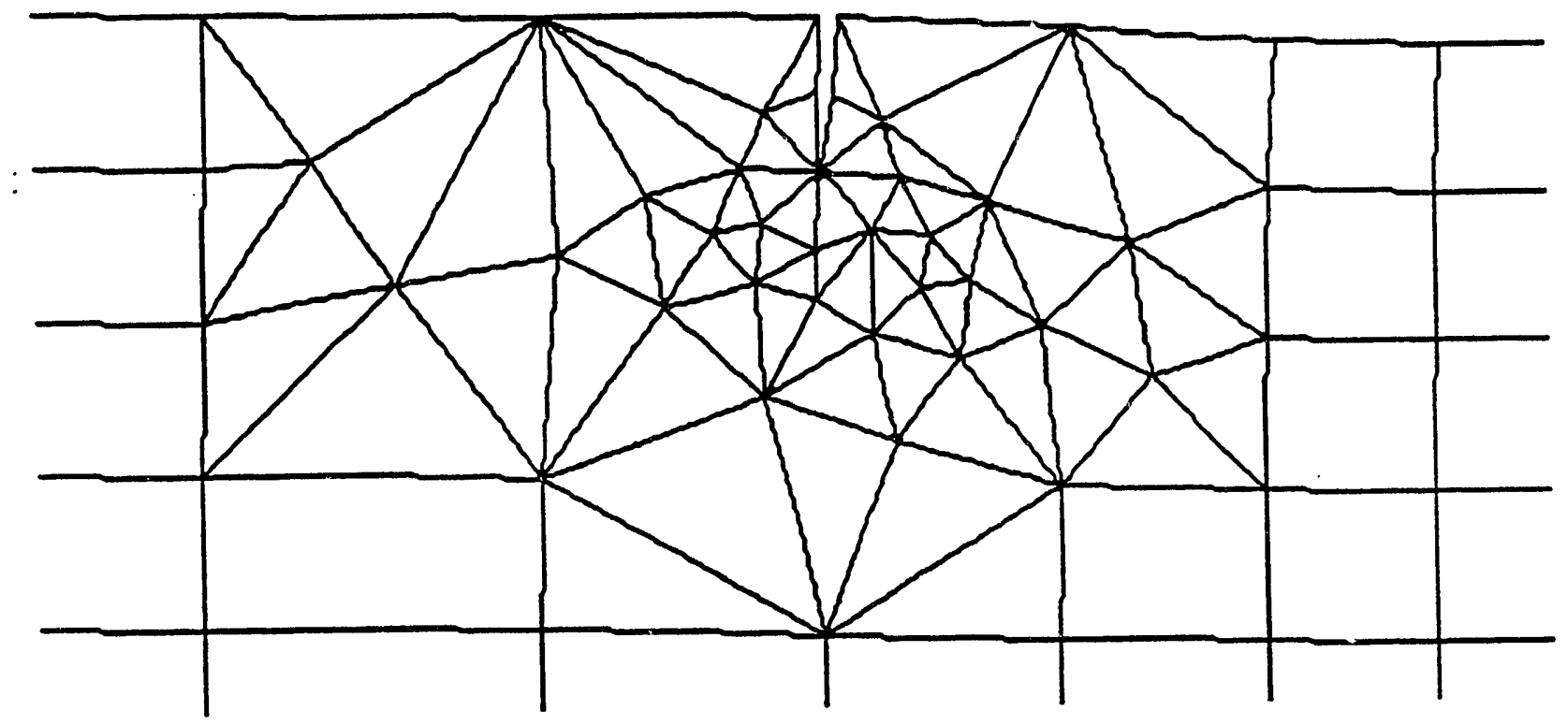

Figure 29. Initial vertical llaw, 0.5 micror; long (1/4 coating thickness). 


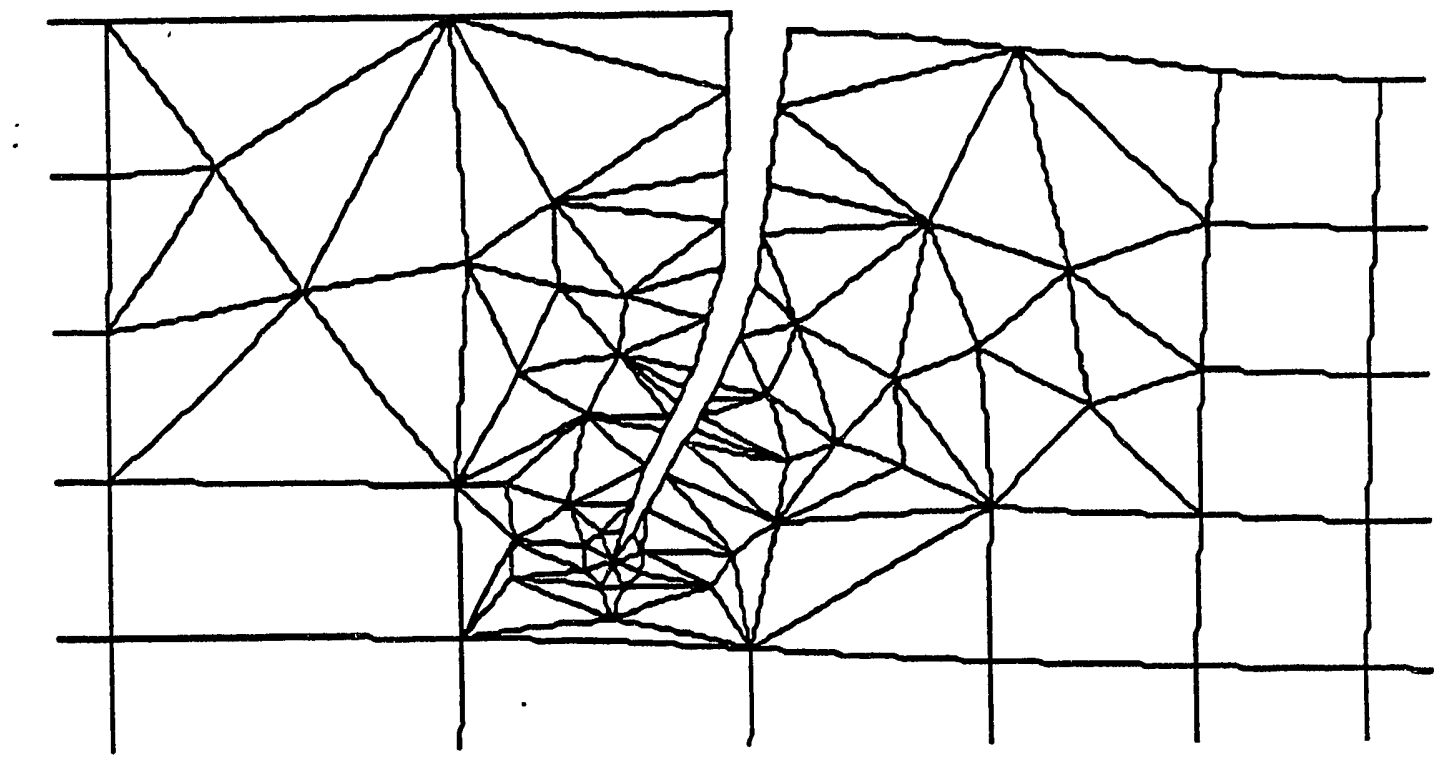

Figure 30. Deformed shape and crack growth direction prior to crossing the bimaterial interface. 


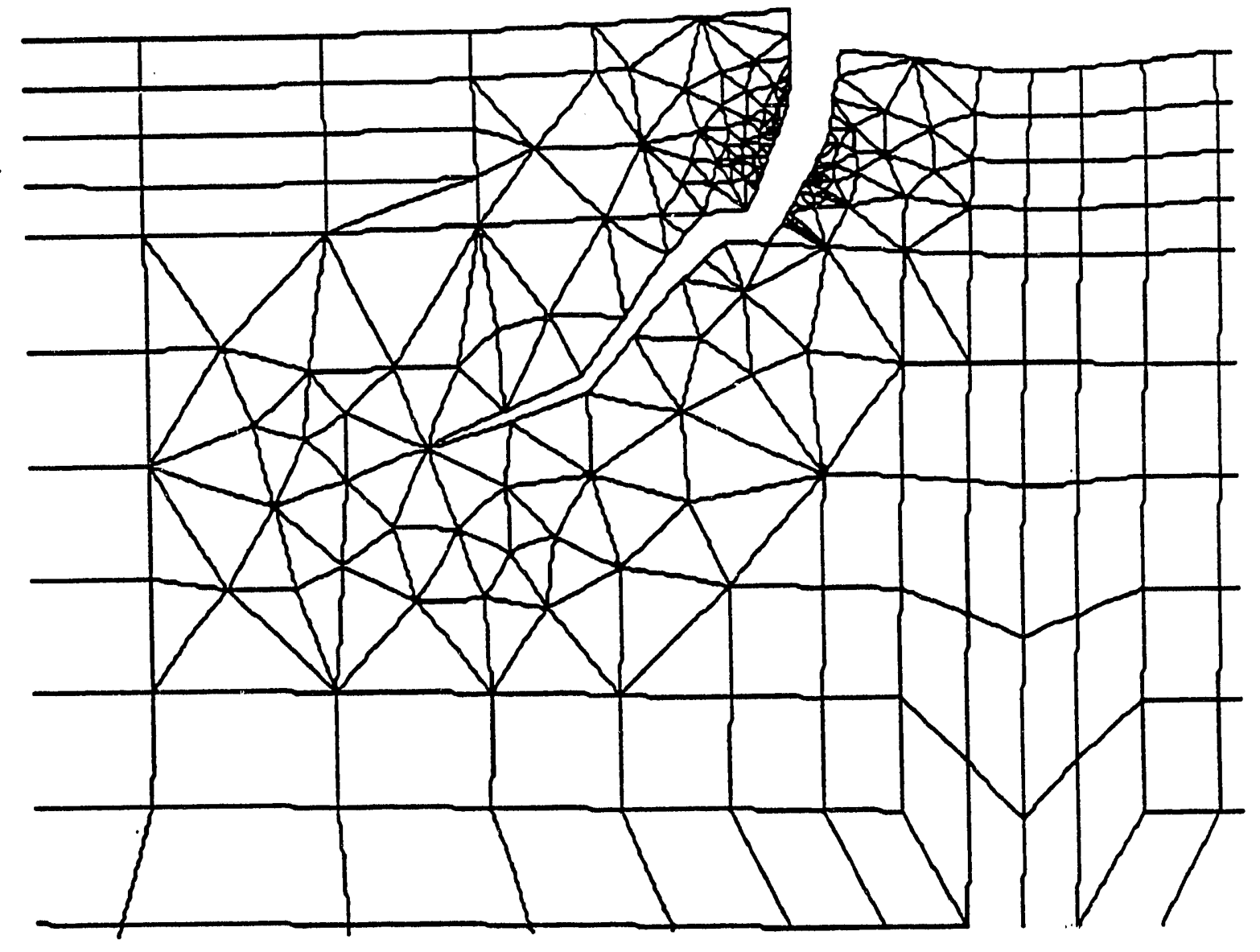

Figure 31. Deformed shape and crack path in final increment. 
1

\section{Multilarer Analzsis - Initial Vertical Flaw}

Simulations of a single-layer fracture were reported in the previous section. Here we describe the model and results for numerical simulation of a single-pass scratch test of a substrate with two coating layers, and crack propagation due to an initial vertical flaw.

\section{Geometry}

The finite element mesh was created to simulate the cross-section of a wide sample (plane-strain) of a double-layer coated substrate. Coating thicknesses were 2 microns, substrate thickness was arbitrary, and assigned a value of 58 microns. The plane of the mesh is shown in Figure 25. The boundary conditions are those shown in Figure 26.

\section{Material Properties}

The top-layer coating material was $\mathrm{Al}_{2} \mathrm{O}_{3}+\mathrm{ZrO}_{2}$, the second (middle) coating layer as AlN, and the substrate was silicon nitride. All materials were modeled as elastic in both thermal and mechanical properties. Material properties were assigned to the coatings, substrate and interface. The interface energy release rate as a function of mode-mixity for both material interfaces is shown in Figure 32. 
Interface Properties

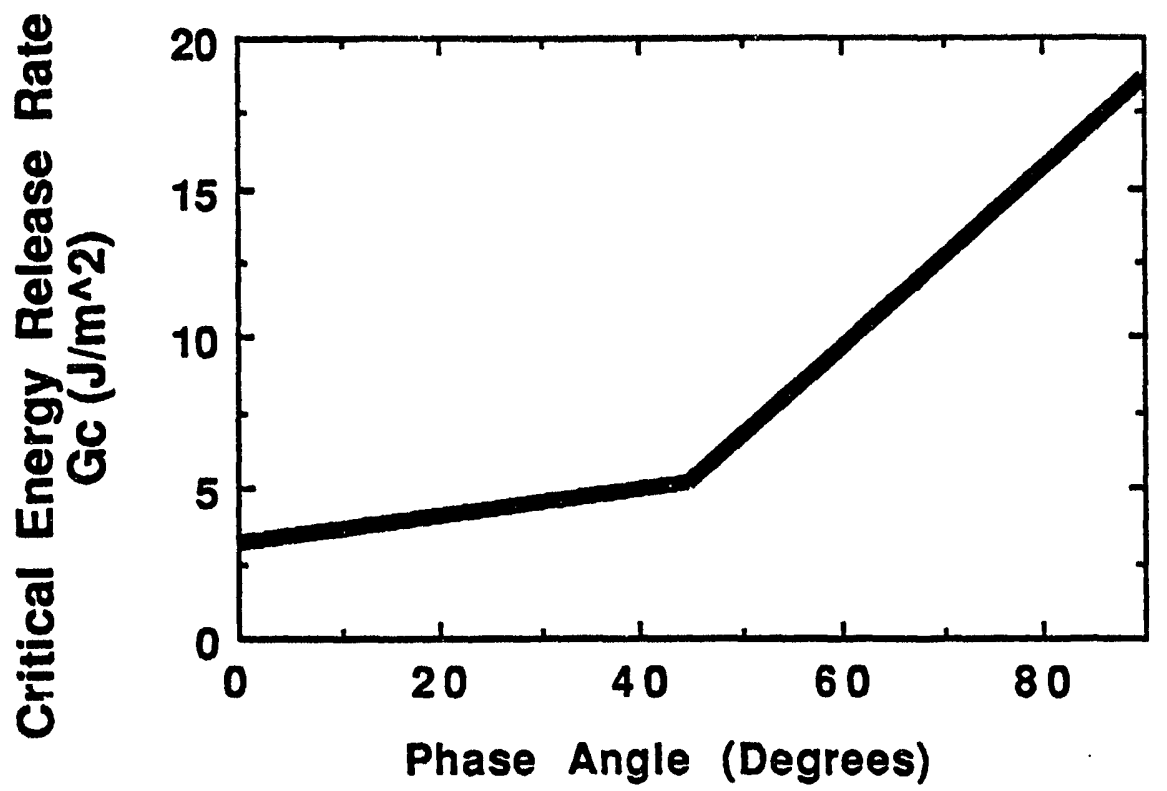

Figure 32. Energy release rate for both interfaces as a function of mode mixity. A mode-mixity of 0.0 describes pure mode I loading at the crack tip, and a mode-mixity of 90 (degrees) describes pure mode II loading at the crack tip.

\section{Crack Propagation Studies}

The crack propagation occurred over 27 crack increments, after which the direction of crack growth remained constant; along the AlN-substrate interface. Since the crack crossed both bimaterial interfaces, the bimaterial interface fracture model was used for several crack growth steps. Other crack growth steps used linear elastic fracture mechanics theory which was solved using finite element methods.

Figure 33 shows the finite element prior to crack growth. The upper four elements (in the vertical direction) comprised the top-layer $\left(\mathrm{Al}_{2} \mathrm{O}_{3}+\mathrm{ZrO}_{2}\right)$. The next four elements in the vertical direction comprised the second layer (AlN). Elements below the upper eight modeled the substrate. A zoom of the initial vertical flaw, showing the original and deformed shape of the coated system is shown in Figure 34. Note that the deformed shape was a result of the thermal, normal and shear loads on the structure. 
Figure 35 illustrates the direction of crack growth as the crack entered the first material interface. The $\mathrm{Al}_{2} \mathrm{O}_{3}+\mathrm{ZrO}_{2}$ layer would no longer provide oxidation resistance. The crack has begun a slight tum away from the applied mechanical loading at this stage in the crack history.

Figure 36 shows the deformed shape for the final crack increment. Note that the crack did not remain in the top interface, but continued through the middle AlN layer to the silicon nitride substrate. These results indicate that both coating layers have been completely fractured. A solution to this type of failure could be to design the first material interface (increased toughness) such that the crack would not penetrate into the second coating layer.

Results indicated that, subject to these loads, a vertical flaw in the coating propagated approximately downward until the first coating-substrate interface region. Once the crack entered this first interface, it traveled for a distance of about $20 \%$ of the coating thickness, then changed direction and advanced into the second coating material. While traversing both coating layers, the crack traveled in a direction nearly normal to the net direction of the applied load. Since the crack continued to the substrate surface, it was anticipated that the surface would be exposed to outer gaseous conditions.

The fracture modeling of coated systems continues with a two-layered coated substrate with initial horizontal flaws; under the same thermal and mechanical loads.

\section{Multilarer Analvsis - Initial Herizental Flaw}

Two analyses have been performed. The first had the initial horizontal flaw positioned at the middle of the second coating layer. In this case, the crack did not cross any of the material interfaces during crack growth. Figures 25 and 26 show the model and boundary conditions prior to crack growth. With regard to the mesh the upper four elements (in the vertical direction) comprised the $\mathrm{Al}_{2} \mathrm{O}_{3}+\mathrm{ZrO}_{2}$ layer coating. The next four element in the vertical direction comprised the second layer (AlN) coating region. Elements below the upper eight modeled the substrate. A zoom of the initial horizontal flaw, showing the original and deformed shape of the coated system is shown in Figure 37. Note that the deformed shape was a result of the 
thermal, normal and shear loads on the structure. Figure 38 illustrates the direction of crack growth in the final stage of simulation. The crack is directed upwards toward the free surface, then curves away from the applied mechanical load.

The second simulation was performed with an initial horizontal crack in the top coating layer. It was positioned in the middle of this layer. A zoom of the initial horizontal flaw, showing the original and deformed shape of the coated system is shown in Figure 39 . Note that the deformed shape was a result of the thermal, normal and shear loads on the structure. Figure 40 illustrates the direction of crack growth in the final stage of simulation. The crack is directed upwards toward the free surface, and the analysis was halted as the crack neared the surface. Since the horizontal cracks were directed away from the substrate, an opportunity exists to design the coating layer such that manufacturing flaws are highly oriented in the horizontal direction, which would promote coating stability and thus oxidation resistance of the substrate.

Since cracks were predicted to move away from the substrate material, the oxidation resistance of the substrate could be preserved during crack growth of this type. It should also be emphasized that this was not the case with initial vertical flaws, which propagated to the substrate. 


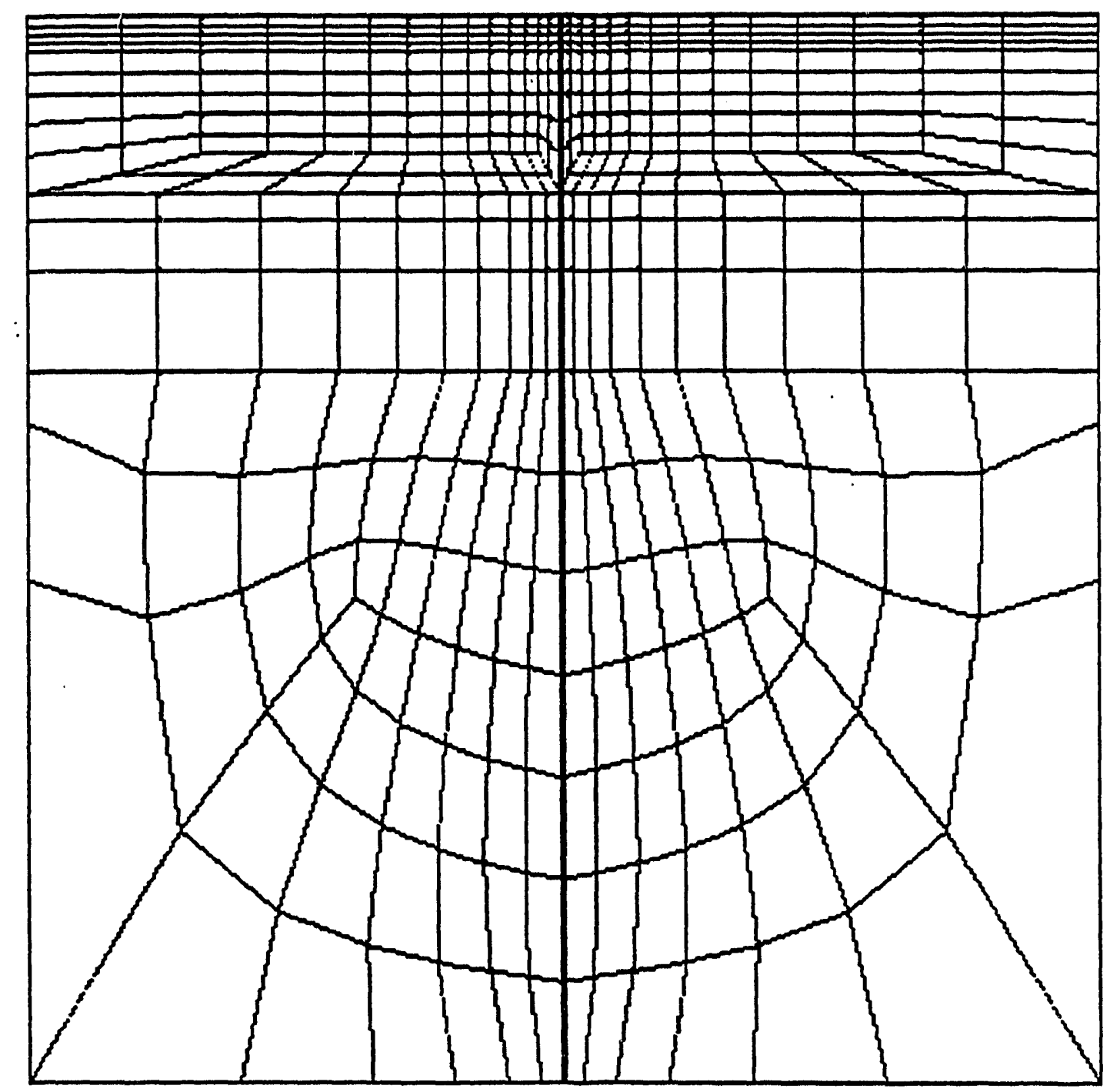

Figure 33. Initial (uncracked) mesh used in the fracture simulation study. The top four elements are the $\mathrm{Al}_{2} \mathrm{O}_{3}+\mathrm{ZrO}_{2}$ coating material. The next four were the AlN coating material. 


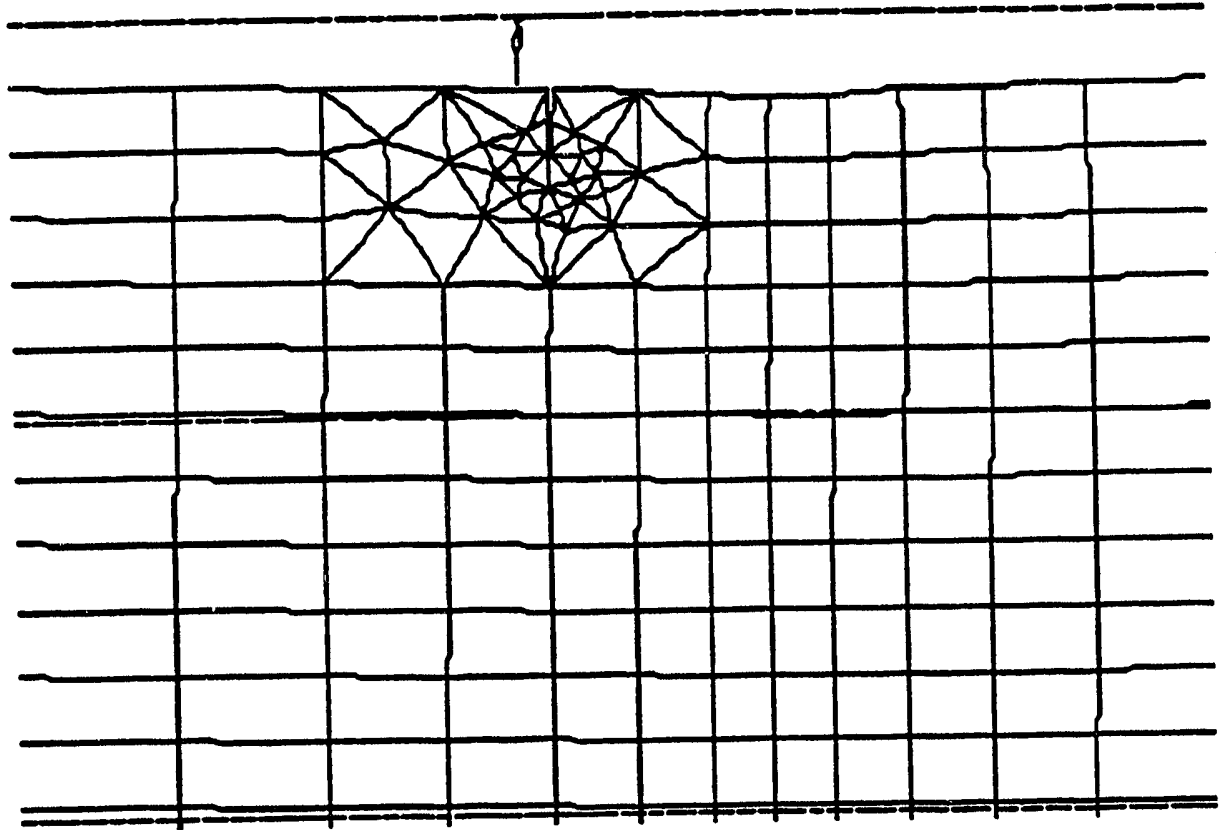

Figure 34. Initial vertical flaw, 0.5 microns long (1/4 coating thickness). Solid lines are deformed geometry (thermal and mechanical loads). Dashed lines are undeformed geometry. 


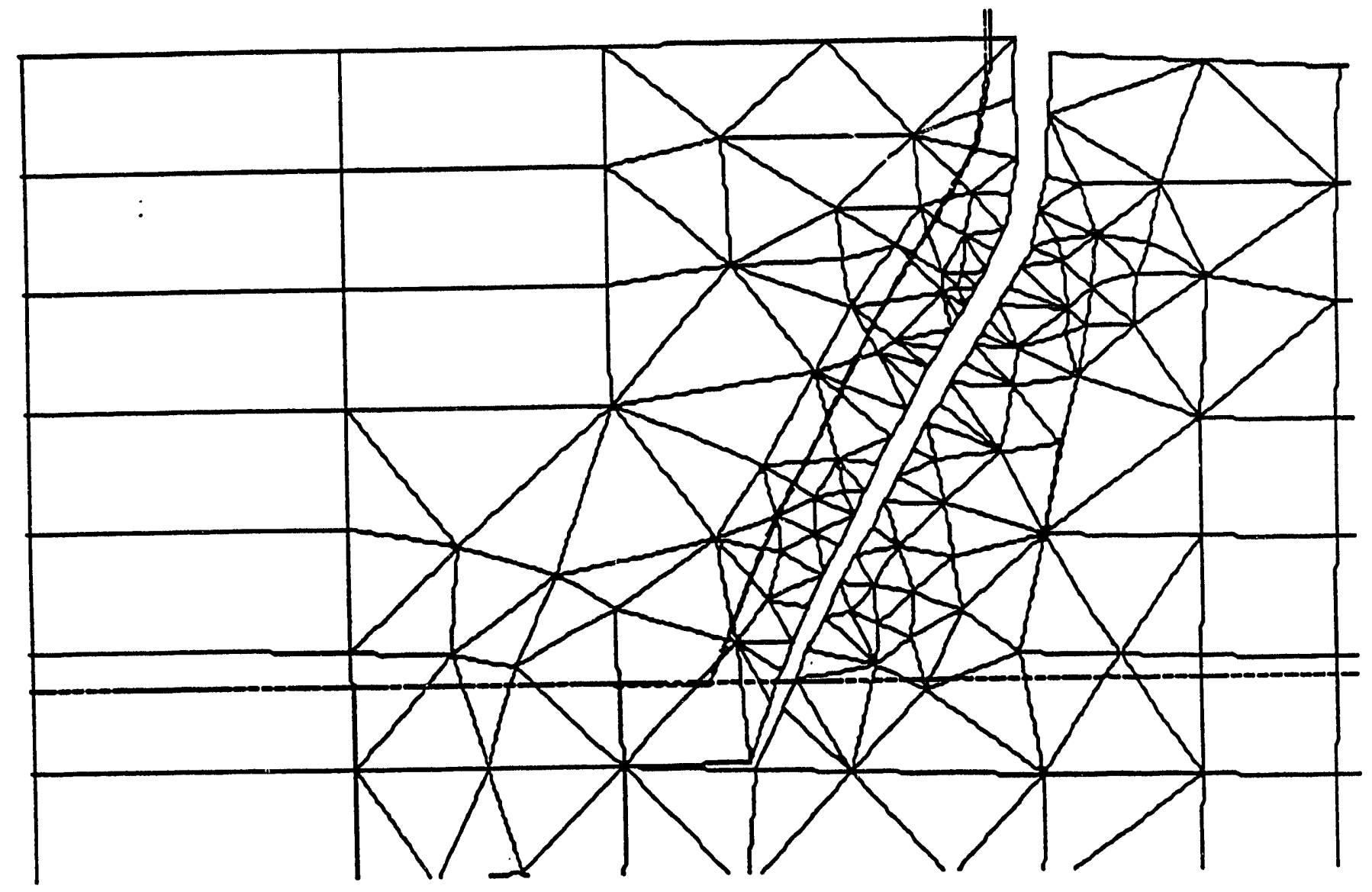

Figure 35. Deformed shape and crack growth direction as the crack encountered the top bimaterial interface. 


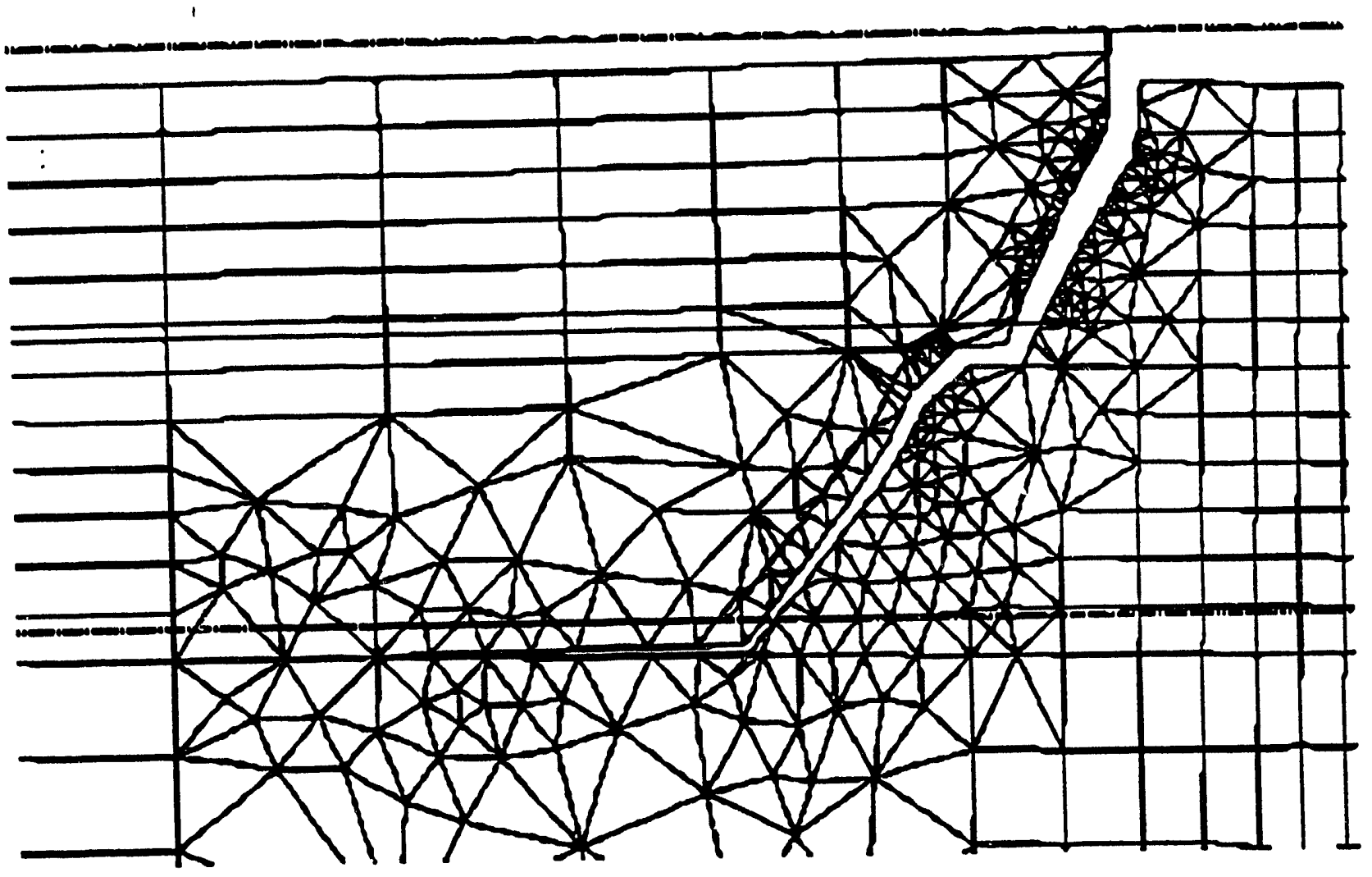

Figure 36. Deformed shape and crack path in final increment. The crack has propagated through both coating layers. 


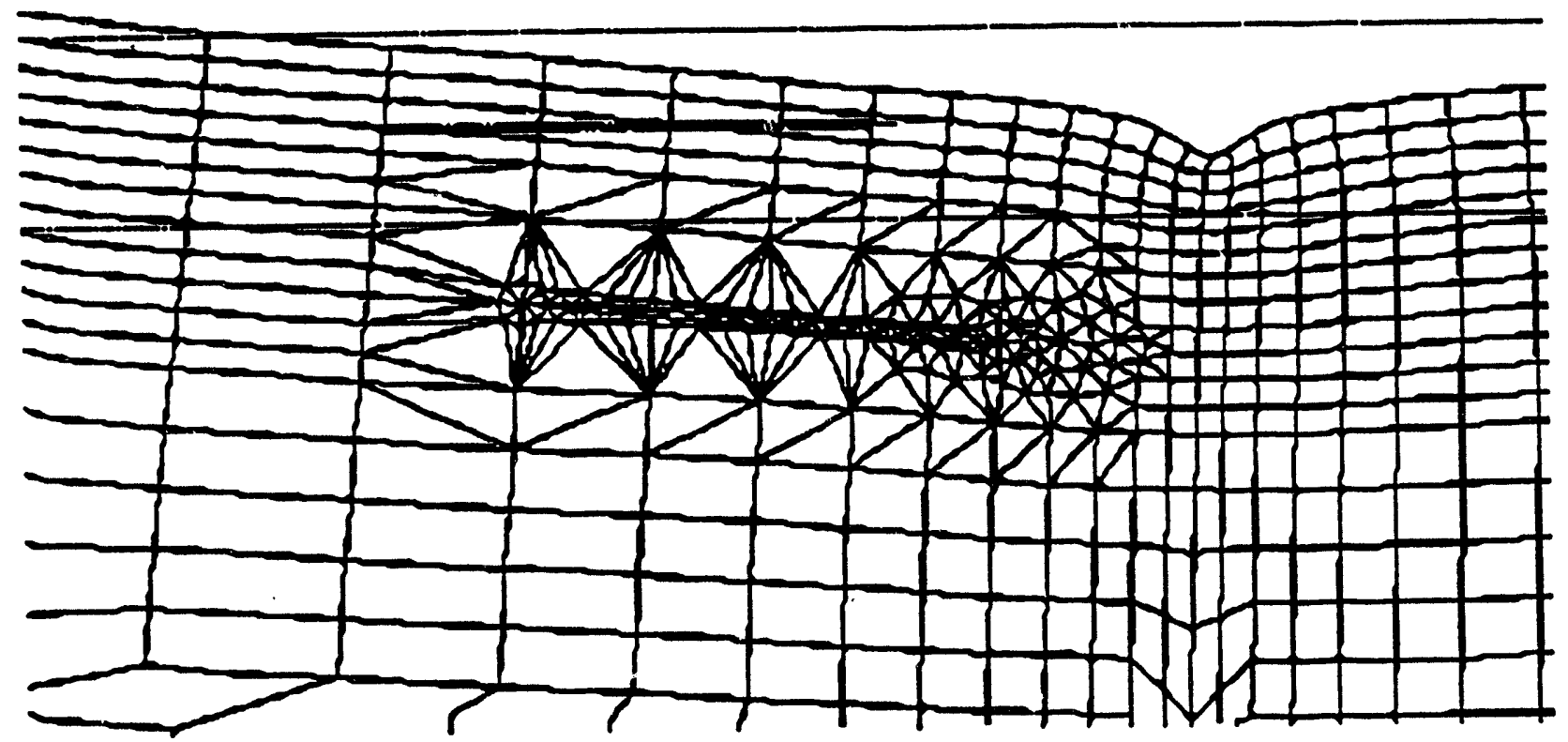

Figure 37. Initial horizontal flaw in the second coating layer. The flaw is positioned at the middle of the layer. Solid lines are deformed geometry (thermal and mechanical loads). Dashed lines are undeformed geometry. 


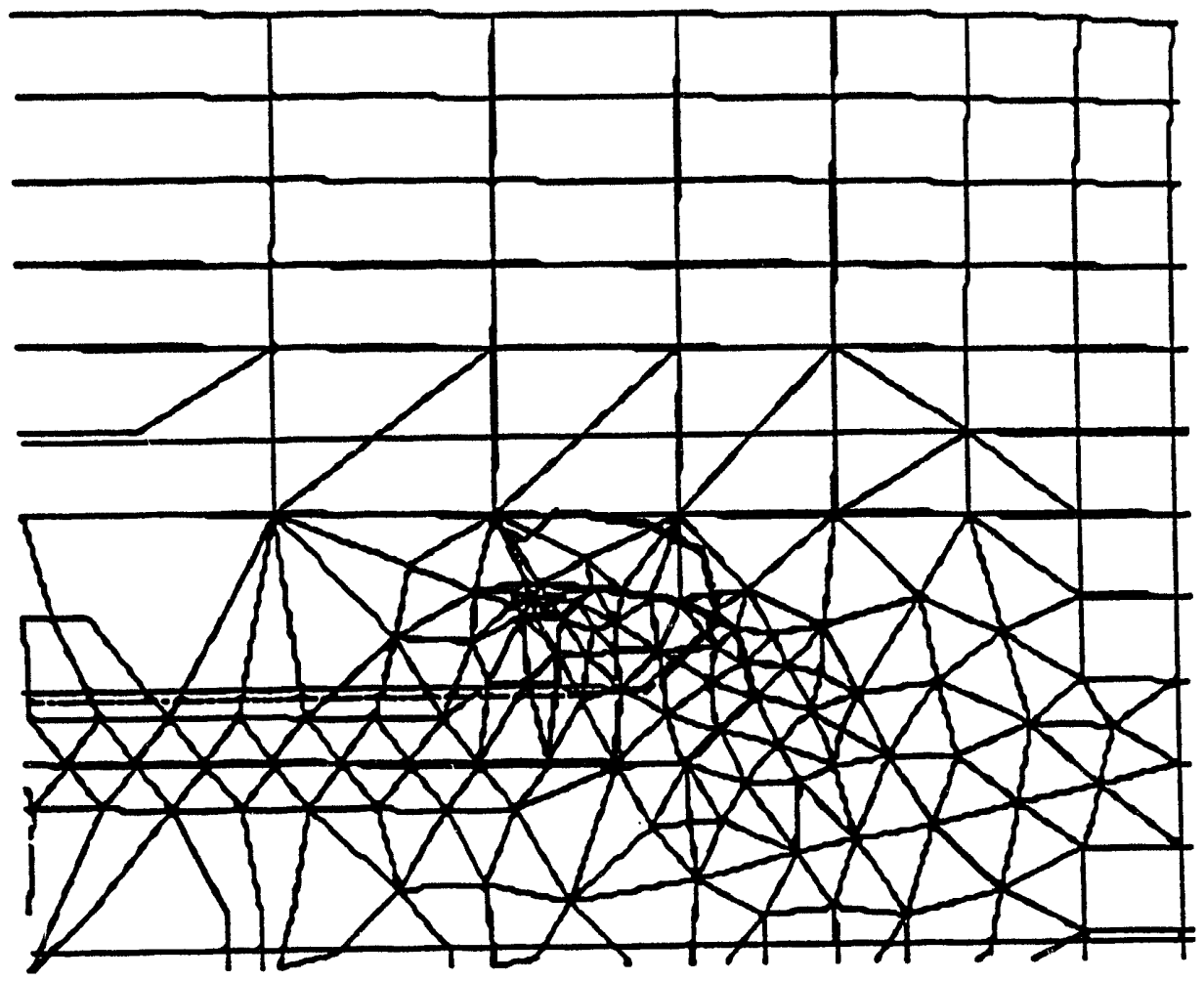

Figure 38. Deformed shape and crack path in final increment for the case where the initial flaw was in the second (middle) coating layer. The crack has been directed away from the substrate. 


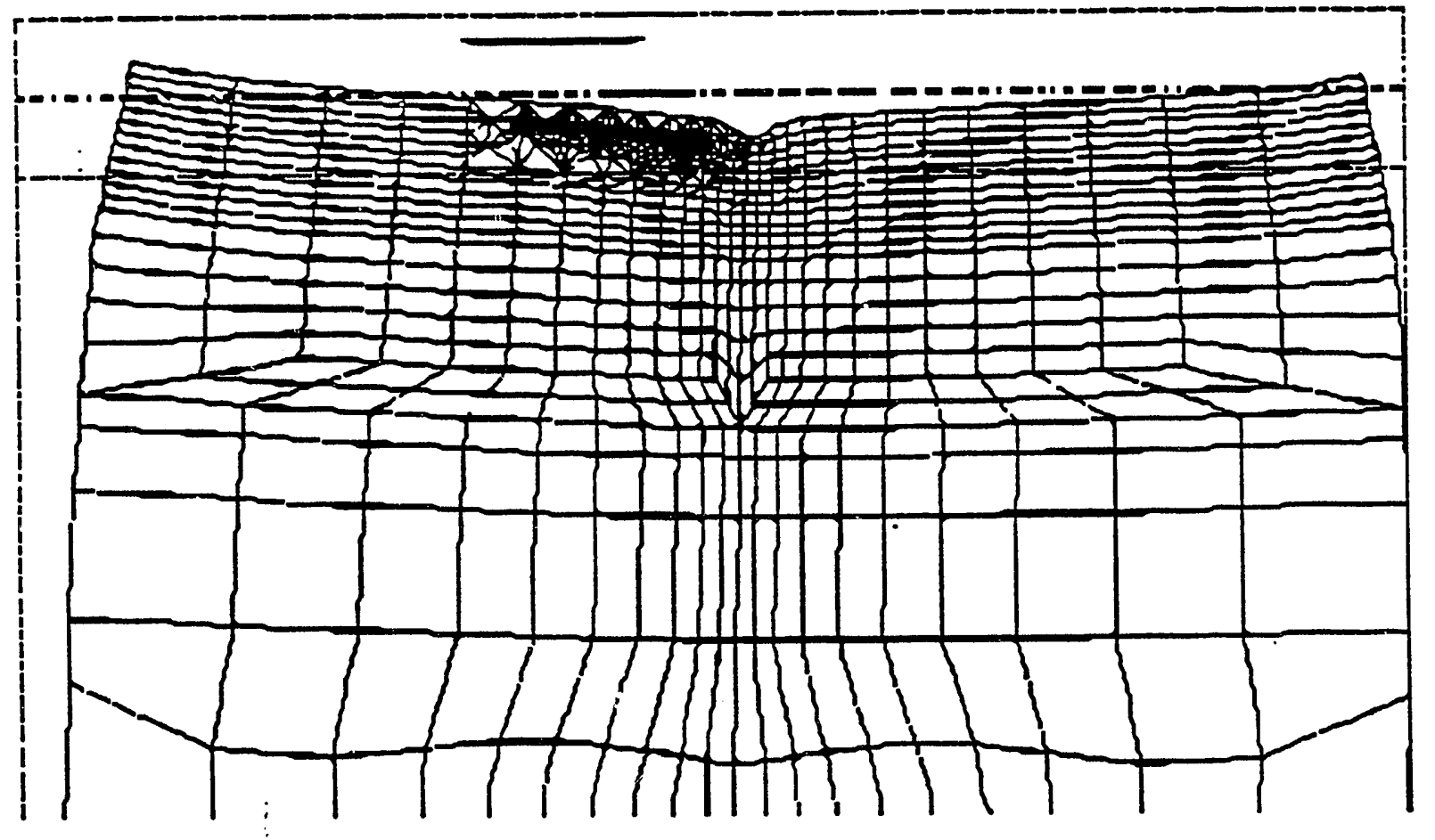

Figure 39. Initial horizontal flaw in the top coating layer. The flaw is positioned at the middle of the top layer. Solid lines are deformed geometry (thermal and mechanical loads). Dashed lines are undeformed geometry. 


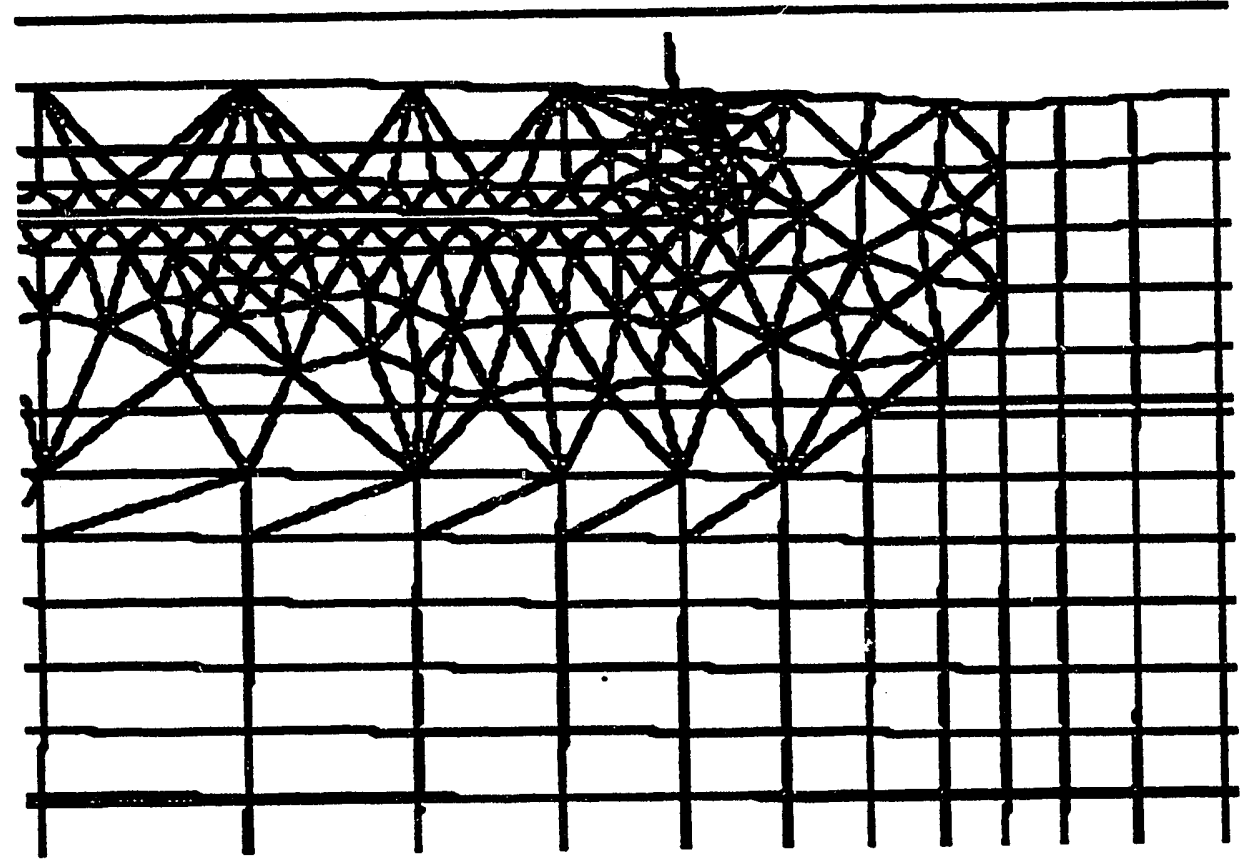

Figure 40. Deformed shape and crack path in final increment for the initial flaw in the top coating layer. The crack has been directed away from the substrate. 


\section{CONCLUSIONS}

A multilayered coating configuration for protection of $\mathrm{Si}_{3} \mathrm{~N}_{4}$ and $\mathrm{SiC}$ based ceramics used in advanced heat engines was designed, deposited, and tested. It consists of an intermediate layer of AlN ( -5 microns) and an outer layer of $\mathrm{Al}_{2} \mathrm{O}_{3}+\mathrm{ZrO}_{2}(\sim 1$ micron). The coatings were deposited by CVD onto the three substrate materials specified by the DOE; reaction bonded $\mathrm{Si}_{3} \mathrm{~N}_{4}$ (RBSN), sintered $\mathrm{SiC}$ (SSC), and HIP'ed $\mathrm{Si}_{3} \mathrm{~N}_{4}$ (HSN). The AlN interlayer was demonstrated to be an effective means of providing good adhesion between the $\mathrm{Al}_{2} \mathrm{O}_{3}+\mathrm{ZrO}_{2}$ coating and the ceramic substrates.

Modeling the grain boundary and lattice diffusion of oxygen through an $\mathrm{Al}_{2} \mathrm{O}_{3}$ layer at elevated temperatures suggested that the coating would be a good diffusion barrier to oxygen. Hovever, experimental results revealed that the composite coating was not oxidation resistant at temperatures above $1000^{\circ} \mathrm{C}$. The lack of protection was attributed to cracks in the $\mathrm{Al}_{2} \mathrm{O}_{3}+\mathrm{ZrO}_{2}$ layer, which allowed oxygen to penetrate and react with AlN.

Finite element methods and fracture mechanics were to model the behavior of brittle multilayer coatings. Detailed analysis of the residual stresses in uncracked coatings on ceramic substrates revealed that the coating thickness, order of coating layers (including grading of the coefficient of thermal expansion), and elastic modulus of the coating all have little effect on the residual stress in the coating. Based on these numerical results, it was concluded that the $\mathrm{Al}_{2} \mathrm{O}_{3}+\mathrm{ZrO}_{2}$ coatings would contain cracks upon cooling to room temperature. These cracks result from the high temperatures used in CVD processing and inherent thermal expansion mismatch between the materials.

Additional modeling was performed to better understand the behavior of cracks in a coating and possibly identify a means to eliminate or stabilize them. The effect of crack propagation durin̄ solid body contact was studied using interface fracture mechanics coupled with finite element analysis. For coatings which contain vertical flaws, the crasks always propagated into the substrate. Further analysis showed that improving the fracture toughness of the interface would not improve the performance of the coating, since the interface was not a weak point. In contrast, the horizontal crack did not 
reach the substrate; it either stayed within that layer or moved away from the substrate and towards the free surface. Therefore, horizontal cracks would not degrade the oxidation performance of a coated substrate.

The possibilities for working around the problem inherent to thin brittle coatings could lie in the area of controlled brittle fracture of multilayers, or by the use of "ductile" layers which would permit stress relief and alleviate pre-service cracking. However, the ductile interlayer would have to be too thick to be effective. PVD methods, which allow the residual stress state to be controlled, or low temperature CVD processes may allow for crack-free coatings to be deposited which would be in a compressive stress state at the operation temperature. It is anticipated that without cracks, the $\mathrm{Al}_{2} \mathrm{O}_{3}+\mathrm{ZrO}_{2}$ composite coating would be an effective means of reducing the contact stress damage and oxidation of $\mathrm{Si}_{3} \mathrm{~N}_{4}$ ceramics.

A method was developed to measure the ultimate tensile strength, fracture toughness, and Weibull modulus of thin brittle coatings on substrates. The fracture stresses of $\mathrm{CVD} \mathrm{Al}_{2} \mathrm{O}_{3}$ coatings on $\mathrm{SiC}$ substrates ranged from $190 \mathrm{MPa}$ to $480 \mathrm{MPa}$, the Weibull modulus ranged from 16 to 28 , and the fracture toughness ranged from $0.5-1.1 \mathrm{MPa} \sqrt{\mathrm{m}}$. This work has shown that the tensile strength of $\mathrm{Al}_{2} \mathrm{O}_{3}$ and $\mathrm{Al}_{2} \mathrm{O}_{3}+\mathrm{ZrO}_{2}$ coatings can be approximated by bulk values, however, the fracture toughness of these coatings was found to be $10-20 \%$ of bulk values.

A single point scratch test was used to assess the protective nature of the Phase II coatings during contact loading on unoxidized samples at room temperature. The coating protected the SSC and RBSN substrates by reducing chipping and cracking of the substrates, however, no significant differences were seen in the scratch resistance of the uncoated and coated HPSN.

Pin-on-disk tests were used to measure the breakaway and kinetic friction coefficients for coated and uncoated materials at room temperature. The $\mathrm{Al}_{2} \mathrm{O}_{3}+\mathrm{ZrO}_{2}$ coating reduced the kinetic friction coefficient of $\mathrm{RBSN}$ and HSN by as much as $50 \%$ in self-mated tests. No apparent reduction in friction was observed for the SSC substrate. An improvement in sliding wear resistance was obtained with $\mathrm{Al}_{2} \mathrm{O}_{3}+\mathrm{ZrO}_{2}$ coated $\mathrm{HSN}$ in the pin-on-disk test, whereas the coatings on RBSN and SSC were ineffective. 


\section{ACRNOWLEDGYENTS}

The authors gratefully acknowledge Dr. D. R. Johnson and D. P. Stinton of Oak Ridge National Laboratory for providing technical guidance and support for this project.

The contributions of the following people at GTE Laboratories are also acknowledged: D. Bazinet, C. D'Angelo, M. J. Downey, J. Heftner, H. Kim, H. S. MackeI, A. Moschetti, D. Oblas, H. Rebenne, S. A. Robillard, F. E. Sivo, and C. Sung.

This research was sponsored in part by the U.S. Department of Energy, Assistant Secretary for Conservation and Renewable Energy, Office of Transportation Systems, as part of the Ceramic Technology Project of the Materials Development Program, under subcontract \# 86X-95915C with Martin Marietta Energy Systems, Inc. 


\section{PUBLICATIONS}

1. J.H. Selverian and D. ONeil, "Mechanical Property Measurement of Ceramic Thin Films on Ceramic Substrates," submitted to Thin Solid Films, March 1992.

2. J.H. Selverian, "Errors in Curve Fitting of Profilometer Data," J. of Vacuum Science \& Technology A, Sept/Oct, (1992).

3. H.E. Rebenne and J.H. Selverian, "Adherent Ceramic Coatings to Reduce Contact Stress Damage of Ceramics," Proc. 26th Automotive Technology Development Contractors' Coordination Meeting, (1990).

4. D.W. Oblas, C. D'Angelo, H.E. Rebenne, and V.K. Sarin, "Ceramics Coatings to reduce Contact Stress Damage of Ceramics: Performance Testing," Proc. 26th Automotive Technology Development Contractors' Coordination Meeting, P-219, p.221-226, (1989).

5. H.E. Rebenne and S.K. Sarin, "Ceramic Coatings to Reduce Contact Stress Damage of Ceramics - Thermodynamic Modeling," Proc. 25th Automotive Technology Development Contractors' Coordination Meeting, P-209, 199.206 (1988)

6. T.-L. Sham and V.K. Sarin, "Residual Stress Calculations in Coating Configurations Using Finite Element Analysis," Ceramics Eng. and Șci., Proc., Vol. 9, (9/10), p. 1189-1198 (1988).

7. V.K. Sarin, "Design Criteria for a Coating to Reduce Contact Stress Damage," Proc. DOE Workshop on Coatings for Advanced Heat Engines, Castine, ME (1987), III, p. 83-89. 


\section{PRESENTATIONS}

1. J.H. Selverian and D. ONeil, "Fracture Toughness and Strength of Thin Films on Substrates," Amer. Cer. Soc. Conf., Minn., MN, April, 1992.

2. J.H. Selverian and D. ONeil, "Strength and Weibull Modulus of Thin Films on Substrates," MRS Fall Conf., Boston, MA, Dec. 3, 1991.

3. j, H, Selverian and H.E. Rebenne, "Effect of CVD Coatings of $\mathrm{Al}_{2} \mathrm{O}_{3}+\mathrm{ZrO}_{2}$ on the MOR Strength of $\mathrm{Si}_{3} \mathrm{~N}_{4}$ and SiC," Amer. Cer. Soc. Conference, Cincinnati, OH, April, 1991.

4. H. E. Rebenne, "High Temperature Oxidation of Ceramic Coatings on Silicon Nitride and Silicon Carbide-Based Substrates," 91st Annual Meeting of the Amer. Cer. Soc., April 24, 1989, Cincinatti, OH, 1989.

5. D.W. Oblas, C. D'Angelo, V.K. Sarin, and H.E. Rebenne, "Ceramic Coatings to Reduce Contact Stress Damage: Characterization," 26th Automotive Technology Development CCM, Dearborn, MI, Oct. 26, 1988.

6. V. K. Sarin, "Fundamentals of Coating Design," 2nd Intl. Conf. on Suriace Modification Technology, Chicago, II, September, 1988.

7. V. K. Sarin, "Residual Stress Calculations in Coating Configurations Using Finite Element Analysis," 12th Annual Conf. on Composites and Advanced Ceramics, Cocoa Beach, FL, January 17, 1988.

8. V.K. Sarin, "Ceramic Coatings to reduce Ceramic-Ceramic Contact Stress," DOE Coatings for Advanced Heat Engin:: Workshop, Castine, ME, July 27, 1987.

9. H.E. Rebenne and V.K. Sarin, "Ceramic Coatings to Reduce Contact Stress Damage of Ceramics - Thermodynamic Modeling," 25th Automotive Technology Development CCM, Dearborn, MI, Oct. 19, 1987. 


\section{PATENTS}

1. "Composite Coatings on Cemented Carbide Substrates," U.S. Patent $4,701,384$.

2. "Composite Coatings on Ceramic Substrates," U.S. Patent 4,702,970.

3. "Process for Depositing a Composite Ceramic Coating on a Cemented Carbide Substrate," U.S. Patent 4,745,010.

4. "Ultrathin Laminate Oxide Coatings and Methods," U.S. Patent $4,749,629$.

5. "A Process for Depositing a Composite Ceramic Coating on a Hard Ceramic Substrate," U.S. Patent 4,751,109.

6. "A Method for Depositing Composite Coatings," filed 1986.

7. "Composite Coatings on Refractory Substrates," filed 1986.

8. "Oxidation Resistant, High Temperature Thermal Cycling Resistant Coatings on Silicon-Based Substrates and Process for the Production Thereof, filed 1986.

9. "Aluminum Nitride Coated Silicon Nitride-Based Cutting Tools," filed 1987.

10. "Aluminum Nitride Coated Silicon Nitride-Based Cutting Tools," filed 1988. 


\section{REFERENCES}

ABI86 'A. Abid, R. Bensalem, B.J. Sealy, "The thermal stability of AlN", J. Mat. Sci.vol 22, 1301-1304 (1986).

BAB83 G.N. Babini, P. Vicenzini, "Oxidation kinetics of hot-pressed silicon nitride", Progress in Nitrogen Ceramics, 427-438 (1983).

BAR79 P. Barlier, J.P. Torre, "On the influence of a gaseous boundary layer on the oxidation of reaction-bonded silicon nitride at $1400 \mathrm{C"}$, J. Mat. Sci, Lett., vol. 14, 235-237 (1979).

BOC82 P. Boch, J.C. Glandus, J. Jarrige, J.P. LeCompte, J. Mexmain, "Sintering, oxidation and mechanical properties of hot pressed aluminum nitride", Ceramics International, vol. 8(1), 34-40 (1982).

CHE78 J.L. Chermant, A. Deschanvres, and F. Osterstock, in R.C. Bradt, D.P.H. Hasselman, and F.F. Lange (eds.) Fracture Mechanics of Ceramics Vol. 4 Crack Growth and Microstructure, Plenum Press, New York. (1978), p. 891.

Cols6 C. Colombier, J. Peng, H. Altena, and B. Lux, "Influence of Trace Impurities on the $\alpha-\mathrm{Al}_{2} \mathrm{O}_{3} \mathrm{CVD}$ in the $\mathrm{AlX}_{3} / \mathrm{CO}_{2} / \mathrm{H}_{2}$-Systems $(\mathrm{X}=\mathrm{Cl}, \mathrm{Br}$, I)," Refractory \& Hard Metals, June, 82-87 (1986)

CS91 Ceramic Source 1991-1992, vol. 7, Pub. The American Ceramic Society, Westerville, Ohio, 1992, Tables 101, 136, \& 139, p. 310, 321, \& 322.

DAN89 C. D'Angelo, H.J. Kim, D.W. Oblas, H. Rebenne, and V.K. Sarin, "Development of Adherent Ceramic Coatings to Reduce Contact Stress Damage of Ceramics," Einal Report, DoE Contract 86X95915C, submitted March, (1989).

DAV80 R.W. Davidge, Mechanical Behaviour of Ceramics, Pub. Cambridge Solid State Science Series, Cambridge University Press, (1980), p. 138.

DUT84 S. Dutta, "Sinterability, strength and oxidation of alpha silicon carbide powders", I. Mat. Sci, vol 19, 1307-1313 (1984).

ERV58 G. Ervin, Jr, "Oxidation Behavior of Silicon Carbide", I. American Ceramir Society, vol. 41(9), 347-352 (1958).

FIS51 J. C. Fisher, "Calculation of Diffusion Penetration Curves for Surface and Grain Boundary Diffusion," I. App. Phys, vol. 22(1), 74-7 (1951). 
FLI87 P.A. Flinn, D.S. Gardner, and W.D. Nix, "Measurement and Interpretation of Stress in Aluminum-Based Metallization as a Function of Thermal History," IEEE Transactions on Electron Devices, vol. ED-34, no. 3, p. 689-698, March (1987).

FUN84 C.D. Fung, J.J. Kopanski, "Thermal oxidation of $3 \mathrm{C}$ silicon carbide single-crystal layers on silicon", Applied Physics Lett, vol 45(7), 757 759 (1984).

GTE81 Advanced Gas Turbine (AGT) Powertrain System Development for Automotive Applications, 2nd semiannual progress report, Contract No. CR-165329, Garrett Turbine Engine Co., Report No. 31-3725(2) (1981).

JOR59 P.J. Jorgensen, M.E. Wadsworth, I.B. Cutler, "Oxidation of Silicon Cartide", I. American Ceramics Soc. vol. 42(12), 613-616 (1959).

JOR61 P.J. Jorgensen, M.E. Wadsworth, I.B. Cutler, "Effects of Water Vapor on Oxidation of Silicon Carbide", I.American Ceramics Soc., vol. 44(6), 258-261 (1961).

KAT83 A.P. Katz, H.A. Lipsitt, T.Mah, and M.G. Mendiratta, J. Mat. Sci., vol. 18, p. 1983, (1983).

KAT87 A.D. Katnani and K.I. Papathomas, "Kinetics and initial stages of oxidation of aluminum nitride: Thermogravimetric analysis and $X$-ray photoelectron spectroscopy study", I. Vac. Sci. Technol. A vol. 5(4), 1335-1340 (1987).

KRE85 A. Krell, J. Woltersdorf, E. Pippel, and D. Schulze, Philo. Mag. A, vol. 51(5), p. 765, (1985).

LAC84 'ं'J. Lackey, D.P. Stinton, G.A. Cerny, L.L. Fehrenbacher, and A.C. Schaffhauser, ORNL Report, ORNL/TM-8959 (1984).

LAV83 V.A. Lavrenko, A.F. Alexeev, "Oxidation of sintered AlN", Ceramics International, vol. 9(3), 80-82 (1983).

LAW75 B.R. Lawn and T.R. Wilshaw, Fracture of Solids, Cambraidge Solid State Science Series, Cambridge University Press, New York, (1975), p. 65.

LIV56 D.T. Livey and P. Murray, I. American Ceramic Society, vol. 39(11), 363, (1956).

LON59 G. Long, L.M. Foster, "Aluminum nitride, a refractory for aluminum to $2000^{\circ} \mathrm{C}$, I_American Ceramic Soc. vol. 42(2), 5359 (1959). 
MAE89 M. Maeda, K. Nakamura, A. Tsuge, "Scale effect of the testing furnace on the oxidation of silicon nitride ceramics", J. Mat. Sci. Lett., vol. 8, 195-197 (1989).

MEI59 J.L. Meijering and M.L. Verheijke, "Oxidation Kinetics in the Case of Ageing Oxide Films", Acta Metallurgica, 7(5), p. 331-338, (1959).

MIE84 D.M. Mieskowski, T.E. Mitchell, A.H. Heuer, "Bubble Formation in Oxide Scales on SiC", J. American Ceramic Soc., January, C-17, (1984).

NIX89 W. D. Nix, Metall. Trans. A 20A, 2217 (1989).

Ois60 Y. Oishi and W. D. Kingery, "Self-Diffusion of Oxygen in Single and Polycrystalline Aluminum Oxide," J. Chem. Phys., vol. 33(2), 480-86 (1960).

POR84 F. Porz, F. Thummler, "Oxidation mechanism of porous silicon nitride", L. Mat. Sci. vol. 19, 1283-1295 (1984).

RUF89 A. W. Ruff and S. Jahanmir, "Measurements of Tribological Behavior of Advanced Materials: Summary of U.S. Results on VAMAS RoundRobin No. 2," NISTIR 89-4170, U.S. Dept. of Commerce, Gaithersburg, MD, (1989).

SAT87 T. Sato, K. Haryu, T. Endo, M. Shimada, "High temperature oxidation of bot-pressed aluminum nitride by water vapour", J. Mat. Sci., vol. 22, 2277-2280 (1987).

SCH87 J. Schienle, and J. Smyth, "High Temperature Coating Study to Reduce Contact Stress Damage of Ceramics," Final Report, Contract No. DEAC05-84R21400, Garrett Turbine Engine Co, (1987).

SCH92 L.S. Schadler and L.C. Noyan, "Experimental Determination of the Strain Transfer Across a Flexible Intermediate Layer in Thin Film Structures as a Function of Flexible Layer Thickness," Mat. Res. Svmp. Proc., Vol. 239, 151-156 (1992).

SHA88 T.-L. Sham and V.K. Sarin, "Residual Stress Calculations in Coating Configurations using Finite Element Analysis," Ceramics Eng and Sci. Proc. Vol. 9 (9,10), 1189-98 (1988).

SIN76a S.C. Singhal, "Thermodynamics and kinetics of oxidation of hotpressed silicon nitride", I. Mat. Sci. vol. 11, 500-509, (1976).

SIN76b S.C Singhal, "Oxidation kinetics of hot-pressed silicon carbide", J. Mat. Sci., vol 11, 1246-1253 (1976). 
SWA89 S.R. Swanson, L of Engineering Materials and Technology vol. 111, 145 (1989) .

TAY60 K.M. Taylor, C. Lenie, "Some pruperties of aluminum nitride", L. Electrochemical Soc., vol. 107(4), 308-314 (1960).

THO90 M.D. Thouless, L_American Ceramic Society vol. 73(7), p. 2144, (1990).

TIM25 S.P. Timoshenko, "Analysis of Bi-Metal Thermostats," J. Optical Soc. Amer., vol. 11, p.233-255, (1925).

TOR87 E. Tor ôk and A. J. Perry, Thin Solid Films, vol. 153, p. 37, (1987).

TOU75 Y. S. Touloukian, R. K. Kirby, R. E. Taylor, and T. Y. R. Lee, Thermal Expansion - Nonmetallic Solids - vol, 13 - Thermophysical Properties of Matter Plenum Press, New York, 1975.

WAR84 R. Warren, C-H. Anderson, "Silicon carbide fibers and their potential for use in composite materials. Part II", Composites, vol 15(2), 101-111, (1984). 


\section{APPENDIX_A - OXIDATION RESULTS}

Table A-1. Weight gain as a function of oxidation time for AlN coated sapphire oxidized in static air at $1000^{\circ} \mathrm{C}$. The weight gain at a given time was calculated from the original weight and the measured weight after a given oxidation time.

\begin{tabular}{|c|c|c|c|c|c|c|}
\hline Sample & $\begin{array}{c}\text { Original } \\
\text { Weight (gm) }\end{array}$ & $2 \mathrm{hr}$ & 8.75 & 30.5 & 125 & 500 \\
\hline \hline & & & & & & \\
A & 2.048404 & $0.022 \mathrm{mg}$ & 0.014 & 0.022 & 0.011 & 0.062 \\
B & 1.885474 & 0.332 & 0.428 & 0.408 & 0.493 & 0.544 \\
C & 1.887054 & 0.192 & 0.191 & 0.155 & 0.066 & 0.079 \\
\hline
\end{tabular}

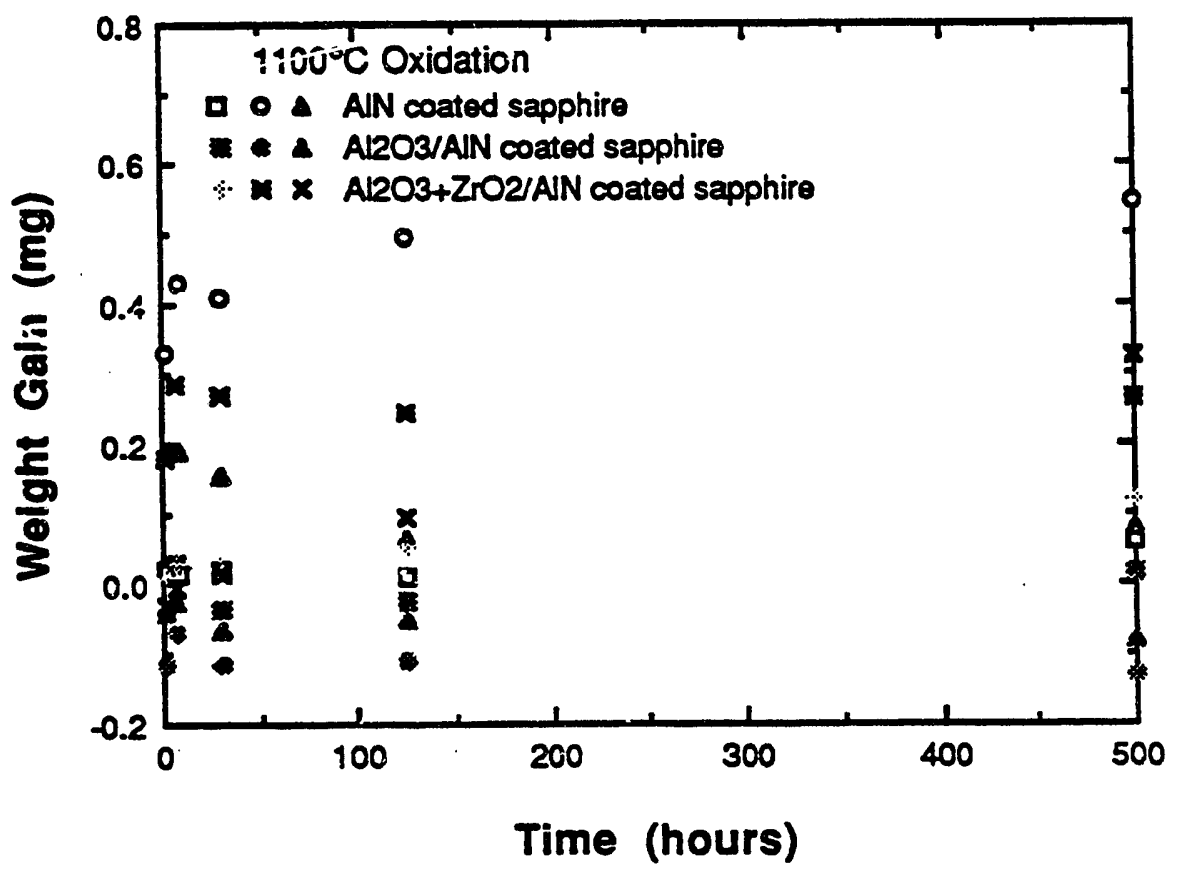

Figure A-1. Weight gain versus time for $\mathrm{AlN}, \mathrm{Al}_{2} \mathrm{O}_{3} / \mathrm{AlN}$, and $\mathrm{Al}_{2} \mathrm{O}_{3}+\mathrm{Z}: \mathrm{O}_{2} / \mathrm{AlN}$ coated sapphire oxidized in static air at $1100^{\circ} \mathrm{C}$. 


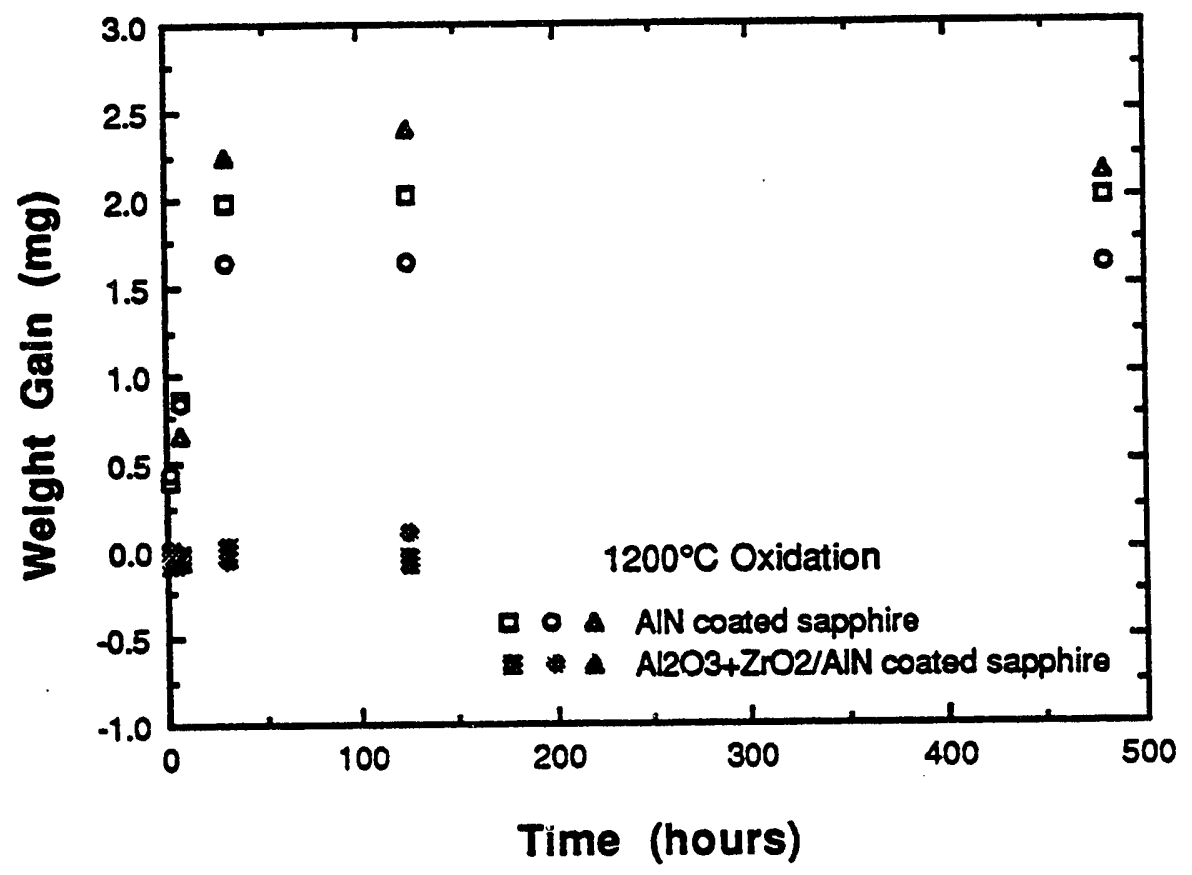

Figure A-2. Weight gain versus time for $\mathrm{AlN}$ and $\mathrm{Al}_{2} \mathrm{O}_{3}+\mathrm{ZrO}_{2} / \mathrm{AlN}$ coated sapphire oxidized in static air at $1200^{\circ} \mathrm{C}$.

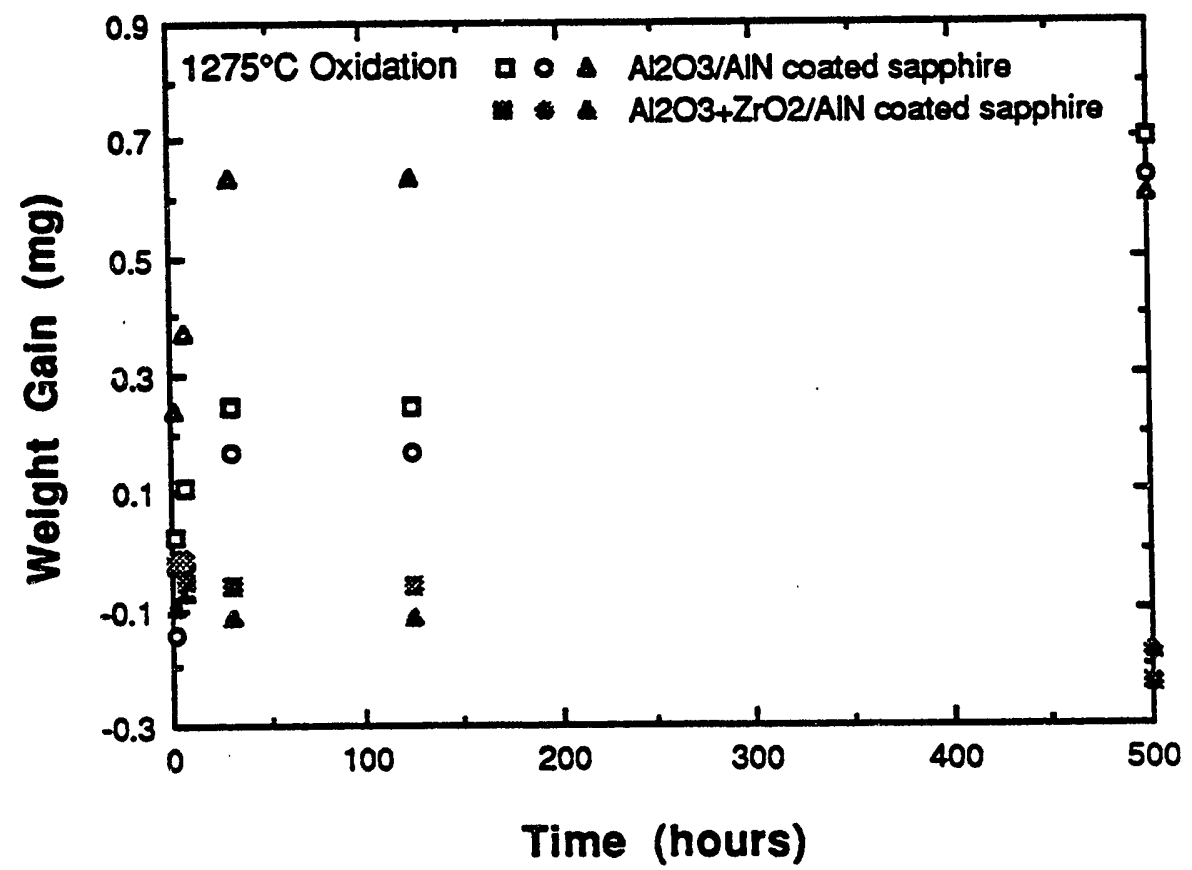

Figure A-3. Weight gain versus time for $\mathrm{Al}_{2} \mathrm{O}_{3} / \mathrm{AlN}$ and $\mathrm{Al}_{2} \mathrm{O}_{3}+\mathrm{ZrO}_{2} / \mathrm{AIN}$ coated sapphire ozidized in static air at $1275^{\circ} \mathrm{C}$. 
Table A-2. Phases identified by X-ray diffraction after oxidation in static air. Samples were sapphire with $\mathrm{AlN}, \mathrm{Al}_{2} \mathrm{O}_{3} / \mathrm{AlN}$, and $\mathrm{Al}_{2} \mathrm{O}_{3}+\mathrm{ZrO}_{2} / \mathrm{AlN}$ coating. Phases associated with substrate reflection are not listed.

\begin{tabular}{|c|c|c|c|}
\hline \multirow{2}{*}{$\begin{array}{l}\text { Oxidation Time } \\
\text { (hours) }\end{array}$} & \multicolumn{3}{|c|}{ Oxidation Temperature } \\
\hline & $1000^{\circ} \mathrm{C}$ & $1200^{\circ} \mathrm{C}$ & $1275^{\circ} \mathrm{C}$ \\
\hline \multicolumn{4}{|l|}{ AlN coated } \\
\hline 2 & $\alpha-\mathrm{Al}_{2} \mathrm{O}_{3}$ & $\alpha-\mathrm{Al}_{2} \mathrm{O}_{3}$ & $\alpha-\mathrm{Al}_{2} \mathrm{O}_{3}$ \\
\hline 8 & $\alpha-\mathrm{Al}_{2} \mathrm{O}_{3}$ & $\alpha-\mathrm{Al}_{2} \mathrm{O}_{3}$ & $\alpha-\mathrm{Al}_{2} \mathrm{O}_{3}$ \\
\hline 30 & $\alpha \cdot \mathrm{Al}_{2} \mathrm{O}_{3}$ & $\alpha-\mathrm{Al}_{2} \mathrm{O}_{3}$ & $\alpha-\mathrm{Al}_{2} \mathrm{O}_{3}$ \\
\hline 125 & $\alpha-\mathrm{Al}_{2} \mathrm{O}_{3}$ & $\alpha-\mathrm{Al}_{2} \mathrm{O}_{3}$ & $\alpha-\mathrm{Al}_{2} \mathrm{O}_{3}$ \\
\hline 500 & $\alpha-\mathrm{Al}_{2} \mathrm{O}_{3}$ & $\ldots$ & $\alpha-\mathrm{Al}_{2} \mathrm{O}_{3}$ \\
\hline \multicolumn{4}{|l|}{$\mathrm{Al}_{2} \mathrm{O}_{3} / \mathrm{AlN}$ coated } \\
\hline 2 & $\cdots$ & $\alpha-\mathrm{Al}_{2} \mathrm{O}_{3}, \mathrm{AlN}$ & $\alpha-\mathrm{Al}_{2} \mathrm{O}_{3}, \mathrm{AlN}$ \\
\hline 8 & $\cdots$ & $\alpha-\mathrm{Al}_{2} \mathrm{O}_{3}$, AlN & $\alpha-\mathrm{Al}_{2} \mathrm{O}_{3}, \mathrm{AlN}$ \\
\hline 30 & $\ldots$ & $\alpha-\mathrm{Al}_{2} \mathrm{O}_{3}, \mathrm{AlN}$ & $\alpha-\mathrm{Al}_{2} \mathrm{O}_{3}$, AlN \\
\hline 125 & $\cdots$ & $\alpha-\mathrm{Al}_{2} \mathrm{O}_{3}$ & $\alpha-\mathrm{Al}_{2} \mathrm{O}_{3}$ \\
\hline 500 & ... & $\alpha-\mathrm{Al}_{2} \mathrm{O}_{3}$ & $\ldots$ \\
\hline \multirow{2}{*}{\multicolumn{4}{|c|}{$\begin{array}{l}\mathrm{Al}_{2} \mathrm{O}_{3}+\mathrm{ZrO}_{2} / \mathrm{AlN} \\
\text { coated }\end{array}$}} \\
\hline & & & \\
\hline 2 & $\ldots$ & $\alpha-\mathrm{Al}_{2} \mathrm{O}_{3}$ & $\alpha-\mathrm{Al}_{2} \mathrm{O}_{3}, \mathrm{ZrO}_{2}$ \\
\hline 8 & ... & $\alpha-\mathrm{Al}_{2} \mathrm{O}_{3}, \mathrm{ZrO}_{2}$ & $\alpha-\mathrm{Al}_{2} \mathrm{O}_{3}, \mathrm{ZrO}_{2}$ \\
\hline 30 & $\cdots$ & $\mathrm{a}-\mathrm{Al}_{2} \mathrm{O}_{3}, \mathrm{ZrO}_{2}$ & $\alpha-\mathrm{Al}_{2} \mathrm{O}_{3}, \mathrm{ZrO}_{2}$ \\
\hline 125 & ... & $\alpha-\mathrm{Al}_{2} \mathrm{O}_{3}, \mathrm{ZrO}_{2}$ & $\alpha-\mathrm{Al}_{2} \mathrm{O}_{3}, \mathrm{ZrO}_{2}$ \\
\hline 500 & $\cdots$ & $\alpha-\mathrm{Al}_{2} \mathrm{O}_{3}, \mathrm{ZrO}_{2}$ & $\cdots$ \\
\hline
\end{tabular}


Table A-j. Weight gain as a function of oxidation time for $\mathrm{Al}_{2} \mathrm{O}_{3} / \mathrm{AlN}$ coated sapphire oxidized in static air at $1100^{\circ} \mathrm{C}, 1200^{\circ} \mathrm{C}$, and $1275^{\circ} \mathrm{C}$. The weight gain at a given time was calculated from the original weight and the measured weight after a given oxidation time.

\begin{tabular}{|c|c|c|c|c|c|c|}
\hline \multirow{2}{*}{ Sample } & \multirow{2}{*}{ Original } & \multicolumn{5}{|c|}{ Weight Gain as a Function of Time } \\
\hline & & $2 \mathrm{hr}$ & 8 & 30 & 125 & 500 \\
\hline $1100^{\circ} \mathrm{C}$ & & & & & & \\
\hline A & 1.678948 & $\cdots$ & 0.032 & -0.033 & -0.023 & 0.017 \\
\hline B & 1.788780 & $-0.115 \mathrm{mg}$ & -0.070 & -0.115 & -0.112 & -0.129 \\
\hline C & $\begin{array}{l}1.697396 \\
.\end{array}$ & -0.041 & -0.026 & -0.066 & -0.051 & -0.082 \\
\hline $1200^{\circ} \mathrm{C}$ & & & & & & \\
\hline $\mathbf{A}$ & 1.417758 & -0.105 & $\cdots$ & $\cdots$ & $\cdots$ & $\cdots$ \\
\hline B & 1.296831 & -0.077 & $\cdots$ & $\cdots$ & $\cdots$ & $\cdots$ \\
\hline C & 1.229500 & -1.080 & $\cdots$ & $\cdots$ & $\cdots$ & $\cdots$ \\
\hline $1275^{\circ} \mathrm{C}$ & & & & & & \\
\hline A & 1.483679 & -0.023 & -0.056 & -0.059 & $\cdots$ & $\cdots$ \\
\hline B & 1.433669 & -0.019 & -0.014 & -0.061 & $\cdots$ & $\cdots$ \\
\hline C & 1.464726 & -0.098 & -0.074 & -0.111 & $\cdots$ & $\cdots$ \\
\hline
\end{tabular}


Table A-4. Weight gain as a function of oxidation time for $\mathrm{Al}_{2} \mathrm{O}_{3}+\mathrm{ZrO}_{2} / \mathrm{AlN}$ coated sapphire oxidized in static air at $1100^{\circ} \mathrm{C}, 1200^{\circ} \mathrm{C}$, and $1275^{\circ} \mathrm{C}$. The weight gain at a given time was calculated from the original weight and the measured weight after a given oxidation time.

\begin{tabular}{|c|c|c|c|c|c|c|}
\hline \multirow{2}{*}{$\begin{array}{c}\text { Sample } \\
\text { Original } \\
\text { Weight (gm) }\end{array}$} & \multicolumn{5}{|c|}{ Weight Gain as a Function of Time } \\
\hline \hline $1100^{\circ} \mathrm{C}$ & & 8 & 30 & 125 & 500 \\
$\mathrm{~A}$ & 1.529552 & $0.008 \mathrm{mg}$ & 0.028 & 0.023 & 0.053 & 0.120 \\
$\mathrm{~B}$ & 1.430195 & 0.181 & 0.285 & 0.268 & 0.245 & 0.265 \\
$\mathrm{C}$ & 1.582685 & -0.030 & -0.005 & 0.015 & 0.095 & 0.325 \\
\hline $1200^{\circ} \mathrm{C}$ & & & & & & \\
$\mathrm{A}$ & 1.280131 & -0.006 & -0.013 & 0.013 & $\ldots$ & $\ldots$ \\
$\mathrm{B}$ & 1.250632 & -0.077 & -0.072 & -0.061 & $\ldots$ & $\ldots$ \\
$\mathrm{C}$ & 1.213560 & -0.080 & -0.060 & -0.046 & $\ldots$ & $\ldots$ \\
\hline $1275^{\circ} \mathrm{C}$ & & & & & & \\
$\mathrm{A}$ & 1.448246 & 0.024 & 0.111 & 0.244 & $\ldots$ & $\ldots$ \\
$\mathrm{B}$ & 1.302016 & -0.146 & -0.026 & 0.168 & $\ldots$ & $\ldots$ \\
$\mathrm{C}$ & 1.467992 & 0.239 & 0.372 & 0.633 & $\ldots$ & $\ldots$ \\
\hline
\end{tabular}


Table A-5. Phases identified by X-ray diffraction after 500 hours of oxidation in static air. Samples include uncoated and AlN coated RBSN, SSC, and HSN.

\begin{tabular}{|c|c|c|}
\hline Sample & Major Phases & Minor Phases \\
\hline $\begin{array}{l}\text { Temperature }=1100^{\circ} \mathrm{C} \\
\text { Uncoated RBSN } \\
\text { Uncoated SSC } \\
\text { Uncoated HSN } \\
\text { AlN/RBSN } \\
\text { AlN/SSC } \\
\text { AlN/HSN }\end{array}$ & $\begin{array}{c}\alpha-\mathrm{Si}_{3} \mathrm{~N}_{4} \\
\operatorname{SiC}(8 \mathrm{H}), \operatorname{SiC}(12 \mathrm{H}) \\
\beta-\mathrm{Si}_{3} \mathrm{~N}_{4} \\
\alpha-\mathrm{Al}_{2} \mathrm{O}_{3}, \alpha-\mathrm{Si}_{3} \mathrm{~N}_{4} \\
\alpha-\mathrm{Al}_{2} \mathrm{O}_{3}, \mathrm{SiC}(8 \mathrm{H}), \mathrm{SiC}(12 \mathrm{H}) \\
\alpha-\mathrm{Al}_{2} \mathrm{O}_{3}\end{array}$ & $\begin{array}{c}\beta-\mathrm{Si}_{3} \mathrm{~N}_{4}, \mathrm{SiO}_{2} \\
\mathrm{SiO}_{2} \\
\alpha-\mathrm{Y}_{2} \mathrm{Si}_{2} \mathrm{O}_{7}, \mathrm{Y}_{2} \mathrm{SiO}_{5}, \mathrm{SiO}_{2} \\
\alpha-\mathrm{Si}_{3} \mathrm{~N}_{4}, \beta-\mathrm{Si}_{3} \mathrm{~N}_{4}, \mathrm{SiO}_{2} \\
\ldots \\
\ldots-\mathrm{Si}_{3} \mathrm{~N}_{4}, \alpha-\mathrm{Y}_{2} \mathrm{Si}_{2} \mathrm{O}_{7}, \\
\mathrm{Y}_{2} \mathrm{SiO}_{5}, \mathrm{SiO}_{2}\end{array}$ \\
\hline $\begin{array}{l}\text { Temperature }=1200^{\circ} \mathrm{C} \\
\text { Uncoated RBSN } \\
\text { Uncoated SSC } \\
\text { Uncoated HSN } \\
\text { AlN/RBSN } \\
\text { AlN/SSC } \\
\text { AlN/HSN }\end{array}$ & $\begin{array}{c}\mathrm{SiO}_{2}, \alpha-\mathrm{Si}_{3} \mathrm{~N}_{4} \\
\mathrm{SiC}(12 \mathrm{H}) \\
\beta-\mathrm{Si}_{3} \mathrm{~N}_{4} \\
\alpha-\mathrm{Al}_{2} \mathrm{O}_{3} \\
\mathrm{SiC}(12 \mathrm{H}), \alpha-\mathrm{Al}_{2} \mathrm{O}_{3} \\
\beta-\mathrm{Si}_{3} \mathrm{~N}_{4}\end{array}$ & $\begin{array}{c}\mathrm{\beta}-\mathrm{Si}_{3} \mathrm{~N}_{4}(?)^{*} \\
\mathrm{SiO}_{2} \\
\mathrm{SiO}_{2}, \mathrm{Y}_{2} \mathrm{Si}_{2} \mathrm{O}_{7} \\
\beta-\mathrm{Si}_{3} \mathrm{~N}_{4}, \mathrm{SiO}_{2}(?) \\
\mathrm{SiO}_{2}(?) \\
\mathrm{Y}_{2} \mathrm{Si}_{2} \mathrm{O}_{7}, \propto-\mathrm{Al}_{2} \mathrm{O}_{3}, \mathrm{SiO}_{2}(?)\end{array}$ \\
\hline $\begin{array}{l}\text { Temperature }=1275^{\circ} \mathrm{C} \\
\text { Uncoated RBSN } \\
\text { Uncoated SSC } \\
\text { Uncoated HSN } \\
\text { AlN/RBSN } \\
\text { AlN/SSC } \\
\text { AlN/HSN }\end{array}$ & $\begin{array}{c}\alpha-\mathrm{Si}_{3} \mathrm{~N}_{4}, \mathrm{SiO}_{2} \\
\mathrm{SiC}(12 \mathrm{H}) \\
\mathrm{Y}_{2} \mathrm{Si}_{2} \mathrm{O}_{7} \\
\alpha-\mathrm{Al}_{2} \mathrm{O}_{3} \\
\mathrm{SiC}(12 \mathrm{H}), \alpha-\mathrm{Al}_{2} \mathrm{O}_{3} \\
\mathrm{AlN} \\
\end{array}$ & $\begin{array}{c}\beta-\mathrm{Si}_{3} \mathrm{~N}_{4} \\
\mathrm{SiO}_{2}, \alpha-\mathrm{Si}_{3} \mathrm{~N}_{4}(?) \\
\beta-\mathrm{Si}_{3} \mathrm{~N}_{4}, \mathrm{SiO}_{2} \\
\mathrm{Si}_{3} \mathrm{~N}_{4}(?) \\
\alpha-\mathrm{Si}_{3} \mathrm{~N}_{4}(?), \mathrm{SiO}_{2}(?) \\
\mathrm{Y}_{2} \mathrm{Si}_{2} \mathrm{O}_{7}\end{array}$ \\
\hline
\end{tabular}

* The question mark denotes uncertainty. 
Table A-6. Phases identified by X-ray diffraction after 500 hour oxidation in static air. Samples had coating of $\mathrm{AlN}, \mathrm{Al}_{2} \mathrm{O}_{3} / \mathrm{AlN}$, and $\mathrm{Al}_{2} \mathrm{O}_{3}+\mathrm{ZrO}_{2} / \mathrm{AlN}$. Phases associated with substrate reflection are not listed.

\begin{tabular}{|c|c|c|c|}
\hline \multirow[t]{2}{*}{ Sample } & \multicolumn{3}{|c|}{ Oxidation Temperature } \\
\hline & $1000^{\circ} \mathrm{C}$ & $1200^{\circ} \mathrm{C}$ & $1275^{\circ} \mathrm{C}$ \\
\hline $\begin{array}{c}\text { AlN coated } \\
\text { RBSN } \\
\text { SSC } \\
\text { HSN }\end{array}$ & $\begin{array}{l}\alpha-\mathrm{Al}_{2} \mathrm{O}_{3} \\
\alpha-\mathrm{Al}_{2} \mathrm{O}_{3} \\
\alpha-\mathrm{Al}_{2} \mathrm{O}_{3}\end{array}$ & $\begin{array}{l}\alpha-\mathrm{Al}_{2} \mathrm{O}_{3} \\
\alpha-\mathrm{Al}_{2} \mathrm{O}_{3} \\
\alpha-\mathrm{Al}_{2} \mathrm{O}_{3}\end{array}$ & $\begin{array}{c}\alpha-\mathrm{Al}_{2} \mathrm{O}_{3} \\
\alpha-\mathrm{Al}_{2} \mathrm{O}_{3} \\
\mathrm{AlN}\end{array}$ \\
\hline $\begin{array}{c}A l_{2} \mathrm{O}_{3} / \mathrm{ALN} \text { coated } \\
\mathrm{RBSN} \\
\\
\mathrm{SSC} \\
\mathrm{HSN}\end{array}$ & $\cdots$ & $\begin{array}{c}\alpha-\mathrm{Al}_{2} \mathrm{O}_{3}, \mathrm{AlN} \\
\alpha-\mathrm{Al}_{2} \mathrm{O}_{3}, \mathrm{AlN} \\
\alpha-\mathrm{Al}_{2} \mathrm{O}_{3}, \mathrm{AIN}(?) \\
\mathrm{AlON}(?)\end{array}$ & $\begin{array}{c}\alpha-\mathrm{Al}_{2} \mathrm{O}_{3}, \mathrm{AlN}, \\
\mathrm{AlON}(?) \\
\alpha-\mathrm{Al}_{2} \mathrm{O}_{3}, \mathrm{AlN} \\
\alpha-\mathrm{Al}_{2} \mathrm{O}_{3}, \mathrm{AlN}(?) \\
\mathrm{AlON}(?)\end{array}$ \\
\hline $\begin{array}{c}\mathrm{Al}_{2} \mathrm{O}_{3}+\mathrm{ZrO}_{2} / \mathrm{AlN} \\
\text { coated } \\
\text { RBSN } \\
\text { SSC } \\
\text { HSN }\end{array}$ & $\begin{array}{l}\cdots \\
\cdots \\
\cdots\end{array}$ & $\begin{array}{c}\alpha-\mathrm{Al}_{2} \mathrm{O}_{3}, \mathrm{ZrO}_{2} \\
\alpha-\mathrm{Al}_{2} \mathrm{O}_{3}, \mathrm{Z} \mathrm{ZO}_{2} \\
\alpha-\mathrm{Al}_{2} \mathrm{O}_{3}, \mathrm{Z}-\mathrm{rO}_{2}, \mathrm{AlN}\end{array}$ & $\begin{array}{c}\alpha-\mathrm{Al}_{2} \mathrm{O}_{3}, \mathrm{ZrO}_{2} \\
\alpha-\mathrm{Al}_{2} \mathrm{O}_{3}, \mathrm{AlN}, \\
\mathrm{ZrO}_{2}(?) \\
\mathrm{ZrO}, \mathrm{AlN}(?), \\
\mathrm{AlON}(?)\end{array}$ \\
\hline
\end{tabular}

* the question mark indicates uncertainty. 


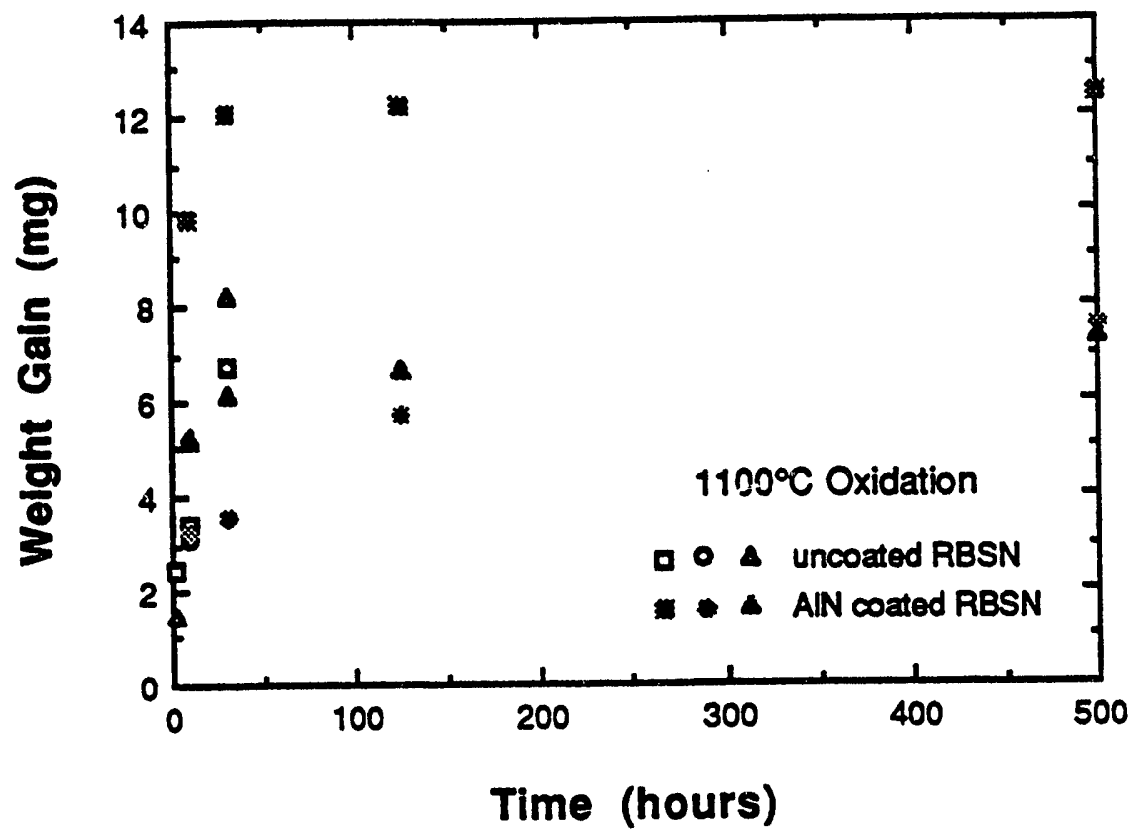

Figure A-4. Weight gain versus time for uncoated and AlN coated RBSN oxidized in static air at $1100^{\circ} \mathrm{C}$.

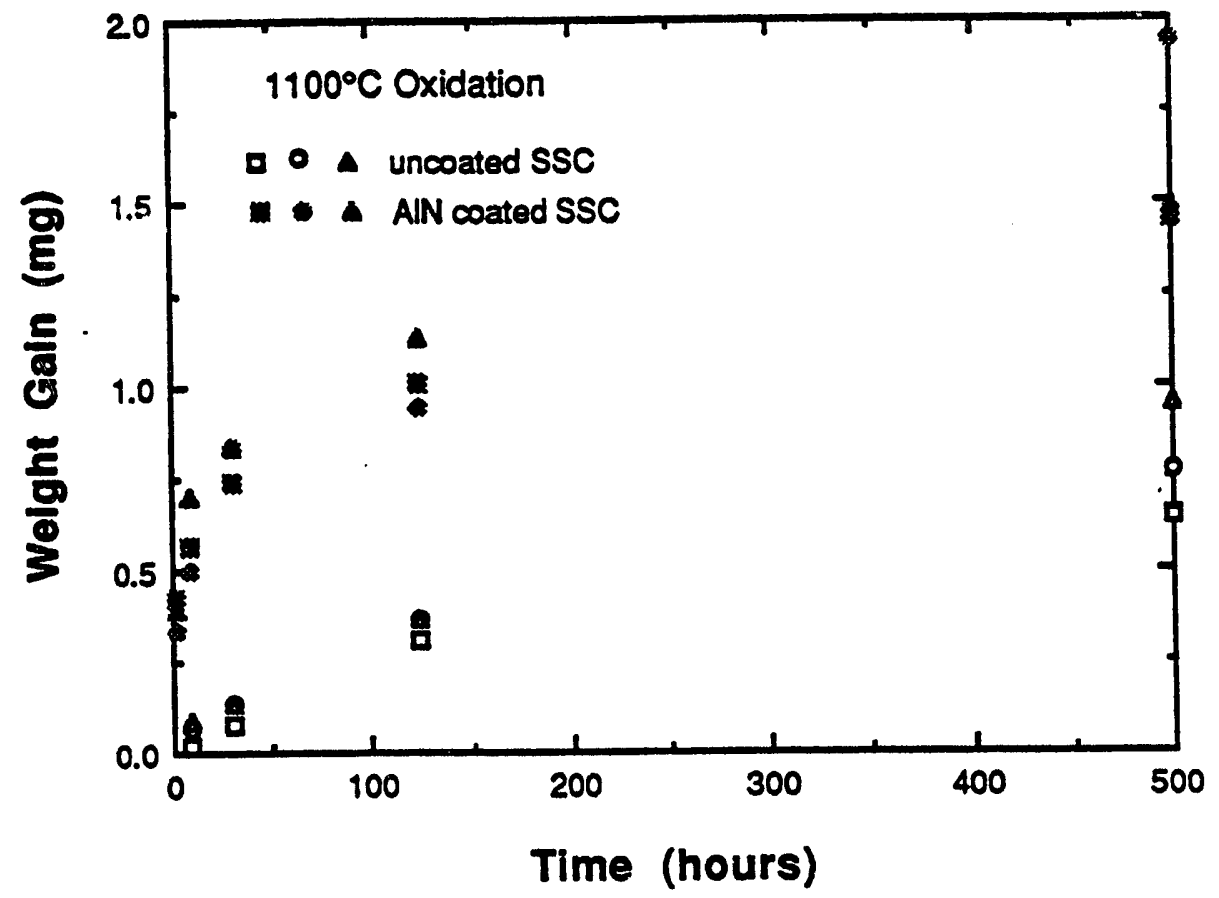

Figure A-5. Weight gain versus time for uncoated and AlN coated SSC oxidized in static air at $1100^{\circ} \mathrm{C}$. 


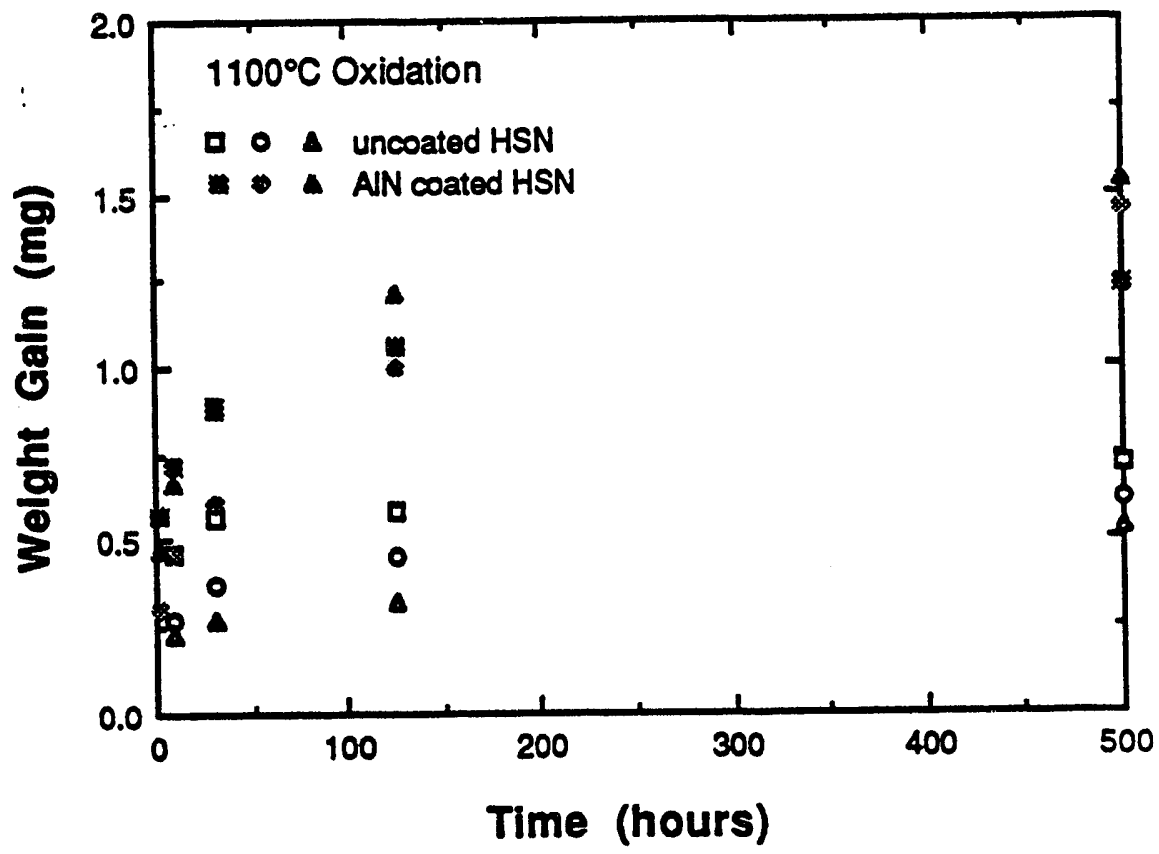

Figure A-6. Weight gain versus time for uncoated and AlN coated HSN oxidized in static air at $1100^{\circ} \mathrm{C}$.

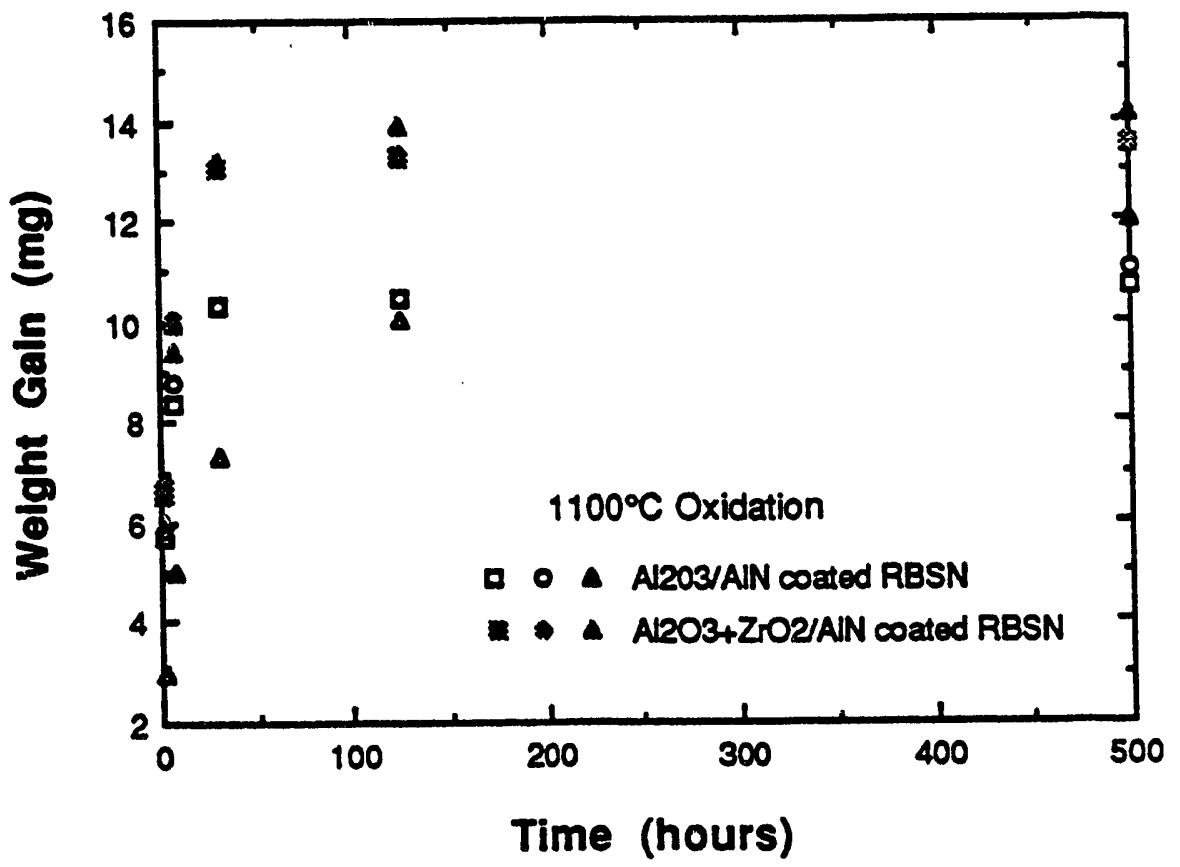

Figure A-7. Weight gain versus time for uncoated and $\mathrm{Al}_{2} \mathrm{O}_{3} / \mathrm{AlN}$ and $\mathrm{Al}_{2} \mathrm{O}_{3}+\mathrm{ZrO}_{2} / \mathrm{AlN}$ coated $\mathrm{RBSN}$ oxidized in static air at $1100^{\circ} \mathrm{C}$. 


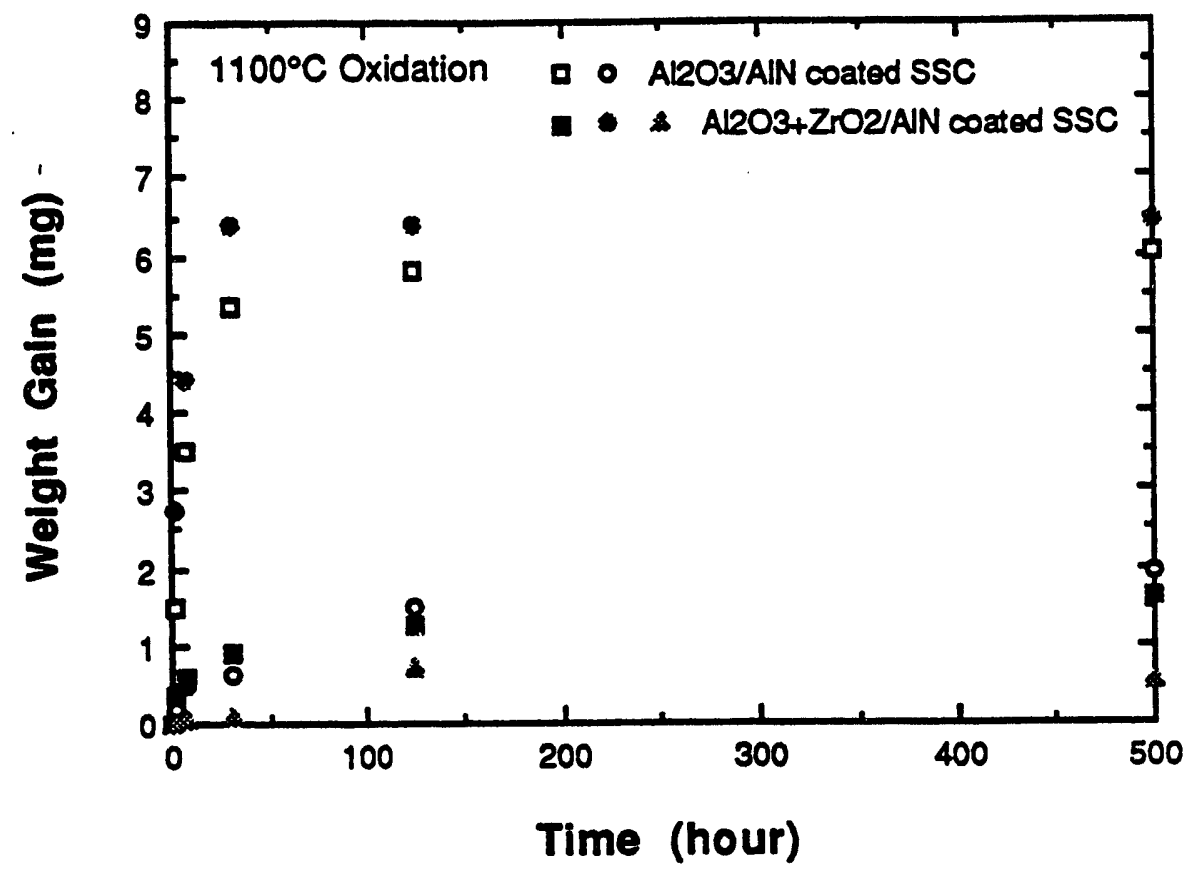

Figure A-8. Weight gain versus time for uncoated and $\mathrm{Al}_{2} \mathrm{O}_{3} / \mathrm{AlN}$ and $\mathrm{Al}_{2} \mathrm{O}_{3}+\mathrm{ZrO} /$ AlN coated SSC oxidized in static air at $1100^{\circ} \mathrm{C}$.

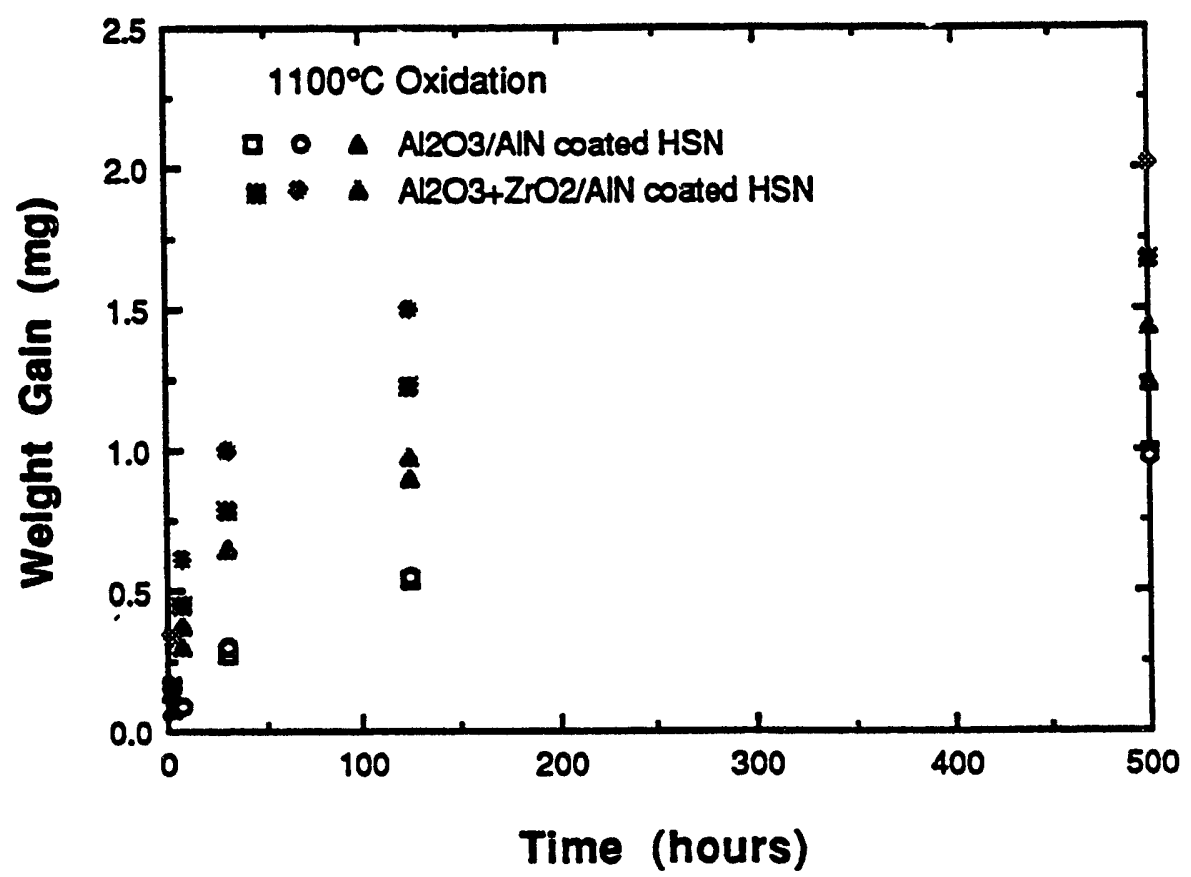

Figure A-9. Weight gain versus time for uncoated and $\mathrm{Al}_{2} \mathrm{O}_{3} / \mathrm{AlN}$ and $\mathrm{Al}_{2} \mathrm{O}_{3}+\mathrm{ZrO}_{2} / \mathrm{AlN}$ coated $\mathrm{HSN}$ oxidized in static air at $1100^{\circ} \mathrm{C}$. 


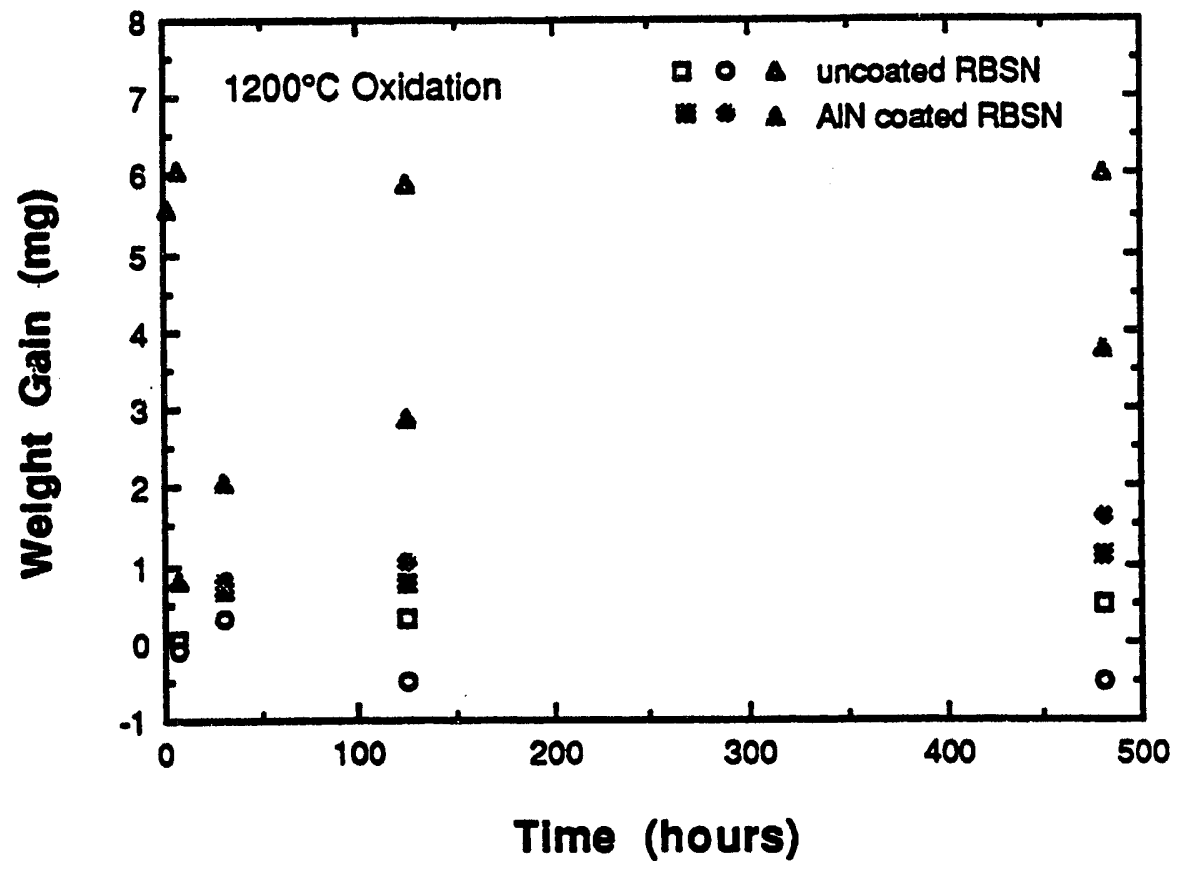

Figure A-10. Weight gain versus time for uncoated and AlN coated RBSN oxidized in static air at $1200^{\circ} \mathrm{C}$.

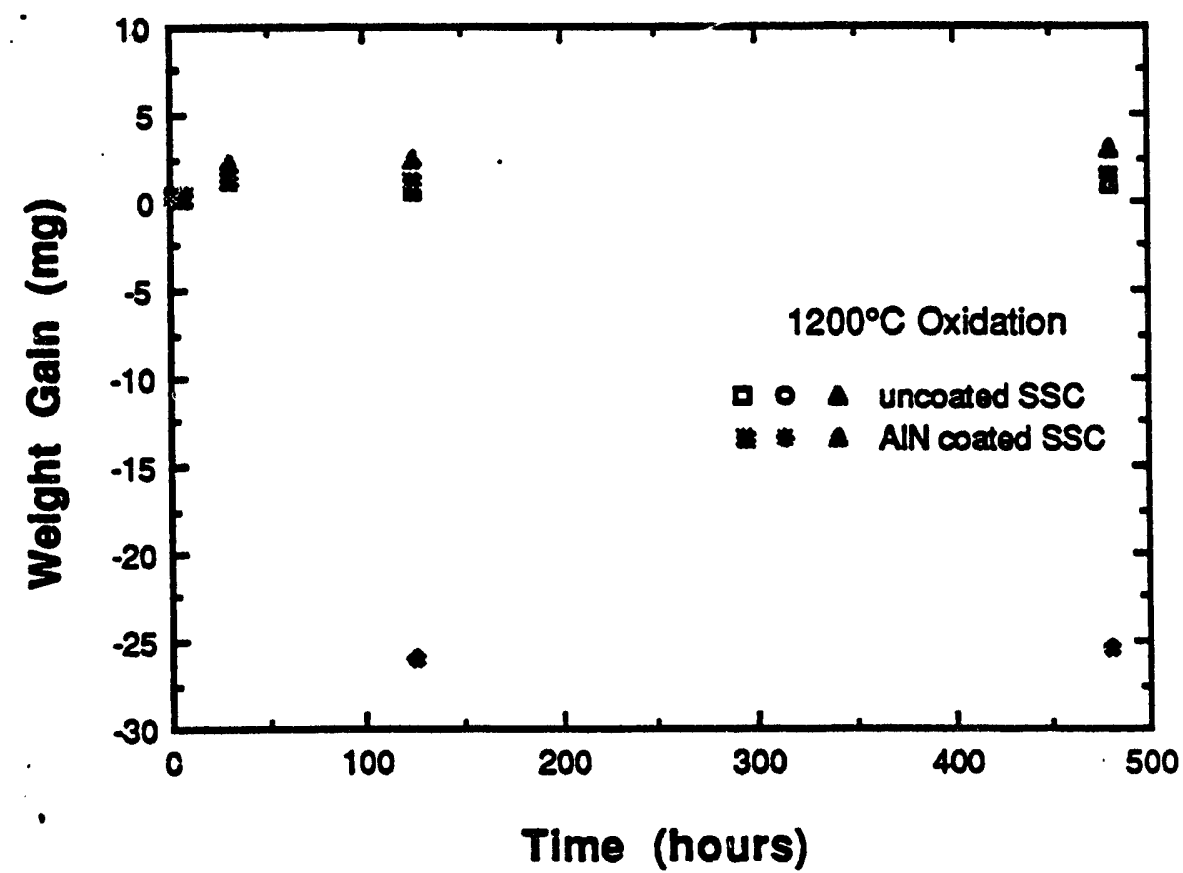

Figure A-11. Weight gain versus time for uncoated and AlN coated SSC oxidized in static air at $1200^{\circ} \mathrm{C}$. 


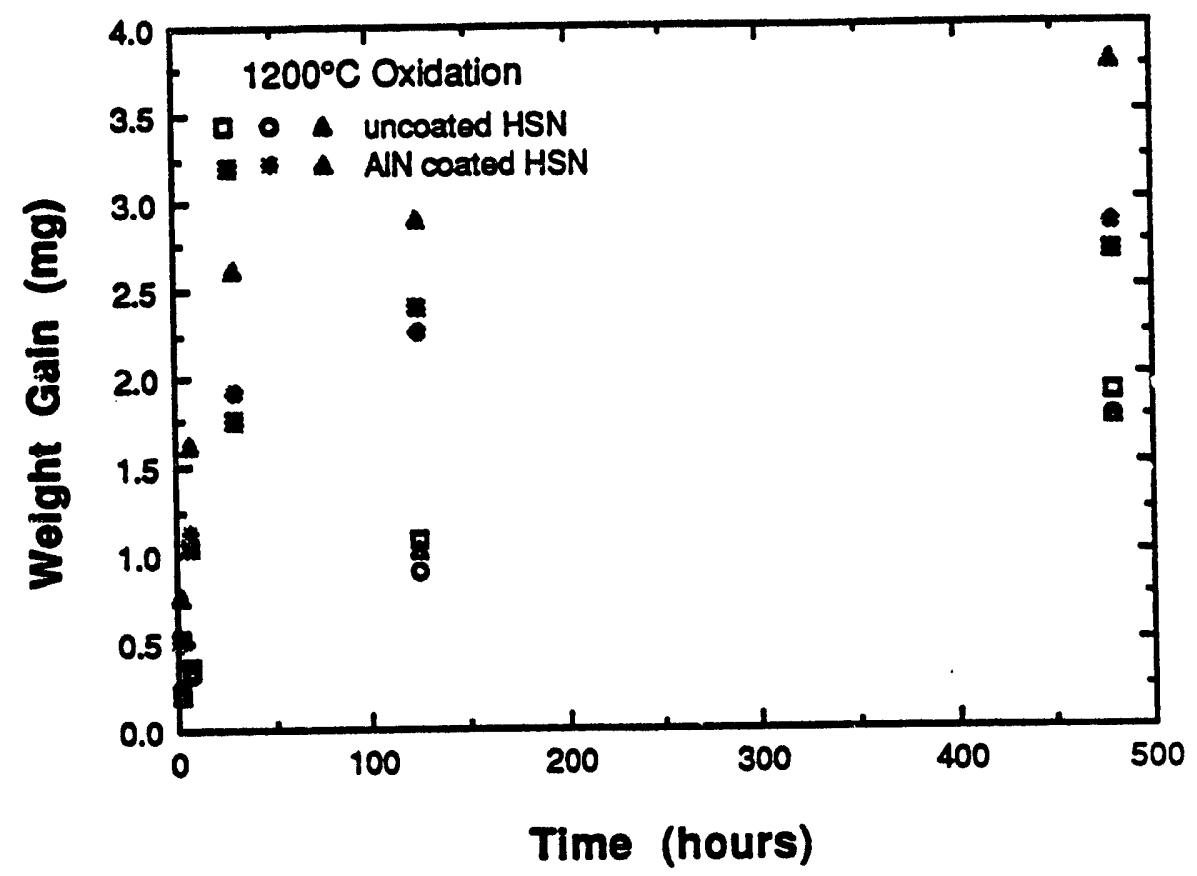

Figure A-12. Weight gain versus time for uncoated and AIN coated HSN oxidized in static air at $1200^{\circ} \mathrm{C}$.

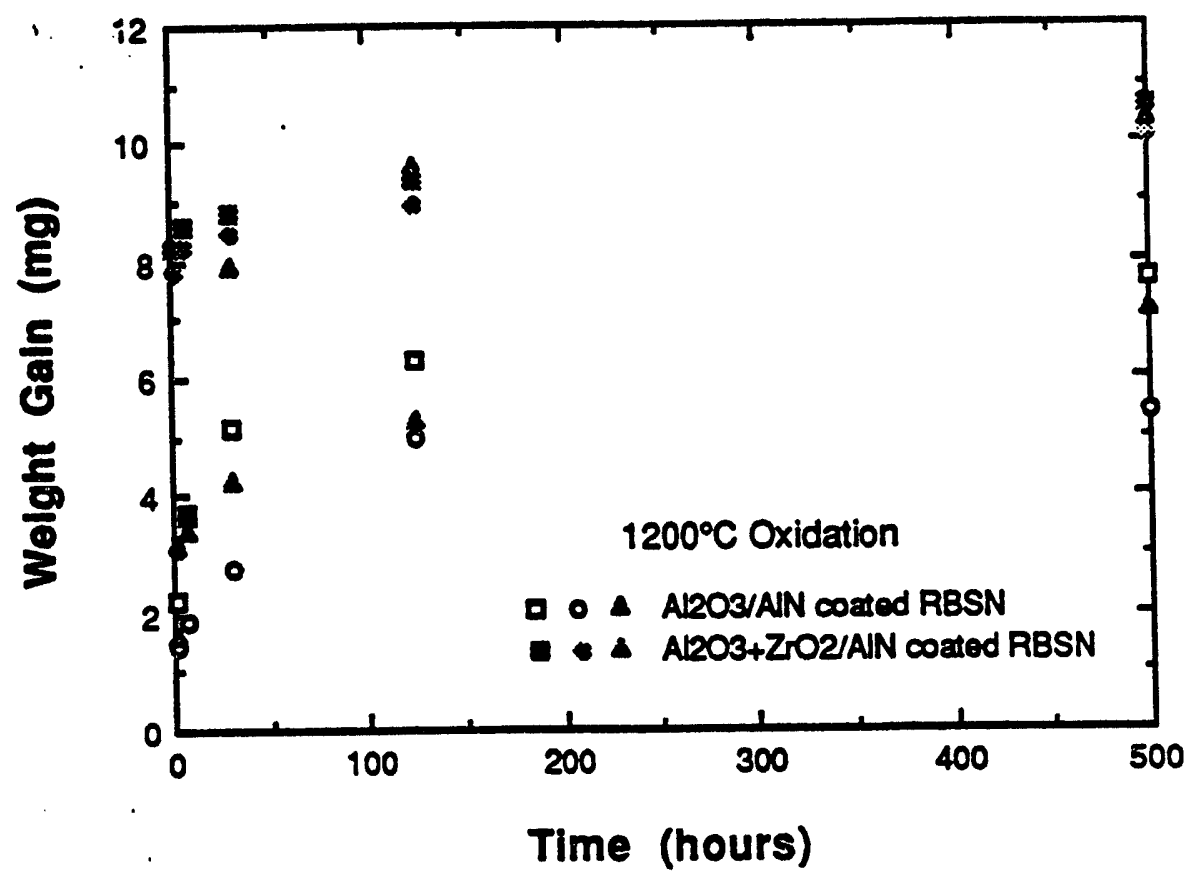

Figure A-13. Weight gain versus time for $\mathrm{Al}_{2} \mathrm{O}_{3} / \mathrm{AlN}$ and $\mathrm{Al}_{2} \mathrm{O}_{3}+\mathrm{ZrO}_{2} / \mathrm{AIN}$ coated RBSN oxidized in static air at $1200^{\circ} \mathrm{C}$. 


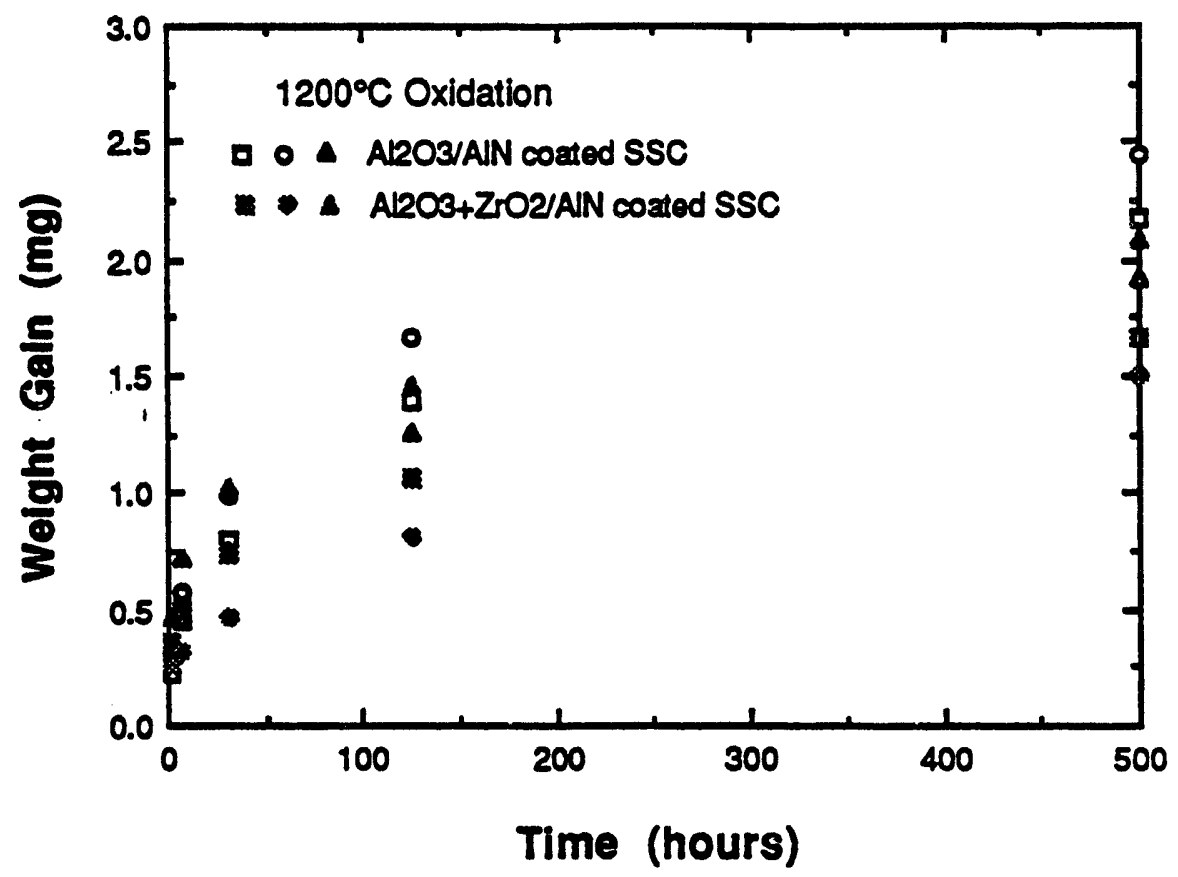

Figure A-14. Weight gain versus time for $\mathrm{Al}_{2} \mathrm{O}_{3} / \mathrm{AlN}$ and $\mathrm{Al}_{2} \mathrm{O}_{3}+\mathrm{ZrO}_{2} / \mathrm{AlN}$ coated SSC oxidized in static air at $1200^{\circ} \mathrm{C}$.

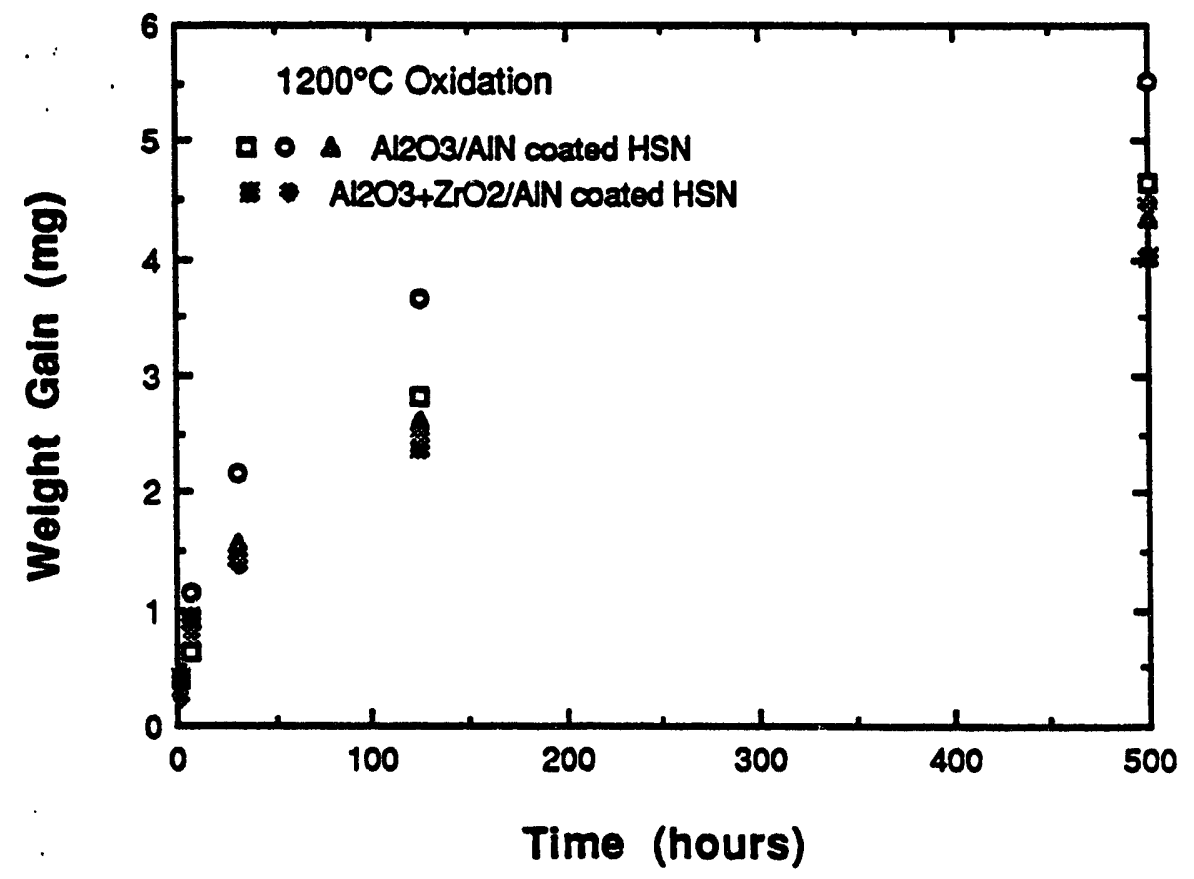

Figure A-15. Weight gain versus time for $\mathrm{Al}_{2} \mathrm{O}_{3} / \mathrm{AlN}$ and $\mathrm{Al}_{2} \mathrm{O}_{3}+\mathrm{ZrO}_{2} / \mathrm{AlN}$ coated HSN oxidized in static air at $1200^{\circ} \mathrm{C}$. 


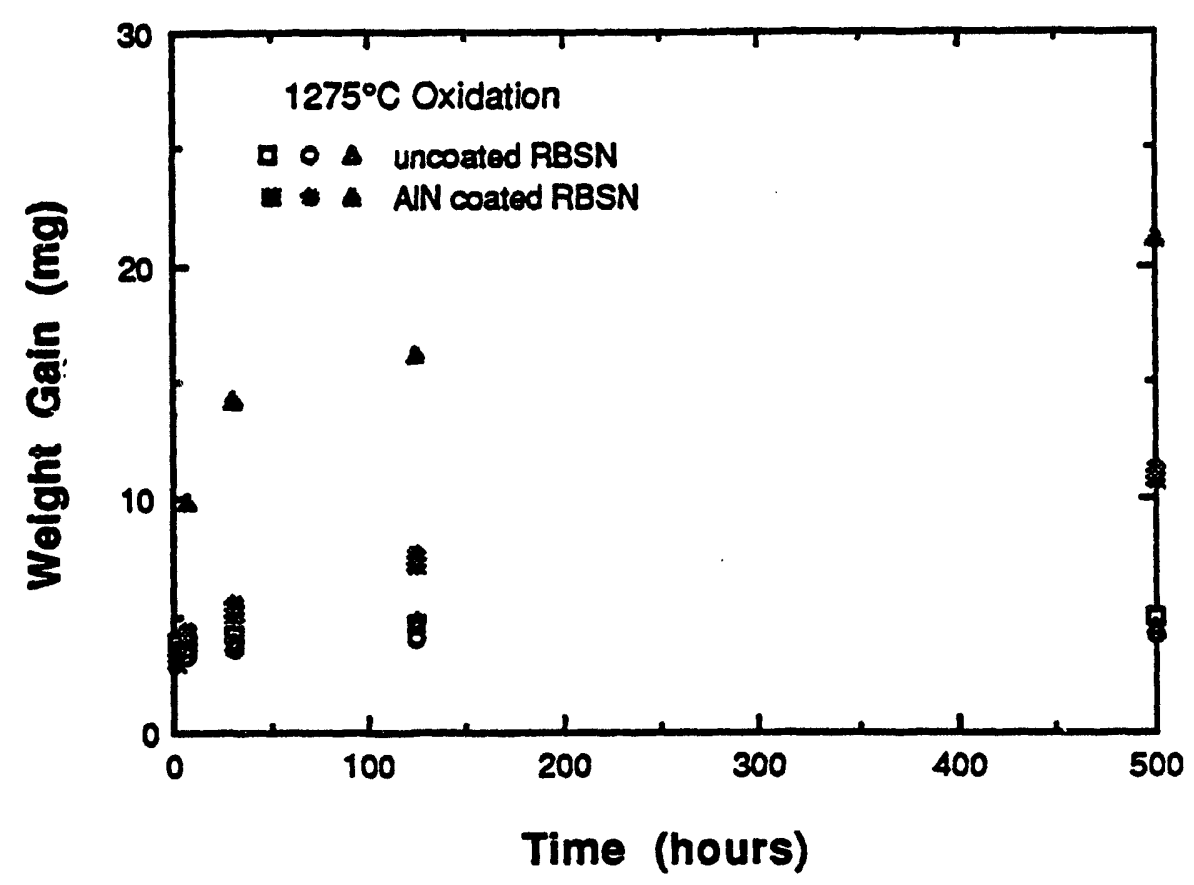

Figure A-16. Weight gain versus time for uncoated and AlN coated RBSN oxidized in static air at $1275^{\circ} \mathrm{C}$.

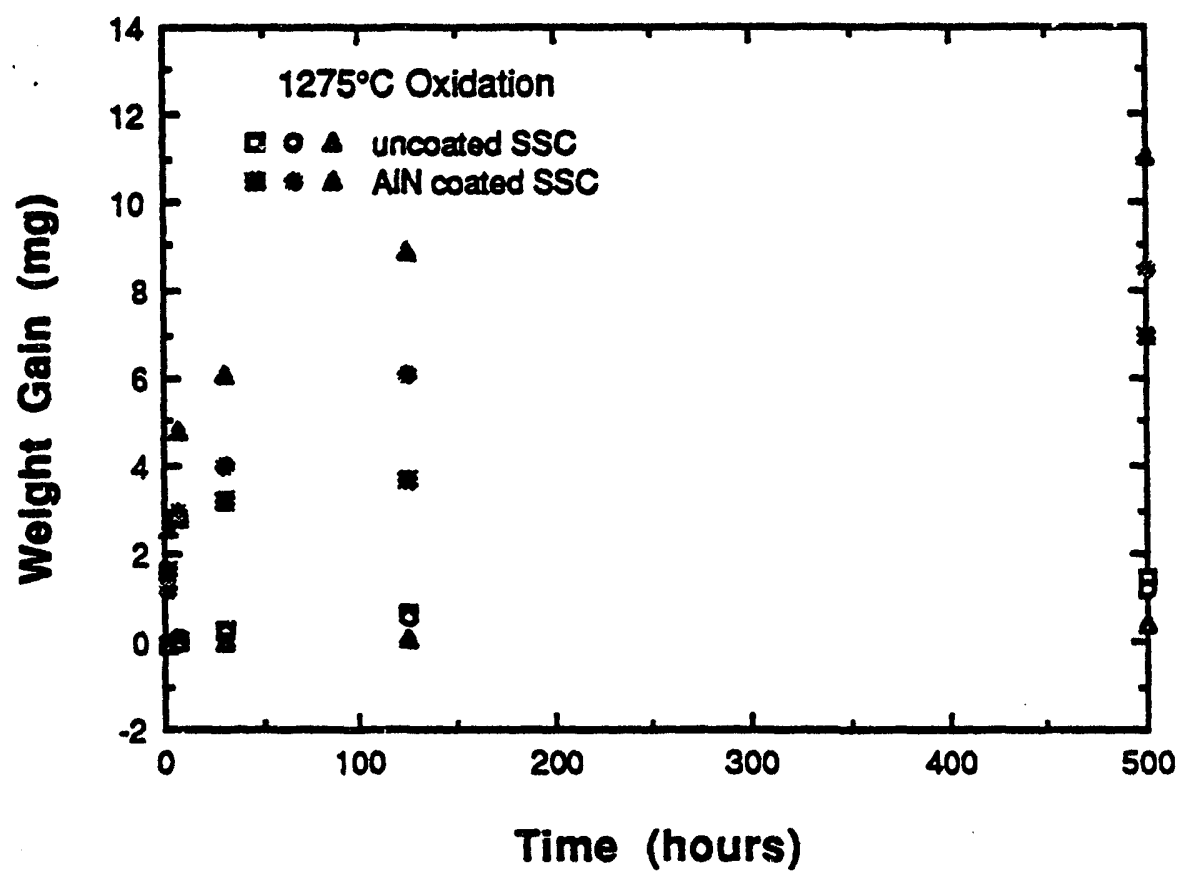

Figure A-17. Weight gain versus time for uncoated and AIN coated SSC oxidized in static air at $1275^{\circ} \mathrm{C}$. 


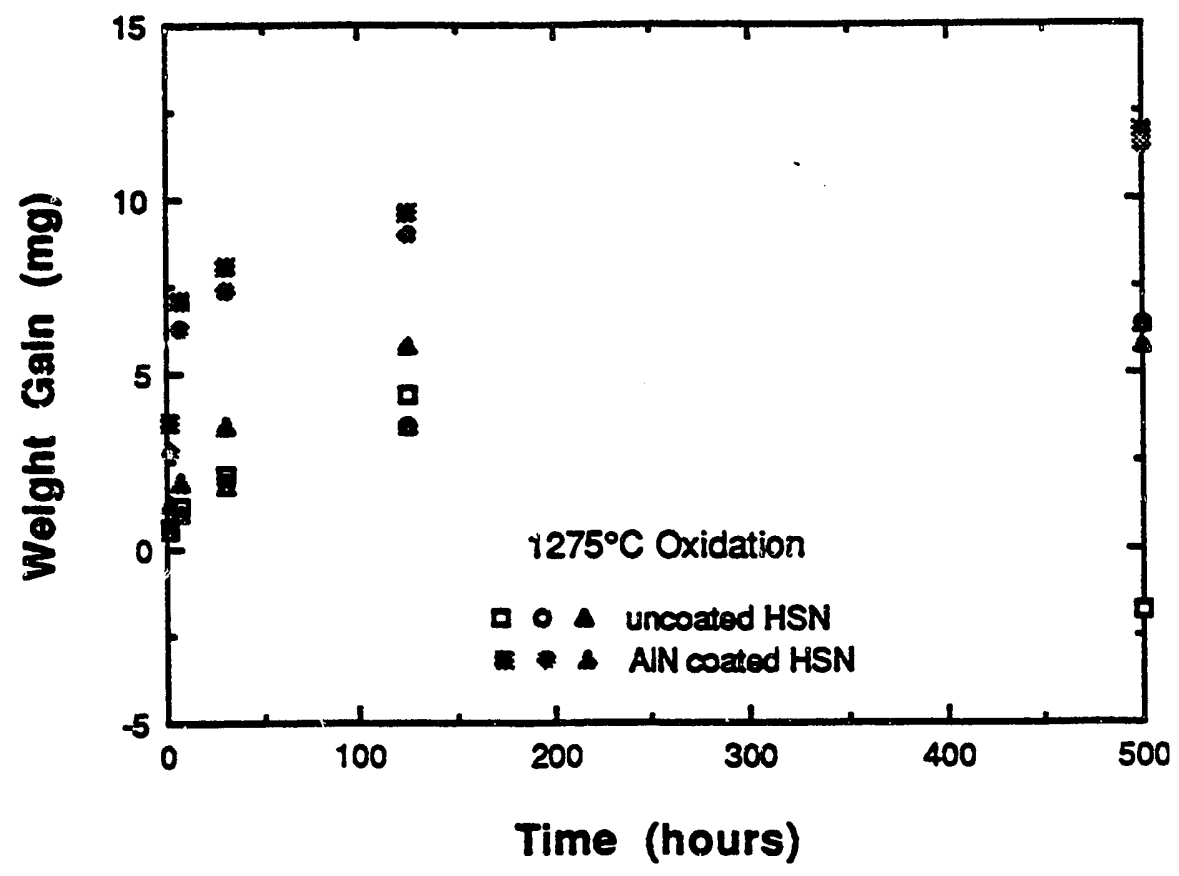

Figure A-18. Weight gain versus time for uncoated and AlN coated HSN oxidized in static air at $1275^{\circ} \mathrm{C}$.

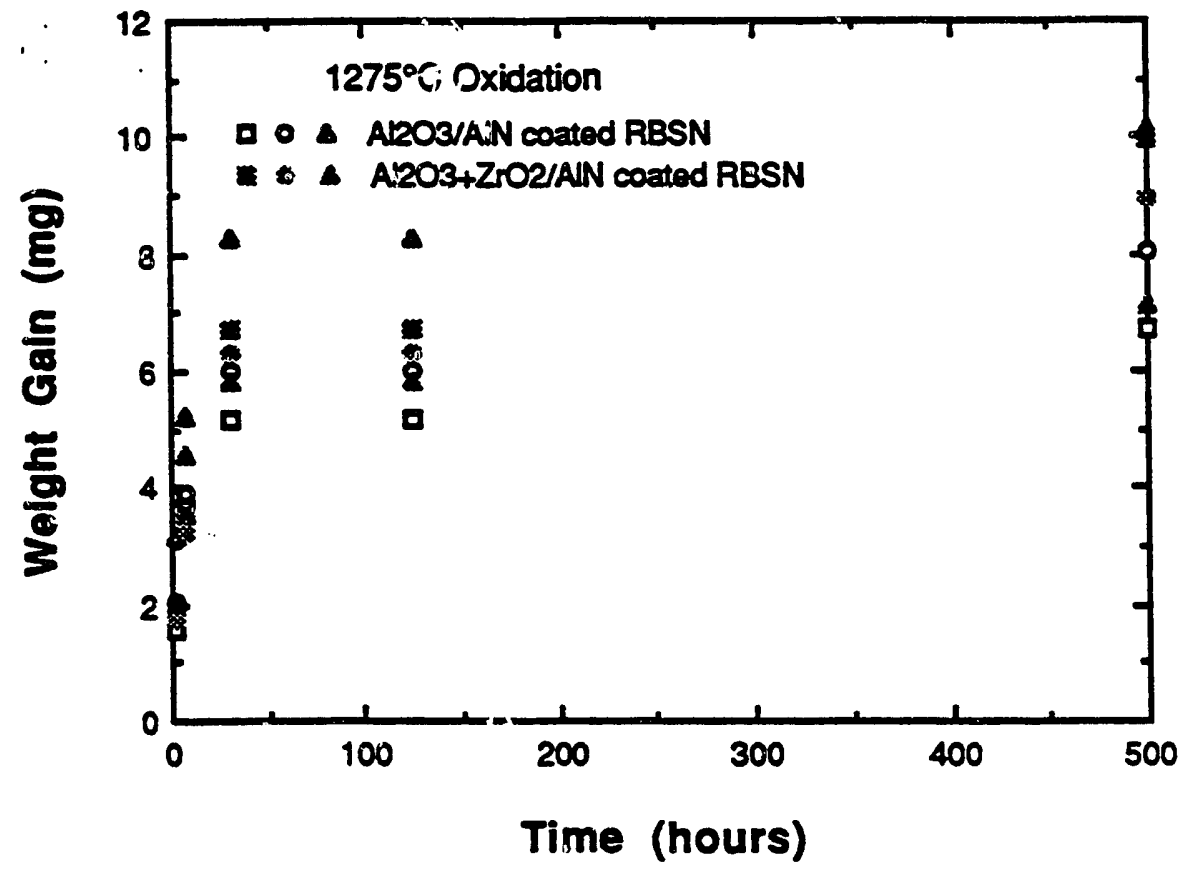

Figure A-19. Weight gain versus time for $\mathrm{Al}_{2} \mathrm{O}_{3} / \mathrm{AlN}$ and $\mathrm{Al}_{2} \mathrm{O}_{3}+\mathrm{Z}^{\mathrm{r}} \mathrm{rO}_{2} / \mathrm{AlN}$ coated RBSN oxidized in static air at $1275^{\circ} \mathrm{C}$. 


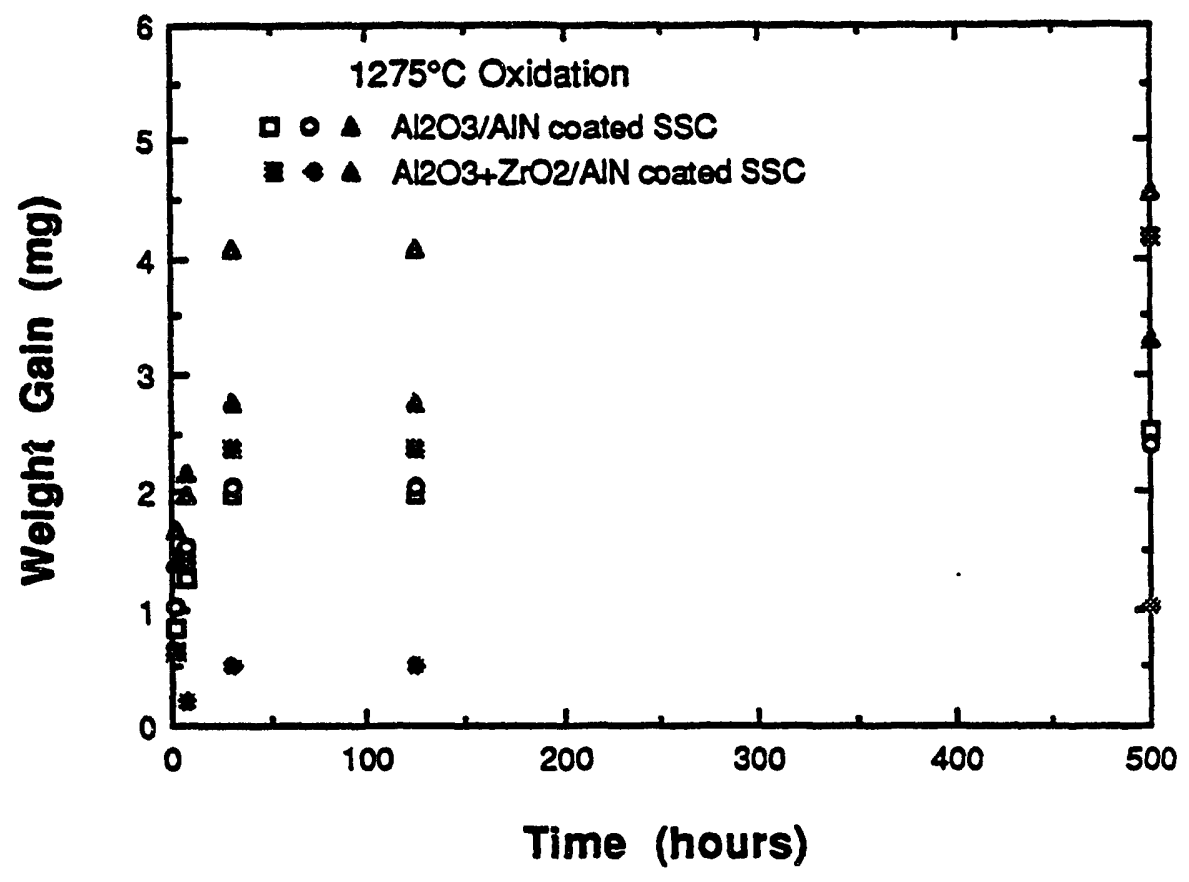

Figure A-20. Weight gain versus time for $\mathrm{Al}_{2} \mathrm{O}_{3} / \mathrm{AlN}$ and $\mathrm{Al}_{2} \mathrm{O}_{3}+\mathrm{ZrO}_{2} / \mathrm{AlN}$ coated SSC oxidized in static air at $1275^{\circ} \mathrm{C}$.

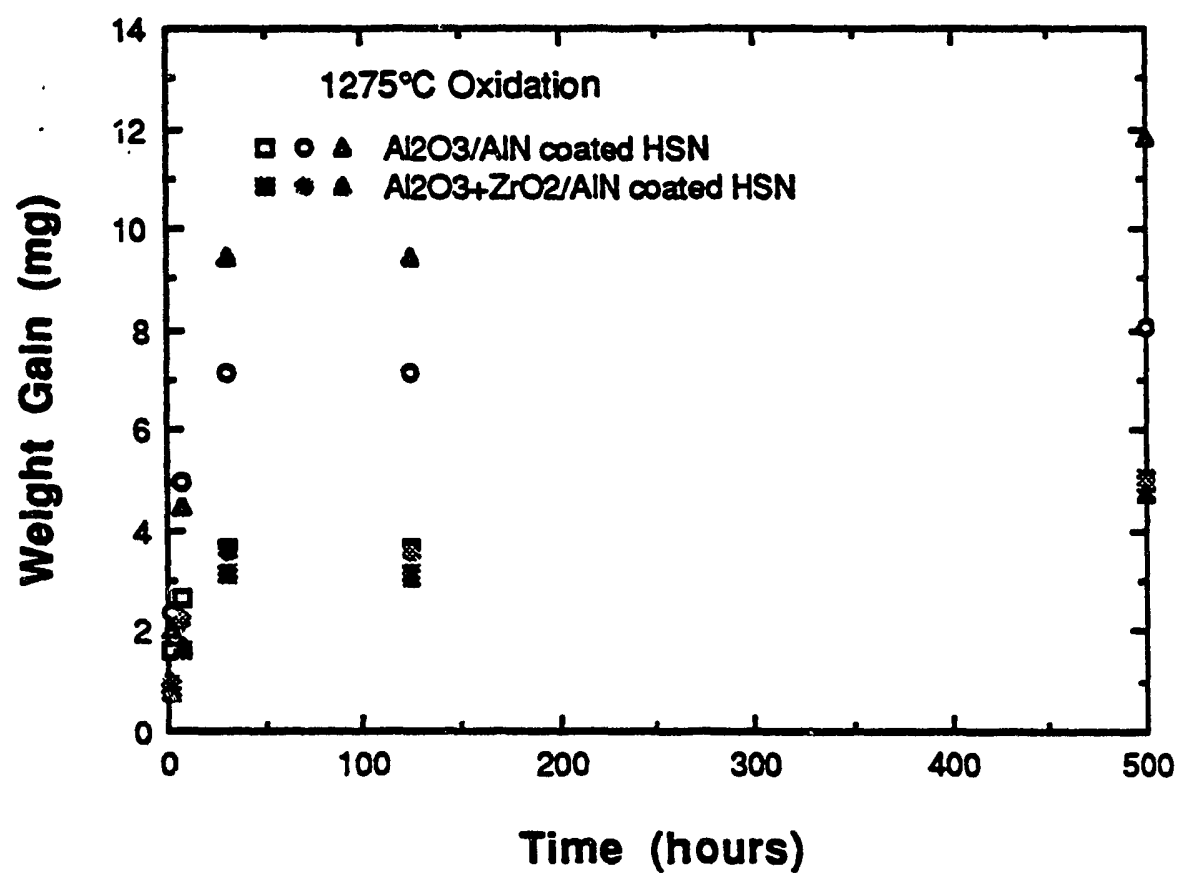

Figure A-21. Weight gain versus time for $\mathrm{Al}_{2} \mathrm{O}_{3} / \mathrm{AlN}$ and $\mathrm{Al}_{2} \mathrm{O}_{3}+\mathrm{ZrO} / \mathrm{AlN}$ coated HSN oxidized in static air at $1275^{\circ} \mathrm{C}$. 


\section{APPENDIX B - METHOD TO MEASURE FRACTURE STRESS AND ERACTURE TOUGHNESS OF COATINGS ON SUBSTRATES}

\section{SUMMARY}

Conventional mechanical property measurement techniques usually cannot be applied to thin ceramic coatings because of the small amount of material involved. A method is described to determine the ultimate tensile strength, fracture toughness, Weibull modulus, and surface energy of micron-sized ceramic coatings on substrates. This technique is based on measuring the radius of curvature of a coated substrate, and equating the resulting calculated stress with a theoretical shear-lag stress distribution morel using a force balance. The properties of chemical vapor deposited coatings of $\mathrm{Al}_{2} \mathrm{O}_{3}$ and $\mathrm{TiN}$ were measured on $\mathrm{SiC}$ and $\mathrm{Si}_{3} \mathrm{~N}_{4}$ substrates. The fracture stresses of these coatings were $190-480 \mathrm{MPa}$, the fracture toughnesses were $0.4-1.1 \mathrm{MPa} \sqrt{\mathrm{m}}$, the Weibull modulii were $10-28$, and the surface energies were $0.3-1.6 \mathrm{~J} / \mathrm{m}^{2}$. This work has shown that the tensile strength of thin brittle coatings can be approximated by bulk values, however, the fracture toughness of a coating can be significantly lower than bulk values.

\section{INTRODUCTION}

In coatings deposited at clevated temperatures, where the coating and substrate materials have different coefficients of thermal expansion, large stresses are generated in the coating after cooling to room temperature. If tensile, these stresses often lead to cracking of the coating, Figure B-1. Nitride, carbide, and oxide chemical vapor deposited (CVD) coatings on silicon nitride substrates for cutting tool applications are examples of coatings which crack on cooling. The technique presently described can be used for coatings deposited by any technique as long as the coating cracks due to thernal stresses and the deposition stress is known. 


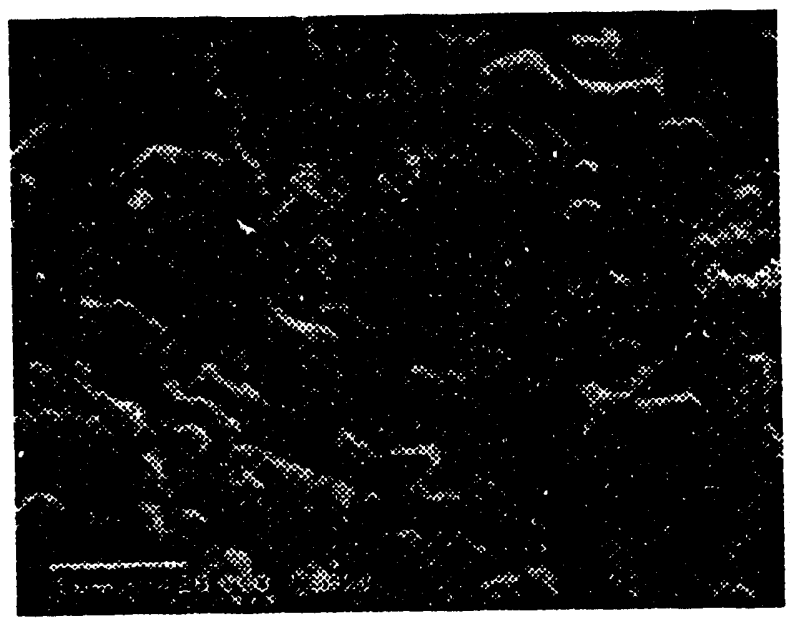

Figure B-1. Scanning electron micrograph of a crack in a coating.

As a coated substrate cools, stress builds up in the coating, Figure B-2. The stress component we are most concerned with is the in-plane normal stress. The word "stress" is used here to denote this component, and for most ceramic coatings this stress can be described by elastic relationships. Since the coating is a ceramic it is described by a distribution of fracture strengths. Once the fracture stress of the weakest part of the coating is reached, the coating will crack ( $\sigma_{f}$ in Figure B-2). During continued cooling, the peak stress increases, additional cracks form in the coating, and the overall stress $\left(\sigma_{m}\right)$ is relaxed. The serrations in Figure B-2 indicate the drop in stress due to cracking and their magnitudes are exaggerated. The coating does not crack again until it is cooled further because of the distribution of failure strengths and because the remaining uncracked coating has a smaller volume and therefore a higher failure strength. The relationship between the stressed volume and failure strength of a ceramic is described by Eq. (B-1) from Davidge [DAV80]:

$$
\frac{\sigma_{1}}{\sigma_{2}}=\left(\frac{V_{2}}{V_{1}}\right)^{1 / m}
$$


where $V_{1}$ is stressed volume $1, V_{2}$ is stressed volume $2, \sigma_{1}$ is the failure stress for volume $v_{1}, \sigma_{2}$ is the failure stress for volume $V_{2}$, and ' $m$ ' is the Weibull modulus of the material.

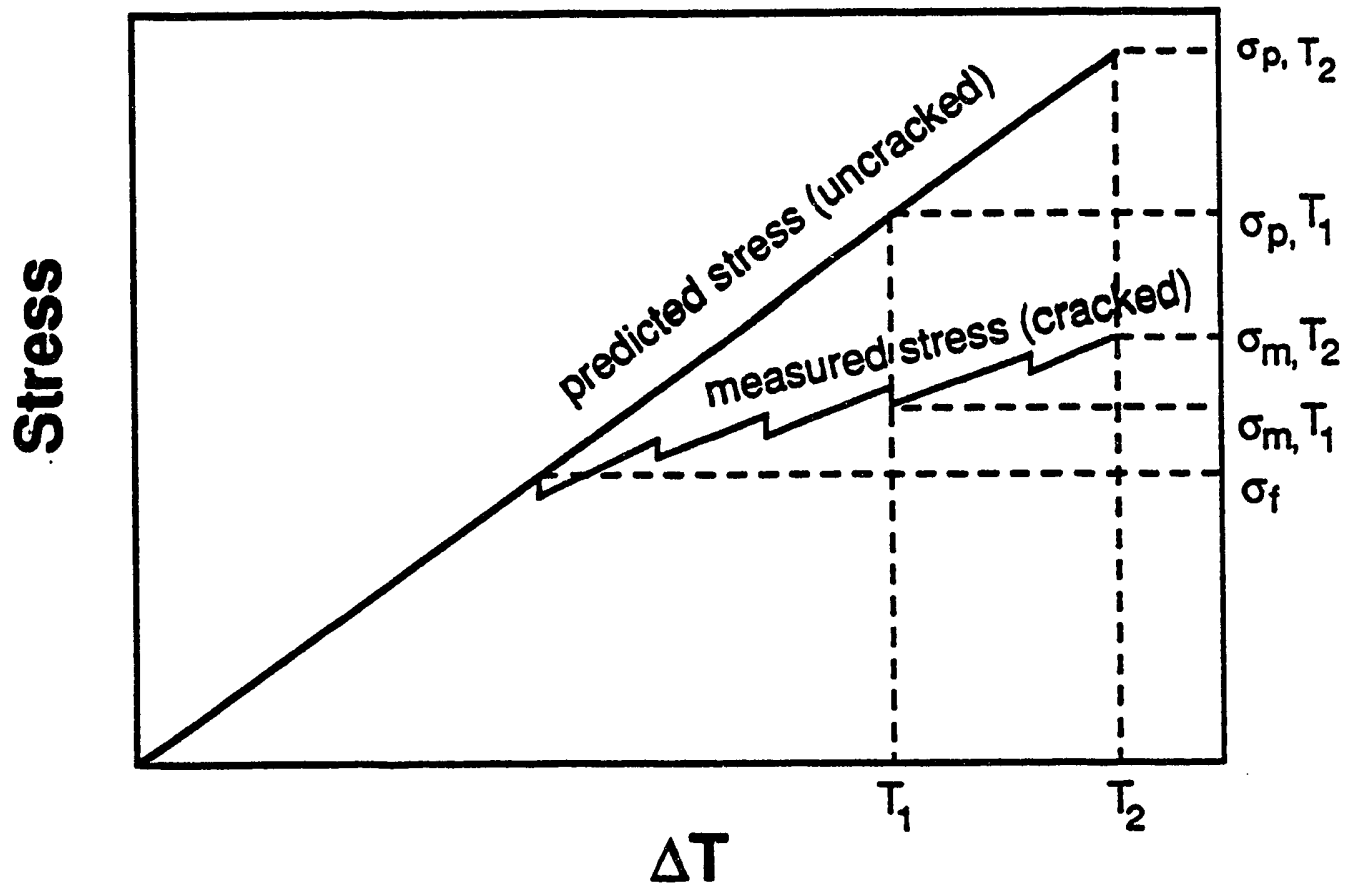

Figure B-2. Schematic of stress versus $\Delta T$ plot for a cracked ceramic coating on a substrate. $\Delta \mathrm{T}$ is the deposition temperature minus the instantaneous temperature, $\sigma_{p}$ is the predicted stress at $T_{1}$ and $T_{2}$ (Eq. B-3), $\sigma_{\mathrm{m}}$ is the measured stress at $T_{1}$ and $T_{2}$ (Eq. B-4), and $\sigma_{\mathrm{f}}$ is the fracture stress of the coating.

The drop in stress that occurred from cracking during cooling of a coated substrate was exploited in this research to extract material properties for the coating. The objective of the study was to determine fracture strength, fracture toughness, and Weibull modulus for a range of coating-substrate material systems by equating the predicted theoretical residual thermal stress 
in the coating (taking into account the stress distribution between cracks in the coating) to the experimentally measured average stress in the coating.

No previous technique has been described which determines the fracture stress of thin coatings in situ on a substrate. In the present study, the theory and methodology are presented for determining the fracture stress $\left(\sigma_{f}\right)$, fracture toughness $\left(\mathrm{K}_{\mathrm{Ic}}\right)$, and Weibull modulus $(m)$ of brittle thin coatings. A useful function of this technique is to study the effect of varying the deposition parameters or microstructure on the strength and Weibull modulus of a coating. An example of this last application is provided as an example.

Stresses in Coatings - Theor

Stresses in Uncracked Coatings

The in-plane stress in a narrow flat bimaterial strip (consisting of materials 1 and 2 ) generated by a change in temperature was derived by Timoshenko [TIM25].

$$
\begin{gathered}
\frac{1}{\rho}=\frac{\left(\alpha_{2}-\alpha_{1}\right)\left(T_{d}-T_{j}\right)}{\frac{t}{2}+\frac{2\left(E_{1} I_{1}+E_{2} I_{2}\right)}{t}\left(\frac{1}{E_{1} t_{1}}+\frac{1}{E_{2} t_{2}}\right)} \\
\sigma=\frac{1}{\rho}\left(\frac{2}{t t_{1}}\left(E_{1} I_{1}+E_{2} I_{2}\right)+\frac{t_{1} E_{1}}{2}\right)
\end{gathered}
$$

where $p$ is the radius of curvature of the strip, $\alpha$ is the coefficient of thermal expansion, $T_{i}$ is the final temperature, $T_{d}$ is the deposition temperature, $E$ is Young's modulus, $I$ is the moment of inertia, $t_{1,2}$ are the individual layer thicknesses, and $t$ is the total thickness $\left(t=t_{1}+t_{2}\right)$. The geometry of the beam is shown in Figure B-3. To convert from narrow beams to wide beams; $E /\left(1-v^{2}\right)$ is substituted for $E$; and $I=t^{3} / 12$ in Eqs. (B-2) and (B-3), where $v$ is Poissons ratio. 


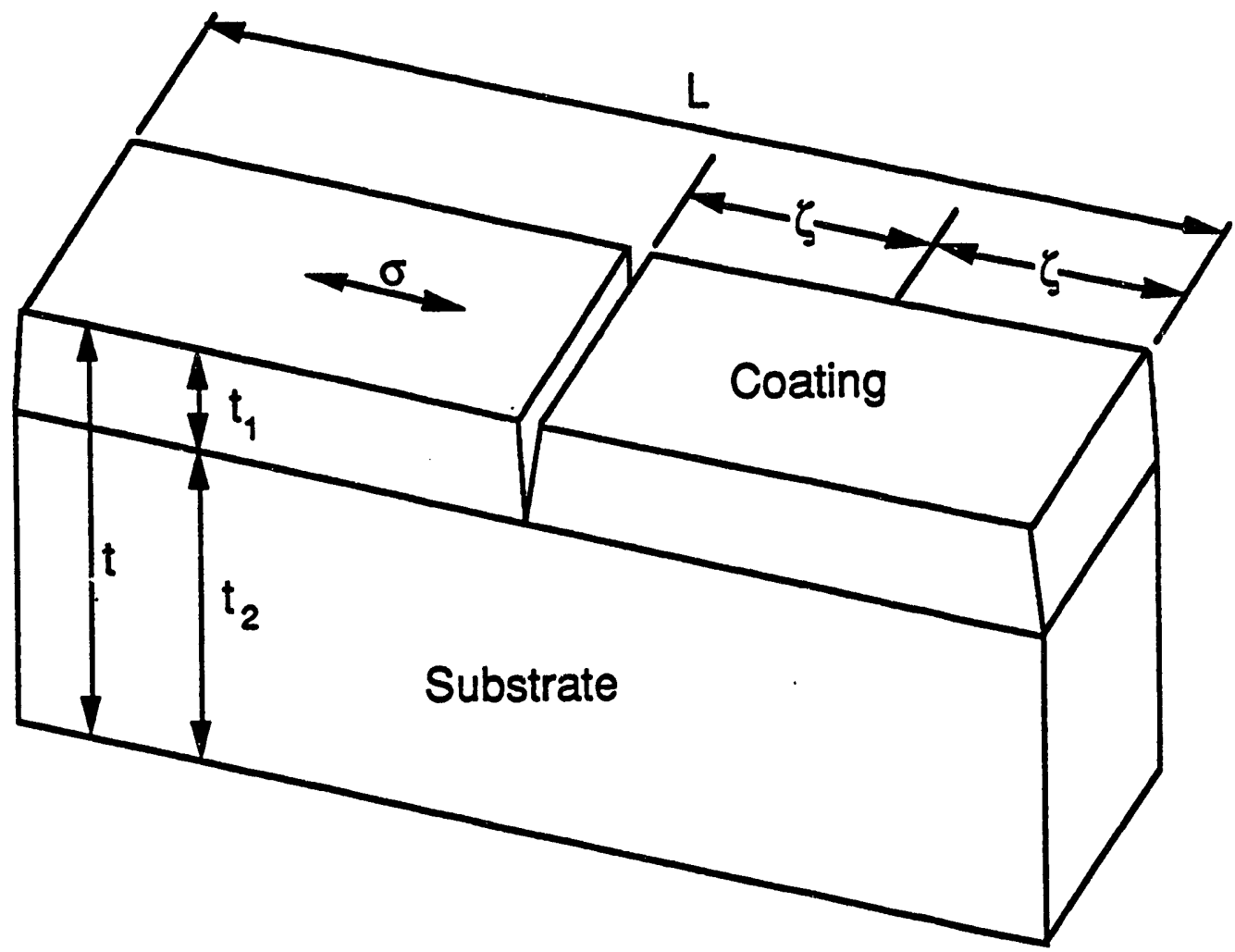

Figure B-3. Schematic of coating on substrate with a single crack. The ends are treated as crack faces. The relative size of the coating was greatly exaggerated to show detail.

The coefficient of thermal expansion and Young's modulus of the materials are treated as temperature dependent quantities and Eqs. (B-2) and (B-3) are numerically integrated to solve for the stress in the coating. Treating the coefficient of thermal expansion as a temperature independent constant can lead to significant errors in materials where these coefficients are strong functions of temperature.

Equation (B-3) was used to predict the stress in an uncracked coating on a substrate subjected to a change in temperature. This predicted stress was referred to as $\sigma_{p}$ in Figure B-2. Use of Eq. (B-3) assumed that the coating was deposited with a known stress at the deposition temperature (assumed 0 in this work) and was crack free. Equation (B-3) gave the maximum stress in 
material 1, which we treated as the coating. The stress in a thin coating is nearly uniform through the thickniss, and the stress in Eq. (B-3) was set equal to the stress in the coating. For a "thin" coating, the stress was independent of coating and substrate thicknesses. For material systems of interest in this study, a coating is considered thin if it was less than $10 \%$ of the substrate thickness. Figure B-4 shows the bending and axial contributions to the stress in a coating as a function of relative coating to substrate thickness from Equation (B-3). At coating thicknesses less than $10 \%$ of the substrate thickness, most of the stress is due to axial loading, and hence, will scale as the coating thickness changes. A "thin film" approximation to Eq. (B-3) was derived by setting $t_{1}$ to zero in the relevant terms [FLI87];

$$
\sigma=\frac{E_{2 t_{2}^{2}}^{2}}{\sigma t_{1}\left(1-v_{2}^{2}\right)}\left(\frac{1}{P_{c}}-\frac{1}{P_{u c}}\right)
$$

where subscripts ' $c$ ' and 'uc' on $p$ refer to the coated and uncoated strip respectively. The term in the parenthesis is used to correct for nonflat uncoated strips. If the uncoated strip is flat $1 / \rho_{c}$ approaches zero and Eq. (B-3) is regained, with $t_{1}=0$. The primary advantage of Eq. $(B-4)$ over Eq. $(B-3)$ is that only substrate properties and the coating thickness are needed to calculate stress in the coating. Measured radii of curvature were substituted into Eq. (B-4) to arrive at a value for the average stress in the coating. This stress was valid for coatings which are cracked or plastically deformed and was referred to as $\sigma_{\mathrm{m}}$ (measured stress) in Figure B-2. 

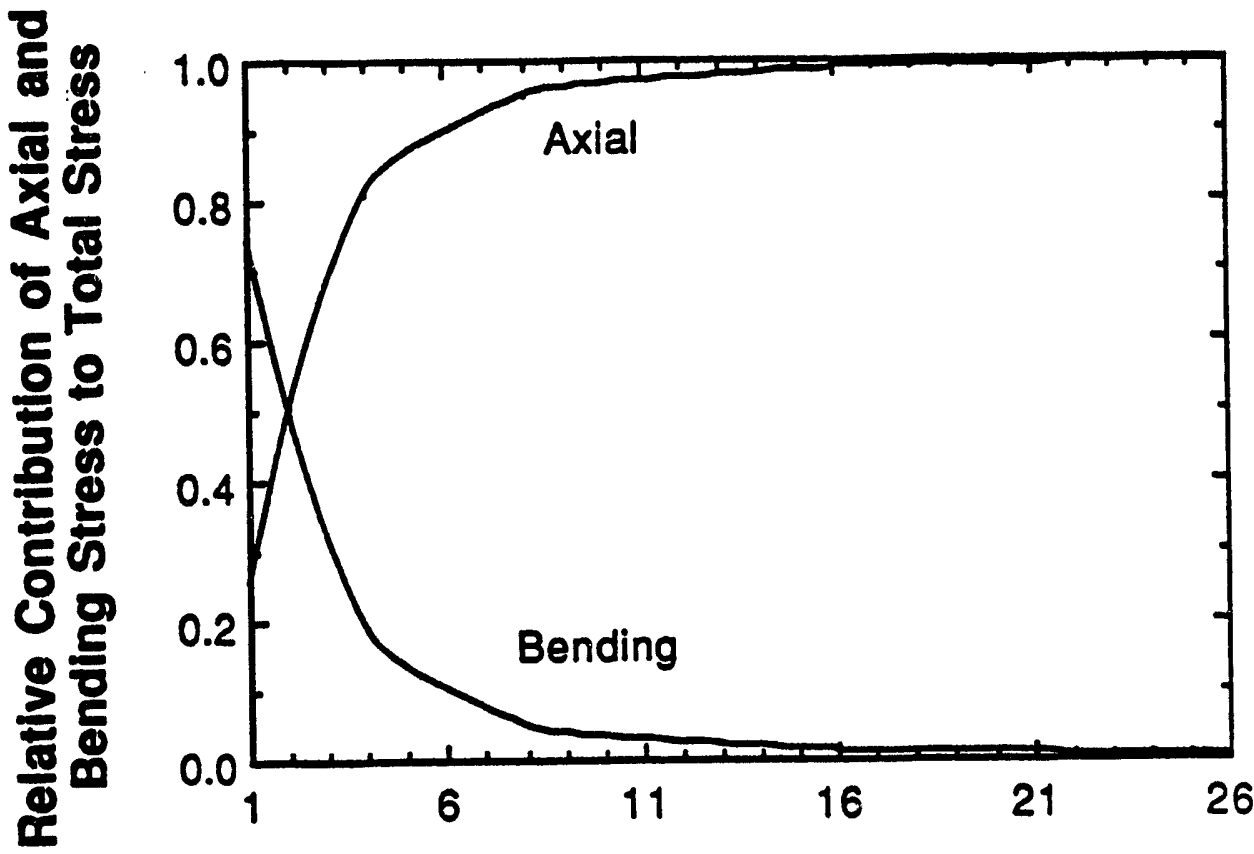

Substrate Thickness/Coating Thickness

Figure B-4. At coating thicknesses less than 10\% of the substrate thickness most of the stress in the coating was due to the axial component and was therefore independent of the coating and substrate thicknesses.

\section{Stresses in Cracked Coatings}

When a coating cracks, stress relaxation occurs in the coating around the crack. The in-plane stress is bounded by zero stress at the crack surface and reaches a steady state level "far" from the crack. The distance over which the stress is reduced is related to the elastic properties of the coating and substrate and to the thickness of the coating. Swanson [SWA89] described the stress distribution in fiber-reinforced materials near a crack, commonly known as shear-lag. It can be applied to thin coatings by considering the fiber as the coating material, and the surrounding matrix as the substrate. His model considered approximate stress distributions, and the equilibrium was considered in an average sense through the thickness of a cracked layer. 
Swanson's treatment was for a fiber in a ply within a composite. However, since shear-lag is a general phenomenon, the form of the shear-lag distribution in a ply near a crack should be similar to that in a coating near a crack.

The in-plane normal stress distribution in a fiber near a free surface (a crack) was given by Swanson as:

$$
\sigma(x)=\sigma_{p}\{\tanh (\beta \zeta) \sinh (\beta x)-\cosh (\beta x)+1\}
$$

where

$$
\begin{gathered}
\beta^{2}=\frac{G_{f}}{t_{f}}\left\{\frac{1}{t_{f} Q_{f}}+\frac{1}{t_{m} Q_{m}}\right\} \\
Q_{f}=\frac{E_{f}}{2\left(1-v_{f}^{2}\right)} \text { and } Q_{m}=\frac{E_{m}}{2\left(1-v_{m}^{2}\right)}
\end{gathered}
$$

' $x$ ' is the position along the coating between cracks ( $x=0$ is the crack face position), $\sigma_{p}$ is the stress far from the crack for noninteracting cracks, $\zeta$ is one-half of the disiance between cracks, $G_{f}$ is the shear modulus of the fiber, $t_{f, m}$ is one-half the thickness of the fiber or matrix, and $E_{f, m}$ is Young's modulus of the fiber or matrix. For the case of a coating on a substrate $t_{f}$ and $t_{m}$ were set to the thickness of the coating and substrate, respectively, resulting in:

$$
\beta^{2}=\frac{G_{1}}{t_{1}}\left\{\frac{1}{t_{1} Q_{1}}+\frac{1}{t_{2} Q_{2}}\right\}
$$

Figure B-5 shows a plot of normalized stress versus distance from a crack face in a coating. The shear-lag stress distribution shown in Figure B-5 is for a 4.7 microns thick $\mathrm{Al}_{2} \mathrm{O}_{3}$ coating on a $\mathrm{SiC}$ substrate for crack spacings of 50,10 , and 5 microns. 


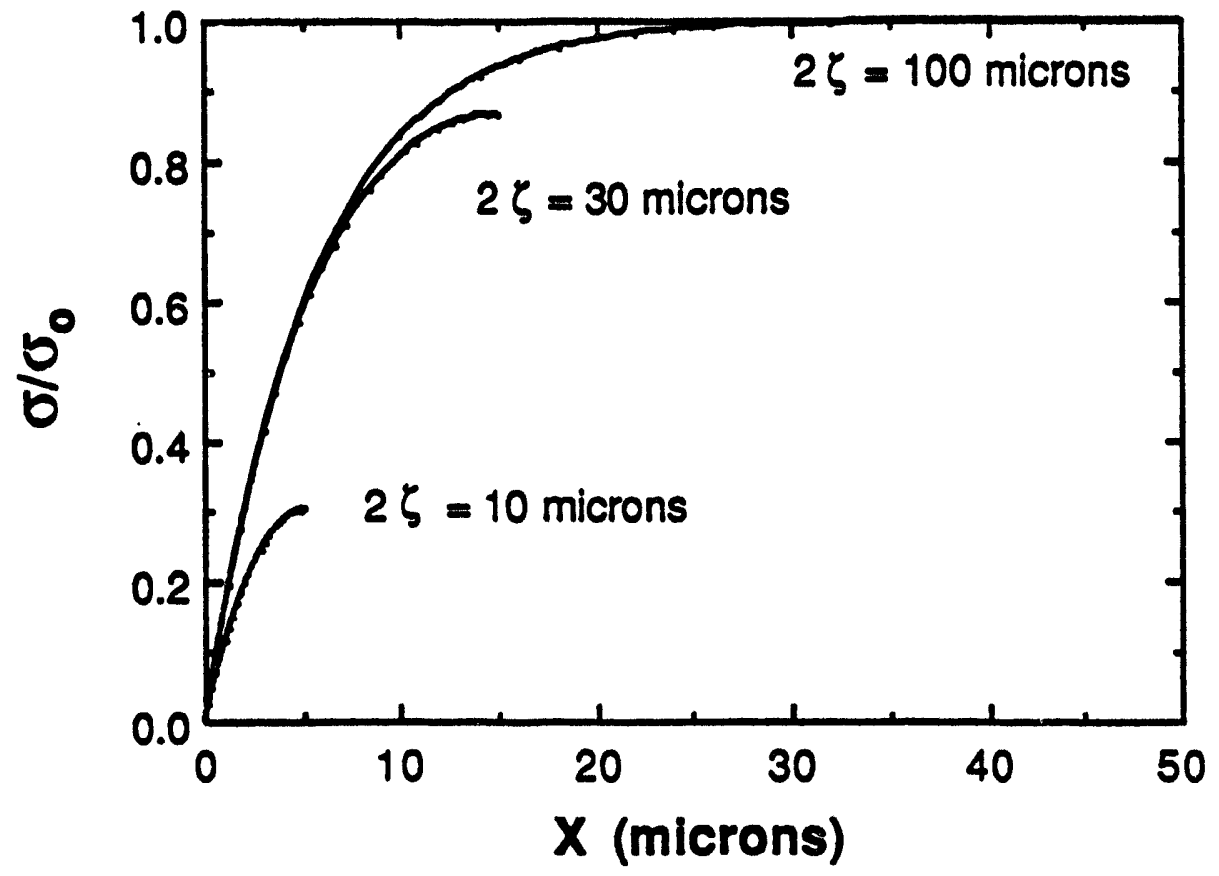

Figure B-5. Plot of the stress distribution in a 4.7 microns $\mathrm{Al}_{2} \mathrm{O}_{3}$ coating on a SiC substrate according to Eq. (B-5) for three different crack spacings (10, 30, and 100 microns). The crack is located at $x=0$.

\section{Determination of the Weibull Modulus. Theory}

The difference between the predicted stress in an uncracked coating $\sigma_{p}$ (calculated with Eq. (B-3)) and the measured stress in the cracked coating $\sigma_{m}$ (calculated with Eq. (B-4)) was used to determine the number of cracks at the temperature of interest. The experimentally determined average stress $\left(\sigma_{m}\right)$ was set equal to the integral of the theoretical stress, including reductions due to shear-lag drops at the crack faces, Figure B-6. 


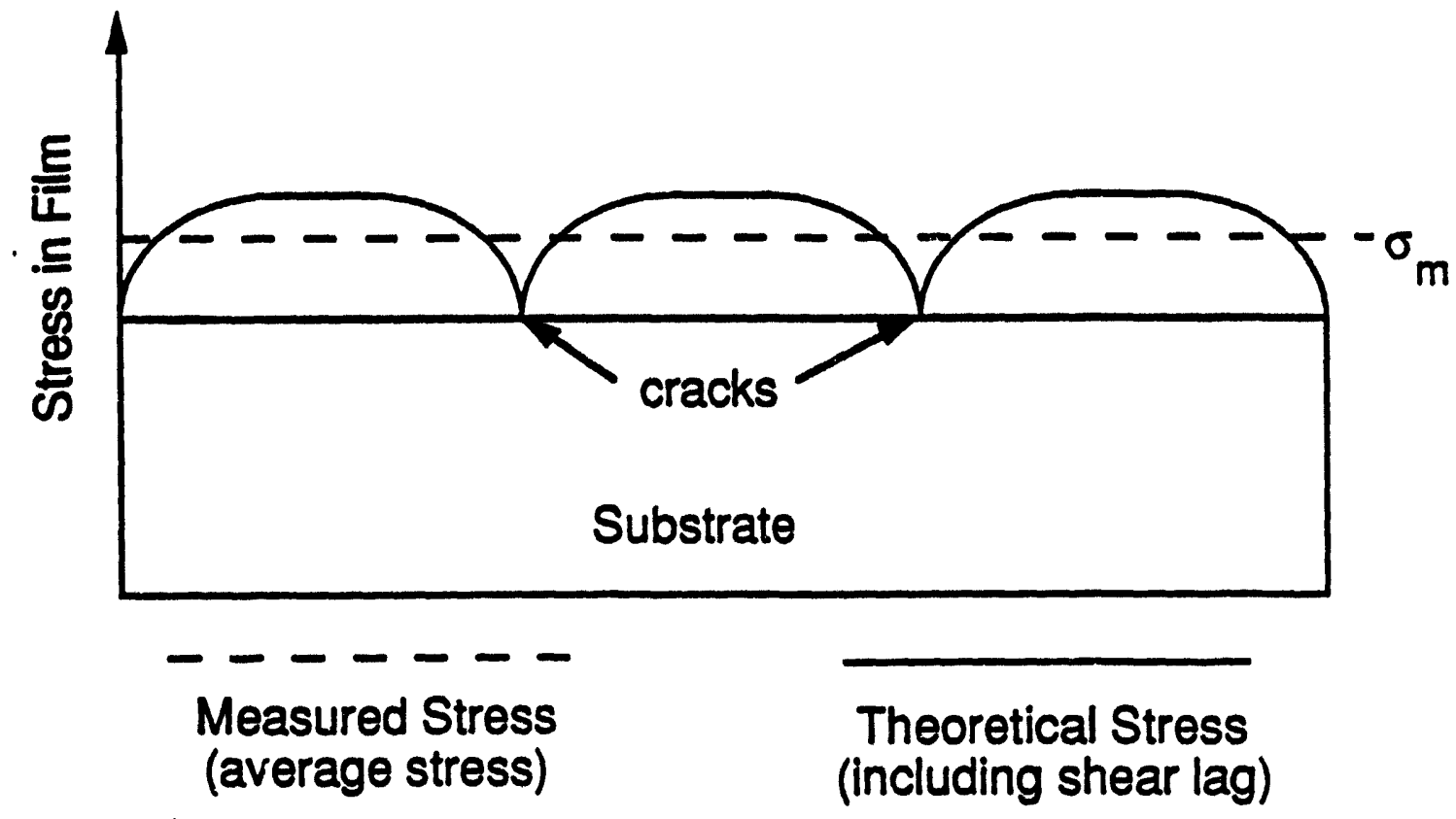

Figure B-6. Plot of theoretical stress in coating and measured stress in coating.

The presence of a crack in a coating caused a drop off in stress near the free edge in accordance with Eq. (B-5). Figure B-7 shows the average stress in a coating as a function of the number of cracks (NC). At a certain crack spacing the stress fields around the cracks begin to interact and the plot of stress versus the number of cracks becomes nonlinear. Equation (B-8) was used to solve for the number of cracks in a coating. The only unknown (NC) was solved for by an iterative procedure.

$$
\sigma_{m}=\frac{2(N C+1)}{L} \int_{0}^{\zeta} \sigma_{p}(\tanh (\beta \zeta) \sinh (\beta x)-\cosh (\beta x)+1) d x
$$

where

$$
\zeta=\frac{L}{2(N C+1)} \text {, }
$$


$\sigma_{m}$ is the measured stress in the cracked coating, $\sigma_{p}$ is the calculated stress in the uncracked coating (from Eq. (B-3)), and $L$ is the total length of the sample. The limits on the integral are determined by the length of the coating between cracks, where that length equals $2 \zeta$. The factor of 2 in Eq. (B-8) arises because the stress distribution in the coating is integrated only over one-half of the distance between cracks due to the symmetry of the problem.

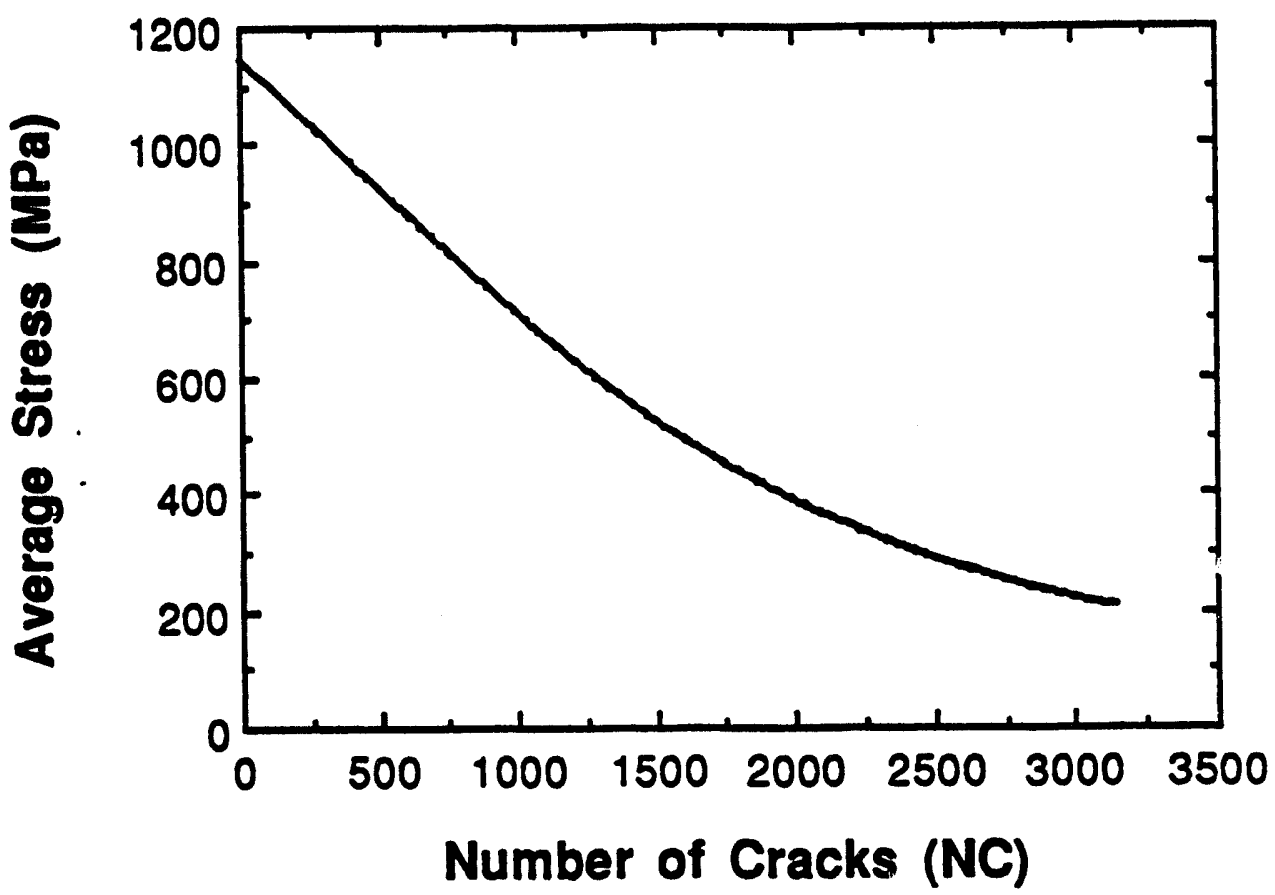

Figure B-7. Plot of number of cracks (NC) versus the average stress in the coating, for a 2.3 microns $\mathrm{Al}_{2} \mathrm{O}_{3}$ coating on SiC, Eq. (B-8).

Once the number of cracks is known the average crack spacing, related to $V_{2}$ in Eq. (B-1), was determined by;

$$
\text { average crack spacing }=2 \zeta=\frac{\mathrm{L}}{\mathrm{NC}+1}
$$


and the volume of the coating that cracked, $V_{b c}$, was given by

$$
V_{b c}=2 \times \text { (average crack spacing) } \times t_{1} \times w
$$

where $t_{1}$ and $w$ were the thickness and width of the coating respectively. The calculations were done for a sample of unit width, i.e. $w=1$.

The Weibull modulus was calculated by rearranging Eq. (B-1) and substituting in the appropriate values resulting in;

$$
\mathrm{m}=\frac{\ln \left(\frac{V_{\mathrm{T} 1}}{V_{\mathrm{T} 2}}\right)}{\ln \left(\frac{\sigma_{\mathrm{T} 2}}{\sigma_{\mathrm{T} 1}}\right)}
$$

The stress values used in Eq. (B-11) are derived from the number of cracks and the shear-lag distribution. The peak value of the shear-lag distribution (Figure B-5) was considered to be the fracture stress of the last segment of coating that cracked.

\section{Determination of Surface Energy - Theory}

\section{Strain Energy Balance}

We preform an energy balance on the cracked and uncracked system. This is summarized in the following equation:

$$
\mathrm{U}_{s}+\mathrm{U}_{\mathrm{c}} \text { (uncracked system) }=\mathrm{U}_{S}+\mathrm{U}_{\mathrm{c}}+2 \mathrm{~L}_{c}(\mathrm{NC}) \gamma \text { (cracked system) }
$$

where $U$ represents an energy component of the system, either the substrate $\left(U_{S}\right)$ or the coating $\left(U_{c}\right)$, and the $2 t_{c}(N C) \gamma$ term represents the surface energy in the system for NC cracks. Each of the components can be described as a function of the radius of curvature of the system (either cracked or 
uncracked), and the material properties of the substrate and coating. The individual components of the energy balance in Eq. (B-12) are derived below. The energy in the substrate depends on the radius of curvature and has the same form for the racked and uncracked cases:

$$
U_{s}=\int_{v} \frac{E_{S}}{2\left(1-v_{s}^{2}\right)} \varepsilon^{2} d v
$$

for a small arc of the substrate of thickness dr:

$$
\mathrm{dU}=\frac{E_{S}}{2\left(1-v_{S}^{2}\right)} \varepsilon^{2}(\mathrm{vol})
$$

where $\varepsilon=\frac{\Delta L}{L}=\frac{(r-R) \theta}{L}$ and vol $=l \mathrm{dr}$ (unit thickness)

where $l$ is the length of the substrate at a radius ' $r$ '. Figure B-8 defines the geometry of the bent substrate. The length of the substrate changes at all values of ' $r$ ' except when $r=N A$ at which $l=L$. Substitution of Eq. (B-15) into Eq. (B-14) gives:

$$
d U=\frac{E_{S}}{2\left(1-v_{S}^{2}\right)} \frac{\Delta L^{2}}{L^{2}} \& d r=\frac{E_{S}}{2\left(1-v_{S}^{2}\right)} \frac{(r \theta-L)^{2}}{L^{2}} r \theta d r
$$

therefore

$$
U_{s}=\int_{u} d U=\int_{R_{\text {inner }}}^{R_{\text {outer }}} \frac{E_{S}}{2\left(1-v_{S}^{2}\right)} \frac{(r \theta-L)^{2}}{L^{2}} r \theta d r
$$




$$
U_{S}=\int_{N A-a}^{N A+b} \frac{E_{S}}{2\left(1-v_{s}^{2}\right)} \frac{(r \theta-L)^{2}}{L^{2}} r \theta d r
$$

where NA is the location of the neutral axis. This was integrated to get:

$$
U_{S}=\frac{E_{s} L_{t}^{3}}{18\left(1-v_{S}^{2}\right) R^{2}} \cdot \frac{5 E_{s} L_{s}^{4}}{216\left(1-v_{S}^{2}\right) R^{3}}
$$

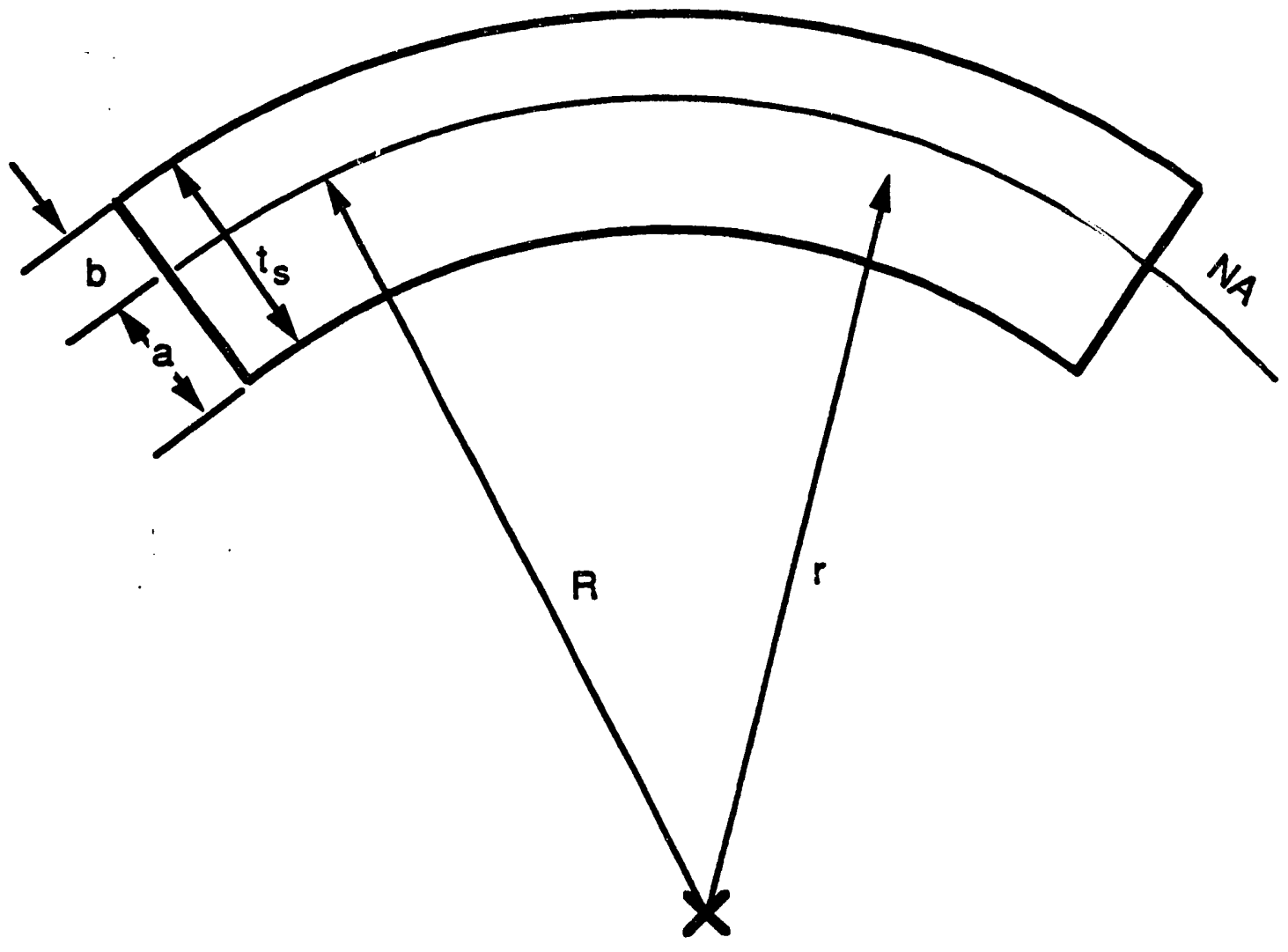

Figure B-8. Schematic of bent substrate. NA is the location of the neutral axis, ' $b$ ' is the distance from the NA to the uncoated side of the substrate, ' $a$ ' is the distance from the coated side to the NA, and ' $r$ ' is the radius to any given location in the substrate. 
The energy of the substrate for the uncracked and cracked system is given by Eq. (B-19) with $R$ equal to the radius of curvature of the uncracked and cracked coated sample, respectively.

The energy in the coating depends on the radius of curvature and has the same form for the cracked and uncracked cases:

$$
U_{c}=\int_{v} \frac{E_{c}}{2\left(1-v_{c}^{2}\right)} e^{2} d v
$$

since the strain is essentially constant through the thickness of a thin film, the integral over the volume equais $v_{c}$ (volume of the coating); Eq. (B-20) reduces to:

$$
\mathrm{U}_{\mathrm{c}}=\frac{\mathrm{E}_{\mathrm{c}}}{2\left(1-v_{\mathrm{c}}^{2}\right)} \varepsilon^{2} \mathrm{v}_{\mathrm{c}}
$$

from the geometry of a bent beam:

$$
\varepsilon_{c}=\frac{\Delta L}{L}=-\frac{2 \theta}{L} \quad \text { and } \quad v_{c}=(L-a \theta) t_{c} \quad \text { (for unit width) }
$$

Substituting Eq. (B-22) into Eq. (B-21) gives:

$$
U_{c}=\frac{E_{c}}{2\left(1-v_{c}^{2}\right)} \frac{(a \theta)^{2}}{L^{2}}(L-a \theta) t_{c}
$$

Setting $\theta=\frac{L}{R}$ and $a=\frac{2 t_{S}}{3}$, gives:

$$
U_{c}=\frac{2 E_{c t_{c} t_{s}^{2}}\left(L-\frac{2}{3} \frac{L_{t}}{R}\right)}{9\left(1-v_{c}^{2}\right) R^{2}}
$$


This applies to both cracked and uncracked cases, with the appropriate radius of curvature. For the cracked case, the stress distribution is not uniform (as it is in the uncracked case), but the energy stored in all of the cracked segments of the coating is the same as the energy given by Eq. (B-24) using the cracked radius of curvature.

Once the energies of the substrate and coating are determined for the uncracked and cracked cases, the surface energy can be solved for by rearranging Eq. (B-12).

$$
\gamma=\frac{\left\{U_{S}+U_{c}(\text { uncracked system })\right\}-\left\{U_{S}+U_{c}(\text { cracked system })\right\}}{2 L_{c} N C}
$$

where $U_{s}$ and $U_{c}$ are given by Eqs. (B-19) and (B-24), respectively, using the uncracked and cracked radius of curvature.

\section{Griffith Energy Balance}

Lawn and Wilshaw [LAW75] describe the relationship between the surface energy $(\gamma)$ and fracture toughness $\left(K_{c}\right)$ of a material derived from Griffith theory and fracture mechanics. Equation (B-26) below describes this relationship;

$$
\gamma=\frac{\left(1-v_{c}^{2}\right) K_{c}^{2}}{2 E_{c}}
$$

\section{EXPERIMENTAL DETAILS}

\section{Coating Procedure}

Samples were coated in a hot-wall CVD reactor made of either graphite or Inconel. Coatings of $\mathrm{Al}_{2} \mathrm{O}_{3}$ and $\mathrm{Al}_{2} \mathrm{O}_{3}+\mathrm{ZrO}_{2}$ were deposited at $950^{\circ} \mathrm{C}$, while TiN coatings were deposited at $970^{\circ} \mathrm{C}$. Metal chlorides, along with other reactant gases were used to deposit the coatings; $\mathrm{Al}_{2} \mathrm{O}_{3}\left(\mathrm{AlCl}_{3}, \mathrm{CO}_{2}, \mathrm{H}_{2}\right.$, and $\mathrm{Ar}$ ), $\mathrm{Al}_{2} \mathrm{O}_{3}+\mathrm{ZrO}_{2}\left(\mathrm{AlCl}_{3}, \mathrm{ZrCl}_{4}, \mathrm{CO}_{2}, \mathrm{H}_{2}\right.$, and $\mathrm{Ar}$ ), and $\mathrm{TiN}\left(\mathrm{TiCl}_{4}, \mathrm{~N}_{2}, \mathrm{H}_{2}\right.$, and $\mathrm{Ar}$ ). The 
$\mathrm{Al}_{2} \mathrm{O}_{3}$ and $\mathrm{Al}_{2} \mathrm{O}_{3}+\mathrm{ZrO}_{2}$ coatings were deposited at low pressures (1.33 $\mathrm{Pa}$ ), while TiN was deposited at atmospheric pressure. $\mathrm{AlCl}_{3}$ and $\mathrm{ZrCl}_{4}$ were generated by passing $\mathrm{Cl}_{2}$ and $\mathrm{H}_{2}$ over the metals held at $\sim 600^{\circ} \mathrm{C}$, while $\mathrm{TiCl}_{4}$.was produced in a bubbler. Deposition of TiN required 1 hour while the $\mathrm{Al}_{2} \mathrm{O}_{3}$ and $\mathrm{Al}_{2} \mathrm{O}_{3}+5 \mathrm{v} / \mathrm{O}$ $\mathrm{ZrO}_{2}$ depositions required 2 - 3 hours.

\section{Residual Stress Measurements}

The stress in a coating was measured from the radius of curvature of the coated substrate using Eq. (B-4). Thin substrates of silicon nitride and silicon carbide (nominally $25.4 \mathrm{~mm} \times 2.54 \mathrm{~mm} \times 0.175 \mathrm{~mm}$ ) were polished to a 0.1 micron surface finish and annealed at $-1200^{\circ} \mathrm{C}$ in vacuum $\left(10^{-2} \mathrm{~Pa}\right.$ at temperature) for one hour to relieve stresses induced during preparation.

Figures B-9 and B-10 show flow charts of the experimental procedure. The radius of curvature (ROC) of the sample was measured with a laser profilometer, and the measured shape was fitted to the equation of a circle to determine the ROC (see Appendix C). The ROC of the uncoated sample ( $\rho_{u c}$ ) was measured at room temperature $\left(20^{\circ} \mathrm{C}\right)$, then one side was coated and the ROC of the coated $\left(p_{\mathrm{c}}\right)$ substrate was measured at $20^{\circ} \mathrm{C}$. These values were used in Eq. $(B-4)$ to calculate $\sigma_{m}$ at $20^{\circ} \mathrm{C}$ for the cracked coating with the number of cracks at $20^{\circ} \mathrm{C}$. The coated substrate was then cooled in liquid nitrogen $\left(-160^{\circ} \mathrm{C}\right)$ then warmed to $20^{\circ} \mathrm{C}$ and the ROC was measured. This value along with the ROC of the uncoated substrate were used in Eq. $(B-4)$ to calculate $\sigma_{m}$ at $20^{\circ} \mathrm{C}$ in the cracked coating with the number of cracks at $-160^{\circ} \mathrm{C}$. Room temperature elastic constants used in these calculations and are listed in Table B-1 and the thermal expansion data are plotted in Figure B-11. 


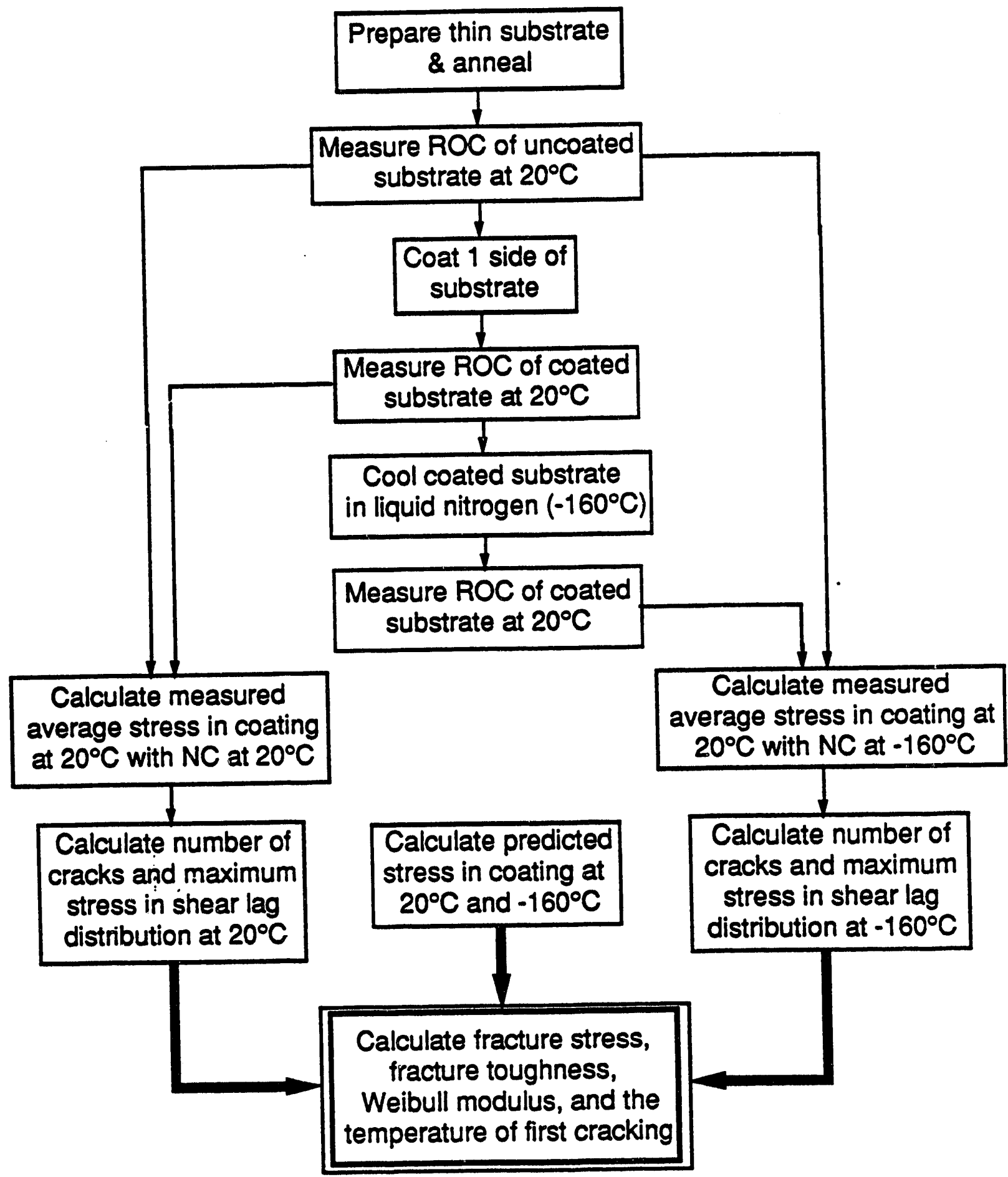

Figure B-9. Flow chart of experimental procedure outlining important steps in the force balance used to calculate the fracture strength, fracture toughness, Weibull modulus, and temperature of first : craciking of thin coatings on substrates. 


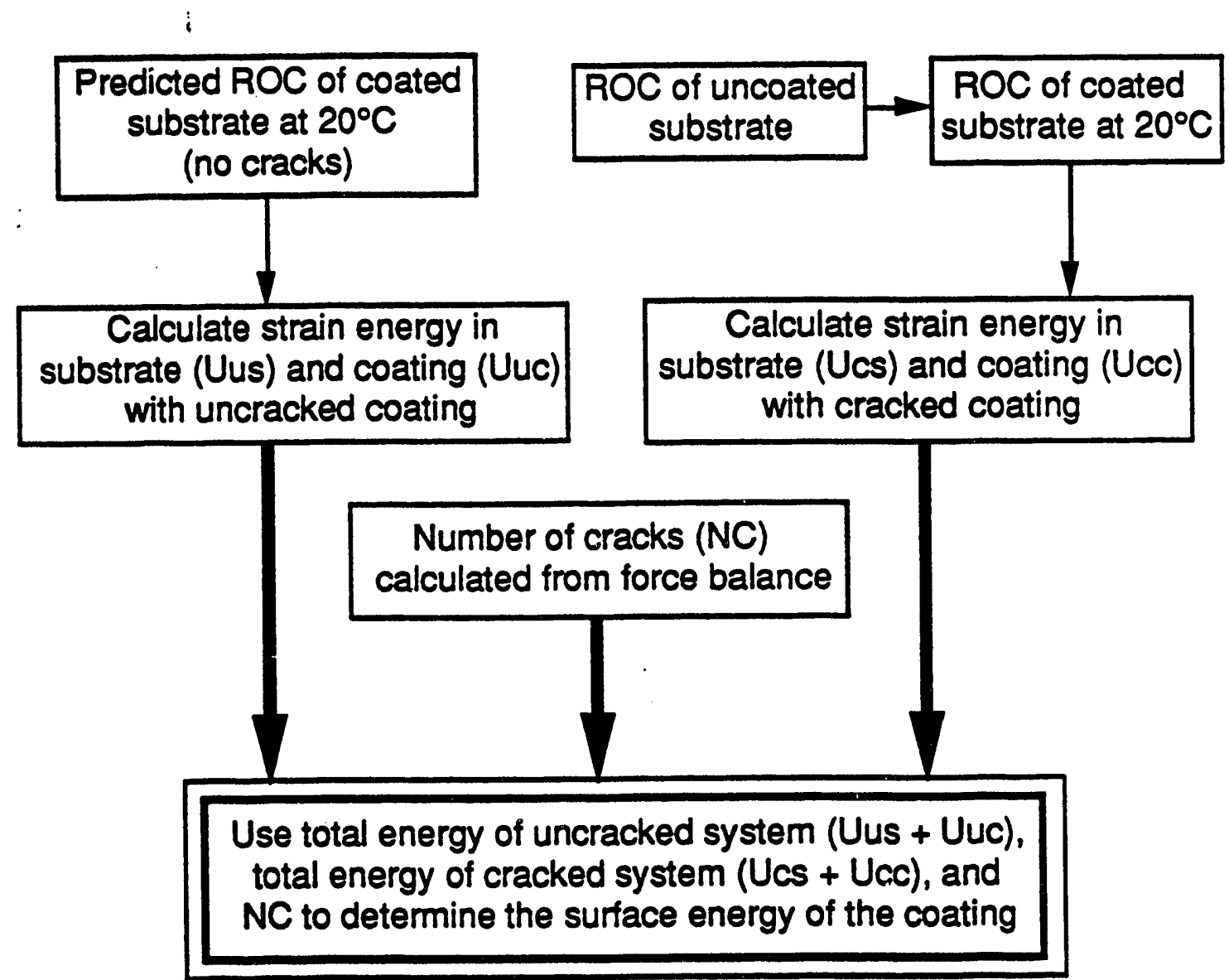

Figure B-10. Flow chart of experimental procedure outlining important steps in the energy balance used to calculate the surface energy of thin coatings on substrates. 
Table B-1. Material elastic constants used in calculations.

\begin{tabular}{|l|c|c|c|}
\hline Material & $\begin{array}{c}\text { Young's Modulus, } \\
\text { E (GPa) }\end{array}$ & $\begin{array}{c}\text { Poisson's Ratio, v } \\
\end{array}$ & $\begin{array}{l}\text { Shear Modulus, } \\
\mathrm{G}=\frac{\mathrm{E}}{2(1-\mathrm{v})}(\mathrm{GPa})\end{array}$ \\
\hline & 380 & & \\
$\mathrm{Al}_{2} \mathrm{O}_{3}$ & 340 & 0.26 & 257 \\
$\mathrm{Al}_{2} \mathrm{O}_{3}+5 \mathrm{v} / 0 \mathrm{ZrO}_{2}$ & 405 & 0.26 & 135 \\
$\mathrm{SiC}$ & 300 & 0.19 & 250 \\
$\mathrm{Si}{ }_{3} N_{4}$ & 0.23 & 195 \\
$\mathrm{TiN}$ & $300-600$ [TOR87] & 0.23 & 167 \\
\hline
\end{tabular}

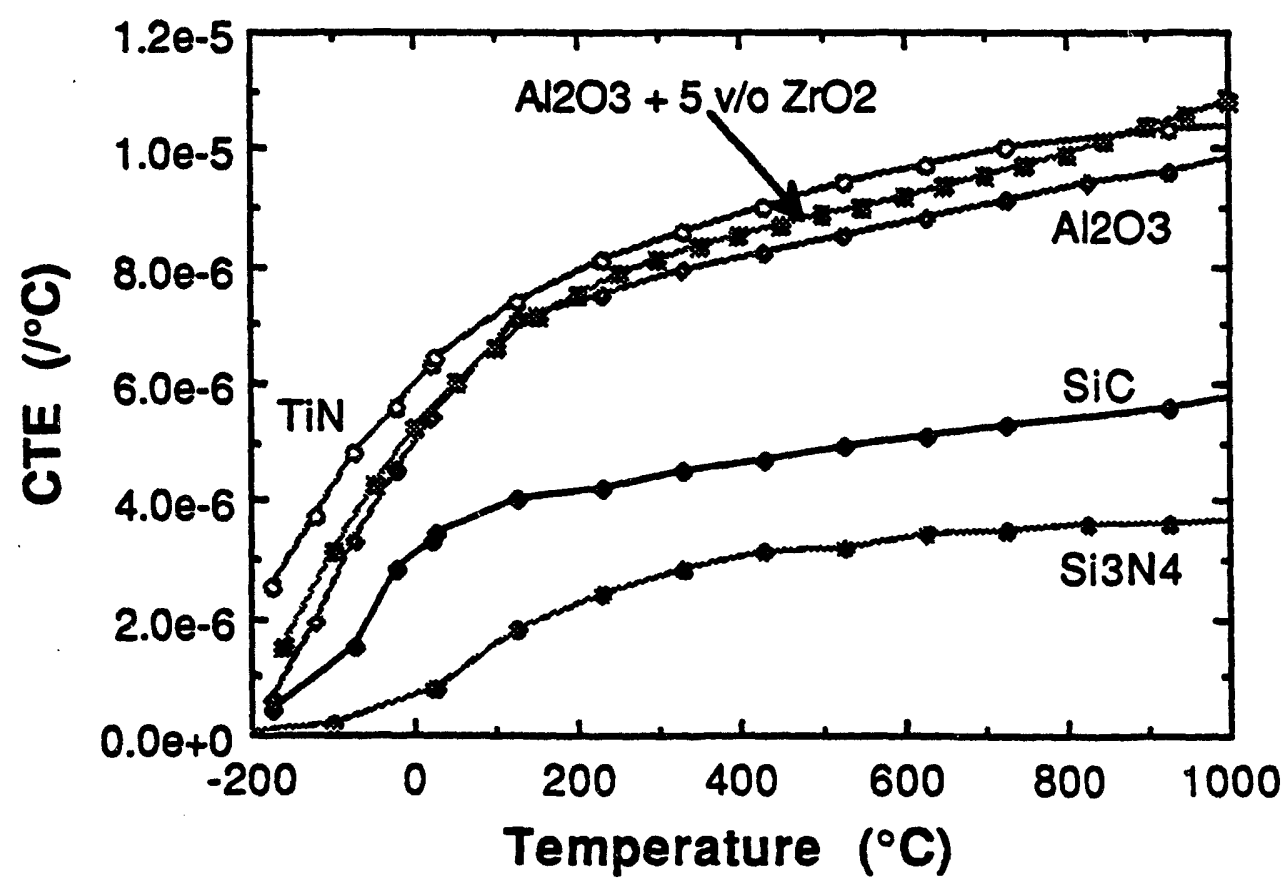

Figure B-11. Plot of the coefficients of thermal expansion for materials used in this study [TOU75]. Data for the $\mathrm{Al}_{2} \mathrm{O}_{3}+5 \mathrm{v} / 0$ $2 \mathrm{rO} \mathrm{O}_{2}$ coating is from the volume weighted average of $\mathrm{Al}_{2} \mathrm{O}_{3}$ and $\mathrm{ZrO}_{2}$. Data for $\mathrm{Si}_{3} \mathrm{~N}_{4}$ at temperatures below $20^{\circ} \mathrm{C}$ was extrapolated. 


\section{RESULTS}

The data used in the calculations and results of these calculations are listed in Tables B-2 and B-3, respectively. A sample with a 2.34 microns $\mathrm{Al}_{2} \mathrm{O}_{3}$ coating deposited at $950^{\circ} \mathrm{C}$ on $\mathrm{SiC}$ in a reactor with a graphite chamber is used as an example to demonstrate these calculations. To determine the ROC, 2000 data points were collected and fit to the equation of a circle. Once the ROC was measured, Eq. (B-4) was used to determine the stress in the coating. The average stress in the coating at $20^{\circ} \mathrm{C}$ and at $20^{\circ} \mathrm{C}$ after cooling to $-160^{\circ} \mathrm{C}$ was given by Eq. (B-12) and Eq. (B-13), respectively. Note that the stress at $20^{\circ} \mathrm{C}$ was lower in the sample that was first cooled to $-160^{\circ} \mathrm{C}$.

$\sigma\left(20^{\circ} \mathrm{C}\right)=\frac{405 \mathrm{GPa}\left(217 \times 10^{-6} \mathrm{~m}\right)^{2}}{6\left(2.34 \times 10^{-6} \mathrm{~m}\right)\left(1-(0.19)^{2}\right)}\left(\frac{1}{4.7676 \mathrm{~m}}-\frac{1}{15.525 \mathrm{~m}}\right)=203 \mathrm{MPa}$

$\sigma\left(20^{\circ} \mathrm{C},-160^{\circ} \mathrm{C}\right)=\frac{405 \mathrm{GPa}\left(217 \times 10^{-6} \mathrm{~m}\right)^{2}}{6\left(2.34 \times 10^{-6} \mathrm{~m}\right)\left(1-(0.19\}^{2}\right)}\left(\frac{1}{4.9232 \mathrm{~m}} \cdot \frac{1}{15.525 \mathrm{~m}}\right)=193 \mathrm{MPa}$

W:th the average stress in the coating known $\left(\sigma_{m}\right)$, the predicted stress $\left(\sigma_{p}\right)$ in the coating as a function of temperature (below the deposition temperature) was calculated from Eq. (B-3). In calculating the predicted stress, a deposition temperature of $950^{\circ} \mathrm{C}$ and final temperatures of $20^{\circ} \mathrm{C}$ and $-160^{\circ} \mathrm{C}$ were used. $\sigma_{m}$ and $\sigma_{p}$ were then used in Eq. (B-8) to solve for the number of cracks at $20^{\circ} \mathrm{C}$ and $-160^{\circ} \mathrm{C}$. The number of cracks in the sample at $-160^{\circ} \mathrm{C}$ was determined using the sample that was cooled to $-160^{\circ} \mathrm{C}$ and measured at $20^{\circ} \mathrm{C}$.

For the coated substrate at $20^{\circ} \mathrm{C}, \sigma_{\mathrm{p}}=1146 \mathrm{MPa}$ and $\sigma_{\mathrm{m}}=203 \mathrm{MPa}$. These values were used in Eq. (B-8) to solve for NC, the crack spacing, and the maximum stress in the shear-lag distribution. For the sample cooled to $-160^{\circ} \mathrm{C}$ and measured at $20^{\circ} \mathrm{C}$; NC was solved for by using $\sigma_{p}=1146 \mathrm{MPa}$ and $\sigma_{m}=193 \mathrm{MPa}$ in Eq. (B-8). Crack spacings of 6.28 microns at $20^{\circ} \mathrm{C}$ and of 6.10 microns at $-160^{\circ} \mathrm{C}$ were calculated, corresponding to stressed volumes of $2.94 \times 10^{-11} \mathrm{~m}^{3}$ and $2.85 \times 10^{-11} \mathrm{~m}^{3}$ for a unit width substrate, respectively. 
Once the number of cracks and the crack spacing were known at $-160^{\circ} \mathrm{C}$, the maximum stress in the shear-lag distribution was solved for using $\sigma_{p}=1262 \mathrm{MPa}$ (the predicted stress at $-160^{\circ} \mathrm{C}$ ) in Eq. (B-5). At $20^{\circ} \mathrm{C}$ the maximum stress was $301 \mathrm{MPa}$ and at $-160^{\circ} \mathrm{C}$ the maximum stress was $316 \mathrm{MPa}$, these values were defined as the fracture stress of the coating at $20^{\circ} \mathrm{C}$ and $-160^{\circ} \mathrm{C}$ for NC cracks. The predicted stress as a function of $\Delta \mathrm{T}$ is plotted along with the calculated/measured maximum stresses at $20^{\circ} \mathrm{C}$ and $-160^{\circ} \mathrm{C}$ in Figure B-12. The intersection of these lines in Figure B-12 was taken as the fracture stress, $240 \mathrm{MPa}$. The fracture stress was the value of stress in the coating at which first fracture occurred. This value appears reasonable compared to reported values of bulk $\mathrm{Al}_{2} \mathrm{O}_{3}$ which are in the range of 100 - $300 \mathrm{MPa}$, Table B-4.

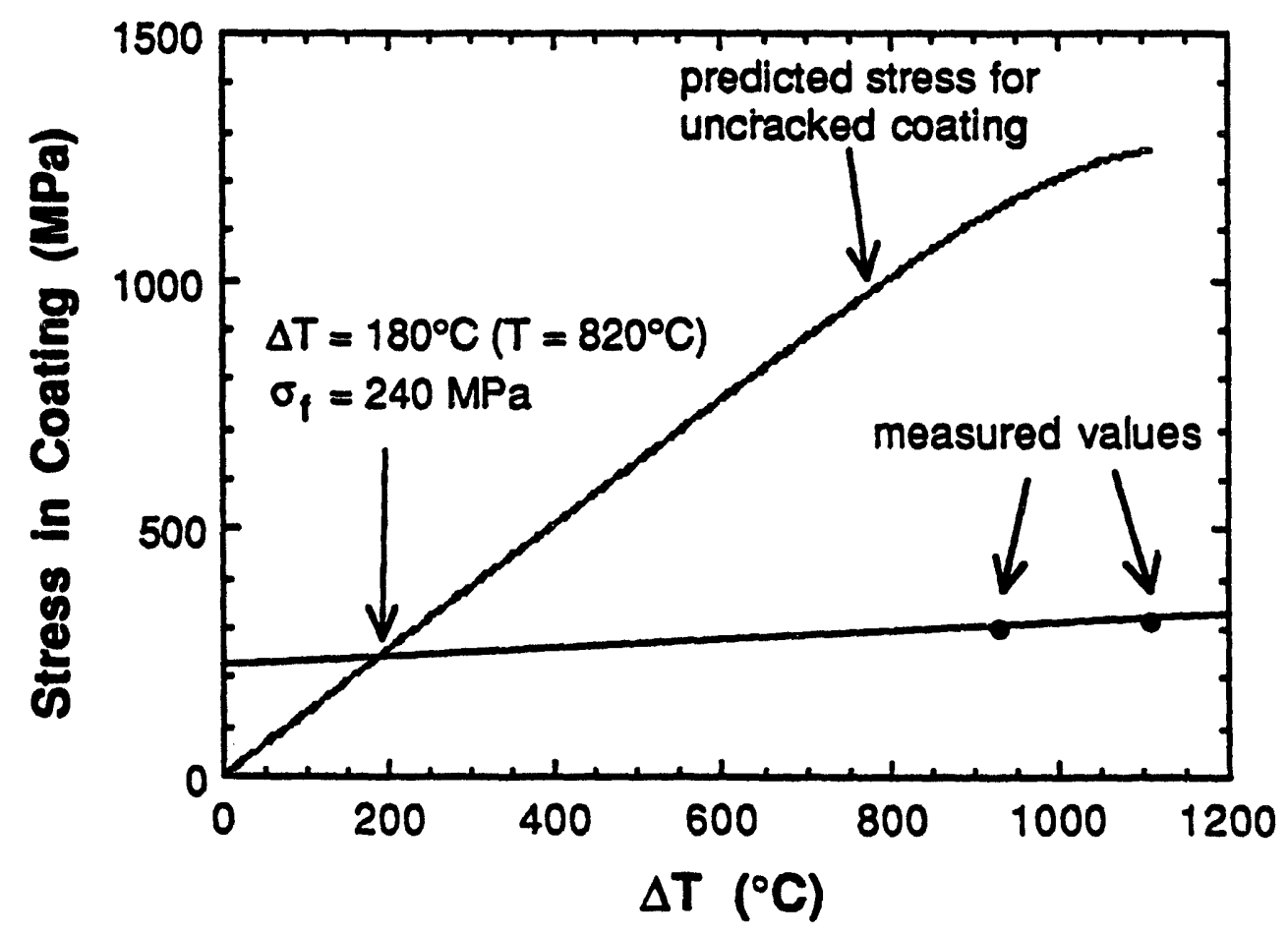

Figure B-12. Plot of stress versus $\Delta \mathrm{T}$ for a 2.34 microns $\mathrm{Al}_{2} \mathrm{O}_{3}$ coating on $\mathrm{SiC}$. The predicted stress was calculated from Eq. (B-3) and the measured maximum stress $\left(^{\bullet}\right)$ was calculated from Eqs. (B-5) and (B-8). 


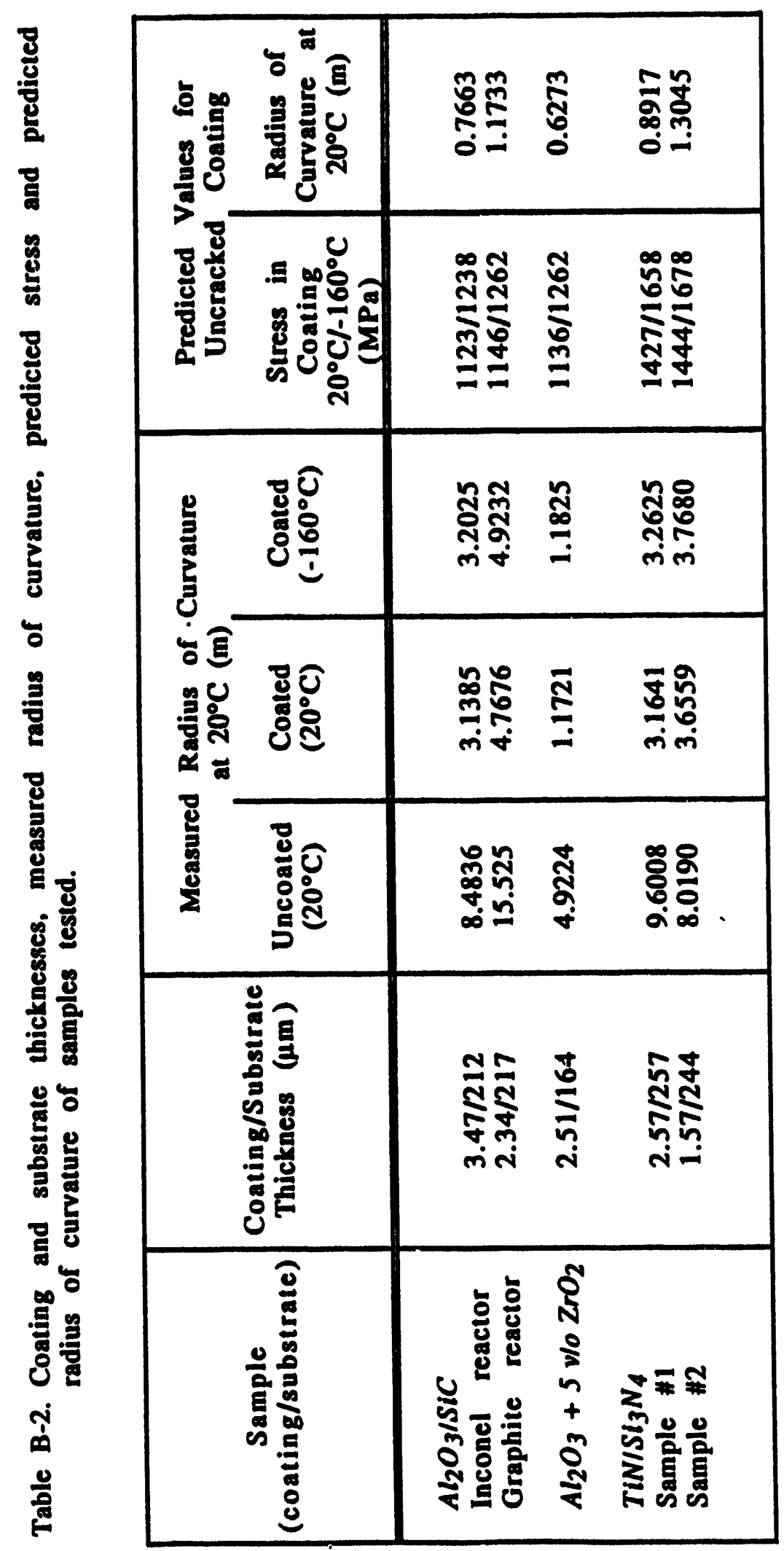




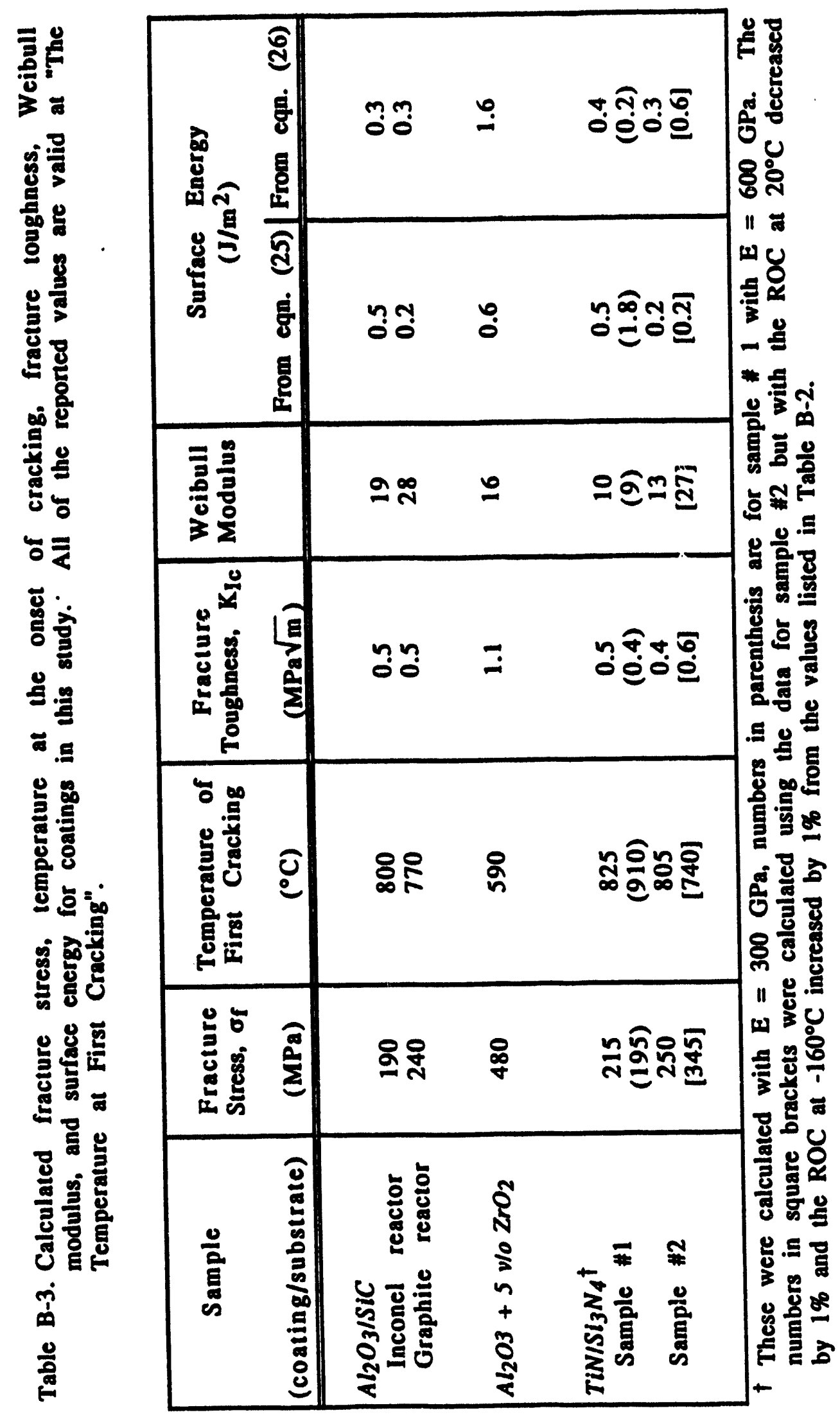


Table B-4. Fracture toughness, tensile strength, and surface energy of bulk ceramics from the literature.

\begin{tabular}{|l|c|c|c|}
\hline Material & $\begin{array}{c}\text { Fracture } \\
\text { Toughness } \\
\mathrm{K}_{\mathrm{Ic}(\mathrm{MPa} \sqrt{\mathrm{m}})} \\
{[\mathrm{CS} 91, \mathrm{CHE} 78]}\end{array}$ & $\begin{array}{c}\text { Tensile Fracture } \\
\text { Strength } \\
\text { of (MPa) } \\
\text { [CS91,KAT83] }\end{array}$ & $\begin{array}{c}\text { Surface Energy } \\
\gamma\left(\mathrm{J} / \mathrm{m}^{2}\right) \\
\text { [LIV56] }\end{array}$ \\
\hline $\mathrm{Al}_{2} \mathrm{O}_{3}$ & 4 & $100-300$ & 0.9 \\
$\mathrm{Al}_{2} \mathrm{O}_{3}+5 \mathrm{v} / 0 \mathrm{ZrO}_{2}$ & $55^{\dagger}$ & $250^{\dagger}$ & $0.9^{* *}$ \\
$\mathrm{TiN}$ & $3.8^{*}$ & $300^{*}+t$ & $1.2^{*}$ \\
\hline
\end{tabular}

t this value includes effects of transformation toughening which is not expected to play a role in coatings.

\# values estimated with Eqs. (B-32) and (B-33).

* values taken to be the same as TiC.

* value form the volume weighted average of $\mathrm{Al}_{2} \mathrm{O}_{3}$ and $\mathrm{ZrO}_{2}$.

The fracture stress was used with the maximum stresses at $20^{\circ} \mathrm{C}$ and $-160^{\circ} \mathrm{C}$ along with the associated volumes to calculate the Weibull modulus of the coating according to Eq. (B-11). The average Weibull modulus for this coating is 29. These calculations are shown in Egs. (B-29) and (B-30).

$$
\mathrm{m}=\frac{\ln \left(\frac{4.68 \times 10^{-8} \mathrm{~m}^{3}}{2.94 \times 10^{-11} \mathrm{~m}^{3}}\right)}{\ln \left(\frac{301 \mathrm{MPa}}{240 \mathrm{MPa}}\right)}=32
$$




$$
m=\frac{\ln \left(\frac{4.68 \times 10^{-8} \mathrm{~m}^{3}}{2.85 \times 10^{-11} \mathrm{~m}^{3}}\right)}{\ln \left(\frac{316 \mathrm{MPa}}{240 \mathrm{MPa}}\right)}=27
$$

A relationship by Thouless [THO90] was used to calculate the mode I fracture toughness of the coating.

$$
\mathrm{K}_{I_{c}}=\frac{\sigma \sqrt{t_{1}}}{0.7}
$$

where $\sigma$ was the fracture stress of the coating, taken as $\sigma_{f}$. Taking $\sigma_{f}$ as $240 \mathrm{MPa}$, the fracture toughness is $0.5 \mathrm{MPa} \sqrt{\mathrm{m}}$. In calculating $\mathrm{K}_{\mathrm{Ic}}$ of the coating, the largest error arises from the uncertainty in the stressed volumes. The accuracy of these volumes depends on NC and the accuracy of the shearlag distribution, Eq. (B-5). This same analysis was repeated for each sample and the results are summarized in Tables B-2 and B-3.

\section{Discussion}

\section{Ceating Properties}

Two $\mathrm{Al}_{2} \mathrm{O}_{3}$ coatings, with significantly different surface morphologies, were deposited at $950^{\circ} \mathrm{C}$ on $\mathrm{SiC}$ substrates for comparison. One coating was deposited in a hot wall reactor with an Inconel chamber, Figure $\mathrm{B}-13 \mathrm{a} . \mathrm{Al}_{2} \mathrm{O}_{3}$ coatings deposited in this reactor were known to be contaminated with nickel which caused the textured morphology, Figure B-13a. A second $\mathrm{Al}_{2} \mathrm{O}_{3}$ coating was deposited in a hot wall reactor with a graphite chamber, Figure B-13b, producing a more compact and uniform coating as compared to that deposited in the Inconel reactor. 


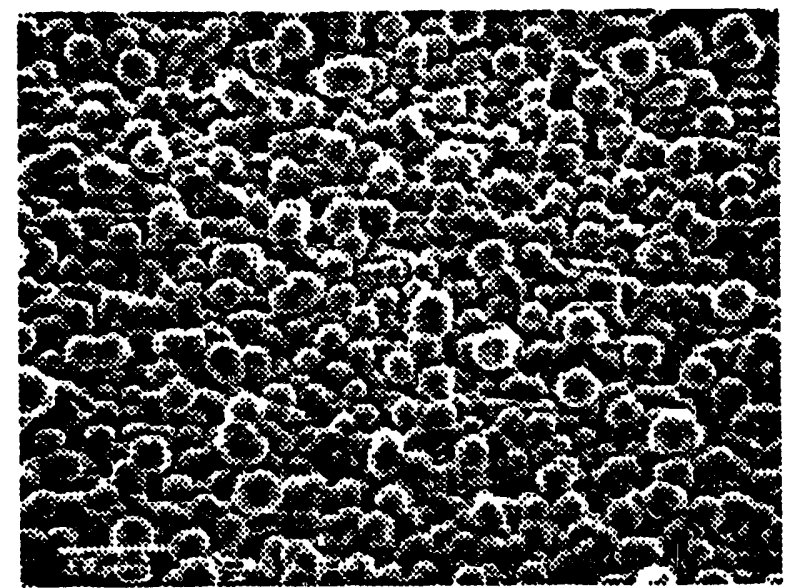

(a)

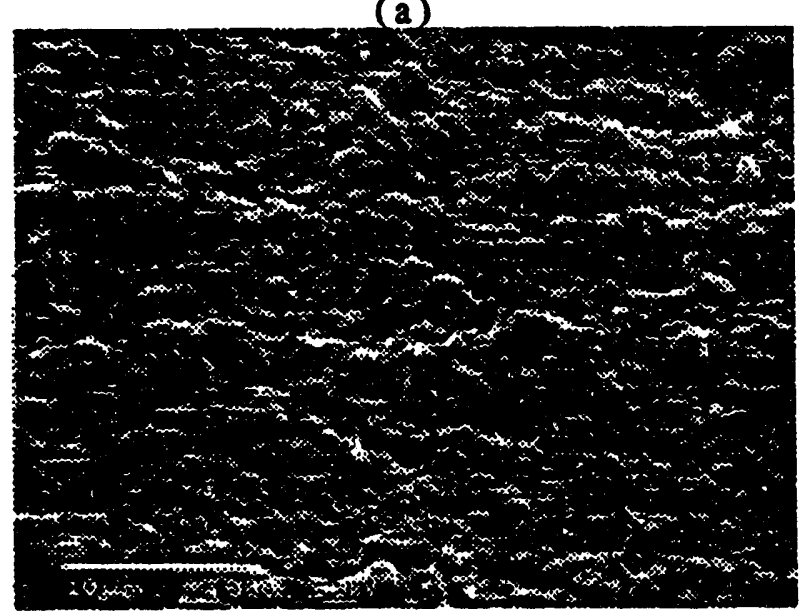

(b)

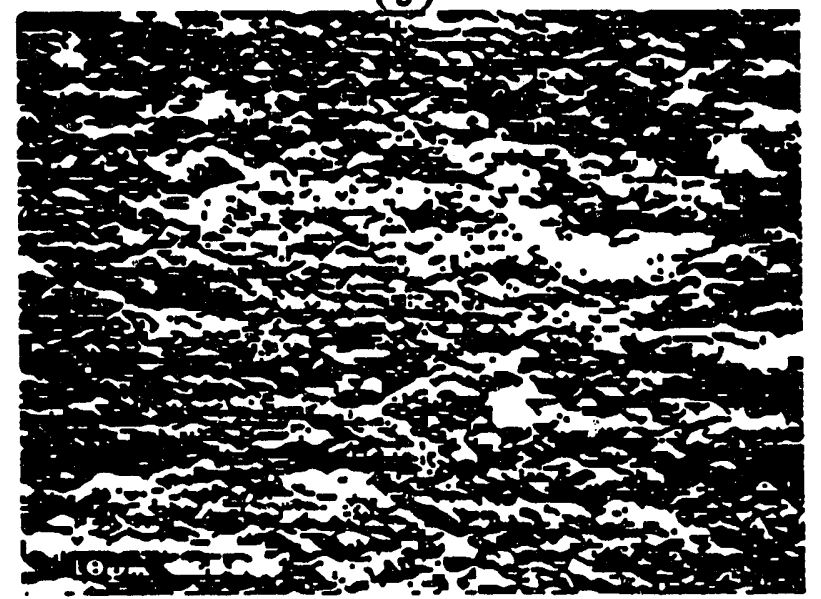

(c)

Figure B-13. Scanning electron micrograph of the coatings deposited on a SiC substrate at $950^{\circ} \mathrm{C}$ in a) $\mathrm{Al}_{2} \mathrm{O}_{3}$ deposited in an Inconel chamber, b) $\mathrm{Al}_{2} \mathrm{O}_{3}$ deposited in a graphite chamber, and c) $\mathrm{Al}_{2} \mathrm{O}_{3}+5 \mathrm{v} / 0$ $\mathrm{ZrO}_{2}$ deposited in a graphite chamber. 
The coating in Figure B-13a was expected to have lower mechanical properties than the coating in Figure B-13b. The textured structure of the coating in Figure B-13a was expected to allow easier crack propagation compared to the uniform structure of the coating (Figure B-13b). Therefore, the coating in Figure B-13a was expected to have lower strength and toughness as compared to the coating in Figure B-13b. These properties were measured and reported in Table B-3. The coating in Figure B-13a had a fracture strength of $190 \mathrm{MPa}$, a fracture toughness of $0.5 \mathrm{MPa} \sqrt{\mathrm{m}}$, and a Weibull modulus of 19, the coating in Figure B-13b had a fracture strength of $240 \mathrm{MPa}$, a fracture toughness of $0.5 \mathrm{MPa} \sqrt{\mathrm{m}}$, and a Weibull modulus of 28 . While the difference in properties between these coatings was anticipated due to their different morphologies, the method described in this work allowed the expected differences to be quantified. It should be noted that the fracture strength and fracture toughness values reported in this study are not room temperature values, but the values at the temperature of first cracking, $800^{\circ} \mathrm{C}$ and $770^{\circ} \mathrm{C}$ for the coatings in Figures B-13a and B-13b respectively.

Figure $\mathrm{B}-13 \mathrm{C}$ shows the surface morphology of the $\mathrm{Al}_{2} \mathrm{O}_{3}+5$ v/o $\mathrm{ZrO}_{2}$ coating on a $\mathrm{SiC}$ substrate deposited in the graphite reactor. This coating has a smoother surface morphology than the pure $\mathrm{Al}_{2} \mathrm{O}_{3}$ coating (Figure $\mathrm{B}-13 \mathrm{~b}$ ). The $\mathrm{Al}_{2} \mathrm{O}_{3}+5$ v/o $\mathrm{ZrO}_{2}$ coating had a fracture strength of $480 \mathrm{MPa}$, a fracture toughness of $1.1 \mathrm{MPa} \sqrt{\mathrm{m}}$, and a Weibull modulus of 16 . The higher strength and toughness of the $\mathrm{Al}_{2} \mathrm{O}_{3}+5 \mathrm{v} / 0 \mathrm{ZrO}_{2}$ coating is primarily attributed to grain refinement of the $\mathrm{Al}_{2} \mathrm{O}_{3}$ by the $\mathrm{ZrO}_{2}$ phase.

Table B-4 lists tensile strength, fracture toughness, and surface energy values from bulk ceramics reported in the literature. Equations (B-32) and (B-33) were used to estimate tensile strength values from 3-pt and 4-pt bending tests [DAV80], since limited tensile strength data was available for ceramics in the literature.

$$
\begin{aligned}
& \sigma_{t}=\frac{\sigma_{3 b}}{1.7} \\
& \sigma_{t}=\frac{\sigma_{4 b}}{1.5}
\end{aligned}
$$


where the Weibull modulus from the 3-pt and 4-pt bend tests was assumed to be $10 ; \sigma_{t}$ was the tensile strength, $\sigma_{3 b}$ is the 3-pt bend strength, and $\sigma_{4} \mathrm{~b}$ is the 4-pt bend strength. The strengths of the $\mathrm{Al}_{2} \mathrm{O}_{3}$ and $\mathrm{TiN}$ coatings are generally higher than those expected for the bulk solid.

The fracture toughness of the $\mathrm{Al}_{2} \mathrm{O}_{3}$ and $\mathrm{TiN}$ coatings are generally lower that the bulk values. The coatings in this study have submicron grain sizes and large grain boundary area, therefore, cracking is expected to occur along the grain boundaries.

The grain boundary fracture toughness for a sintered $\mathrm{Al}_{2} \mathrm{O}_{3}+0.3$ vol \% $\mathrm{MgO}$ was reported as $0.32 \cdot 0.98 \mathrm{MPa} \sqrt{\mathrm{m}}$, which was $0.1 \cdot 0.4$ of the bulk fracture toughness [KRE85]. this agrees well with the value of $0.5 \mathrm{MPa} \sqrt{\mathrm{m}}$ (Table B-3). Further comparisons are made on the basis of grain boundary fracture toughness, defined as 0.1-0.4 of the bulk fracture toughness. The calculated fracture toughness value of a TiN coating on $\mathrm{Si}_{3} \mathrm{~N}_{4} \quad(0.5 \mathrm{MPa} \sqrt{\mathrm{m}}$ in Table B-3) also compares well with the estimated grain boundary fracture toughness of bulk TiN, $0.4-1.5 \mathrm{MPa} \sqrt{\mathrm{m}}$. Therefore, the properties used to describe coatings should be grain boundary properties when available.

The surface energy of the coatings were determined by two methods described. in the introduction section, a strain energy balance, Eq. (B-25), and a Griffith energy balance, Eq. (B-26). The surface energies calculated with Eq. (B-25) are lower than those in Table B-4 from Livey and Murray [LIV56]. This is attributed to the value of NC used in Eq. (B-25). The crack spacing in the $\mathrm{Al}_{2} \mathrm{O}_{3}$ coating was calculated to be approximately 6 microns. As the degree of shear-lag increases NC decreases and $\gamma$ increases. The other properties of the coating depend on NC to a much lesser extent then $\gamma$ and are not significantly effected when NC changes. The surface energies calculated with Eq. (B-26) are also significantly different from those listed in Table B-4. This may be due to the cracking process not being at equilibrium, as suggested by Lawn and Wilshaw [LAW75]. In general, the present method does not allow for accurate values of the surface energy to be determined. However, a more rigorous form of the shear-lag distribution may give better agreemeni between measured and expected surface energies.

We attempted to measure the crack spacing directly as a check on the calculated value of NC but could only find isolated cracks which were 
extremely fine. The crack opening was estimated for the $\mathrm{Al}_{2} \mathrm{O}_{3}+\mathrm{ZrO}_{2}$ coating on $\mathrm{SiC}$ as follows:

$$
\text { crack opening }=\frac{\left(\varepsilon_{s}-\varepsilon_{c}\right) L}{N C}
$$

where $\varepsilon_{s}$ is the strain in the substrate due to the temperature change (from Eq. (B-2)) and $\varepsilon_{c}$ is the strain in the coating due to the measured stress $\left(\sigma_{m}\right)$.

$$
\text { crack opening }=\frac{\left(3.6 \times 10^{-3}-\frac{480 \mathrm{MPa}}{340 \mathrm{GPa}}\right) 0.0254 \mathrm{~m}}{1527}=3.6 \times 10^{-8} \mathrm{~m}
$$

The crack is expected to be approximately 36 nanometers wide which is 0.7 $\mathrm{mm}$ wide on a micrograph taken at a magnification of $20,000 \mathrm{x}$. This indicates the difficulty in observing and photographing such a small feature on the relatively rough surfaces of the coatings studied.

\section{Limitations on Modeling and Experimental Data}

Young's modulus for TiN was reported to range from $300-600 \mathrm{GPa}$. Both values ( 300 and $600 \mathrm{GPa}$ ) were used with the experimental data from TiN coated $\mathrm{Si}_{3} \mathrm{~N}_{4}$ sample \#1 to determine the sensitivity of the analysis to uncertainty in the Young's modulus of the coating material. The calculated values of the fracture strength, fracture toughness, and Weibull modulus are $215 \mathrm{MPa}, 0.5 \mathrm{MPa} \sqrt{\mathrm{m}}$, and 10 for a Young's modulus of $300 \mathrm{GPa}$ and $195 \mathrm{MPa}, 0.4$ $\mathrm{MPa} \sqrt{\mathrm{m}}$, and 9 for a Young's modulus of $600 \mathrm{GPa}$. Therefore, this analysis is essentially insensitive to uncertainty in the coating elastic properties, with the exception of the surface energy.

The TiN coated $\mathrm{Si}_{3} \mathrm{~N}_{4}$ samples in Tables $\mathrm{B}-2$ and $\mathrm{B}-3$ were coated simultaneously and used to compare the repeatability of the measurement technique. Figure B-14 shows that these 2 samples have very similar surface morphologies and are expected to have similar microstructures. The fracture strengths of these samples are within $15 \%$, the fracture toughnesses are within $20 \%$, the Weibull modulus are within $30 \%$, and the surface energies are within $25 \%$. These percentages differences are taken to represent the relative error in each measured property. 


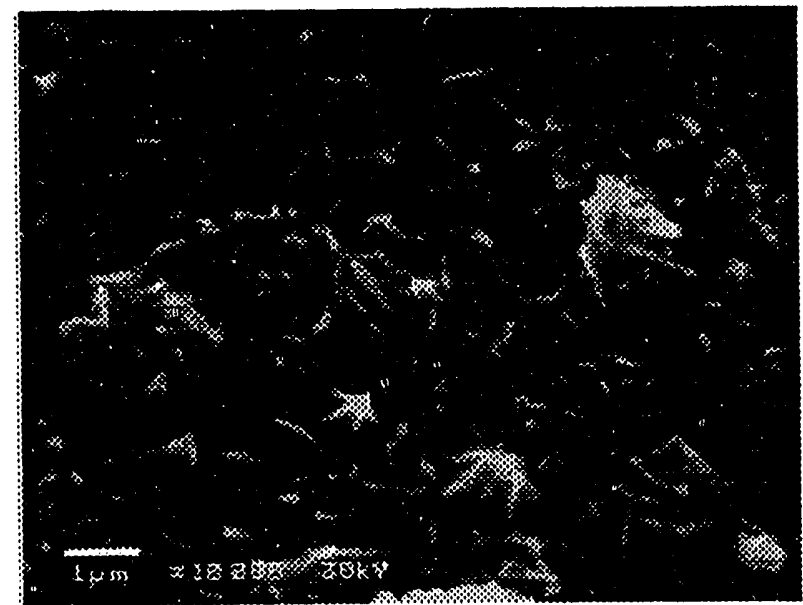

(a)

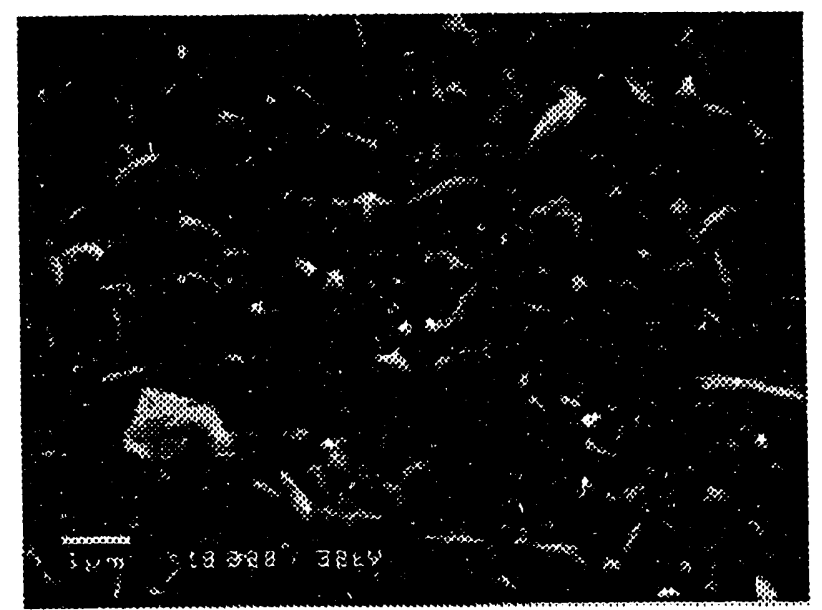

(b)

Figure B-14. Scanning electron micrograph of the coatings deposited on a SiC substrate at $970^{\circ} \mathrm{C}$ in a) TiN sample \# 1, b) TiN sample \#2. 
The leading sources of error are the difficulty in determining the radius of curvature of the sample and the error in the thickness of the coating. A $1 \%$ error in the radius of curvature results in an error of $40 \%$ in the fracture strength, $50 \%$ in the fracture toughness, $100 \%$ in the Weibull modulus, and $0-100 \%$ in the surface energy. A $5 \%$ error in the thicknesses of the coating and substrate results in a $15 \%$ error in the fracture strength. The errors associated with measuring the radius of curvature are discussed in Appendix C.

In determining the fracture stress of the coating, $\sigma_{f}$, two values of measured stress were used (Figure B-12). Any non-linearity in measured stress as a function of measurement temperature will result in changes in the fracture stress of the coating. The curvature of this non-linear region was related to the Weibull modulus through Eq. (B-1). However, in order to fit a more accuraie line to the data points, data at several more temperatures are needed. Since for practical reasons these additional temperatures would fall between the existing data (taken at $20^{\circ} \mathrm{C}$ and $-160^{\circ} \mathrm{C}$ ) these points would not. allow a more accurate curve to be fit. The Weibull modulus calculated from $\sigma_{f}$ and the corresponding values at $20^{\circ} \mathrm{C}$ and $-160^{\circ} \mathrm{C}$ were 32 and 27 , respectively. Since these two values are close to one another, the error introduced by the straight line approximation cannot be too large, thus the straight line approximation appears reasonable. The straight line approximation resulted in the calculated fracture stress of the coating being higher than the actual fracture stress of the coating. It would be more satisfactory if the error was conservative.

The largest error in calculating the Weibull modulus is from calculating the volume that corresponds to the fracture stress. This volume is calculated from the number of cracks. The number of cracks is a strong function of the shear-lag distribution. As the amount of lag increases the number of cracks decreases and the Weibull modulus decreases.

The approach taken in this work has. demonstrated the viability of measuring the tensile strength, fracture toughness, and Weibull modulus of a coating. In comparing the measured properties of coatings to the bulk properties of the coating material, it was found that bulk properties provide a reasonable approximation to coating strength. However, the fracture 
toughness of a coating was markedly lower than the bulk fracture toughness of the same material. The discrepancy between the fracture toughness of the coating and bulk materials was attributed to the large amount of intergranular fracture that occurred in fine grained coating materials.

\section{CONCLUSIONS}

In modelling and design applications the bulk properties of a material are used in place of coating properties due to the difficulty of measuring the mechanical of coatings. A simple method for quantitatively measuring the fracture stress, fracture toughness, and Weibull modulus of thin brittle coatings on a substrate was developed. This method involves measuring the radius of curvature of the coated sample at room temperature.

Two $\mathrm{Al}_{2} \mathrm{O}_{3}$ coatings on $\mathrm{SiC}$ substrates were compared. One had a compact coating structure and the other had a textured coating structure. The compact coating had a fracture strength of $240 \mathrm{MPa}$, a fracture toughness of $0.5 \mathrm{MPa} \sqrt{\mathrm{m}}$, a Weibull modulus of 28 , and a surface energy of $0.3 \mathrm{~J} / \mathrm{m}^{2}$. The textured coating had a fracture strength of $190 \mathrm{MPa}$, a fracture toughness of $0.5 \mathrm{MPa} \sqrt{\mathrm{m}}$, and a Weibull modulus of 19 , and a surface energy of $0.3 \mathrm{~J} / \mathrm{m}^{2}$.

A composite $\mathrm{Al}_{2} \mathrm{O}_{3}+\mathrm{Z}_{\mathrm{rO}_{2}}$ coating on a $\mathrm{SiC}$ substrate had a fracture strength of $480 \mathrm{MPa}$, a fracture toughness of $1.1 \mathrm{MPa} \sqrt{\mathrm{m}}$, a Weibull modulus of 16 and a surface energy of $1.6 \mathrm{~J} / \mathrm{m}^{2}$.

A TiN coating on a $\mathrm{Si}_{3} \mathrm{~N}_{4}$ substrate had a fracture strength of $230 \mathrm{MPa} \pm 35$, a fracture toughness of $0.5 \mathrm{MPa} \sqrt{\mathrm{m}} \pm 0.1$, a Weibull modulus of $12 \pm 3$, and a surface energy of $0.3 \pm 1 \mathrm{~J} / \mathrm{m}^{2}$.

Uncertainty in the coating and substrate thicknesses along with uncertainty in the radius of curvature are the leading sources of error in the method. The surface energies determined by this technique do not agree well with expected values. A more exact form of the shear-lag distribution is expected to result in more accurate surface energies. 


\section{APPENDIX_C - CURVE FITTING OF PROFILOMETER DATA}

\section{BACKGROUND}

Stresses in thin films on substrates can be measured by the beam bending technique [NIX89]. The technique involves measuring the radius of curvature of a coated substrate. The stress in the film $\left(\sigma_{f}\right)$ is related to the Young's modulus of the film (E), the film thickness ( $\left.t_{f}\right)$, the substrate thickness $\left(t_{s}\right)$ and, the radius of curvature $(R)$ by Equation $C-1$ :

$$
\sigma_{f}=\frac{t_{s}^{2} E}{6 t_{f} R}
$$

A new technique was developed for measuring the fracture stress and fracture toughness of films on substrates which is based on measuring the radius of curvature of a coated substrate (Appendix B) The samples used to measure the fracture stress and fracture toughness were limited to lengths of $10 \mathrm{~mm}$ and $20 \mathrm{~mm}$, due to material availability. The radii of curvature of the samples ranged from $0.5 \mathrm{~m}$ to $10.0 \mathrm{~m}$. In developing this technique, the software supplied with the laser profilometer poorly fit the data to the equation of a circle. A new FORTRAN curve fitting routine was written and tested with simulated profilometer data to evaluate its accuracy.

\section{EXPERIMENTS AND RESULTS}

A PC-based laser profilometer (Rodenstock model RM600) was used for data acquisition. Software accompanying the profilometer included a routine to calculate the radius of curvature. This routine was tested with standards of known radius of curvature $(0.500 \mathrm{~m}, 1.000 \mathrm{~m}$ and $5.000 \mathrm{~m})$. In acquiring the profilometer data, 2000 data points were taken and scans of $10 \mathrm{~mm}$ and $20 \mathrm{~mm}$ were used, for reasons stated above. In most cases the results from the fitting routine were unsatisfactory, see Figure $\mathrm{C}-1$. The results for the $0.5 \mathrm{~m}$ radius of curvature standard were accurate. However, for the $1.0 \mathrm{~m}$ and $5.0 \mathrm{~m}$ radius of 
curvature standards the difference between the calculated and actual radii ranged from $5 \%$ to several thousand percent.

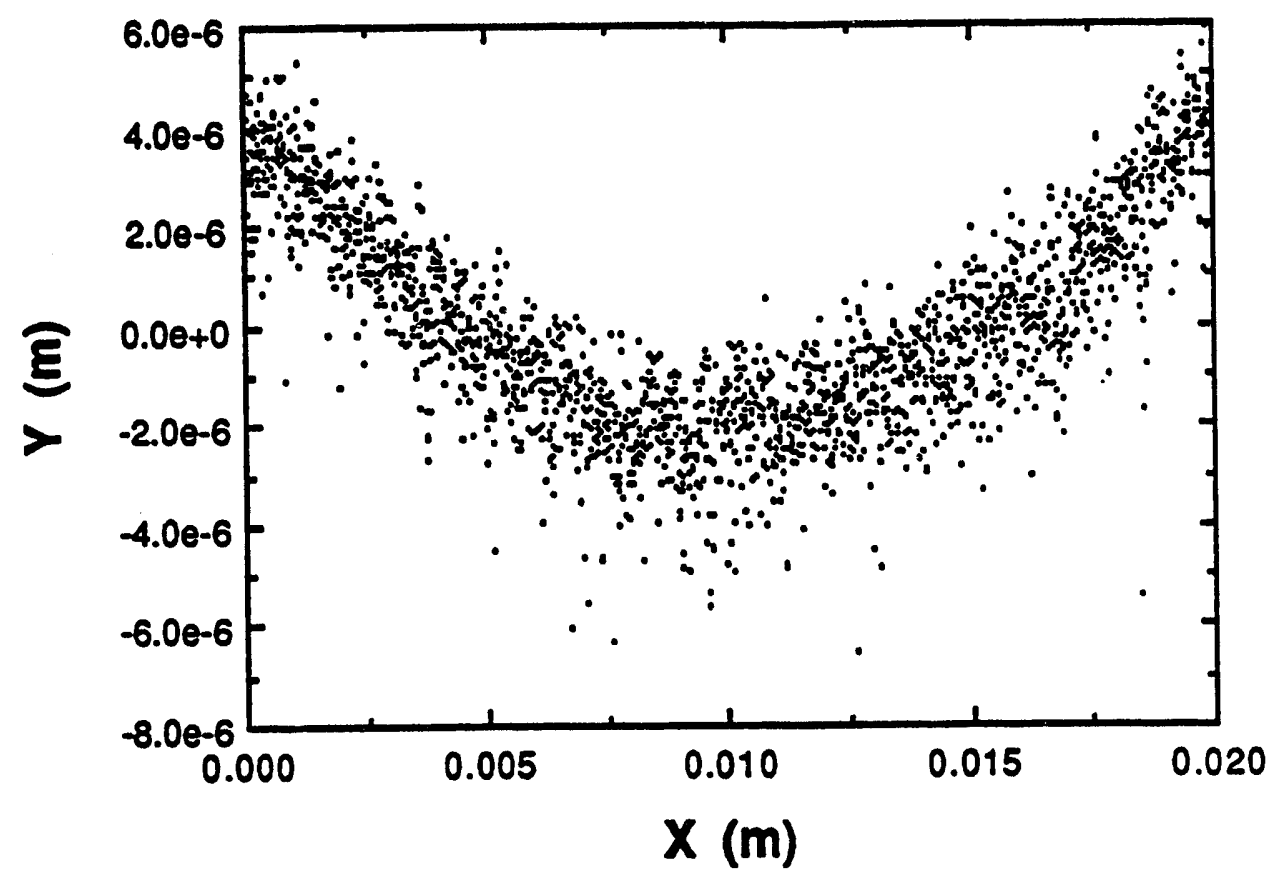

Figure C-1. Plot of experimental profilometer data. In this example the RMS noise is approximately 0.94 microns and the radius of curvature was calculated to be $7.861 \mathrm{~m} \pm 5 \%$ using the "GUESS" routine (see end of Appendix), compared to $6.229 \mathrm{~m}$ calculated by the Rodenstock software.

A new routine "POINT_FIT" was written to fit the profilometer data to the equation of a circle, Equation C-2.

$$
R^{2}=(x+A)^{2}+(y+B)^{2}
$$

where $R$ is the radius of curvature, $x$ and $y$ are the data points, and $A$ and $B$ are constants. This subroutine is included at the end of this appendix along with a routine "GUESS" to supply an initial guess for $R, A$, and $B$.

Profilometer data simulating samples with different radii of curvature were computer generated and fitted to the equation of a circle using the 
subroutines to test these routines for accuracy and robustness. Noise was introduced into the data to assess the sensitivity of the fitting procedure. All noise values reported refer to the root mean square (RMS) level. Two distributions were used to generate the noise, a Gaussian distribution and a uniform distribution, see Figure C-2. Each set of generated data contained 2000 points. The results were largely insensitive to the number of data points. Scan lengths of $10 \mathrm{~mm}, 20 \mathrm{~mm}$, and $50 \mathrm{~mm}$ were tested and radius of curvature values from $0.5 \mathrm{~m}$ to $10.0 \mathrm{~m}$ were used. These scan lengths and radii of curvature values were selected because they were typical values encountered.

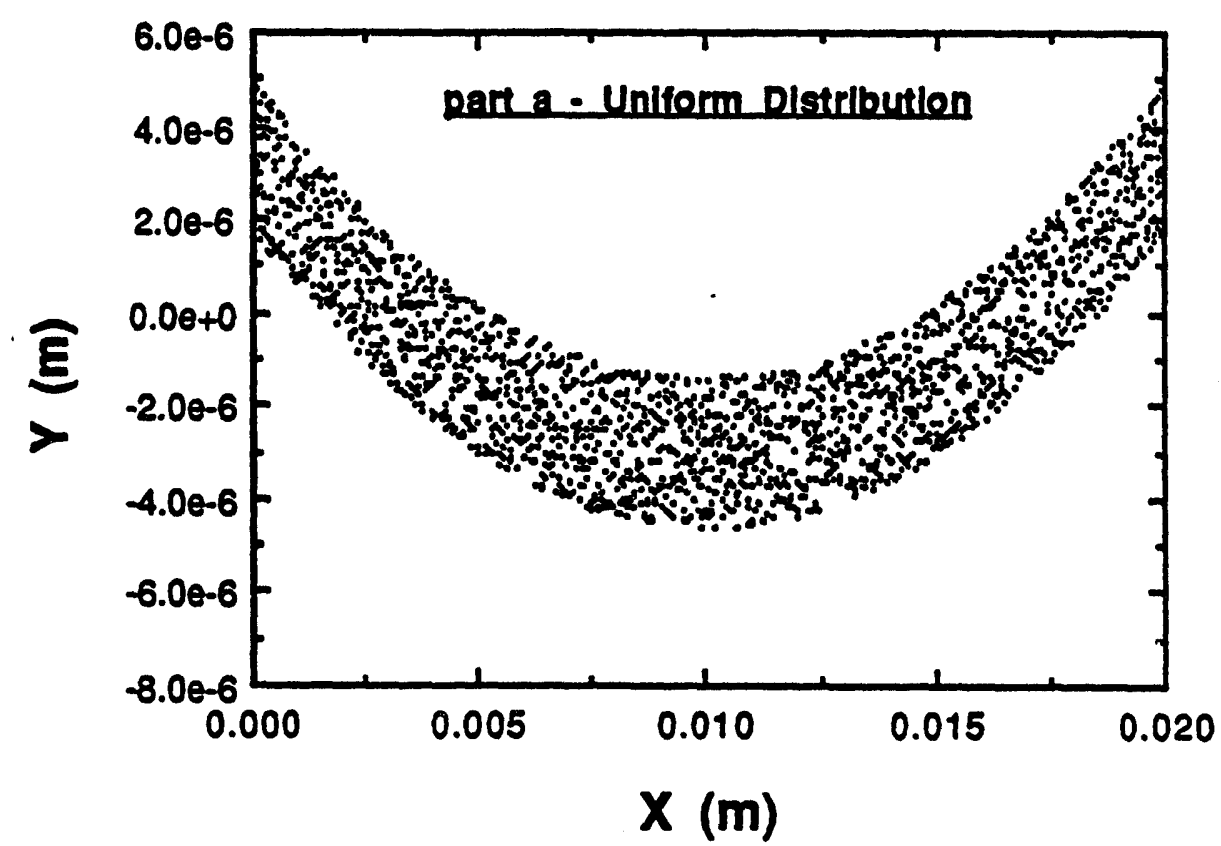

Figure C-2a. Plot of computer generated data for a radius of curvature of 7.861 $m$ and an RMS noise level of 0.94 microns with a uniform distribution, calculated $R=8.002 \mathrm{~m}$. The calculated radius of curvature value is within $2 \%$ of the actual radius of curvature of $7.861 \mathrm{~m}$. 


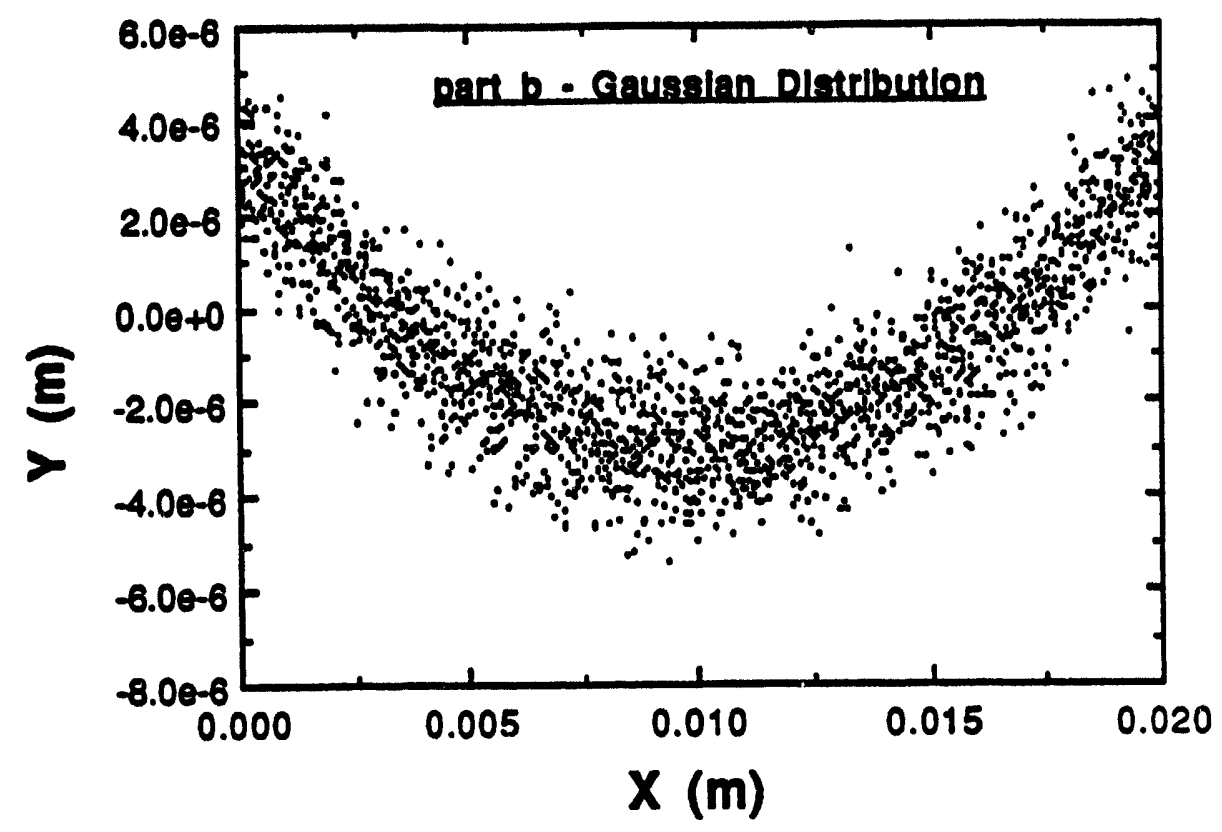

Figure C-2b. Plot of computer generated data for a radius of curvature of 7.861 $m$ and an RMS noise level of 0.94 microns with a Gaussian distribution, calculated $R=8.204 \mathrm{~m}$. The calculated radius of curvature value is within $4 \%$ of the actual radius of curvature of $7.861 \mathrm{~m}$.

A plot of the fitted radius of curvature versus the signal-to-noise ratio $(\mathrm{S} / \mathrm{N})$ is shown in Figure C-3 for the Gaussian noise distribution. This plot shows that as the signal-to-noise ratio decreases (noise increases) the accuracy decreases to the point that the calculated radius of curvature is unreliable. The critical value of the signal-to-noise ratio was 1.8 for the Gaussian distribution and 0.7 for the uniform distribution. A S/N ratio of 1.8 was used as the minimum acceptable $S / N$ ratio for the profilometer data because the Gaussian distribution (Figure $\mathrm{C}-2 \mathrm{~b}$ ) matched the experimental distribution (Figure $\mathrm{C}-1$ ) better than the uniform distribution (Figure C-2a). Figure C-4 shows the value of the noise which corresponds to the signal-tonoise ratio of 1.8 as a function of radius of curvature. Figure C-5 shows the error in the radius of curvature as a function of $S / N$. As $S / N$ increases the error approaches zero, and when the $S / N$ drops below the critical $S / N$ value of 
1.8 the error increases very rapidly. In general, as the radius of curvature increases the accuracy of the fit decreases; as the noise increases the accuracy of the fit decreases; and as the scan length increases the accuracy of the fit increases.

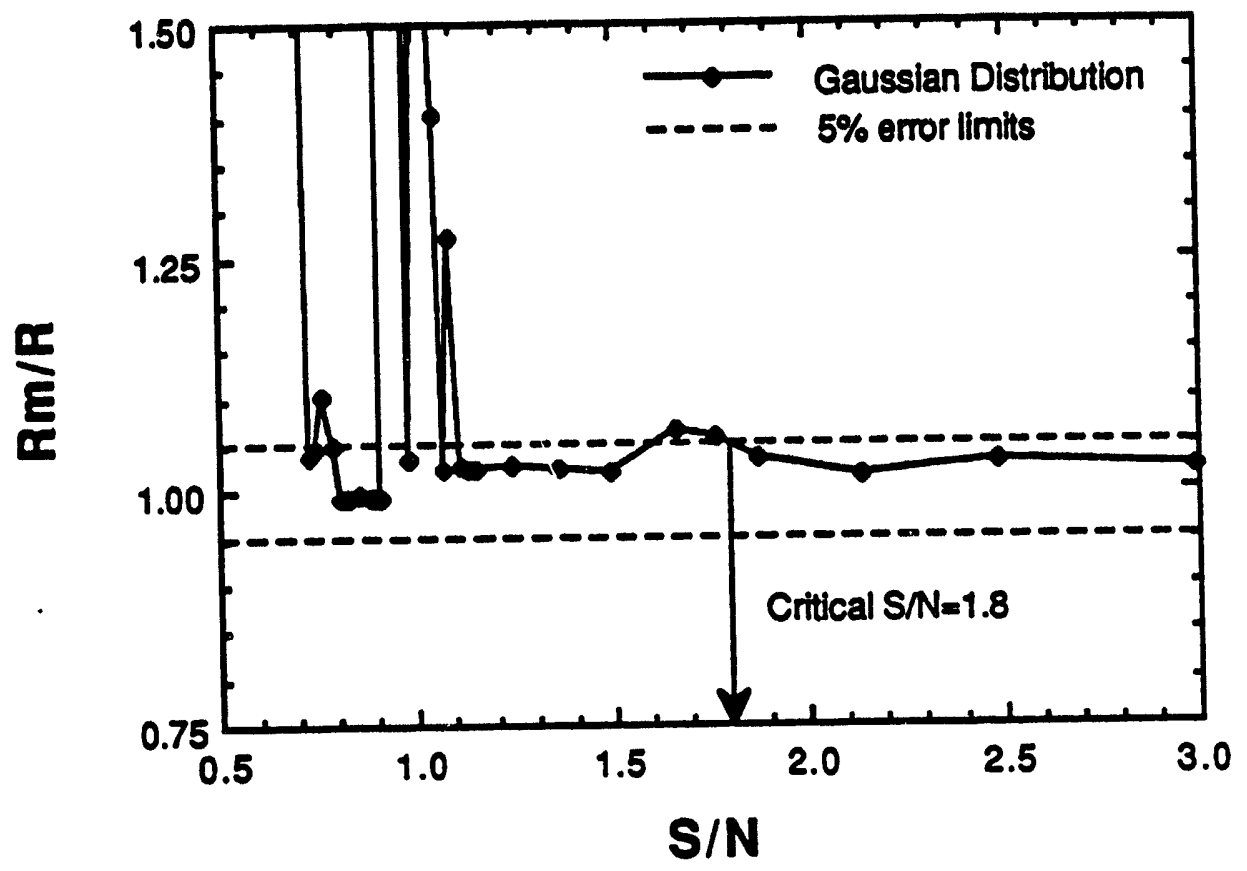

Figure C-3. Ratio of the calculated radius of curvature to the actual radius of curvature versus the signal-to-noise ratio for data sets with 2000 data points. For the Gaussian distribution the critical $S / N$ ratio was 1.8 and for the uniform distribution it was 0.7. Only the results from the Gaussian distribution are shown. 


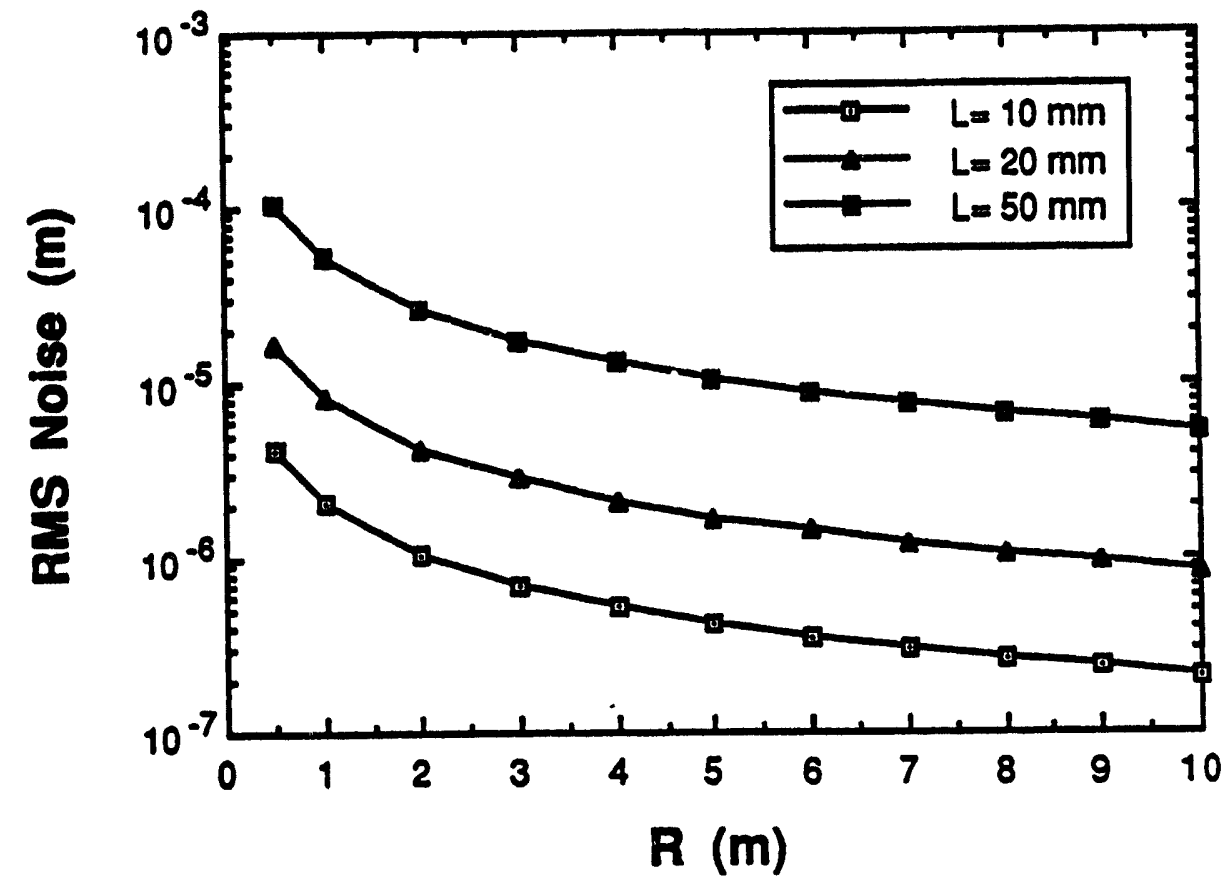

Figure C-4. Values of the maximum RMS noise level for which the fitted radius of curvature is within $5 \%$ of the true radius of curvature. A critical S/N ratio of 1.8 was used.

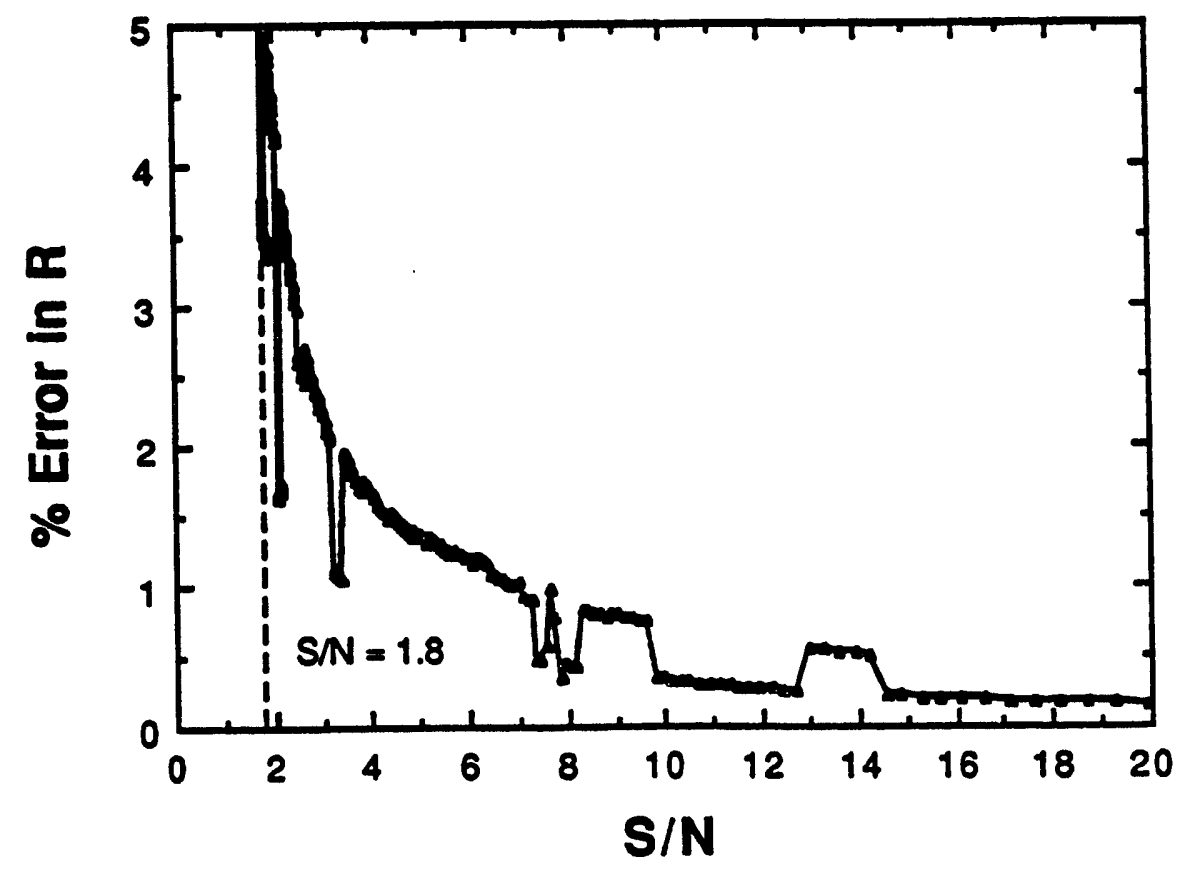

Figure C-5. Plot of error in the radius of curvature versus $S / N$. 


\section{CONCLUSIONS}

Routines used to fit profilometer data to the equation of a circle are very sensitive to noise in experimental data, the scan length, and the actual radius of curvature being measured. A routine for fitting profilometer data to the equation of a circle was described and its behavior was characterized with simulated data of known radius of curvature and noise level.

The signal-to-noise ratio has to be greater than 1.8 to measure the radius of curvature within $5 \%$ of the true value. High values of the signal-tonoise ratio are favored by small radius of curvatures, small scatter in the data, and long scan lengths.

COMPUTER ROUTINES FOR CURVE FITTING OF PROFILOMETER DATA

These subroutines are written in FORTRAN and fit experimental data to the Equation of a circle by solving for the A, B, and $R$ values in Equation C-2.

Subroutine GUESS supplies the initial guess for the fitting routine, POINT_FTT. GUESS works by evaluating Equation C-2 at 3 different points and solving these 3 equations for values of $R, A$, and $B$. To reduce the effects of data scatter NCP sets of points are used and averaged to obtain an initial guess. GUESS requires input arrays of $X$ and $Y$ values of dimension NP, and the number of sets of equations that are averaged (NCP), and stores the initial values of $R, A$, and $B$ in variables $R O, A O$, and $B O$.

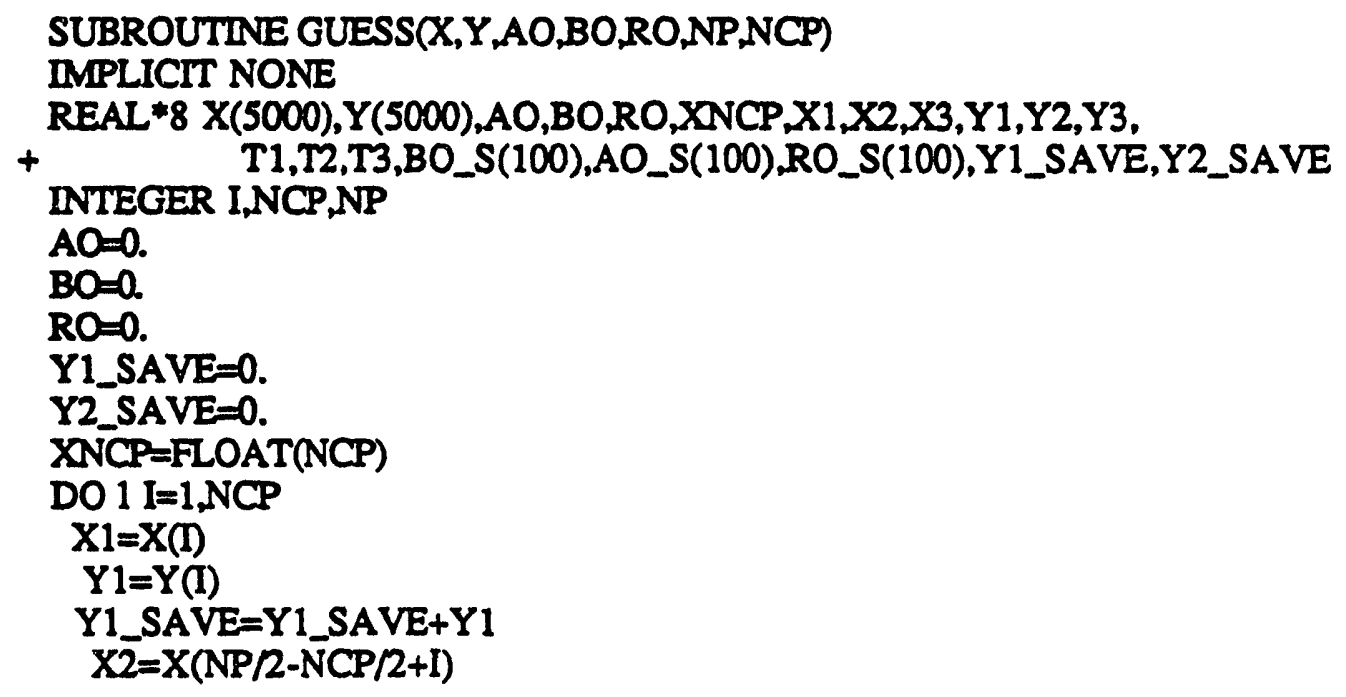




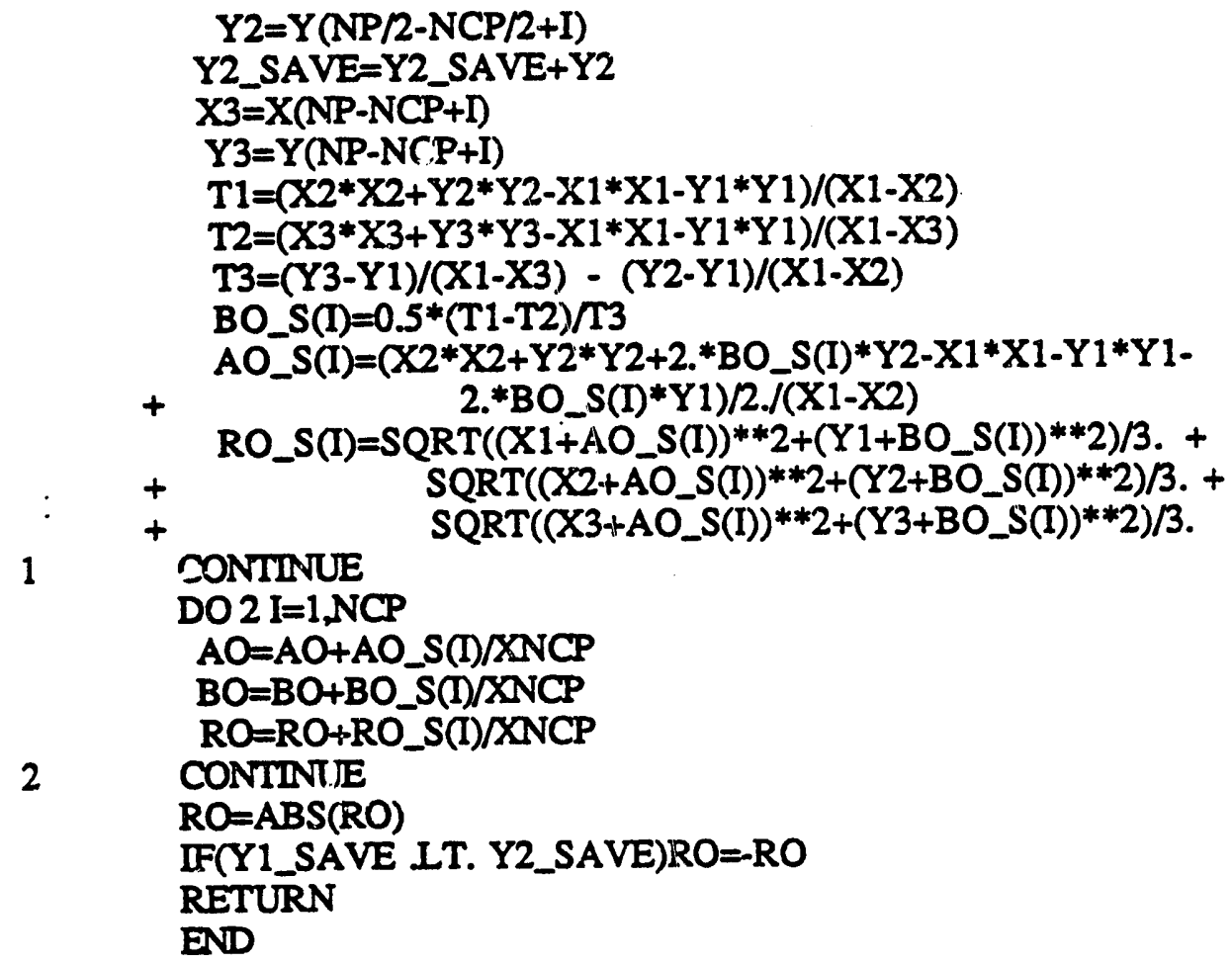

Subroutine POINT_FIT fits experimental data to Equation C-2. It requires arrays of $X$ and $Y$ values of dimension NP, an initial guess for the $R$, $A, B$ values (R_AVE, AO, and BO), and the value of NCP. R_AVE contains the initial guess of $R$ at the beginning and the final value of $R$ on exit. Several parameters control the accuracy of the calculation; NUM_C controls the number of fitting steps used to solve for A and B, NUM_TOTAL controls the number of fitting steps used to solve for R_AVE, STEP is the increment size used to change the values of $A$ and $B$ during fitting, $D$ is how much STEP is reduced by, and TOL is used to terminate the routine. The routine is ended when either NUM_C or NUM_TOTAL is reached, or vihen the change in R_AVE is less than TOL*ERR_R. ERR_R is defined as the absolute magnitude of the average deviation of $R(i)$ from $R \_A V E$.

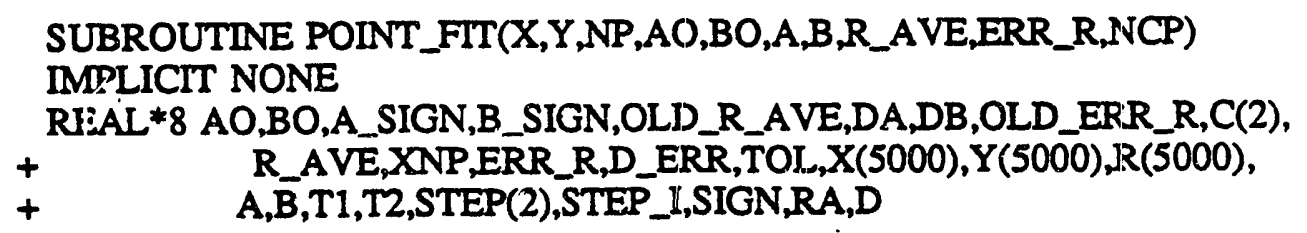


INTEGER TOTAL_FIT,I,NP,NUM_C,NUM_TOTAL,FIT(2),II,NCP

COMMON/CC2NUM_C,NUM_TOTAL,STEP_I,D,TOL

C

C

C

C

C

GET 'BEST' A \& B VALUES BY MINMMIZING VARIATION IN R

$$
A=C(1) ; \quad B=C(2)
$$

APPROXIMATE STARTING VALUES OF STEP=0.25, $\mathrm{D}=5$., TOL=1.E-4

XNP=FLOAT(NP)

$C(1)=A O$

$\mathrm{C}(2)=\mathrm{BO}$

STEP(1)=STEP_I

STEP(2)=STEP_I

TOTAL_FIT $=0$

SIGN $=1.0$

OLD_R_AVE=1.E6

TOTAL_FIT $=0$

100 DO $999 \mathrm{I}=1,2$

OLD_ERR_R=1.E6

FIT $\overline{(I})=0$

22 CONTINUE

R_AVE $=0.0$

DO $20 \mathrm{II}=1, \mathrm{NP}$

$\mathrm{R}(\mathrm{II})=\mathrm{SQRT}((\mathrm{X}(\mathrm{II})+\mathrm{C}(1)) * * 2+(\mathrm{Y}(\mathrm{II})+\mathrm{C}(2)) * * 2)$

20 CONTINUE

R_AVE=R_AVE/XNP

ERR_R $=0.0$

DO 21 II $=1, N P$

ERR_R=ERR_R+ABS(R_AVE-R(II))/XNP

21 CONIINUE

D_ERR=ERR_R-OLD_ERR_R

OLD_ERR_R=ERR_R

$F I T(I)=F I T(I)+1$

IF(FIT(I) .EQ. NUM_C)GOTO 30

IF(D_ERR .GT. 0.)THEN

SIGN=-SIGN

$\operatorname{STEP}(\mathrm{I})=S T E P(\mathrm{I}) / \mathrm{D}$

ENDIF

IF( ABS(D_ERR) ITT. TOL*ERR_R )GOTO 30

$\mathrm{C}(\mathrm{I})=\mathrm{C}(\mathrm{I}) *(1 .+\operatorname{SIGN} * \operatorname{STEP}(\mathrm{I}))$

GOTO22

30 CONTINUE

999 CONTINUE

$A=C(1)$

$B=C(2)$

TOTAL_FIT=TOTAL_FIT+1 
$\mathrm{T} 1=0$.

$\mathrm{T} 2=0$.

DO $1901 \mathrm{I}=1, \mathrm{NCP}$

$\mathrm{T} 1=\mathrm{T} 1+\mathrm{Y}(\mathrm{I})$

$\mathrm{T} 2=\mathrm{T} 2+\mathrm{Y}(\mathrm{NP} / 2-\mathrm{NCP} / 2+\mathrm{I})$

1901 CONTINUE

\section{RA=ABS(R_AVE)}

IF(T1 IT. T2)RA=-R_AVE

IF(TOTAL_FIT EQ.NUM_TOTAL)GOTO 918

IF(ABS(OLD_R_AVE-R_AVE) .GT. TOL*R_AVE)THEN

OLD_R_AVE=R_AVE

GOTO 100

ENDIF

R_AVE=ABS(R_AVE)

918 IF(T1 .LT. T2)R_AVE=-R_AVE RETURN

END 


\section{APPENDIX D - SIMPLE COMPOSITE PLATE AND BEAM THEORY}

\section{COMPOSITE PLATE THEORY}

Firstly, individual layer stiffnesses are calculated by

$$
\begin{aligned}
& Q_{11}^{k}=\frac{E_{1}^{k}}{1-v_{12}^{k} v_{21}^{k}} \\
& Q_{22}^{k}=\frac{E_{2}^{k}}{1-v_{12}^{k} v_{21}^{k}}
\end{aligned}
$$

$$
\begin{aligned}
& Q_{12}^{k}=Q_{21}^{k}=\frac{v_{21}^{k} E_{1}^{k}}{1-v_{12}^{k} v_{21}^{k}} \\
& Q_{66}^{k}=G_{12}^{k}
\end{aligned}
$$

If the layer is anisotropic, the stiffnesses of each of the layers are rotated to the principal directions of the plate by using the tensor rotation transformation

$$
\begin{gathered}
{\left[\begin{array}{c}
\sigma_{x} \\
\sigma_{y} \\
\left.\tau_{x y}\right]_{k}
\end{array}\right]=[T]^{-1}[Q] \begin{array}{c}
k \\
{[T]}
\end{array}\left[\begin{array}{c}
\varepsilon_{x} \\
\varepsilon_{y} \\
\frac{1}{2} \gamma_{x} y
\end{array}\right]_{k}} \\
{[T]=\left[\begin{array}{ccc}
m^{2} & n^{2} & 2 m n \\
n^{2} & m^{2} & -2 m n \\
-m n & m n & m^{2}-n^{2}
\end{array}\right]}
\end{gathered}
$$

where

$$
m=\cos \theta \text { and } n=\sin \theta
$$

where $\theta$ is described in a counter-clockwise direction. Next, each of the transformed layer stiffnesses are assembled into a global stiffness matrix of the form: 


$$
\left[\begin{array}{l}
N_{x} \\
N_{y} \\
N_{x y} \\
M_{x} \\
M_{y} \\
M_{x y}
\end{array}\right]=\left[\begin{array}{llllll}
A_{11} & A_{12} & A_{16} & B_{11} & B_{12} & B_{16} \\
A_{12} & A_{22} & A_{26} & B_{12} & B_{22} & B_{26} \\
A_{16} & A_{26} & A_{66} & B_{16} & B_{26} & B_{66} \\
B_{11} & B_{12} & B_{16} & D_{11} & D_{12} & D_{16} \\
B_{12} & B_{22} & B_{26} & D_{21} & D_{22} & D_{26} \\
B_{16} & B_{26} & B_{66} & D_{61} & D_{62} & D_{66}
\end{array}\right]\left[\begin{array}{c}
\varepsilon_{x}^{0} \\
\varepsilon_{y}^{0} \\
\gamma_{x y}^{0} \\
K_{x} \\
k_{y} \\
k_{x y}
\end{array}\right]
$$

where

$$
\begin{aligned}
& A_{i j}=\sum_{k=1}^{N} Q_{i j}^{k}\left(h_{k}-h_{k}-1\right) \\
& B_{i j}=\frac{1}{2} \sum_{k=1}^{N} Q_{i j}^{k}\left(h_{k}^{2}-\sum_{k-1}^{2}\right) \quad(i, j=1,2,6) \\
& D_{i j}=\frac{1}{3} \sum_{k=1}^{N} Q_{i j}^{k}\left(h_{k}^{3}-3-1, k-1\right.
\end{aligned}
$$

The goal is to solve for the mid-plane strain and curvatures of the coated structure, due the applied loads, then to use the strain values to backcalculate for all the stress components through the thickness of each of the materials in the structure. Thermal forces (due to cooling) are

$$
\begin{aligned}
& N_{x}^{t}=\sum_{k-1}^{N}\left(Q_{11}^{k} \alpha_{x}^{k}+Q_{12}^{k} \alpha_{y}^{k}+Q_{16}^{k} \alpha_{x y}^{k}\right)\left(h_{k-h}-1\right) \Delta T^{k} \\
& N_{y}^{t}=\sum_{k-1}^{N}\left(Q_{12}^{k} \alpha_{x}^{k}+Q_{22}^{k} \alpha_{y}^{k}+Q_{26}^{k} \alpha_{x y}^{k}\right)\left(h_{k}-h k-1\right) \Delta T^{k} \\
& N_{x y}^{t}=\sum_{k-1}^{N}\left(Q_{16}^{k} \alpha_{x}^{k}+Q_{26}^{k} \alpha_{y}^{k}+Q_{66}^{k} \alpha_{x y}^{k}\right)\left(h_{k-h}-h-1\right) \Delta T^{k}
\end{aligned}
$$




$$
\begin{aligned}
& M_{x}^{t}=\frac{1}{2} \sum_{k=1}^{N}\left(Q_{11}^{k} \alpha_{x}^{k}+Q_{12}^{k} \alpha_{y}^{k}+Q_{16}^{k} \alpha_{x y}^{k}\right)\left(h_{k}^{2}-h_{k-1}^{2}\right) \Delta T^{k} \\
& M_{y}^{t}=\frac{1}{2} \sum_{k-1}^{N}\left(Q_{12}^{k} \alpha_{x}^{k}+Q_{22}^{k} \alpha_{y}^{k}+O_{26}^{k} \alpha_{x y}^{k}\right)\left(h_{k}^{2}-h_{k-1}^{2}\right) \Delta T^{k} \\
& M_{x y}^{t}=\frac{1}{2} \sum_{k-1}^{N}\left(Q_{16}^{k} \alpha_{x}^{k}+Q_{26}^{k} \alpha_{y}^{k}+O_{66}^{k} \alpha_{x y}^{k}\right)\left(h_{k}^{2}-h_{k-1}^{2}\right) \Delta T^{k}
\end{aligned}
$$

and the total load on the structure is the sum of any mechanical loads and moments (here zero) with these thermal loads. The global stiffness matrix is then inverted to get

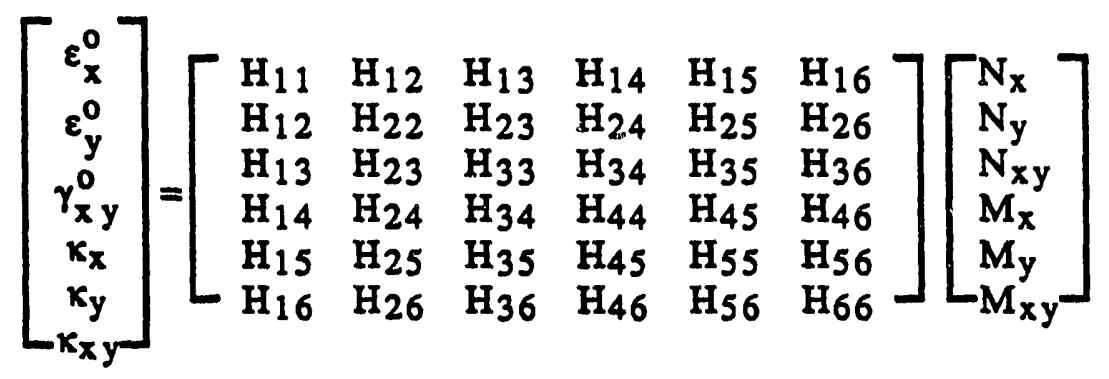

and the mid-plane strain and curvature can then be solved for by any matrix solution method. Mid-plane strain and curvatures are used to find the strains through the entire thickness of the coated substrate

$$
\begin{aligned}
& \varepsilon_{x}=\varepsilon_{x}^{0}+2 k_{x} \\
& \varepsilon_{y}=\varepsilon_{y}^{0}+z k_{y} \\
& \gamma_{x y}=\gamma_{x y}^{0}+z k_{x y}
\end{aligned}
$$


Now that strains have been resolved, stress can be found by

$$
\begin{aligned}
& \sigma_{x}^{k}=Q_{11}^{k}\left(\varepsilon_{x}^{k}-\alpha_{x}^{k} \Delta T^{k}\right)+Q_{12}^{k}\left(\varepsilon_{y}^{k}-\alpha_{y}^{k} \Delta T^{k}\right)+Q_{16}^{k}\left(\gamma_{x y}^{k}-\alpha_{x y}^{k} \Delta T^{k}\right) \\
& \sigma_{y}^{k}=Q_{21}^{k}\left(\varepsilon_{x}^{k}-\alpha_{x}^{k} \Delta T^{k}\right)+Q_{22}^{k}\left(\varepsilon_{y}^{k}-\alpha_{y}^{k} \Delta T^{k}\right)+Q_{26}^{k}\left(\gamma_{x y}^{k}-\alpha_{x y}^{k} \Delta T^{k}\right) \\
& \tau_{x y}^{k}=Q_{61}^{k}\left(\varepsilon_{x}^{k}-\alpha_{x}^{k} \Delta T^{k}\right)+Q_{62}^{k}\left(\varepsilon_{y}^{k}-\alpha_{y}^{k} \Delta T^{k}\right)+Q_{66}^{k}\left(\gamma_{x y}^{k}-\alpha_{x y}^{k} \Delta T^{k}\right)
\end{aligned}
$$

Each of the $\varepsilon_{\mathrm{ij}}^{k}$ terms vary through the thickness a very small amount relative to the $\alpha \Delta T$ strain terms, thus leading to the sharp discontinuities in the in-plane stress terms when traversing material interfaces.

This theory has been implemented in a FORTRAN computer code, which also includes material properties of the specific material systems used here.

\section{NOMENCLATURE}

$E_{i} \quad-$ Young's Modulus

$\gamma_{i j}$ - Poisson's Ratio

$\mathrm{G}_{\mathrm{ij}}$ - Shear Modulus

$\mathrm{Q}_{\mathrm{ij}}$ - Stiffness Component

$T_{i j}$ - Rotation Transformation Component

$\varepsilon_{\mathrm{i}}^{0} \quad$ - Mid-plane Strain

$\kappa_{i}$ - Mid-plane Curvature

$\mathrm{N}_{\mathrm{i}}$ - Applied Forces

$\mathbf{M}_{\mathbf{i}}$ - Applied Moments

h - Total Thickness

$h_{i}$ - Distance from Mid-plane to Interfaces

$\alpha_{i}$ - Coefficient of Thermal Expansion

$\Delta \mathrm{T}$ - Temperature Change 


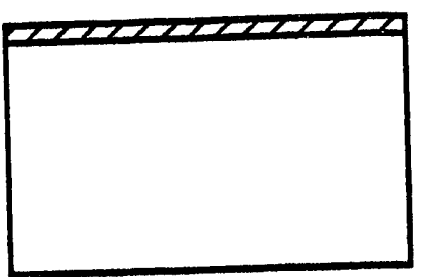

$1 \mu \mathrm{m}$

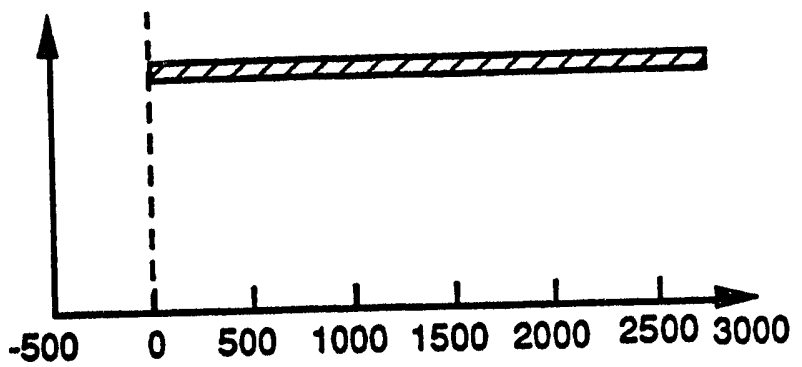

\begin{tabular}{l|l} 
Compressive & Tensile
\end{tabular}

In-plane normal stress (MPa)

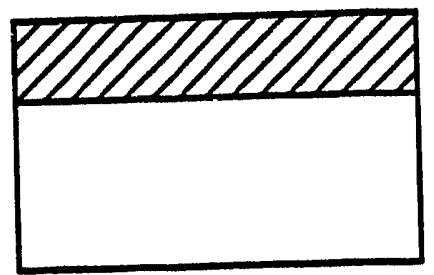

$4 \mu \mathrm{m}$

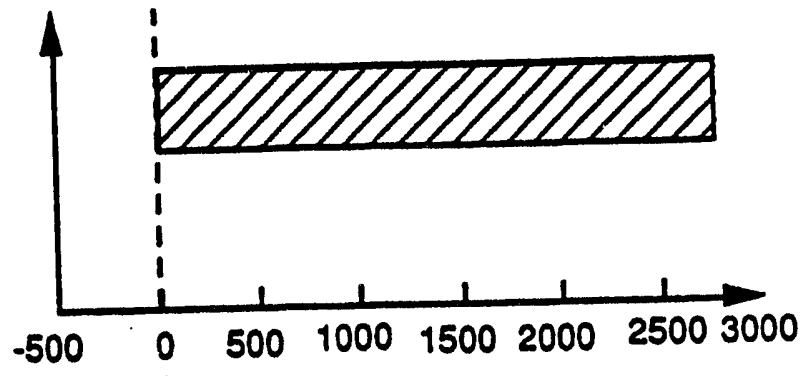

Compressive $\mid \overrightarrow{\text { Tensile }}$

In-plane normal stress (MPa)

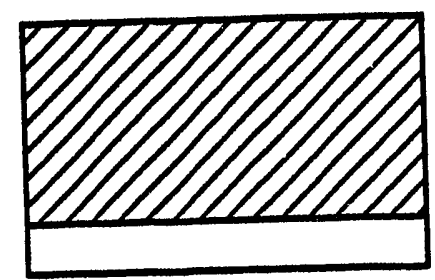

$\square \triangle \mathrm{Al}_{2} \mathrm{O}_{3}+\mathrm{ZrO}_{2}$ $\square \mathrm{Si}_{3} \mathrm{~N}_{4}$
$10 \mu \mathrm{m}$

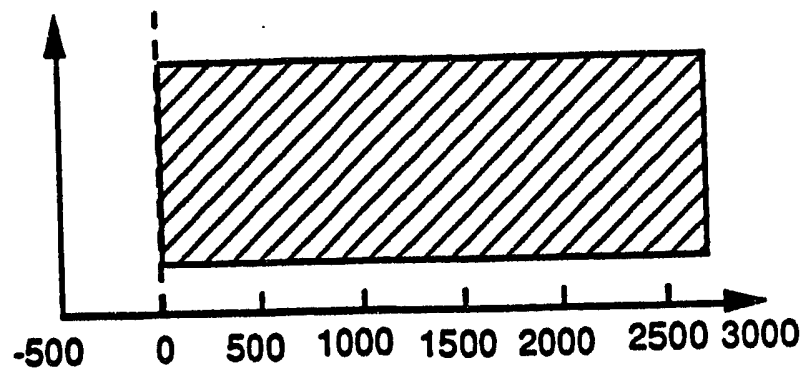

Compressive $\mid$\begin{tabular}{r|r} 
Tensile \\
\hline
\end{tabular}

In-plane normal stress (MPa)

Figure D-1 In-plane residual stresses for a $\mathrm{Si}_{3} \mathrm{~N}_{4}$ substrate coated with alumina-zirconia without an interlayer. Stresses for 1,4 and 10 microns coating thicknesses are shown. Thickness of the coating layer has negligible effect on residual stress. 

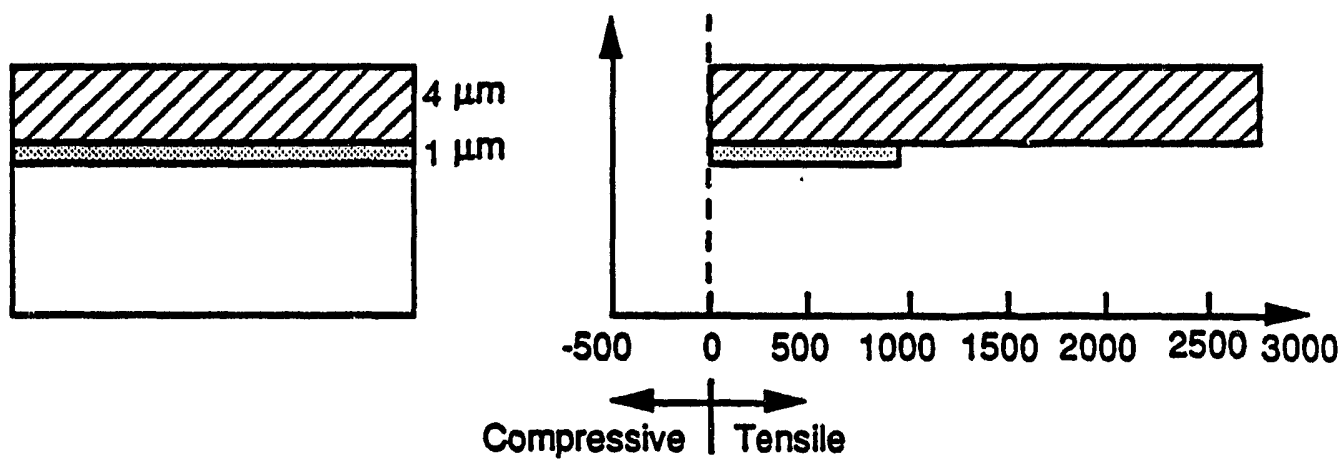

In-plane normal stress (MPa)
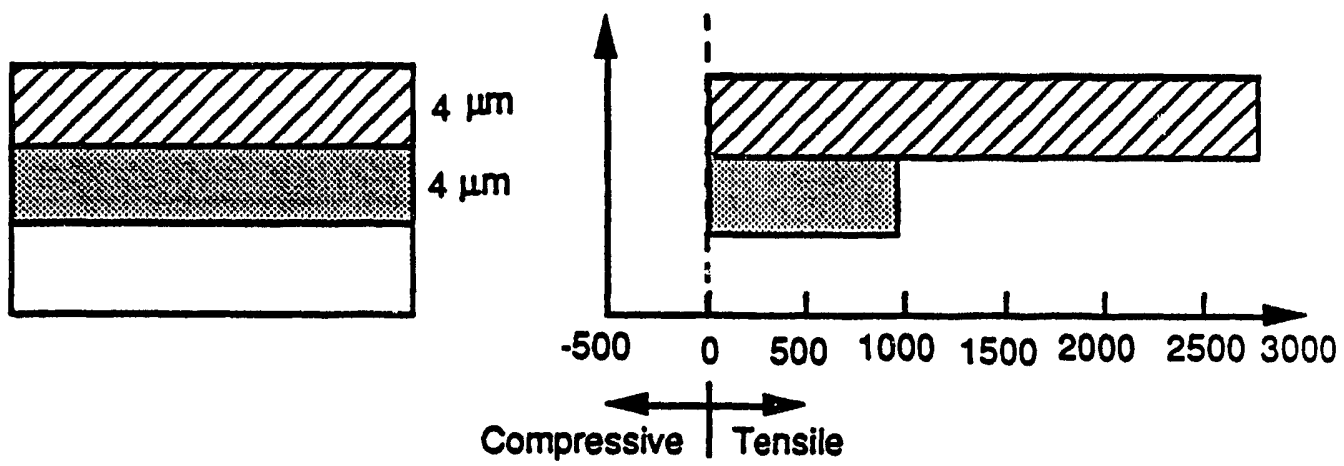

In-plane normal stress (MPa)
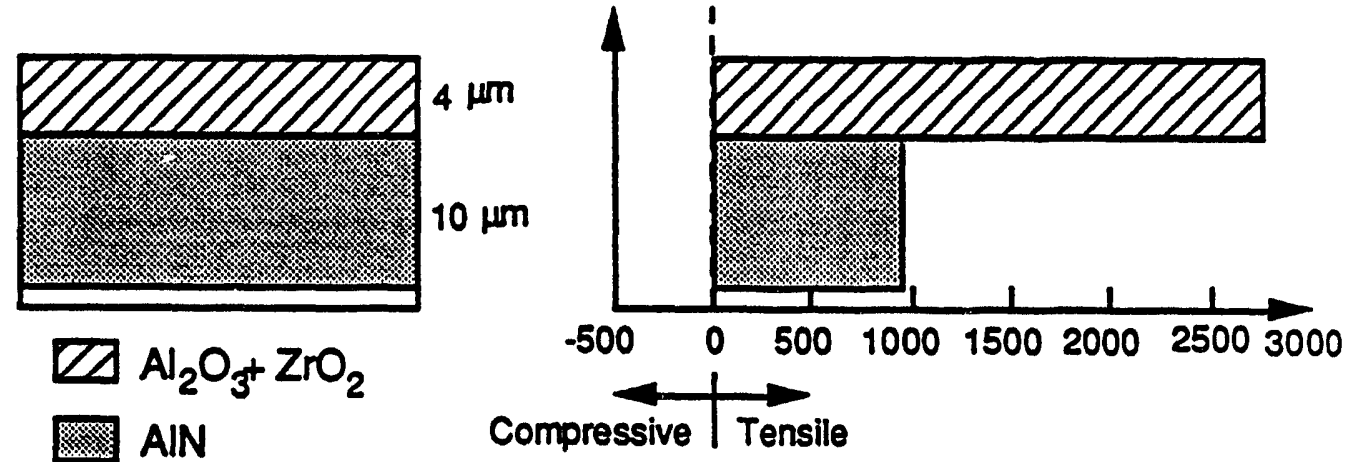

$Z \mathrm{Al}_{2} \mathrm{O}_{3}+\mathrm{ZrO}_{2}$

AIN

$\square \mathrm{Si}_{3} \mathrm{~N}_{4}$

In-plane normal stress (MPa)

Figure D-2. In-plane residual stresses for a $\mathrm{Si}_{3} \mathrm{~N}_{4}$ substrate coated with alumina-zirconia with an AlN interlayer. Stresses for 1, 4 and 10 microns interlayer thicknesses are shown. Thickness of the interlayer has negligible effect on residual stress. 

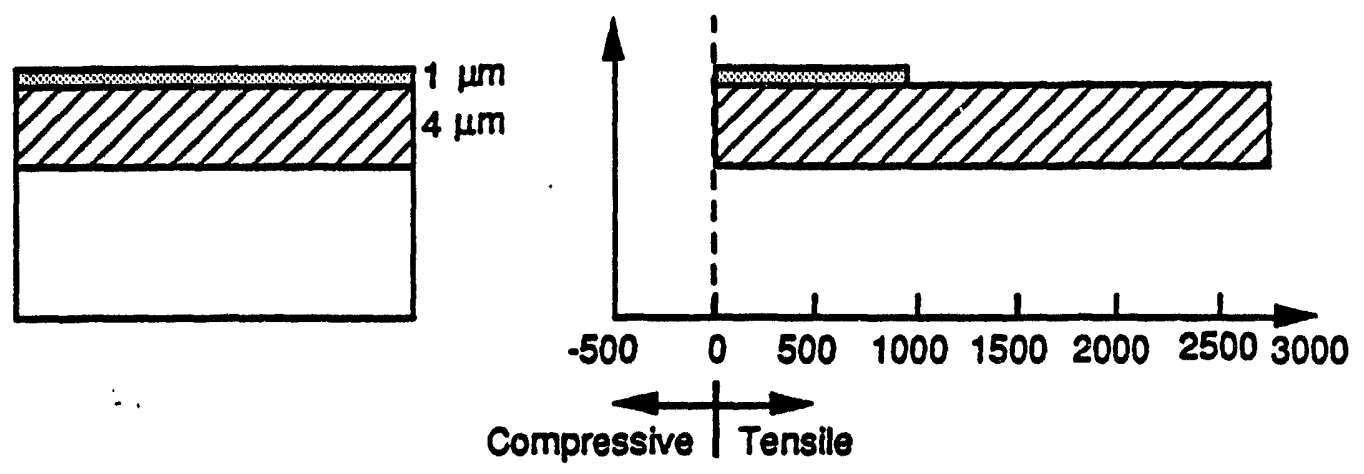

In-plane normal stress (MPa)
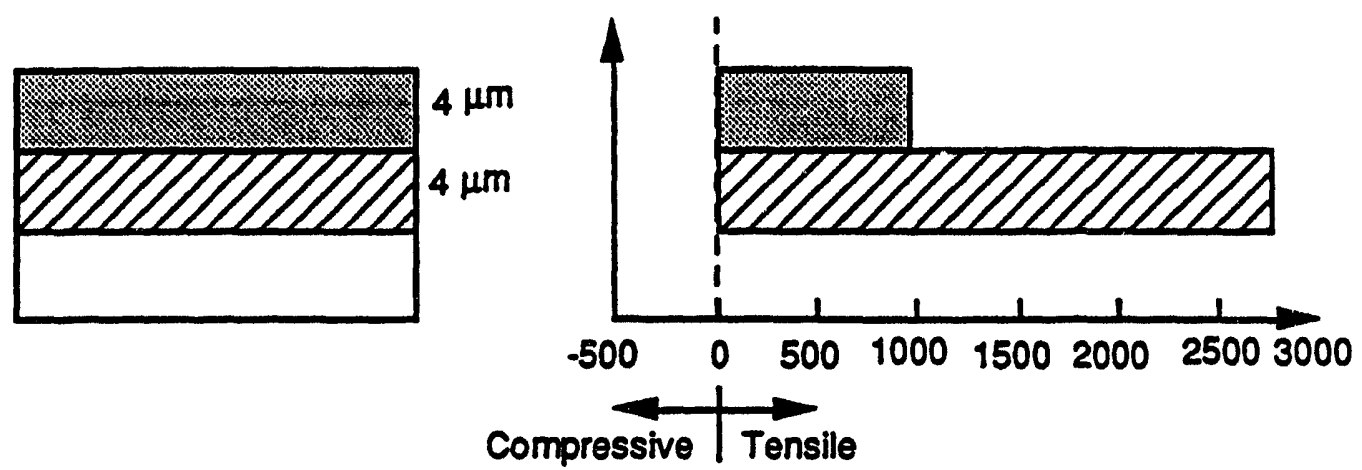

In-plane normal stress (MPa)
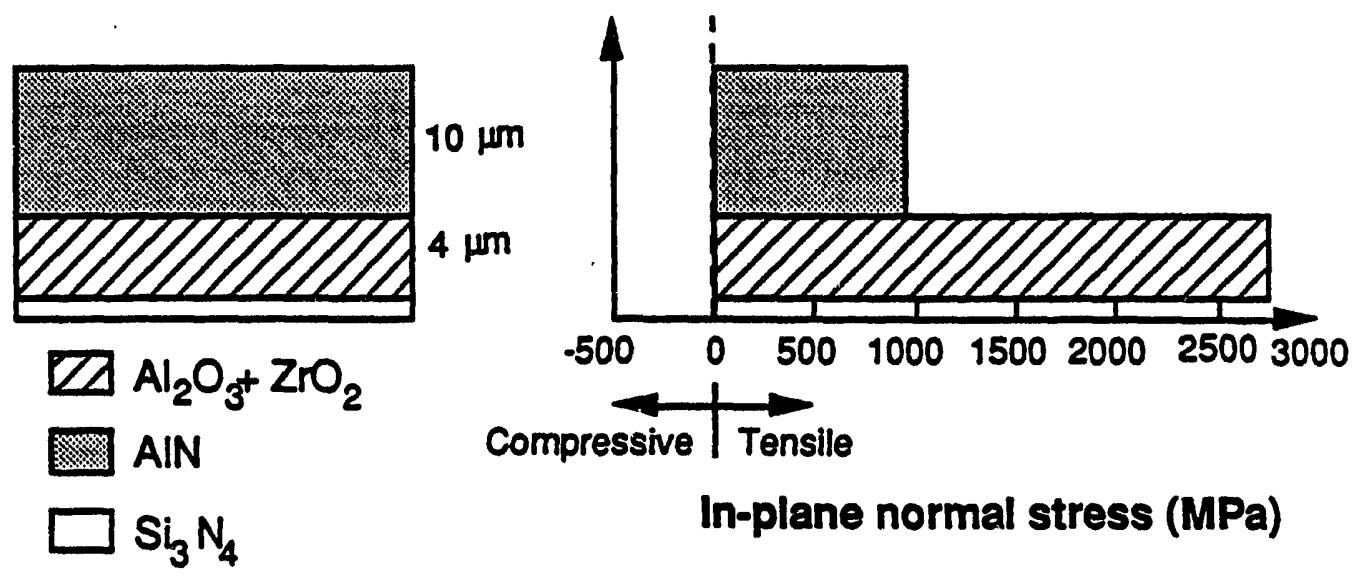

In-plane normal stress (MPa)

Figure D-3. In-plane residual stresses for a $\mathrm{Si}_{3} \mathrm{~N}_{4}$ substrate coated with AlN and an alumina-zirconia interlayer (coating order is reversed from the previous figure). Stresses for 1,4 and 10 microns interlayer thicknesses are shown. Comparing to the previous figure, order of the coating layers has negligible effect on residual stress. 


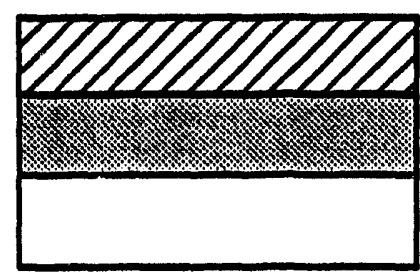

$\square \mathrm{Ai}_{2} \mathrm{O}_{3}+\mathrm{ZrO}_{2}$

AIN

$\square$ SiC

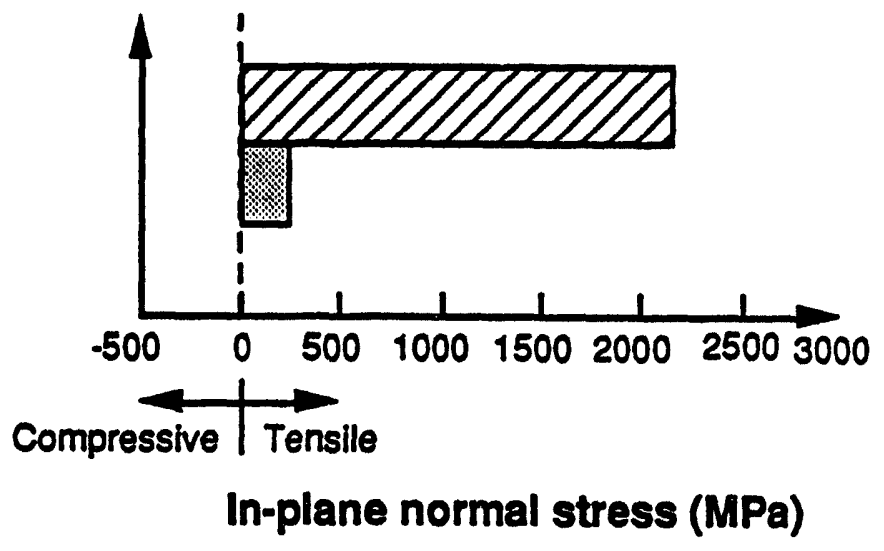

In-plane normal stress (MPa)

Figure D-4. In-plane residual stresses for a SiC substrate coated with AIN and alumina-zirconia. Stresses shown are applicable for a wide range of coating thicknesses. 


\section{INTERNAL DISTRIBUTION}

Central Research Library (2)

Document Reference Section

Laboratory Records Department (2)

Laboratory Records, ORNL RC

ORNL Patent Section

M\&C Records Office (3)

L. F. Allard, Jr.

L. D. Armstrong

P. F. Becher

R. F. Bernal

T. M. Besmann

P. J. Blau

A. Bleier

E. E. Bloom

$\mathrm{K}$ W. Boling

R. A. Bradley

C. R. Brinkman

V. R. Bullington

R. S. Carlsmith

P. T. Carlson

G. M. Caton

S. J. Chang

R. H. Cooper, Jr.

B. L. Cox

D. F. Craig

S. A. David

J. H. DeVan

J. L. Ding

M. K. Ferber

F. M. Foust

W. Fulkerson

R. L. Graves

D. L. Greene

M. H. Harris

E. E. Hoffman
C. R. Hubbard

M. A. Janney

M. G. Jenkins

D. R. Johnson

D. Joslin

R. R. Judkins

M. A. Karnitz

M. R. Kass

B. L. P. Keyes

H. D. Kimrey, Jr.

K. C. Liu

E. L. Long, Jr.

W. D. Manly

R. W. McClung

D. J. McGuire

J. R. Merriman

T. A. Nolan

A. E. Pasto

J. L. Rich

J M Robbins

M. L. Santella

A. C. Schaffhauser

S. Scott

G. M. Slaughter

E. J. Soderstrom

D. P. Stinton

R. W. Swindeman

V. J. Tennery

T. N. Tiegs

J. R. Weir, Jr.

B. H. West

F. W. Wiffen

S. G. Winslow

J. M. Wyrick

C. S. Yust 


\section{EXTERNAL DISTRIBUTION}

Pioneering Research Information Center E. I. DuPond de Nemours \& Co., Inc. Experimental Station P. O. Box 80302

Wilmington, DE 19880-0302

James H. Adair

University of Florida

Materials Science and Engineering

317 MAE Bldg.

Gainesville, FL 32611-2066

Donald F. Adams

University of Wyoming

Mechanical Engineering Department

P. O. Box 3295

Laramie, WY 82071

Jalees Ahmad

AdTech Systems Research, Inc.

1342 North Fairfield Road

Dayton, OH 45432-2698

Yoshio Akimune

NISSAN Motor Co., Ltd.

Materials Research Laboratory

1 Natsushima-Cho

Yokosuka 237

JAPAN AIR MAII

Mufit Akinc

Iowa State University

322 Spedding Hall

Ames, IA 50011

Ilhan A. Aksay

University of Washington

Materials Science and Engineering

Department, FB-10

Seattle, WA 98195
R. G. Alexander

BASE, 26 Malvern Close

Kettering Northants NN16 AJP

UNITED KINGDOM AIR MAIL

Richard L. Allor

Ford Motor Company

Material Systems

Reliability Department

20000 Rotunda Drive

P.O. Box 2053, Room S-2031

Dearborn, MI 48121-2053

Richard T. Alpaugh

U.S. Department of Energy

Advanced Propulsion Division

CE-322, Forrestal Building

Washington, DC 20585

Joseph E. Amaral

Instron Corporation

Corporate Engineering Office

100 Royale Street

Canton, MA 02021

Edward M. Anderson

Aluminum Company of America

North American Industrial

Chemicals Division

P.O. Box 300

Bauxite, AR 72011

Norman C. Anderson

Ceradyne, Inc.

Ceramic-to-Metal Division

3169 Redhill Avenue

Costa Mesa, CA 92626

Don Anson

Battelle Columbus Laboratories

Thermal Power Systems

505 King Avenue

Columbus, OH 43201-2693 
Thomas Arbanas

G.B.C. Materials Corporation

580 Monastery Drive

Latrobe, PA 15650-2698

Frank Armatis

3M Company

3M Center

Building 60-1N-01

St. Paul, MN 55144-1000

Everett B. Arnold

Detroit Diesel Corporation

Mechanical Systems Technology

13400 Outer Drive, West

Detroit, MI 48239-4001

Richard M. Arons

PA Consulting Group

279 Princeton Road

Hightstown, NJ 08550

Bertil Aronsson

Sandvik AB

S-12680

Stockholm Lerkrogsvagen 19

SWEDEN AIR MAII

Dennis Assanis

University of Illinois

Department of Mechanical Engineering

1206 W. Green Street

Urbana, Il 61801

William H. Atwell

Dow Corning Corporation

3901 South Saginaw Road

MS:540

Midland, MI 48686-0995

V. S. Avva

North Carolina A\&T State University

Department of Mechanical Engineering

Greensboro, NC 27411
Patrick Badgley

Adiabatics, Inc

3385 Commerce Drive

Columbus, IN 47201

Sunggi Baik

Pohang Institute of Science \& Technology

Department of Materials Science and

Engineering

P.O. Box 125

Pohang 790-600

KOREA AIR MAII

John M. Bailey

Caterpillar, Inc.

Technical Center, Building L

P.O. Box 1875

Peoria, Il 61656-1875

Bob Baker

Ceradyne, Inc.

3169 Redhill Avenue

Costa Mesa, CA 92626

Frank Baker

Aluminum Company of America

Alcoa Technical Center

Alcoa Center, PA 15069

J. G. Baldoni

GTE Laboratories Inc.

40 Sylvan Road

Waltham, MA 02254

Clifford P. Ballard

Allied-Signal, Inc.

Ceramics Program

P.O. Box 1021

Morristown, NJ 07962-1021

B. P. Bandyopadhyay

Toyohashi University of Technology

School of Production Systems Engineering

Tempaku-Cho Toyohashi 440

JAPAN AIR MAIL 
Y. M. Barnard

Ruston Gas Turbines Limited

Metallurgical Laboratory

P. O. Box 1

Lincoln LN2 5DJ

ENGLAND AIR MAII

Harold N. Barr

Hittmas Corporation

9190 Red Branch Road

Columbia, MD 21045

Renald D. Bartoe

Vesuvius McDanel

510 Ninth Avenue

Box 560

Beaver Falls, PA 15010-0560

David L. Baty

Babcock \& Wilcox-LRC

P.O. Box 11165

Lynchburg, VA 24506-1165

Donald F. Baxter, Jr.

ASM International

Advanced Materials and Processes

Materials Park, OH 44073-0002

M. Brad Beardsley

Caterpillar, Inc.

Advanced Materials Technology

Technical Center Bldg. E

P.O. Box 1875

Peoria, IL 61656-1875

John C. Bell

Shell Research Limited

Thornton Research Centre

P.O. Box 1, Chester, Ch1 3SH

ENGI_AND AIR MAII

Albert H. Bell, III

General Motors Technical Center

30200 Mound Road

Engineering Building/W3 Tur'sine

Warren, MI 48090-9010
M. Bentele

Xamag, Inc.

259 Melville Avenue

Fairfield, CT 06430

Larry D. Bentsen

BF Goodrich Company

R\&D Center

9921 Brecksville Road

Brecksville, OH 44141

Joseph C. Bentz

ENCERATEC

2525 Sandcrest Drive

Columbus, IN 47203

Louis Beregszazi

Defiance Precision Products

P.O. Drawer 428;

Defiance, $\mathrm{OH} 43512$

Tom Bernecki

Northwestern University

BIRI

1801 Maple Avenue

Evanston, II 601201-3135

Charles F. Bersch

Institute for Defense Analyses

1801 North Beauregard Street

Alexandria, VA 22311

Ram Bhatt

NASA Lewis Research Center

21000 Brookpark Road

Cleveland, OH. 44135

Deane I. Biefiller

Caterpillar, Iuc.

Engineering and Research Materials

Technical Center, Building E

P.O. Box 1875

Peoria, IL 61656-1875 
John. W. Bjerklie

Consolidated Natural Gas

Service Co., Inc.

Research Department

CNG Tower

Pittsburgh, PA 15222-3199

William D. Bjorndahl

TRW, Inc.

One Space Park

Building 01, Room 2040

Redondo Beach, CA 90278

Keith A. Blakely

Advanced Refractory Technologies, Inc.

699 Hertel Avenue

Buffalo, NY 14207

Edward G. Blanchard

Netzsch Inc.

119 Pickering Way

Exton, PA 19341

Keith Blandford

Boride Products, Inc.

2879 Aero Park Drive

Traverse City, MI 49684

Bruce Boardman

Deere and Company Technical Center 3300 River Drive

Moline, II 61265

Russell Bockstedt

Hoechst Celanese Corporation

15 U JFK Parkway

Short Hills, NJ 07078

M. Boehmer

DLR German Aerospace Research

Establishment

Postfach 906058

D-5000 Koln 90

GERMANY AIR MAIL
Lawrence P. Boesch

EER Systems Corp.

1593 Spring Hill Road

Vienna, VA 22182-2239

Donald H. Boone

Boone \& Associates

2412 Cascade Drive

Walnut Creek, CA 94598-4313

Tom Booth

Allied-Signal Aerospace Company

AiResearch Los Angeles Division

2525 West 190th Street

Torrance, CA 90509-2960

Tibor Bornemisza

Sundstrand Power Systems

4400 Ruffin Road

San Diego, CA 92186-5757

J.A.M. Boulet

University of Tennessze

Department of Eng;neering

Science and M:chanics

310 Perkins Hall

Knoxville, TN 37996-2030

H. Kent Bowen

Massachusetts Institute of Technology

77 Massachusetts Avenue

Room E40-434

Cambridge, MA 02139

Leslie J. Bowen

Materials Syster.s

53 Hillcrest Road

Concord, MA 01742

Steven C. Boyce

Air Force Office of

Scientific Research

AFOSR/NA Eldg. 410

Bolling AFB DC 20332-6448 
Steve Bradley

UOP Research Center

50 East Algonquin Road

Des Plaines, II 60017-6187

Michael C. Brands

Cummins Engine Company, Inc.

P.O. Box 3005

Mail Code 50179

Columbus, IN 47201

Raymond J. Bratton

Westinghouse Science and

Technology Center

1310 Beulah Road

Pittsburgh, PA 15235

John J. Brennan

United Technologies Corporation

R.escarch Center

Silver Lane, MS:24

East Hartford, CT 06108

Jeff D. Bright

Ceramatec, Inc.

2425 South 900 West

Salt Lake City, UT 84108

Terrence K. Brog

Coors Ceramics Company

Corporate Development and Technology

4545 McIntyre Street

Golden, CO 80403

Gunnar Broman

317 Fairlane Drive

Spartanburg, SC 29302

Al Brown

High-Tech Materials Alert

P.O. Box 882

Dayton, NJ 08810
Jesse Brown

Virginia Polytechnic Institute and State University

Center for Advanced Ceramic Materials

Blacksburg, VA 24061-0256

Sherman D. Brown

University of Illinois

Materials Science and

Engineering Department

105 South Goodwin Avenue

204 Ceramics Building

Urbana, IL 61801

S. L. Bruner

Ceramatec, Inc.

2425 South 900 West

Salt Lake City, UT 84119

Adolfo Brusaferro

Keramont Corporation

4231 South Fremont Avenue

Tucson, AZ 85714

Walter Bryzik

U.S. Army Tank Automotive Command

R\&D Center

Propulsion Systems Division

Warren, MI 48397-5000

S. T. Buljan

GTE Laboratories, Inc.

40 Sylvan Road

Waltham, MA 02254

S. J. Burden

GTE Valenite

1711 Thunderbird

Troy, MI 48084

Curt V. Burkland

AMERCOM, Inc.

8928 Fullbright Avenue

Chatsworth, CA 91311 
Bill Bustamante

AMERCOM, Inc.

8928 Fullbright Street

Chatsworth, CA 91311

Oral Buyukozturk

Massachusetts Institute of Technology

77 Massachusetts Avenue

Room 1-280

Cambridge, MA 02139

David A Caillet

Ethyl Corporation

451 Florida Street

Baton Rouge, LA 70801

Frederick J. Calnan

Heany Industries, Inc.

249 Briarwood Lane

P.O. Box 38

Scottsville, NY 14546

Roger Cannon

Rutgers University

Ceramics Department

P.O. Box 909

Piscataway, NJ 08855-0909

Scott Cannon

P.O. Box 567254

Atlanta, GA 30356

Harry W. Carpenter

19945 Acre Street

Northridge, CA 91324

David Carruthers

Kyocera Industrial Ceramics Company

P.O. Box 2279

Vancouver, WA 98668-2279

Calvin H. Carter, Jr.

Cree Research, Inc.

2810 Meridian Parkway

Durham, NC 27713
J. David Casey

35 Atlantis Street

West Roxbury, MA 02132

Jere G. Castor

J. C. Enterprise

5078 North 83rd Street

Scottsdale, AZ 85250

James D. Cawley

Case Western Reserve University

Materials Science and

Engineering Department

Cleveland, $\mathrm{OH} 44106$

Thomas C. Chadwick

Den-Mat Corporation

P.O. Box 1729

Santa Maria, CA 93456

Ronald H. Chand

Chand Kare Technical Ceramics

2 Coppage Drive

Worcester, MA 01603

Robert E. Chaney

EG\&G Idaho, Inc.

Idaho National Engineering Laboratory

P.O. Box 1625

Idaho Falls, ID 83415-3525

Frank C. Chang

U.S. Army Materials

Technology Laboratory

AMTL-EMM

405 Arsenal Street

Watertown, MA 02172

Robert M. Chapman

Allied-Signal Aerospace Company 1001 Pennsylvania Avenue, N.W.

Suite 700 South

Washington, DC 20004 
William Chapman

Williams International Corporation

2280 West Maple Road

Walled Lake, MI 48390-0200

Charlie Chen

LECO Corporation

P.O. Box 211688

Augusta, GA 30917

Frank Childs

EG\&G Idaho, Inc.

Idaho National Engineering Laboratory

P.O. Box 1625

Idaho Falls, ID 83415-3527

William J. Chmura

Torrington Company

59 Field Street

Torrington, CT 06790-4942

Tsu-Wei Chou

University of Delaware

Center for Composite Materials

201 Spencer Laboratory

Newark, DE 19716

R. J. Christopher

Ricardo Consulting Engineers

Bridge Works

Shoreham-By-Sea West Sussex

BN43 5FG

ENGLAND AIR MAIL

Joel P. Clark

Massachusetts Institute of Technology

Room 8-409

Cambridge, MA 02139

Giorgio Clarotti

Commission of the European Communities

DGXII-C3, M075, 1-53;

200 Rue de la Loi

B-1049 Brussels

BELGIUM AIR MAII
W. J. Clegg

ICI Advanced Materials

P.O. Box 11

The Heath, Runcorn Cheshire

WA7. 4QE

ENGLAND AIR MAIL

Joseph Cleveland

GTE Products Corporation

Hawes Street

Towanda, PA 18848-0504

Gloria M. Collins

ASTM

1916 Race Street

Philadelphia, PA 19103

William C. Connors

Sundstrand Aviation Operations

Materials Science and

Engineering Department

4747 Harrison Avenue

P.O. Box 7002

Rockford, II 61125-7002

John A. Coppola

Carborundum Company

P.O. Box 156

Niagara Falls, NY 14302

Normand D. Corbin

Norton Company, Advanced Ceramics

Goddard Road

Northboro, MA 01532-1545

Douglas Corey

Allied-Signal Aerospace Company

2525 West 190th Street

MS:T52

Torrance, CA 90504-6099

Keith P. Costello

Chand/Kare Technical Ceramics

2 Coppage Drive

Worcester, MA 01603-1252 
Ed L. Courtright

Pacific Northwest Laboratory

MS:K3-59

Richland, WA 99352

Anna Cox

Mitchell Market Reports

P.O. Box 23

Monmouth Gwent NP5 4YG

UNITED KINGDOM AIR MAII

J. Wesley Cox

BIRL

1801 Maple Avenue

Evanston, IL 60201-3135

Art Cozens

Instron Corporation

3414 Snowden Avenue

Long Beach, CA 90808

Robert C. Craft

American Ceramic Society, Inc.

757 Brooksedge Plaza Drive

Westerville, OH 43081

Mark Crawford

New Technology Week

4604 Monterey Drive

Annandale, VA 22003

Richard A. Cree

Markets \& Products, Inc.

P.O. Box 14328

Columbus, OH 43214-0328

Les Crittenden

Vesuvius McDanel

Box 560

Beaver Falls, PA 15010

William J. Croft

U.S. Army Materials

Technology Laboratory

405 Arsenal Street

Watertown, MA 02172
M. J. Cronin

Mechanical Technology, Inc.

968 Albany-Shaker Road

Latham, NY 12110

Gary M. Crosbie

Ford Motor Company

1430 Culver Avenue

S-2079, SRL Building

Dearborn, MI 48121-4036

Floyd W. Crouse, Jr.

U.S. Department of Energy

Morgantown Energy

Technology Center

Collins Ferry Road

P.O. Box 880

Morgantown, WV 26505

John Cuccio

Allied-Signal Aerospace Company

Garrett Auxiliary Power Division

P.O. Box 5227, MS:1302-2Q

Phoenix, AZ 85010

Raymond Cutler

Ceramatec, Inc.

2425 South 900 West

Salt Lake City, UT 84119

Charles D'Angelo

GTE Laboratories, Inc.

40 Sylvan Road

Waltham, MA 02154

Stephen C. Danforth

Rutgers University

Ceramic Engineering Department

P.O. Box 909

Piscataway, NJ 08855-0909

Sankar Das Gupta

Electrofuel Manufacturing Co., Ltd.

9 Hanna Avenue

Toronto Ontario MGK-1W8

CANADA AIR MAIL 
Charles Davis

Sverdrup Technology, Inc., MSFC

620 Discovery Drive

Huntsville, AL 35806

Frank Davis

Allied Signal Aerospace Co.

7550 Lucerne Dr., \# 203

Middleburg Heights, OH 44130

Robert F. Davis

North Carolina State University

Materials Engineering Department

229 Riddick Laboratory

P.O. Box 7907

Raleigh, NC 27695

Thomas DeAngelis

Carborundum Company

Niagara Falls R\&D Center

P.O. Box 832

Niagara Falls, NY 14302

George DeBell

Ford Motor Company

Material Systems Reliability Department

20000 Rotunda Drive

P.O. Box 2053, Room S-2023

Dearborn, MI 48121-2053

Michael DeLuca

AMP-AKZO

West Lane

Aquebogue, NY 11931

Gerald L. DePoorter

Colorado School of Mines

Metallurgical and Materials

Engineering Department

Golden, CO 80401

J. F. DeRidder

Omni Electro Motive, Inc.,

12 Seely Hill Road

Newfield, NY 14867
Nick C. Dellow

Materials Technology Publications

40 Sotheron Road

Watford Herts WD1 2QA

UNITED KINGDOM AIR MAII

L. R. Dharani

University of Missouri-Rolla

224 M.E.

Rolla, MO 65401

Douglas A. Dickerson

Union Carbide Specialty Powders

1555 Main Street

Indianapolis, IN 46224

John Dodsworth

Vesuvius Research \& Development

Technical Ceramics Group

Box 560

Beaver Falls, PA 15010

B. Dogan

Institut fur Werkstofforschung

GKSS-Forschungszentrum

Geesthacht GmbH

Max-Planck-Strasse

D-2054 Geesthacht

GERMANY AIR MAII

Jean-Marie Lrapier

FN Moteurs S.A.

Material and Processing

B-4041 Milmort (Herstal)

BELGIUM AIR MAII

Kenneth C. Dreitlein

United Technologies

Research Center

Silver Lane

East Hartford, CT 06108 
Robin A.L. Drew

McGill University

Department of Mining and

Metallurgical Engineering

3450 University Street

Montreal Quebec H3A 2A7

CANADA AIR MAII

Winston H. Duckworth

$\mathrm{BCL}$

Columbus Division

505 King Avenue

Columbus, OH 43201-2693

Bill Durako

Sundstrand Aviation Operations

Department 789-6

4747 Harrison Avenue

P.O. Box 7002

Rockford, II 61125-7002

Ernest J. Duwell

212 Elm Street

Hudson, WI 54016

Chuck J. Dziedzic

Coors Ceramics Company

Structural Products Group

17750 West 32nd Avenue

Golden, CO 80401

Robert J. Eagan

Sandia National Laboratories

Engineered Materials \& Processes Center

Org 1700

P.O. Box 5800

Albuquerque, NM 87185-5800

Jeffrey Eagleson

Lanxide Corporation

1001 Connecticut Avenue, N.W.

Washington, DC 20036
Harry E. Eaton

United Technologies Corporation

Research Center

Silver Lane

East Hartford, CT 06108

Harvill C. Eaton

Louisiana State University

Office of Research and Economic

Development

240 Thomas Boyd Hall

Baton Rouge, LA 70803

Christopher A Ebel

Carborundum Company

Technology Division

P.O. Box 337

Niagara Falls, NY 14302

J. J. Eberhardt

U.S. Department of Energy

Office of Transportation Materials

CE-34

Washington, DC 20585

Jim Edler

Eaton Corporation

26201 Northwestern Highway

P.O. Box 766

Southfield, MI 48037

William A. Ellingson

Argonne National Laboratory

Materials Science \& Technology Division

9700 South Cass Avenue

Argonne, IL 60439

William S. Ellis

Machined Ceramics

629 N. Graham St.

$N$. Industrial Park

Bowling Green, KY 42101 
Glen B. Engle

Nuclear \& Aerospace Materials

Corporation

16716 Martincoit Road

Poway, CA 92064

Jeff Epstein

Ceramic Technologies, Inc.

2107 Jamara Lane

Houston, TX 77077

Kenneth A Epstein

Dow Chemical U.S.A.

Ceramics and Advanced Materials

800 Building

Midland, MI 48667

Art Erdemir

Argonne National Laboratory

Materials and Components

Technology Division

9700 South Cass Avenue

Argonne, II 60439

E. M. Erwin

Lubrizol Corporation

1819 East 225th Street

Euclid, OH 44117

Kenji Esaki

Toyota Technical Center

U.S.A., Inc.

2000 Town Center, Suite 500

Southfield, MI 48075

John N. Eustis

U.S. Department of Energy

Industrial Energy Efficiency Division

CE-221

Washington, DC 20585

Robert C. Evans

NASA Lewis Research Center

Terrestrial Propulsion Office

21000 Brookpark Road, MS:86-6

Cleveland, $\mathrm{OH} 44135$
W. L. Everitt

Kyocera International, Inc.

8611 Balboa Avenue

San Diego, CA 92123

Gordon Q. Evison

332 South Michigan Avenue

Suite 1730

Chicago, Il 60604

John W. Fairbanks

U.S. Department of Energy

Advanced Propulsion Division

CE-322

Washington, DC 20585

Tim Fawcett

Dow Chemical Company

Central Research, Advanced

Ceramics Laboratory

1776 Building

Midland, MI 48674

Robert W. Fawley

Sundstrand Power Systems

Division of Sundstrand Corporation

4400 Ruffin Road

P.O. Box 85757

San Diego, CA 92186-5757

John J. Fedorchak

GTE Products Corporation

Hawes Street

Towanda, PA 18848-0504

Jeff T. Fenton

Vista Chemical Company

900 Threadneedle

Houston, TX 77079

Larry Ferrell

Babcock \& Wilcox

Old Forest Road

Lynchburg, VA 24505 
Raymond R. Fessler

\section{BIRL}

Industrial Research Lab

1801 Maple Avenue

Evanston, II 60201

Ross F. Firestone

Ross Firestone Company

188 Mary Street

Winnetka, II 60093-1520

Sharon L. Fletcher

Arthur D. Little, Inc.

15 Acorn Park

Cambridge, MA 02140-2390

Thomas F. Foltz

Textron Specialty Materials

2 Industrial Avenue

Lowell, MA 01851

Renee G. Ford

Materials and Processing Report

P.O. Box 72

Harrison, NY 10528

John Formica

Supermaterials

2020 Lakeside Avenue

Cleveland, $\mathrm{OH} 44114$

Edwin Frame

Southwest Research Institute

Dir ision 2

P.O. Drawer 28510

San Antonio, TX 78284

Armanet Francois

French Scientific Mission

4101 Reservoir Road, N.W.

Washington DC 20007-2176

R. G. Frank

Technology Assessment Group 10793 Bentley Pass Lane

Loveland, OH 45140
David J. Franus

Forecast International

22 Commerce Road

Newtown, CT 06470

Marc R. Freedman

NASA Lewis Research Center

21000 Brookpark Road

MS:49-3

Cleveland, $\mathrm{OH} 44135$

Douglas Freitag

LTV Missiles Division

P.O. Box 650003

MS:WT-21

Dallas, TX 75265

Brian R.T. Frost

Argonne National Laboratory

9700 South Cass Avenue

Building 900

Argonne, II 60439

Lawrence R. Frost

Instron Corporation

100 Royall Street

Canton, MA 02021

George A. Fryburg

Norton/TRW Ceramics

7A-4 Raymond Avenue

Salem, NH 03079

Xiren Fu

Shanghai Institute of Ceramics

Chinese Academy of Sciences

1295 Ding-xi Road

Shanghai 200050

CHINA AIR MAII

John Gahimer

P.O. Box 1302

Dublin, OH 43017 
J. P. Gallagher

University of Dayton Research Institute

300 College Park, JPC-250

Dayton, OH 45469-0120

Tom Garritano

University of Tennessee

Science Alliance

101 South College

Kncxville, TN 37996-1328

Joy A Garwood

Norton Company

Advanced Ceramics

Goddard Road

Northboro, MA 01532-1545

H. Maury Gatewood

Reynolds Metals Company

Corporate R\&D

Fourth and Canal Streets

P.O. Box 27003

Richmond, VA 23261

L. J. Gauckler

ETH-Zurich

Sonneggstrasse 5

CH-8092 Zurich 8092

SWITZERLAND AIR MAII

Peter A. Gaydos

Battelle Columbus Laboratories

505 King Avenue

Columbus, OH 43201

George E. Gazza

U.S. Army Materials

Technology Laboratory

Ceramics Research Division

405 Arsenal Street

Watertown, MA 02172-0001
D. Gerster

CEA-DCOM

33 Rue De La Federation

Paris 75015

FRANCE AIR MAIL

John Ghinazzi

Coors Technical Ceramics Company

1100 Commerce Park Drive

Oak Ridge, TN 37830

Robert Giddings

General Electric Company

Research Laboratory

P.O. Box 8

Schenectady, NY 12301

A. M. Glaeser

University of California

Materials Science and Mineral Engineering

Lawrence Berkeley Laboratory

Hearst Mining Building

Berkeley, CA 94720

Joseph W. Glatz

Naval Air Propulsion Center

Systems Engineering Division

P.O. Box 7176, PE24

Trenton, NJ 08628

W. M. Goldberger

Superior Graphite Company

R\&D

2175 East Broad Street

Columbus, OH 43209

Allan E. Goldman

U.S. Graphite, Inc.

907 West Outer Drive

Oak Ridge, TN 37830

Stephen T. Gonczy

Allied Signal Research

P.O. Box 5016

Des Plaines, II 60017 
Jeffrey M. Gonzales

GTE Products Corporation

Hawes Street

Towanda, PA 18848-0504

Robert J. Gottschall

U.S. Department of Energy

ER-131, MS:G-236

Washington, DC 20545

Earl Graham

Cleveland State University

Department of Chemical Engineering

Euclid Avenue at East 24th Street

Cleveland, $\mathrm{OH} 44115$

William A. Graham

Lanxide Corporation

P.O. Box 6077

Newark, DE 19714-6077

Robert E. Green, Jr.

Johns Hopkins University

Materials Science and Engineering

Department

Baltimore, MD 21218

Lance Groseclose

General Motors Corporation

Allison Gas Turbine Division

P.O. Box 420, MS:W-5

Indianapolis, IN 46206

Mark F. Gruninger

Union Carbide Corporation

Specialty Powder Business

1555 Main Street

Indianapolis, IN 46224

Ernst Gugel

Cremer Forschungsinstitut

GmbH\&Co.KG

Oeslauer Strasse 35

D-8633 Roedental 8633

GERMANY AIR MAII
Donald L. Guile

Corning Glass Works

SP-DV-1-9

Corning, NY 14831

Bimleshwar P. Gupta

Solar Energy Research Institute

Mechanical and Industrial

Technology Division

1617 Cole Boulevard

Golden, CO 80401

John P. Gyekenyesi

NASA Lewis Research Center

21000 Brookpark Road, MS:6-1

Cleveland, OH 44135

Nabil S. Hakim

Detroit Diesel Corporation

13400 West Outer Drive

Detroit, MI 48239

Philip J. Haley

General Motors Corporation

Vehicular Engineering

P.O. Box 420, MS:T12A

Indianapolis, IN 46236

Judith Hall

Fiber Materials, Inc.

Biddeford Industrial Park

5 Morin Street

Biddeford, ME 04005

Y Hamano

Kyocera Corporation

5-22 Kitainoue-Cho, Higashino

Yamashina-Ku Kyoto 607

Japan AIR MAII

Y. Harada

IIT Research Institute

Nometallic Materials and Composites

10 West 35th Street

Chicago, II 60616 
R. A. Harmon

25 Schalren Drive

Latham, NY 12110

Norman H. Harris

Hughes Aircraft Company

P.O. Box 800520

Saugus, CA 91380-0520

Alan M. Hart

Dow Chemical Company

Advanced Ceramics Laboratory

1776 Building

Midland, MI 48674

Pat E. Hart

Battelle Pacific Northwest Laboratories

Ceramics and Polymers

Development Section

P.O. Box 999

Richland, WA 99352

Stephen D. Hartline

Norton Company

Advanced Ceramics

Goddard Road

Northboro, MA 01532-1545

Michael H. Haselkorn

Caterpillar, Inc.

Engineering Research Materials

Technical Center, Building E

P.O. Box 1875

Peoria, IL 61656-1875

N. B. Havewala

Corning, Inc.

SP-PR-11

Corning, NY 14831

John Haygarth

Teledyne WAA Chang Albany

P.O. Box 460

Albany, UR 97321
Norman L. Hecht

University of Dayton Research Institute 300 College Park

Dayton, OH 45469-0172

Peter W. Heitman

General Motors Corporation

Allison Gas Turbine Division

P.O. Box 420, MS:W-5

Indianapolis, IN 46206-0420

Robert W. Hendricks

Virginia Polytechnic Institute and State University

Materials Engineering Department

210 Holden Hall

Blacksburg, VA 24061-0237

Wynne Henley

Hertel Cutting Technologies, Inc.

1000 Clearview Court

Oak Ridge, TN 37830

Thomas L. Henson

GTE Products Corporation

Chemical \& Metallurgical Division

Hawes Street

Towanda, PA 18848

Thomas P. Herbell

NASA Lewis Research Center

21000 Brookpark Road

MS:49-3

Cleveland, OH 44135

Marlene Heroux

Rolls-Royce, Inc.

2849 Paces Ferry Road

Suite 450

Atlanta, GA 30339-3769

Robert L. Hershey

Science Management Corporation 1255 New Hampshire Ave., N.W.

Suite 1033

Washington, DC 20036 
Hendrik Heystek

Bureau of Mines

Tuscaloosa Research Center

P.O. Box L

University, AL 35486

Wallace C. Higgins

Norwal Unlimited

P.O. Box 1258

Alfred, NY 14802

Robert V. Hillery

GE Aircraft Engines

One Neumann Way, M.D. H85

Cincinnati, OH 45215

Arthur Hindman

Instron Corporation

100 Royall Street

Canton, MA 02021

Jon Hines

American Ceramic Society, Inc.

757 Brooksedge Plaza Drive

Westerville, OH 43081-6136

Hans Frich Hintermann

CSEM

Materials and Micromechanics

Division

Nue Breguet 2

Neuchatel 2000

SWITZERLAND AIR MAIL

Shinichi Hirano

Mazda R\&D of North America, Inc.

1203 Woodridge Avenue

Ann Arbor, MI 48105

Tommy Hiraoka

NGK Locke, Inc.

1000 Town Center

Southfield, MI 48075
John M. Hobday

U.S. Department of Energy

Morgantown Energy Technology Center

Collins Ferry Road

P.O. Box 880

Morgantown, WV 26507

Clarence Hoenig

Lawrence Livermore National Laboratory

P.O. Box 808, Mail Code L-369

Livermore, CA 94550

Thomas Hollstein

Fraunhofer-Institut fur

Werkstoffmechanik IWM

Wohlerstrabe 11

D-7800 Freiburg

GERMANY AIR MAII

Richard Holt

National Research Council of Canada

Structures and Materials Laboratory

Ottawa Ontario K1A 0R6

CANADA AIR MAIL

A. T. Hopper

Battelle Columbus Laboratories

Metals and Ceramics Department

505 King Avenue

Columbus, $\mathrm{OH}$ 43201-2693

Michael Horgan

Materials Engineering Magazine

1100 Superior Avenue

Cleveland, OH 44114

Woodie Howe

Coors Technical Ceramics Company

1100 Commerce Park Drive

Oak Ridge, TN 37830

Stephen M. Hsu

National Institute of Standards and Technology

Gaithersburg, MD 20899 
Hann S. Huang

Argonne National Laboratory

9700 South Cass Avenue

Argonne, II 60439-4815

Gene Huber

Precision Ferrites \& Ceramics

5576 Corporate Drive

Cypress, CA 90630

M. L. Huckabee

GTE Laboratories, Inc.

40 Sylvan Road

Waltham, MA 02254

Harold A. Huckins

Princeton Advanced Technology, Inc.

56 Finley Road

Princeton, NJ 08540

Fred R. Huettic

Advanced Magnetics, Inc.

45 Corey Lane

Mendham, NJ 07945

Brian K Humphrey

Lubrizol Petroleum Chemicals Co.

3000 Town Center, Suite 1340

Southfield, MI 48075-1201

Robert M. Humrick

Dylon Ceramic Technologies

3100 Edgehill Road

Cleveland Heights, OH 44118

Lorretta Inglehart

National Science Foundation

Division of Materials Research

1800 "G" Street, N.W.,

Room 408

Washington, DC 20550

Michael S. Inoue

Kyocera International, Inc.

KII Library, 8611 Balboa Avenue

San Diego, CA 92123-1580
Osama Jadaan

University of Wisconsin-Platteville

General Engineering Division

1 University Plaza

Platteville, WI 53818

Curtis A. Johnson

General Electric Company

Corporate R\&D

Room MB-187

P.O. Box 8

Schenectady, NY 12301

Sylvia Johnson

SRI International

333 Ravenswood Avenue

Menlo Park, CA 94025

Thomas A. Johnson

Lanxide Corporation

1300 Marrows Road

P.O. Box 6077

Newark, DE 19714-6077

W. S. Johnson

Indiana University

One City Centre, Suite 200

Bloomington, IN 47405

Walter F. Jones

Air Force Office of Scientific Research

AFOSR/NA

Bolling Air Force Base

Washington, DC 20332-6448

Jill E. Jonkouski

U.S. Department of Energy

9800 South Cass Avenue

Argonne, IL 60439-4899

L. A. Joo

Great Lakes Research Corporation

P.O. Box 1031

Elizabethton, TN 37643 
A. David Joseph

SPX Corporation

700 Terrace Point

Muskegon, MI 49443

Adam Jostsons

Australian Nuclear Science \& Technology Organization

Lucas Heights Research Laboratories

New Illawarra Road

Lucas Heights New South Wales

AUSTRALIA AIR MAIL

Matthew K. Juneau

Ethyl Corporation

451 Florida Street

Baton Rouge, LA 70801

Hartmut Kainer

Didier-Werke AG

Anlagentechnik Wiesbaden

Abraham-Lincoln-Str. 16

D-62 Wiesbaden

GERMANY AIR MAIL

Tom Kalamasz

Norton/TRW Ceramics

7A-4 Raymond Avenue

Salem, NH 03079

Lyle R. Kallenbach

Phillips Petroleum Company

R\&D

Mail Drop:123AL

Bartlesville, OK 74004

Nick Kamiya

Kyocera Industrial Ceramics Corporation 2700 River Road

Des Plaines, II 60018

Roy Kamo

Adiabatics, Inc.

3385 Commerce Park Drive

Columbus, IN 47201
Chih-Chun Kao

Industrial Technology Research Institute

Materials Research Laboratories

195 Chung-Hsing Road, Sec. 4

Chutung Hsinchu 3:1015 R.O.C.

TAIWAN AIR MAIL

Keith R. Karasek

Allied-Signal, Inc.

Engineered Materials Research Center

50 East Algonquin Road

P.O. Box 5016

Des Plaines, IL 60017-5016

Martha R. Kass

U.S. Department of Energy

Oak Ridge Operations

Building $4500 \mathrm{~N}$

P.O. Box 2008, MS:6269

Oak Ridge, TN 37831-6269

Robert E. Kassel

Ceradyne, Inc.

3169 Redhill Avenue

Costa Mesa, CA 92626

Allan Katz

Wright Laboratory

Metals and Ceramics Division

WL/MLLM

Wright-Patterson AFB, OH 45433

R. Nathan Katz

Worcester Polytechnic Institute

Dept. of Mechanical Engineering

100 Institute Road

Worcester, MA 01609

Ted Kawaguchi

Tokai Carbon America, Inc.

375 Park Avenue, Suite 3802

New York, NY 10152 
Noritsugu Kawashima TOSHIBA Corporation

Mechanical Engineering Laboratory

4-1 Ukishima-Cho

Kawasaki-Ku Kawasaki 210

JAPAN AIR MAII

I. isa Kempfer

Penton Publishing

Materials Engineering

1100 Superior Avenue

Cleveland, $\mathrm{OH}$ 44114-2543

Frederick L. Kennard, III

General Motors Corporation

AC Rochester

Department 32-24, EB

1300 North Dort Highway

Flint, MI 48556

David O. Kennedy

Lester B. Knight Cast

Metals Inc.

549 West Randolph Street

Chicago, II 60661

George Keros

Photon Physics

3175 Penobscot Building

Detroit, MI 48226

Pramod K. Khandelwal General Motors Corporation Allison Gas Turbine Division P.O. Box 420, MS:W05

Indianapolis, IN 46206

Jim R. Kidwell

Allied-Signal Aerospace Company Garrett Auxiliary Power Division

P.O. Box 5227

Phoenix, AZ 85010
Han J. Kim

GTE Laboratories, Inc.

40 Sylvan Road

Waltham, MA 02254

Shin Kim

Korea Institute of Machinery \& Metals 66 Sangnam-dong, Changwon

Kyungnam 641-010

KOREA AIR MAII

W. C. King

Mack Truck, Z-41

1999 Pennsylvania Avenue

Hagerstown, MD 21740

Carol Kirkpatrick

MSE, Inc.

CDIF Technical Library

P.O. Box 3767

Butte, MT 59702

Tony Kirn

Caterpillar, Inc.

Defense Products Department, JB7

Peoria, II 61629

James D. Kiser

NASA Lewis Research Center 21000 Brookpark Road, MS:49-3

Cleveland, OH 44135

Max Klein

Gas Research Institute

Thermodynamics

8600 West Bryn Mawr Avenue

Chicago, Il 60631

Richard N. Kleiner

Coors Ceramics Company

4545 McIntyre Street

Golden, CO 80403 
Stanley J. Klima

NASA Lewis Research Center

21000 Brookpark Road

MS:6-1

Cleveland, $\mathrm{OH} 44135$

Chris E. Knapp

Norton Advanced Ceramics

of Canada Itd.

8001 Daly Street

Niagara Falls, Ontario L2G 6S2

CANADA AIR MAII

Albert S. Kobayashi

University of Washington

Mechanical Engineering Department

MS:FU10

Seattle, WA 98195

Shigeki Kobayashi

Toyota Central Research Labs, Inc.

Nagakute Aichi 480-11

JAPAN AIR MAII

Richard A Kole

Z-Tech Corporation

8 Dow Road

Bow, NH 03304

E. Kostiner

University of Connecticut

Chemistry Department, U-60

Storrs, CT 06269-3060

Kenneth A. Kovaly

Technical Insights, Inc.

P.O. Box 1304

Fort I.ee, NJ 07024-9967

Ralph G. Kraft

Spraying Systems Company

North Avenue at Schmale Road

Wheaton, IL 60189-7900
Saunders B. Kramer

U.S. Department of Energy

Advanced Propulsion Division

CE-322, Forrestal Building

Washington, DC 20585

Arthur Kranish

Trends Publishing, Inc.

1079 National Press Building

Washington, DC 20045

A. S. Krieger

Radiation Science, Inc.

P.O. Box 293

Belmont, MA 02178

Pieter Krijgsman

Ceramic Design International

Holding B.V.

P.O. Box 68

Hattem 8050-AB

THE NETHERLANDS AIR MAII

Waltraud M. Kriven

University of Illinois

Materials Science and

Engineering Department

105 South Goodwin Avenue

Urbana, II 61801

Edward J. Kubel, Jr.

ASM International Advanced

Materials \& Processes

Materials Park, OH 44073

Dave Kupperman

Argonne National Laboratory

9700 South Cass Avenue

Argonne, IL 60439

Oh-Hun Kwon

Norton Company

Advanced Ceramics

Goddard Road

Northboro, MA 01532-1545 
W. J. Lackey

Georgia Institute of Technology

Materials Science and Technology

Atlanta, GA 30332

Jai Lala

Tenmat Ltd., 40 Somers Road

Rugby Warwickshire CV22 7DH

ENGLAND AIR MAIL

Hari S..Lamba

General Motors Corporation

Electro-Motive Division

930' West 55th Street

LidGrange, II 60525

Richard L. Landingham

Lawrence Livermore National

Laboratory

Ceramics, Corrosion, and

Thermochemistry

P.O. Box 808, L-369

Livermore, CA 94550

Charles J. Landry

Chand Kare Technical Ceramics

712 Flat Hill Road

Lumenburg, MA 01462

Manfred W. Langer

Volkswagen AG

Material Technology

3180 Wolfsburg 1

GERMANY AIR MAIL

James Lankford

Southwest Research Institute

Department of Materials Sciences

6220 Culebra Road

San Antonio, TX 78228-0510

Stanley B. Lasday

Business News Publishing Co.

Manor Oak One

1910 Cochran Road, Suite 630

Pittsburgh, PA 15220
Mark S. Laser

Solar Turbines, Inc.

2211 Erie Street

San Diego, CA 92110

S. K. Lau

Carborundum Company

Technology Division

P.O. Box 832, B-100

Niagara Falls, NY 14302

Edward A Lauder

Advanced Composite Materials

Corporation

1525 South Buncombe Road

Greer, SC 29651-9208

J. Lawrence Lauderdale

Babcock \& Wilcox

Contract Research Division

1850 "K" Street, Suite 950

Washington, DC 20006

Harry A. Lawler

Carborundum Company

Technology Division

P.O. Box 832

Niagara Falls, NY 14302

Jean F. LeCostaouec

Textron Speciality Materials

2 Industrial Avenue

Lowell, MA 01851

Benson P. Lee

Interscience, Inc.

9718 Lake Shore Boulevard

Cleveland, OH 44108

Burtrand I. Lee

Clemson University

Department of Ceramic

Engineering

Olin Hall

Clemson, SC 29634-0907 
June-Gunn Lee

KIST

Structural Ceramic Lab

P.O. Box 131, Cheong-Ryang

Seoul 130-650

KOREA AIR MAII

Ran-Rong Lee

Ceramics Process Systems Corporation

155 Fortune Boulevard

Milford, MA 01757

Stan Levine

NASA Lewis Research Center

21000 Brookpark Road

MS:49-3

Cleveland, $\mathrm{OH} 44135$

Alan V. Levy

Lawrence Berkeley Laboratory

One Cyclotron Road, MS:62-203

Berkeley, CA 94720

Ai-Kang Li

Materials Research Laboratories, ITRI

195-5 Chung-Hsing Road, Sec. 4

Chutung Hsinchu 31015 R.O.C.

TAIWAN AIR MAII

Winston W. Liang

Hong Kong Industrial

Technology Centre Co. Ltd.

78 Tat Chee Avenue

4/F, HKPC Building

Howloon

HONG KONG AIR MAIL

Robert Licht

Norton Company

Advanced Ceramics

Goddard Road

Northboro, MA 01532-1545
E. Lilley

Norton Company

Advanced Ceramics

Goddard Road

Northboro, MA 01532-1545

Laura J. Lindberg

Allied-Signal Aerospace Company

Garrett Fluid Systems Division

1300 West Warner

MS: 93-901-1207-4TT

P.O. Box 22200

Tempe, AZ 85284-2200

Leonard C. Lindgren

General Motors Corporation

Allison Gas Turbine Division

P.O. Box 420, Speed Code:T-20A

Indianapolis, IN 46206-0420

Hans A. Lindner

Cremer Forschungsinstitut

GmbH\&Co.KG

Oeslauer Strasse 35

D-8633 Rodental 8866

GERMANY AIR MAII

Ronald E. Loehman

Sandia National Laboratories

Chemistry \& Ceramics

Department 1840

P.O. Box 5800

Albuquerque, NM 87185

Jeffrey C. Logas

Winona State University

Composite Materials Engineering

115 Pasteur Hall

Winona, MN 55987

Bill Long

Babcock \& Wilcox

P.O. Box 11165

Lynchburg, VA 24506 
William D. Long

Wacker Chemicals (USA), Inc.

ESK Engineered Ceramics

50 Locust Avenue

New Canaan, CT 06840

L. A. Lott

EG\&G Idaho, Inc.

Idaho National Engineering Laboratory

P.O. Box 1625

Idaho Falls, ID 83415-2209

Raouf O. Loutfy

MER Corporation

7960 South Kolb Road

Tucson, AZ 85706

Gordon R. Love

Aluminum Company of America

Alcoa Technical Center

Alcoa Center, PA 15069

Lydia Luckevich

Ortech International

2395 Speakman Drive

Mississauga Ontario L5K 1B3

CANADA AIR MAII

James W. MacBeth

Carborundum Company

Structural Ceramics Division

P.O. Box 1054

Niagara Falls, NY 14302

H. MacLaren

General Electric Company

Thomson Laboratory, Materials

Engineering 36807

1000 Western Avenue

Lynn, MA 01910

George Maczura

Aluminum Company of America

Industrial Chemicals Division

670 One Allegheny Square

Pittsburgh, PA 15212
David Maginnis

Tinker AFB

OC-ALC/LIIRE

Tinker AFB OK 73145-5989

Frank Maginnis

Aspen Research, Inc.

220 Industrial Boulevard

Moore, OK 73160

Tai-il Mah

Universal Energy Systems, Inc.

Ceramics and Composites

Research

4401 Dayton-Xenia Road

Dayton, OH 45432

Kenneth M. Maillar

Barbour Stockwell Company

83 Linskey Way

Cambridge, MA 02142

Lorenzo Majno

Instron Corporation

100 Royall Street

Canton, MA 02021

S. G. Malghan

National Institute of Standards and Technology

I-270 \& Clopper Road

Gaithersburg, MD 20899

Lars Malmrup

United Turbine $A B$

Box 13027

Malmo S-200 44

SWEDEN AIR MAII

John Mangels

Ceradyne, Inc.

3169 Redhill Avenue

Costa Mesa, CA 92626 
Russell V. Mann

Matec Applied Sciences, Inc.

75 South Street

Hopkinton, MA 01748

William R. Manning

Champion Aviation Products Division

Old Norris Road

P.O. Box 686

Liberty, SC 29657

Ken Marnoch

Amercom, Inc.

8928 Fullbright Avenue

Chatsworth, CA 91311

Robert A. Marra

Aluminum Company of America

Alcoa Technical Center

Advanced Ceramics Center - E

Alcoa Center, PA 15069

Chauncey L. Martin

3M Company

3M Center, Building 60-1N-01

St. Paul, MN 55144

Steven C. Martin

Advanced Refractory

Technologies, Inc.

699 Hertel Avenue

Buffalo, NY 14207

Kelly J. Mather

Williams International Corporation

2280 West Maple Road

P.O. Box 200

Walled Lake, MI 48088

James P. Mathers

3M Company

3M Center

Building 201-3N-06

St. Paul, MN 55144
Ron Mayville

Arthur D. Little, Inc.

15-163 Acorn Park

Cambridge, MA 02140

F. N. Mazadarany

General Electric Company

Research Laboratory

Building K-1, Room MB-159

P.O. Box 8

Schenectady, NY 12301

James W. McCauley

Alfred University

NYS College of Ceramics

Binns-Merrill Hall

Alfred, NY 14802

Louis R. McCreight

2763 San Ramon Drive

Rancho Palos Verdes, CA 90274

Colin F. McDonald

McDonald Thermal Engineering

1730 Castellana Road

La Jolla, CA 92037

B. J. McEntire

Norton Company, TRW Ceramics

Goddard Road

Northboro, MA 01532-1545

Chuck McFadden

Coors Ceramics Company

600 9th Street

Golden, CO 80401

Henry McFadden

Magnetic Bearings, Inc.

Engineering Library

609 Rock Road

Radford, VA 24141 
Thomas D. McGee

Iowa State University

Materials Science and

Engineering Department

110 Engineering Annex

Ames, IA 50011

Carol McGill

Corning Inc.

Sullivan Park, FR-02-08

Corning, NY 14831

T. C. McLaren

Cameron Forged Products

Company

P.O. Box 1212

Houston, TX 77251-1212

James McLaughlin

Sundstrand Power Systems

4400 Ruffin Road

P.O. Box 85757

San Diego, CA 92186-5757

Matt McMonigle

U.S. Department of Energy

Improved Energy Productivity

Division

CE-231

Washington, DC 20585

Dennis McMurtry

EG\&G Idaho, Inc.

Idaho National Engineering

Laboratory

P.O. Box 1625

Idaho Falls, ID 83415

J. C. McVickers

Allied-Signal Aerospace Company

Garrett Auxiliary Power Division

Bldg. 1303-206

P.O. Box 5227, MS:9317-2

Phoenix, AZ 85010
D. B. Meadowcroft

National Power Technology

and Environmental Centre

Kelvin Avenue

Leatherhead Surrey

KT22 7SE

ENGLAND AIR MAIL

Jo Meglen

11004 Birdfoot Court

Reston, VA 22091

Joseph J. Meindl

Reynolds International, Inc.

6603 West Broad Street

P.O. Box 27002

Richmond, VA 23261-7003

Michael D. Meiser

Allied-Signal Aerospace Company

Garrett Ceramic Components Division

2525 West 190th Stree:

P.O. Box 2960, MS:T21

Torrance, CA 90509-2960

George Messenger

National Research Council of

Canada

Engine Laboratory

Building M-7

Ottawa Ontario K1A OR6

CANADA AIR MAIL

D. Messier

U.S. Army Materials Technology

Laboratory

SLCMT-EMC

405 Arsenal Street

Watertown, MA 02172-0001

Arthur G. Metcalfe

Arthur G. Metcalfe and

Associates, Inc.

2108 East 24th Street

National City, CA 91950 
R. Metselaar

Eindhoven University

Centre for Technical Ceramics

P.O. Box 513

Eindhoven $5600 \mathrm{MB}$

THE NETHERLANDS AIR MAIL

David J. Michael

Harbison-Walker Refractories Company

P.O. Box 98037

Pittsburgh, PA 15227

Ken Michaels

Chrysler Motors Corporation

Ceramics Development

Metallurgical Processes

P.O. Box 1118, CIMS:418-17-09

Detroit, MI 48288

Bernd Michel

Institute of Mechanics

Fracture and Micromechanics

Department

P.O. Box 408

D-9010 Chemnitz

GERMANY AIR MAIl

David E. Miles

Commission of the European

Communities

rue de la Loi, 200

B-1049 Brussels

BELGIUM AIR MAIL

Carl E. Miller

AC Rochester

1300 North Dort Highway,

MS:32-31

Engineering Building B

Flint, MI 48556

Charles W. Miller, Jr.

Centorr Furnaces/Vacuum Industries

542 Amherst Street

Nashua, NH 03063
R. Mininni

Enichem America

2000 Cornwall Road

Monmouth Junction, NJ 08852

Michele V. Mitchell

Allied-Signal Aerospace

Company

Garrett Ceramic Components

Division

2525 West 190th Street

P. O. Box 2960, MS:T21

Torrance, CA 90501-2960

Howard Mizuhara

WESGO

477 Harbor Boulevard

Belmont, CA 94002

Helen Moeller

Babcock \& Wilcox

P.O. Box 11165

Lynchburg, VA 24506-1165

Francois R. Mollard

Concurrent Technologies Corporation

1450 Scalp Avenue

Johnstown, PA 15904-3374

Phil Mooney

Panametrics

NDE Division

221 Crescent Street

Waltham, MA 02254

Geoffrey P. Morris

3M Company

3M Traffic Control Materials

Division

Bldg. 209-BW-10, 3M Center

St. Paul, MN 55144-1000 
Jay A. Morrison

Rolls-Royce, Inc.

Engineering and Information

Center, Overlook 1

2849 Paces Ferry Road,

Suite 450

Atlanta, GA 30339-3769

Joel P. Moskowitz

Ceradyne, Inc.

3169 Redhill Avenue

Costa Mesa, CA 92626

Brij Moudgil

University of Florida

Material Science and

Engineering

Gainesville, FL 32611

Christoph J. Mueller

Sprechsaal Publishing Group

P.O. Box 2962, Mauer 2

D-8630 Coburg GERMANY AIR MAII

Thomas W. Mullan

Vapor Technologies Inc.

345 Route 17 South

Upper Saddle River, NJ 07458

M. K. Murthy

MKM Consultants International

10 Avoca Avenue, Unit 1906

Toronto Ontario M4T 2B7

CANADA AIR MAIL

David L. Mustoe

Custom Technical Ceramics

8041 West I-70 Service Road,

Unit 6

Arvada, CO 80002
Curtis V. Nakaishi

U.S. Department of Energy

Morgantown Energy Technology

Center

Collins Ferry Road

P.O. Box 880

Morgantown, WV 26507-0880

Yoshio Nakamura

Faicera Research Institute

2-5-8 Hiyakunin-cho Shinjuku-Ko

Tokyo

JAPAN AIR MAIL

K S. Narasimban .

Hoeganaes Corporation

River Road

Riverton, NJ 08077

Samuel Natansohn

GTE Laboratories, Inc.

40 Sylvan Road

Waltham, MA 02254

Robert Naum

Applied Resources, Inc.

P.O. Box 241

Pittsford, NY 14534

Malcolm Naylor

Cummins Engine Company, Inc.

P.O. Box 3005, Mail Code 50183

Columbus, IN 47202-3005

Jeffrey Neil

GTE Laboratories, Inc.

40 Sylvan Road

Waltham, MA 02254

Fred A. Nichols

Argonne National Laboratory

9700 South Cass Avenue

MCT - Building 212

Argonne, II 60439 
H. Nickel

Furschungszentrum Jüelich (KFA)

P.O. Box 1913

Jüelich 1-5170 BRD NRW

GERMANY AIR MAII

Dale E. Niesz

Rutgers University

Center for Ceramic Research

P.O. Box 909

Piscataway, NJ 08855-0909

David M. Nissley

United Technologies Corporation

Pratt \& Whitney Aircraft

400 Main Street, MS:163-10

East Hartford, CT 06108

Bruce E. Novich

Ceramics Process Systems Corporation

155 Fortune Boulevard

Milford, MA 01757

Daniel Oblas

GTE Laboratories, Inc.

40 Sylvan Road

Waltham, MA 02254

Don Ohanehi

Magnetic Bearings, Inc.

1908 Sussex Road

Blacksburg, VA 24060

D. O'Neil

GTE Laboratories, Inc.

40 Sylvan Road

Waltham, MA 02254

Robert Orenstein

General Electric Company

55-112, River Road

Schenectady, NY 12345
Norb Osborn

Aerodyne Dallas

151 Regal Row,

Suite 120

Dallas, TX 75247

Richard Palicka

Cercom, Inc.

1960 Watson Way

Vista, CA 92083

Muktesh Paliwal

GTE Products Corporation

Hawes Street

Towanda, PA 18848

Joseph E. Palko

General Electric Company

55-113, River Road

Schenectady, NY 12345

Joseph E. Palko

General Electric Company

55-113, River Road

Schenectady, NY 12345

Joseph N. Panzarino

Norton Company

Advanced Ceramics

Goddard Road

Northboro, MA 01532-1545

Pellegrino Papa

Corning Inc.

MP-WX-02-1

Corning, NY 14831

E. Beth Pardue

MPC

8297 Williams Ferry Road

Lenoir City, TN 37771 
Soon C. Park

3M Company

3M Center

Building 142-4N-02

P.O. Box 2963

St. Paul, MN 55144

Hartmut Paschke

Schott Glaswerke

Christoph-Domer-Strasse 29

D-8300 Landshut

GERMANY AIR MAII

Marina R. Pascucci

GTE Laboratories, Inc.

40 Sylvan Road

Waltham, MA 02254

James W. Patten

Cummins Engine Company, Inc.

Materials Engineering

P.O. Box 3005, Mail

Code 50183

Columbus, IN 47202-3005

Robert A. Penty

Eastman Kodak Company

KAD/D73 - 35612

901 Elmgrove Road

Rochester, NY 14653

Robert W. Pepper

Textron Specialty Materials

2 Industrial Avenue

Lowell, MA 01851

Peter Perdue

Detroit Diesel Corporation

Research Advanced Development

Group

13400 Outer Drive West

Speed Code L-04

Detroit, MI 48239-4001
Bruce Peters

Dow Chemical Company

Building 52

Midland, MI 48667

John J. Petrovic

Los Alamos National Laboratory

Group MST-4, MS:G771

Los Alamos, NM 87545

Frederick S. Pettit

University of Pittsburgh

Pittsburgh, PA 15261

Ben A. Phillips

Phillips Engineering Company

721 Pleasant Street

St. Joseph, MI 49085

Richard C. Phoenix

Ohmtek, Inc.

2160 Liberty Drive

Niagara Falls, NY 14302

Bruce J. Pletka

Michigan Technological

University

Metallurgical and Materials

Engineering Department

Houghton, MI 49931

John P. Pollinger

Allied-Signal Aerospace Company

Garrett Ceramic Components

Division

2525 West 190th Street

P.O. Box 2960, MS:T21

Torrance, CA $90509-2960$

P. Popper

High Technology Ceramics

International Journal

22 Pembroke Drive

Westlands Newcastle-under-Lyme

Staffs ST5 2JN

ENGLAND AIR. MAli. 
F. Porz

Universitat Karlsruhe

Institut fur Keramik Im

Maschinendau

Postfach 6980

D-7500 Karlsrube

\section{GERMANY AIR MAIL}

Harry L. Potma

Royal Netherlands Embassy

Science and Technology

4200 Linnean Avenue, N.W.

Washington, DC 20008

Bob R. Powell

General Motors Research

Laboratories

Metallurgy Department

30500 Mound Road

Box 9055

Warren, MI 48090-9055

Stephen C. Pred

ICD Group, Inc.

1100 Valley Brook Avenue

Lyndhurst, NJ 07071

Karl M. Prewo

United Technologies Research Center

411 Silver Lane

MS:24

East Hartford, CT 06108

Peter E. Price

Industrial Materials

Technology, Inc.

P.O. Box 9565

Andover, MA 01810

Joseph M. Proud

GTE Laboratories, Inc.

Materials Science Laboratory

40 Sylvan Road

Waltham, MA 02254
Vimal K. Pujari

Norton Company

Advanced Ceramics

Goddard Road

Northboro, MA 01532-1545

George Quinn

National Institute of

Standards and Technology

Ceramics Division, Bldg. 223

Gaithersburg, MD 20899

Ramas V. Raman

Ceracon, Inc.

1101 North Market Boulevard,

Suite 9

Sacramento, CA 95834

Charles F. Rapp

Owens Corning Fiberglass

2790 Columbus Road

Granville, OH 43023-1200

Dennis W. Readey

Colorado School of Mines

Department of Metallurgy and Materials Engineering

Golden, CO 80401

Wilfred J. Rebello

PAR Enterprises, Inc.

12601 Clifton Hunt Lane

Clifton, VA 22024

Harold Rechter

Chicago Fire Brick Company

R\&D

7531 South Ashland Avenue

Chicago, II 60620

Robert R. Reeber

U.S. Army Research Office

P.O. Box 12211

Research Triangle Park, NC 27709 
K. L. Reifsnider

Virginia Polytechnic Institute and State University

Department of Engineering

Science and Mechanics

Blacksburg, VA 24061

Paul E. Rempes

McDonnell Douglass

Aircraft Company

P.O. Box 516,

Mail Code: 0642263

St. Louis, MO 63166-0516

Gopal S. Revankar

John Deere Company

Metals Research

3300 River Drive

Moline, II 61265

K T. Rhee

Rutgers University

Mechanical Engineering

P.O. Box 909

Piscataway, NJ 08854

James Rhodes

Advanced Composite Materials

Corporation

1525 South Buncombe Road

Greer, SC 29651

Roy W. Rice

W. R. Grace and Company

7379 Route 32

Columbia, MD 21044

David W. Richerson

2093 East Delmont Drive

Salt Lake City, UT 84117

Tomas Richter

J. H. France Refractories

1944 Clarence Road

Snow Shoe, PA 16874
Michel Rigaud

Ecole Polytechnique

Campus Universite De Montreal

P.O. Box 6079, Station A

Montreal, P.Q Quebec H3C 3A7

CANADA AIR MAII

R. E. Riman

Rutgers University

Ceramics Engineering

Department

P.O. Box 909

Piscataway, NJ 08855-0909

Barry Ringstrom

Superior Graphite Company

P.O. Box 2373

Smyrna, GA 30081

John E. Ritter

University of Massachusetts

Mechanical Engineering

Department

Amherst, MA 01003

Frank L. Roberge

Allied-Signal Aerospace

Company

Garrett Auxiliary Power

Division

P.O. Box 5227

Phoenix, AZ 85010

W. Eric Roberts

Advanced Ceramic Technology, Inc. 990 "F" Enterprise Street

Orange, CA 92667

Y. G. Roman

TNO TPD Keramick

P.O. Box 595

Einhoven 5600 AN

HOLLAND AIR MAII 
Michael Rossetti

Arthur D. Little, Inc.

15 Acorn Park

Cambridge, MA 01240

Barry R. Rossing

Lanxide Corporation

1300 Marrows Road

Newark, DE 19714-6077

Steven L. Rotz

Lubrizol Corporation

29400 Lakeland Boulevard

Wickliffe, OH 44092

Bruce Rubinger

Global Competitiveness, Inc.

One Devonshire Place,

Suite 1011

Boston, MA 02109

Robert Ruh

Wright Laboratory

WLMILM

Wright-Patterson AFB, OH 45433

Robert J. Russell

17 Highgate Road

Framingham, MA 01701

L. William Sabley

Supermaterials Company

24400 Highland Road

Richmond Heights, OH 44143

Jon Salem

NASA Lewis Research Center

21000 Brookpark Center

Cleveland, OH 44135

W. A. Sanders

NASA Lewis Research Center 21000 Brookpark Road,

MS:49-3

Cleveland, OH 44135
J. Sankar

North Carolina A\&T State

University

Department of Mechanical

Engineering

Greensboro, NC 27411

Yasushi Sato

NGK Spark Plugs (U.S.A.), Inc.

1200 Business Center Drive,

Suite 300

Mt. Prospect, II 60056

Maxine L. Savitz

Allied-Signal Aerospace Company

Garrett Ceramic Components

Division

2525 West 190th Street

P. O. Box 2960, MS:T21

Torrance, CA $90509-2960$

Ashok Saxena

GTRI

Materials Engineering

Atlanta, GA 30332-0245

David W. Scanlon

Instron Corporation

100 Royall Street

Canton, MA 02021

Charles A. Schacht

Schacht Consulting Services

12 Holland Road

Pittsburgh, PA 15235

James Schienle

Allied-Signal Aerospace

Company

Garrett Auxiliary Power

Division

2739 East Washington Street

P.O. Box 5227, MS:1302-2P

Phoenix, AZ 85010 
John C. Schneider

San Juan Technologies

P.O. Box 49326

Colorado Springs, CO 80949-9326

Gary Schnittgrund

Rocketdyne, BA05

6633 Canoga Avenue

Canoga Park, CA 91303

Mark Schomp

Lonza, Inc.

Corporate Headquarters

17-17 Route 208

Fair Lann, NJ 07410

Joop Schoonman

Delft University of Technology

Laboratory for Inorganic Chemistry

P.O. Box 5045

2600 GA Delft

THE NETHERLANDS AIR MAIL

John Schuldies

Industrial Ceramic Technology, Inc.

37 Enterprise Drive

Ann Arbor, MI 48103

Robert B. Schulz

U.S. Department of Energy

Office of Transportation Materials

CE-34

Washington, DC 20585

Murray A. Schwartz

Materials Technology Consulting, Inc.

30 Orchard Way, North

Potomac, MD 20854

Peter Schwarzkopf

SRI International

333 Ravenswood Avenue

Menlo Park, CA 94025
William T. Schwessinger

Multi-Arc Scientific Coatings

1064 Chicago Road

Troy, MI 48083-4297

W. D. Scott

University of Washington

Materials Science Department

Mail Stop:FB10

Seattle, WA 98195

Nancy Scoville

Thermo Electron Technologies

74 West Street

P.O. Box 9046

Waltham, MA 02254-9046

Brian Seegmiller

Coors Ceramics Company

600 9th Street

Golden, CO 80401

T. B. Selover

AICRE/DIPPR

3575 Traver Road

Shaker Heights, OH 44122

J. H. Selverian

GTE Laboratories, Inc.

40 Sylvan Road

Waltham, MA 02254

Charles E. Semler

Semler Materials Services

4160 Mumford Court

Columbus, $\mathrm{OH} 43220$

Thomas Service

Service Engineering Laboratory

324 Wells Street

Greenfield, MA 01301 
Kish Seth

Ethyl Corporation

R\&D Laboratories

P.O. Box 341

Baton Rouge, LA 70821

Karleen Seybold

Allied-Signal Aerospace Company

Garrett Auxiliary Power Division

P.O. Box 5227

Phoenix, AZ 85010

William J. Shack

Argonne National Laboratory

9700 South Cass Avenue

Building 212

Argonne, II 60439

Peter T. B. Shaffer

Technical Ceramics

Laboratories, Inc.

4045 Nine/McFarland Drive

Alpharetta, GA 30201

Richard K Shaltens

NASA Lewis Research Center

21000 Brookpark Road,

MS:301-2

Cleveland, OH 44135

Robert S. Shane

238 Hemlock Road

Wynnewood, PA 19096

Daniel Shanefield

Rutgers University

Ceramics Engineering Department

P.O. Box 909

Piscataway, NJ 08855-0909

Ravi Shankar

Chromalloy

Research and Technology

Division

Blaisdell Road

Orangeburg, NY 10962
Terence Sheehan

Alpex Wheel Company

727 Berkley Street

New Milford, NJ 07646

Dinesh K. Shetty

University of Utah

304 EMRO, Dept. of Materials

Science and Engineering

Salt Lake City, UT 84112

Masahide Shimizu

Ceramic Society of Japan

2-2-503 Takiyama 6-chome

Higashikurume-Shi Tokyo 203

JAPAN AIR MAII

John Shipinski

Toyota Technical Center

U.S.A., Inc.

Technical Research Department

2000 Town Center, Suite 500

Southfield, MI 48075

Thomas Shreves

American Ceramic Society, Inc.

Library

757 Brooksedge Plaza Drive

Westerville, OH 43081-2821

Jack D. Sibold

Coors Ceramics Company

Contracts for Corporate

Technology

4545 McIntyre Street

Golden, CO 80403

George H. Siegel

Point North Associates, Inc.

P.O. Box 907

Madison, NJ 07940 
Johann Siebels

Volkswagen AG

Werkstofftechnologie

Postfach

3180 Wolfsburg 1

GERMANY AIR MAII

Richard Silberglitt

Technology Assessment and

Transfer, Inc.

133 Defense Highway, \#212

Annapolis, MD 21401

Mary Silverberg

Norton Company

Advanced Ceramics Library

Goddard Road

Northboro, MA 01532-1545

Gurpreet Singh

Department of the Navy

Internal Combustion \& Gas

Turbine Engine Division

Code 56X31

Washington, DC 20362-5101

Maurice J. Sinnott

University of Michigan

Chemical and Metallurgical

Engineering

5106 IST Building

Ann Arbor, MI 48109-2099

John Skildum

3M Company

3M Center

Building 224-2S-25

St. Paul, MN 55144

David P. Smith

Hoskins, Rees \& Smith

1910 Cochran Road

Manor Oak II, Suite 658

Pittsburgh, PA 15220
Richard H. Smoak

Smoak \& Associates

3554 Hollyslope Road

Altadena, CA 91001-3923

Jay R. Smyth

Allied-Signal Aerospace Company

Garrett Auxiliary Power Division

2739 East Washington Street

P.O. Box 5227

MS:93-173/1303-207

Phoenix, AZ 85010

Rafal A Sobotowski

British Petroleum Company

Technical Center, Broadway

3092 Broadway Avenue

Cleveland, OH 44115

A. G. Solomah

SAC International Ltd.

1445 Bonhill Road, \# 13

Mississauga Ontario L5T 1V3

CANADA AIR MAII

S. Somiya

Nishi Tokyo University

3-7-19 Seijo, Setagaya

Tokyo 157

JAPAN AIR MAII

Boyd W. Sorenson

DuPont Lanxide Composites

1300 Marrows Road

P.O. Box 6077

Neward, DE 19707

Charles A. Sorrell

U.S. Department of Energy

Advanced Industrial Concepts Division

CE-232

Washington, DC 20585 
C. Spencer

EA Technology

Capenhurst Chester

CH1 6ES

UNITED KINGDOM AIR MAII

Allen Spizzo

Hercules, Inc.

Hercules Plaza

Wilmington, DE 19894

Richäd M. Spriggs

Alfred University

Center for Advanced Ceramic

Technology

Alfred, NY 14802

Charles Spuckler

NASA Lewis Research Center

21000 Brookpark Road

MS: 5-11

Cleveland, OH 44135-3191

M. Srinivasan

Material Solutions

P.O. Box 663

Grand Island, NY 14702-0663

Gordon L. Starr

Cummins Engine Company, Inc.

Design \& Technology

P.O. Box 3005

Mail Code 50182

Columbus, IN 47202-3005

Jim Stevenson

Windrock, Incorporated

835 Innovation Drive

Knoxville, TN 37932
Tom Stillwagon

Allied-Signal Aerospace

Company

Garrett Ceramic Components

Division

2525 West 190th Street

P. O. Box 2960, MS:T21

Torrance, CA 90509-2960

H. M. Stoller

TPL Inc.

3754 Hawkins, N.E.

Albuquerque, NM 87109

Harold L. Stocker

General Motors Corporation

Allison Gas Turbine Division

P.O. Box 420

Indianapolis, IN 46206

Paul D. Stone

Dow Chemical USA

1776 "Eye" Street, N.W.,

Suite 575

Washington, DC 20006

Roger S. Storm

Carborundum Company

Technology Division

P.O. Box 337

Niagara Falls, NY 14302-0337

F. W. Stringer

Aero \& Industrial

Technology Ltd.

P.O. Box 46, Wood Top

Burnley Lancashire BB11 4BX

UNITED KINGDOM AIR MAIL

Thomas N. Strom

NASA Lewis Research Center

21000 Brookpark Road

MS:86-6

Cleveland, OH 44135 
M. F. Stroosnijder

Institute for Advanced Materials

Joint Research Centre

21020 Ispra (VA)

ITALY AIR MAIl

Karsten Styhr

30604 Ganado Drive

Rancho Palos Verdes, CA 90274

T. S. Sudarshan

Materials Modification, Inc. 2929-P1 Eskridge Center

Fairfax, VA 22031

M. J. Sundaresan

University of Miami

Mechanical Engineering

Department

P.O. Box 248294

Coral Gables, FL 33124

Patrick L. Sutton

U.S. Department of Energy

Advanced Propulsion Division

CE-322

Washington, DC 20585

Willard H. Sutton

United Technologies Corporation

Research Center, MS:24

Silver Lane

East Hartford, CT 06108

Ron Sviben

100 Indel Avenue

Rancocas, NJ 08073

J. J. Swab

U.S. Army Materials Technology Laboratory

Ceramics Research Division

SLCMT-EMC

405 Arsenal Street

Watertown, MA 02172
Robert E. Swanson

Metalworking Technology, Inc.

1450 Scalp Avenue

Johnstown, PA 15904

Scott L. Swartz

Battelle Columbus

Laboratories

Metals and Ceramics

505 King Avenue

Columbus, OH 43201

Steve Szaruga

Air Force Wright Aeronautical

Laboratory

Materials Directorate

WL/MLBC

Wright-Patterson

AFB, OH 45433-6533

Yo Tajima

NGK Spark Plug Company, Ltd.

NTK Technical Ceramic Division

2808 Iwasaki

Komaki-shi Aichi-ken 485

JAPAN AIR MAII

Fred Teeter

5 Tralee Terrace

East Amherst, NY 14051

Monika O. Ten Eyck

Carborundum Company

Technology Division

P.O. Box 832

Niagara Falls, NY 14302

David F. Thompson

Corning Glass Works

SP-DV-02-1

Corning, NY 14831

Merle L. Thorpe

Hobart Tafa Technologies, Inc.

146 Pembroke Road

Concord, NH 03301 
Eberhard Tiefenbacher

Daimler-Benz AG Abt. F1S

Mercedes-Strabe 136

Stuttgart 60

GERMANY AIR MAIL

T. Y. Tien

University of Michigan

Materials Science and

Engineering Department

Dow Building

Ann Arbor, MI 48103

D. M. Tracey

Norton Company

Advanced Ceramics

Goddard Road

Northboro, MA 01532-1545

Dick Trippett

General Motors Corporation

Allison Gas Turbine Division

P.O. Box 420, MS:W-16

Indianapolis, IN 46206-0420

L. J. Trostel, Jr.

Box 199

Princeton, MA 01541

W. T. Tucker

General Electric Company

Corporate R\&D

Building K1-4C35

P.O. Box 8

Schenectady, NY 12301

Masanori Ueki

Nippon Steel Corporation

Central R\&D Bureau

1618 Ida

Nakahara-Ku Kawasaki 211

JAPAN AIR MAIl
Filippo M. Ugolini

ATA Studio

Via Degli Scipioni, 268A

ROMA 00192

ITALY AIR MAII

Donald L. Vaccari

General Motors Corporation

Allison Gas Turbines

P.O. Box 420

Speed Code 549

Indianapolis, IN 46206-0420

Carl F. Van Conant

Boride Products, Inc.

2879 Aero Park Drive

Traverse City, MI 49684

Marcel H. Van De Voorde

Commission of the European

Communities

Institute for Advanced

Materials

Joint Research Centre

P.O. Box 2

1755 ZG Petten

THE NETHERLANDS AIR MAIl

O. Van Der Biest

Katholieke Universiteit Leuven

Departement Metaalkunde en

Toegepaste

de Croylaan 2

B-3030 Leuven

BELGIUM AIR MAII

Michael Vannier

Washington University,

St. Louis

Mallinckrodt Institute of Kadiology

510 South Kings Highway

St. Louis, MO 63110 
Stan Venkatesan

Southern Coke \& Coal

Corporation

P.O. Box 52383

Knoxville, TN 37950

V. Venkateswaran

Carborundum Company

Niagara Falls R\&D Center

P.O. Box 832

Niagara Falls, NY 14302

Dennis Viechnicki

U.S. Army Materials Technology

Laboratory

405 Arsenal Street

Watertown, MA 02172-0001

Ted Vojnovich

U.S. Department of Energy

Office of Energy Research,

ER-42

Washington, DC 20585

John D. Volt

E. I. Dupont de Nemours \&

Company, Inc.

P.O. Box 80262

Wilmington, DE 19880

John B. Wachtman

Rutgers University

Ceramics Department

P.O. Box 909

Piscataway, NJ 08855

Shigetaka Wada

Toyota Central Research

Labs, Inc.

Nagakute Aichi 480-11

JAPAN AIR MAII
Janet Wade

Allied-Signal Aerospace

Company

Garrett Auxiliary Power

Division, Department 93-772

P.O. Box 5227, MS:1303-2

Phoenix, AZ 85010

Richard L. Wagner

Ceramic Technologies, Inc.

537 Turtle Creek South Drive,

Suite 24D

Indianapolis, IN 46227

J. Bruce Wagner, Jr.

Arizona State University

Center for Solid State Science

Tempe, AZ 85287-1704

Daniel J. Wahlen

Kohler, Co.

444 Highland Drive

Kohler, WI 53044

Ingrid Wahlgren

Royal Institute of Technology

Studsvik Library

S-611 82 Nykoping

SWEDEN AIR MAIL

Ron H. Walecki

Allied-Signal Aerospace Company

Garrett Ceramic Components Division

2525 West 190th Street

P.O. Box 2960, MS:T21

Torrance, CA $90509-2960$

Michael S. Walsh

Vapor Technologies Inc.

2100 Central Avenue

Boulder, CO 80301 
Chien-Min Wang

Industrial Technology Research Institute

Materials Research Laboratories

195 Chung-Hsing Road, Sec. 4

Chutung Hsinchu 31015 R.O.C.

TAIWAN AIR MAII

Robert M. Washburn

ASMT

11203 Colima Road

Whittier, CA 90604

S. F. Wayne

GTE Laboratories, Inc.

40 Sylvan Rd.

Waltham, MA 02254

Gerald Q. Weaver

Carborundum Specialty Products

42 Linus Allain Avenue

Gardner, MA 01440-2478

Karen E Weber

Detroit Diesel Corporation

Technology and Planning

13400 West Outer Drive

Detroit, MI 48239-4001

R. W. Weeks

Argonne National Laboratory

MCT-212

9700 South Cass Avenue

Argonne, II 60439

J. K. Weddell

DuPont Fibers

Experimental Station, E302

Wilmington, DE 19880-0302

Ludwig Weiler

ASEA Brown Boveri AG

Corporate Research

Eppelheimer Str. 82

D-6900 Heidelberg

GERMANY AIR MAII
James Wessel

Dow Corning Corporation 1800 "M" Street, N.W.,

Suite 325 South

Washington, DC 20036

Robert D. West

Therm Advanced Ceramics

P.O. Box 220

Ithaca, NY 14851

Thomas J. Whalen

Ford Motor Company

26362 Harriet

Dearborn Heights, MI 48127

Ian A. White

Hoeganaes Corporation

River Road

Riverton, NJ 08077

Alan Whitehead

General Electric Company

1 River Road, 55-111

Schenectady, NY 12345

Sheldon M. Wiederhorn

National Institute of

Standards and Technology

Building 223, Room A329

Gaithersburg, MD 20899

John F. Wight

Alfred University

McMahon Building

Alfred, NY 14802

D. S. Wilkinson

McMaster University

Materials Science and

Engineering Department

1280 Main Street, West

Hamilton Ontario L8S 4L7

CANADA AIR MAII 
James C. Williams

Genera' Electric Company

Engineering Materials

Technology Labs

One Neumann Way

Mail Drop: H85

Cincinnati, OH 45215-6301

Janette R. Williams

Kollmorgen Corporation

PCK. Technology Division

150 Motor Parkway, \# 262

Hauppauge, NY 11788-5108

Steve J. Williams

RCG Hagler Bailly, Inc. 1530 Wilson Boulevard,

Suite 900

Arlington, VA 22209-2406

Craig A. Willkens

Norton Company

Advanced Ceramics

Goddard Road

Northboro, MA 01532-1545

Roger R. Wills

TRW, Inc.

Valve Division

1455 East 185th Street

Cleveland, OH 44110

David Gordon Wilson

Massachusetts Institute of Technology

Mechanical Engineering

Department

77 Massachusetts Avenue,

Room 3-455

Cambridge, MA 02139

Matthew F. Winkler

Seaworthy Systems, Inc.

P.O. Box 965

Essex, CT 06426
Gerhard Winter

Hermann C. Starck Berlin GmbH, Werk Goslar

P.O. Box 2540

D-3380 Goslar 3380

GERMANY AIR MAIL

W. L Winterbottom

Ford Motor Company

Material Systems Reliability

Department

20000 Rotunda Drive

SRL, Room E-3182

P.O. Box 2053

Dearborn, MI 48121

David G. Wirth

Coors Ceramies Company

600 9th Street

Golden, CO 80401

Thomas J. Wissing

Eaton Corporation

Engineering \& Research Center

P.O. Box 766

Southfield, MI 48037

James C. Withers

MER Corporation

7960 South Kolb Road

Building $F$

Tucson, AZ 85706

Dale E. Wittmer

Southern Illinois University

Mechanical Engineering

Department

Carbondale, II 62901

Warren W. Wolf

Owens Corning Fiberglass

2790 Columbus Road, Route 16

Granville, OH 43023 
Egon E. Wolff

Caterpillar Inc.

Technical Center

P.O. Box 1875

Peoria, In 61656-1875

George W. Wolter

Howmet Turbine Components

Corporation

Technical Center

699 Benston Road

Whitehall, MI 49461

James C. Wood

NASA Lewis Research Center 21000 Brookpark Road

MS:86-6

Cleveland, OH 44135

Marrill Wood

LECO Corporation

Augusta Division

P.O. Box 211688

Augusta, GA 30917-1688

Wayne L. Worrell

University of Pennsylvania

Department of Materials

Science and Engineering

3231 Walnut Street

Philadelphia, PA 19104

John F. Wosinski

Corning Inc.

ME-2 E-5 H8

Corning, NY 14830

Ian G. Wright

Battelle Columbus Laboratories

505 King Avenue

Columbus, OH 43201
Ruth Wroe

ERDC

Metals \& Materials Industries

Division

Capenhurst Chester CH1 6ES

ENGLAND AIR MAII

Bernard J. Wrona

Advanced Composite Materials

Corporation

1525 South Buncombe Road

Greer, SC 29651

Carl C. M. Wu

Naval Research Laboratory

Ceramic Branch, Code 6373

Washington, DC 20375

John C. Wurst

University of Dayton Research

Institute

300 College Park

Dayton, OH 45469-0101

Neil Wyant

ARCH Development Corp.

9700 South Cass Avenue

Building 202

Argonne, II 60439

Roy Yamamoto

Texaco Inc.

P.O. Box 509

Beacon, NY 12508-0509

John Yamanis

Allied-Signal, Inc.

Ceramics Program

P.O. Box 1021

Morristown, NJ 07962-1021 
Harry C. Yeh

Allied-Signal Aerospace

Company

Garrett Ceramic Components

Division

2525 Wes: 190th Street

P.O. Box 2960, MS:T21

Torrance, CA $90509-2960$

Hiroshi Yoiroyama

Hitachi Research Lab

4026 Xuji-Cho

Hitachi-shi Tbaraki 319-12

JAPAN AIR MAIL

Thomas M. Yonushonis

Cummins Engine Company, Inc.

P.O. Bcx 3005

Mail Code 50183

Columbus, IN 47202-3005

Thomas J. Yost

Corning, Inc.

Technical Produrts Division,

Main Plant 21-1-2

Corning, NY 14831

Jong Yung

Sundstrand Aviation Operations

Department 789-6

4747 Harrison Avenue

Rockford, II 61125

A. L Zadoks

Caterpillar Inc.

Technical Center, Building, L

P.O. Box 1875

Peoria, IL 61656-1875
Avi Zangvil

University of mlinois

Materials Research Laboratory

104 South Goodwin Avenue:

Urbana, IL 61801

Charles H. Zenuk

Transtech

6569 East Calle Cavalier

Tucson, AZ 85715

Anne Marie Zerega

U.S. Department of Energy

Office of Energy Research,

ER-42

Washington, DC 20585

Carl Zweben

General Electric Company

P.O. Box 8555, VFSC/V4019

Philadelphia, PA 19101

Klaus M. Zwilsky

National Research Council

National Materials Advisory Board

2101 Constitution Avenue

Washington, DC 20418

Department of Energy

DOE Field Office, Oak Ridge

Assistant Manager for Energy

Research and Development

P.O. Box 2001

Oak Ridge, TN 37831-8501

Department of Energy (10)

Office of Scientific and

Technical Information

Office of Information Services

P.O. Box 62

Oak Ridge, TN 37831 

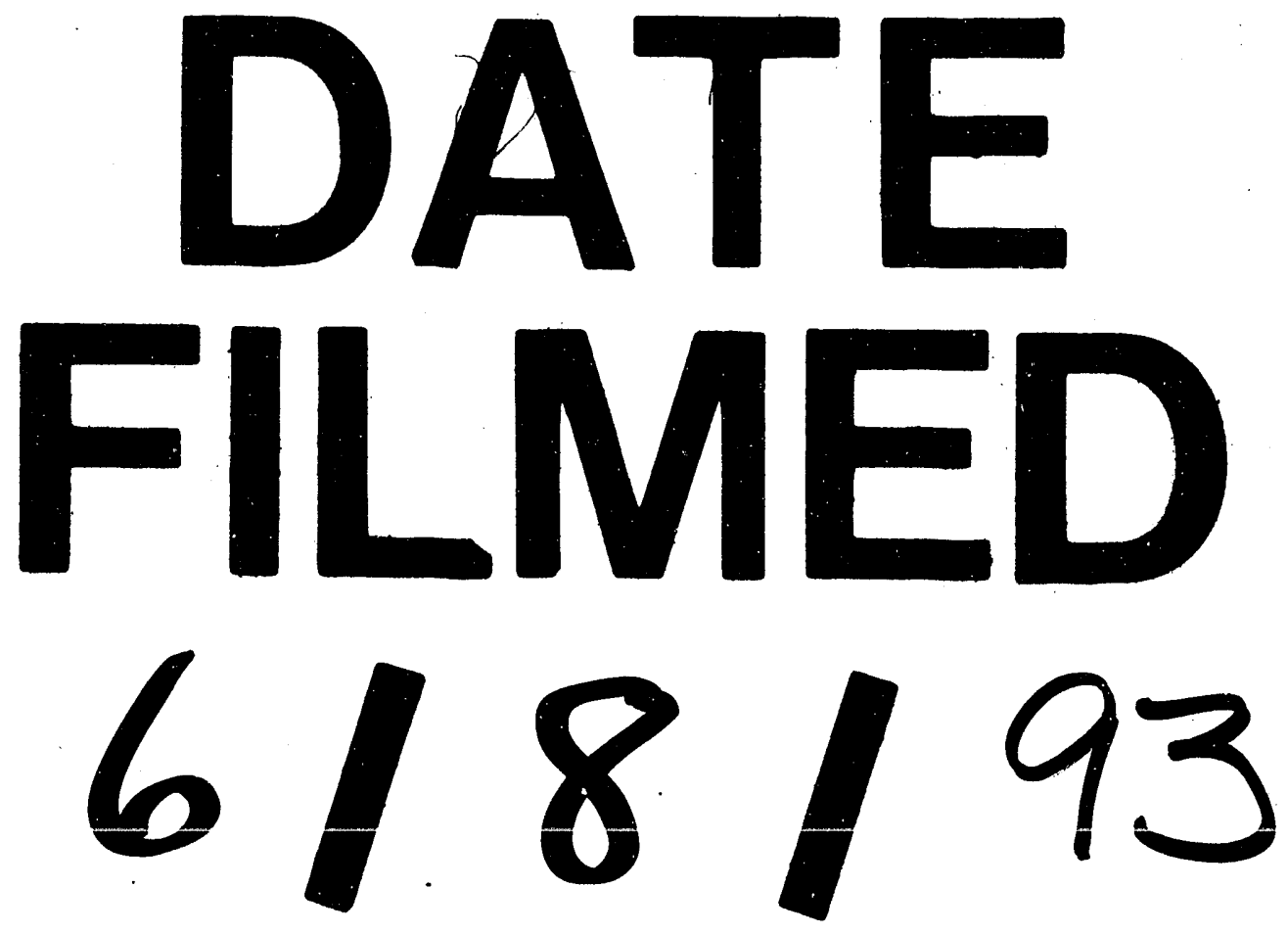
